\title{
Bronchial response in COPD measured by forced oscillation technique
}

Citation for published version (APA):

Wouters, E. F. M. (1987). Bronchial response in COPD measured by forced oscillation technique. [Doctoral Thesis, Maastricht University]. Rijksuniversiteit Limburg.

https://doi.org/10.26481/dis.19871120ew

Document status and date:

Published: 01/01/1987

DOI:

10.26481/dis.19871120ew

Document Version:

Publisher's PDF, also known as Version of record

\section{Please check the document version of this publication:}

- A submitted manuscript is the version of the article upon submission and before peer-review. There can be important differences between the submitted version and the official published version of record.

People interested in the research are advised to contact the author for the final version of the publication, or visit the DOI to the publisher's website.

- The final author version and the galley proof are versions of the publication after peer review.

- The final published version features the final layout of the paper including the volume, issue and page numbers.

Link to publication

\footnotetext{
General rights rights.

- You may freely distribute the URL identifying the publication in the public portal. please follow below link for the End User Agreement:

www.umlib.nl/taverne-license

Take down policy

If you believe that this document breaches copyright please contact us at:

repository@maastrichtuniversity.nl

providing details and we will investigate your claim.
}

Copyright and moral rights for the publications made accessible in the public portal are retained by the authors and/or other copyright owners and it is a condition of accessing publications that users recognise and abide by the legal requirements associated with these

- Users may download and print one copy of any publication from the public portal for the purpose of private study or research.

- You may not further distribute the material or use it for any profit-making activity or commercial gain

If the publication is distributed under the terms of Article $25 \mathrm{fa}$ of the Dutch Copyright Act, indicated by the "Taverne" license above, 


\section{BRONCHIAL RESPONSE IN COPD \\ MEASURED BY \\ FORGED OSGILLATION TECHNIQUE}

\section{PROEFSCHRIFT}

ter verkrijging van de graad van doctor in de geneeskunde aan de Rijksuniversiteit Limburg te Maastricht, op gezag van de Rector Magnificus,

Prof. Dr. F.I.M. Bonke, volgens het besluit van het College van Dekanen, in het openbaar te verdedigen

op vrijdag 20 november 1987 des namiddags te vier uur

door

EMIEL FRANS MARIA WOUTERS

geboren te Geel op 16 mei 1953 
Promotores: Prof. Dr. B.F. Visser

Prof. Dr. L.H. Greve

Referenten: Prof. Dr. K.P. Van de Woestijne

Prof. Dr. H.A.J. Struyker Boudier

(c) 1987 by E. F.M. Wouktra

Uniwersity Hospital Maasticht, P.O. Box 1918,6201 BX Maastricht, The Netherlands.

Niets wit deze uitgave mag worden werveelvotudigd enfol operbar gemaakt door middel van dnuk, foto kopie, microfiln of op welke andere wijze dan ook, zonder vooralgande schriftelije toestemraing van de auscur:

No part of this book may be leptoduced in sany form, by print, photoprint, microfilm, or any other means without writuen permission from the author.

I.S.B.N. $90-9001898-0$

Printed in the Nathertands by Leiter-Nypels, Marastaicht. 
Aan: Mijn ouders

Rita

Kirsten

Elke

Birgit 
Het onderzock werd mede mogelijk gemaakt door steun van het Nederlands Asthma Fonds te Leusden en van Glaxo B.V. te Nieuwegein. 


\section{GONTENTS}

1. General introduction. 10

2. Models of the respiratory system. 11

2.0. Introduction. 11

2.1. Electrical principles. 11

2.1.1. Resistance and capacitance. 12

2.1.2. Resistance, capacitance and inductance. 12

2.2. Mordel of Otis. Parallel time-constant distribution. 14

2.3. Model of Mead. 16

2.4. Madel of Leuven. 17

2.5. Electrical analogon of mechanical systems. 20

2.6. Morphometric model of the respiratory system. 21

$\begin{array}{ll}2.6 .1 . & \text { Airway resistance. } \\ 21\end{array}$

2.6.2. Inertance of air in the airways. 23

3. Forced oscillometry of the respiratory system. 29

3.1. Historical review. 29

3.2. Forced pseudo-random noise oscillation technique. 33

3.2.1. Methods. 33

3.2.2. Results of measurements. $\quad 35$

3.2.3. Frequency dependence. $\quad 35$

3.2.3.1. Model analysis. $\quad 37$

3.2.3.1.1. Influence of peripheral resistance. $\quad 37$

3.2.3.1.2. Influence of airway compliance. $\quad 39$

3.2.3.1.3. Influence of lung compliance. 41

3.2.3.2. Influence of age. 41

3.2.3.3. Influence of lung volumes. 43

3.2.3.4. Frequency dependence of pulmonary resistance, chest wall resistance and resistance of the total respiratory system. 45

3.2.4. Impedance of the cheeks. 45

4. Extended spectrum oscillometry in clinical practice. 49

5. Forced expiratory flow and oscillometric impedance measurement in evaluating airway obstruction. 
6. Impedance measurement of the respiratory system during air and helium-oxygen breathing in normal subjects.

7. Impedance measurement during air and helium-oxygen breathing before and after salbutamol in normal subjects.

8. Impedance measurement of the respiratory system during air and helium-oxygen breathing before and after ipratropium bromide in normal subjects.

9. Impedance measurement of the respiratory system before and after salbutamol in COPD patients.

10. Impedance measurement during air and helium-oxygen breathing before and after salbutamol in COPD patients.

11. Influence of two regimens of salbutamol on impedance parameters after histamine induced bronchoconstriction.

12. Effects of ipratropium bromide on respiratory impedance after cold air challenge in asthmatic subjects.

13. Contribution of impedance measurement of the respiratory system to the bronchial challenge tests.

14. Summary.

15. Samenvatting. 


\section{List of abbreviations}

$\mathrm{Hz}$ : hertz

COPD : chronic abstructive pulmonary diseases

a.c. : alternating current

E : potential difference

t : : time

$\omega \quad: 2 \pi f$

$\pi \quad: 3.14159$

$f \quad:$ frequency

C : capacitance

$L \quad$ : indluctance

$R \quad$ : resistance

Z : impedance

Y : admittance

$T \quad$ : time-constant $=$ the product $R C$

$C_{\mathrm{e}} \quad:$ effective compliance

$R_{\mathrm{e}} \quad$ : effective resistance

$R_{\text {c }} \quad:$ central airway resistance

$R_{\mathrm{p}} \quad$ : peripheral airway resistance

$R_{\mathrm{W}} \quad$ : chest wall resistance

$C_{\mathrm{L}} \quad:$ capacitance of the lung

$C_{\mathrm{A}} \quad:$ capacitance of the airways

$C_{\mathrm{W}} \quad$ : chest wall capacitance

$L_{\mathrm{A}} \quad:$ inductance of air in the airways

rs : respiratory system

j $\quad: \sqrt{-1}$

$R_{\mathrm{L}} \quad:$ real part of the peripheral impedance

$X_{\mathrm{L}} \quad$ : imaginary part of the peripheral impedance

$X \quad$ : reactance

r : radius

$\eta \quad$ : viscosity

l. : length

$\rho \quad:$ density

$D \quad$ : diameter

$p \quad$ : pressure

$f_{0} \quad$ : resonant frequency

FOT : forced oscillation technique

$C_{\mathrm{g}}$

: isothermic gas capacitance 
IVC : inspiratory vital capacity

FVC : the wolume of gas that can be exhaled after a maximal inspiration

FRC : functional residual capacity

$\mathrm{FEV}_{1} \quad$ : forced expiratory volume in $1 \mathrm{~s}$

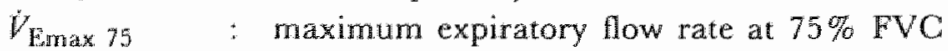

$\dot{V}_{\text {Enax }} 50$ : maximum expiratory flow rate at $50 \%$ FVC

$\dot{V}_{\text {Enax }} 25$ : maximum expiratory flow rate at $25 \%$ FVC

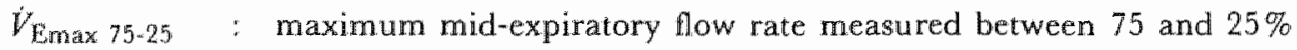
of the total FVG

Emax : maximum expiratory flow rate

He : helium

$\mathrm{O}_{2} \quad$ : oxygen

$\mathrm{SF}_{6} \quad:$ sulphurhexafluoride

$R_{\text {aw }} \quad$ : airway resistance measured by means of whole body plethysmography

$\mathrm{CO}_{2} \quad$ : carbondioxide

$\mathbb{N}_{2} \quad$ : nitrogen

BTPS : body temperature and pressure, saturated with water vapor

$\mathrm{PG}_{20} \mathrm{FEV}_{1}$ : the concentration of a constricting agent responsible for a fall of $\mathrm{FEV}_{1}$ of $20 \%$ of its baseline value

EPP : equal pressure point

$G \quad$ : conductance 


\section{CHAPTER 1}

\section{GENERAL INTRODUCTION}

The forced oscillation technique has been developed by Dubois et al. (1) in 1956 to measure the total resistance of the respiratory system. When voluntary relaxation of the respiratory muscles at the end of the expiration was necessary during the measurements of Dubois et al., Mead (2) showed that the forced oscillations can be superimposed on the normal breathing pattern.

Initially, to determine the variations of resistance with frequency, the subject had to be forced at various frequencies. Several frequencies were used in succession or a composite signal was used and the corresponding frequencies present in mouth pressure and flow signals were isolated by filtering.

By the fast Fourier transform technique, it was possible to submit the respiratory system to a signal made up of a large number of frequencies and to analyse its response at each of these frequencies. Lándsér et al. (3) used impulses, containing all harmonics of $2 \mathrm{~Hz}$ up to $30 \mathrm{~Hz}$ and determined the resistance and reactance of the respiratory system at these frequencies. The frequency spectrum was extended by Lándsér et al. up to $52 \mathrm{~Hz}$ (4) and this spectrum was used in our studies.

Impedance measurement of the respiratory system is now a non-invasive technique, easily and rapidly to perform.

No active co-operation of the patient is needed and therefore this technique can also be applied in children (5). The measurement is not preceded by a maximal inspiration and is therefore very suited for serial determinations because the measurement does not modify the bronchial muscle tone. In addition, by impedance measurement of the respiratory system it may be possible to provide information about the distribution of resistance in the respiratory system (6).

Therefore, it seemed interesting to study this technique in different clinical conditions.

Firstly, the resistance and reactance of the respiratory system were measured between 4 and $52 \mathrm{~Hz}$ in healthy subjects and in patients with severe chronic airway obstruction. "The findings were analyzed using a modified Mead's model, incorporating the compressibility of alveolar gas.

Secondly, impedance parameters obtained by the forced pseudo-random noise oscillation technique were compared with the results of maximal forced expiratory spirometry in hundred out-patients of the pulmonary department Maastricht. Thirdly, we studied normal subjects to analyse two components of the respiratory system: resistance of the central airways and inertance of air in airways. 
It was intended to modify resistance of the central airways in two ways:

- pharmacologically, by inhalation of beta-2-sympaticomimetic and anticholinergic drugs.

- physically, by inhalation of a low density gas mixture.

Because inertance of air in the airways is dependent of the density of the inhaled gas mixture, impedance measurements were performed during air breathing and during breathing a low density gas mixture, composed of $80 \%$ helium and $20 \%$ oxygen.

Fourthly, impedance measurements were performed in COPD patients. It is generally accepted that peripheral resistance is increased in these patients and that therefore airway compliance plays a definite role $(6,7)$.

The influences of beta-2-sympaticomimetics and of a decreased kinematic viscosity on resistance and reactance of the respiratory system were studied in this patient group.

Fifthly, it seemed also interesting to use the forced oscillation technique to assess in asthmatics the mechanics of airway obstruction induced pharmacologically by inhalation of histamine and physically by cold air challenge. After induced bronchoconstriction, the mechanics of airway dilation were studied in these asthmatics after inhalation of sympaticomimetic and anticholinergic drugs.

Sixthly, we evaluated the possible contribution of the impedance measurement of the respiratory system to bronchial challenge tests, hypothesizing that adding this technique to the conventional response measurement possibly could contribute to discriminate between asthmatics and non-asthmatics.

\section{References}

1. Dubois $A B$, Brody $A W$, Lewis DH, Burgess BF. Oscillation mechanics of lungs and chest in man. J Appl Physiol 1956;8:587-94.

2. Mead J. Control of respiratory frequency. J Appl Physiol 1960;15:325-36.

3. Lándsêr F J, Nagels J, Demedts M, Billiet $L$, Van de Woestijne KP. A new method to determine frequency characteristics of the respiratory system. I Appl Physiol 1976;41:101-06.

4. Landsér F J, Polko AH, Visser BF. Oscillatory measurement of total respiratory impedance with extended spectrum up to $52 \mathrm{~Hz}_{\text {n }}$

Arch Internat Physiol Biochim 1983;91:12.

5. Duiverman EJ, Clément J, Van de Woestijne KP, Neijens HJ, Van den Bergh ACM, Kerrebijn $\mathrm{KF}$. Forced oscillation technique, reference values for resistance and reactance over a frequency spectrum of $2-26 \mathrm{~Hz}$ in healthy children aged 2.3-12.5 years.

Bull Europ Physiopath Resp 1985;21:171-78.

6. Nagels J, Lándsér FJ, Van der Linden $L_{\text {, }}$, Clément J, Van de Woestijne KP. Mechanical properties of lungs and chest wall during spontaneous breathing.

J Appl Physiol 1980;49:408-16.

7. Mead J. Contribution of compliance of airways to frequency-dependent behavior of lungs. J Appl Physiol 1969;26:670-73. 


\section{CHAPTER 2}

\section{MODELS OF THE RESPIRATORY SYSTEM.}

\subsection{Intraduction}

In 1955, Mead et al. (1) reported that in patients with pulmonary emphysema the compliance of the lungs depends on the breathing frequency and they suggested that this phenomenon and the uneven ventilation associated with this disease may have a common mechanical basis.

In a classic paper, Otis et al. (2) analyzed the concept of regional differences in the mechanical behaviour of parallel-ventillated lung units on the basis of a simple two-compartment lung modell.

The lung model as described by Otis et al. has been extended to include additional factors expected to affect the pulmonary response to frequency changes. Mead (3) analyzed the contribution of the airways to the frequency-dependent behaviour of the lung and his analysis has focused on the role of an increase of the peripheral resistance as a major determinant of the frequency-dependent behaviour of compliance and resistance.

Inertial factors were ignored in the analysis of Otis et all. (2) and Mead (3).

The model of Leuven as described by Nagels et al. (4) incorporated components expressing the mechanical properties of the central airways and chest wall.

The distribution of airway resistance and inertance along the tracheobronchial tree is further analyzed on the basis of the symmetrical morphometric lung model of Weibel (5).

\subsection{Electrical principles}

The relationship between the mechanical properties of the respiratory system and frequency is studied by sinusoidal waves of known frequency or waveforms with appropriate frequency spectra.

Electrical models are helpful to explain the behaviour of the respiratory system with frequency.

Some basic electrical principles for sinusoidal alternating currents (a.c.) will be discussed (6).

For a sinusoidal waveform, we may write $E_{t}=E_{\mathrm{m}} \sin \omega t$, where $E_{t}$ is the potential difference at time $t, E_{\mathrm{m}}$ is the maximal potential difference ( $\sin \omega t= \pm 1$ ) and $\omega$ equals $2 \pi f$, where $f$ is the frequency of a.c..

In an a.c. circuit with a resistance $R$ and negligible capacitance $(C)$ and inductance $(L), I_{t}=I_{\mathrm{m}} \sin \omega t$, where $I_{t}$ is the current at time $t$. 
In an a.c. circuit with $E_{t}=E_{\mathrm{m}} \sin \omega t$, an inductance $L$ and a negligible $R$, current $I$ lags the potential difference by $\pi / 2$ or $90^{\circ}$ :

$I_{t}=I_{\mathrm{m}} \sin (\omega t+\phi)$

where $\phi=-\pi / 2$.

For all values of $t$, supposing $\phi=-\pi / 2: I_{\mathrm{m}}=E_{\mathrm{m}} / \omega L$.

$\omega L$ is equivalent to a resistance for the a.c. current and is indicated by $Z_{L}$ (impedance of inductance).

Considering an a.c. circuit with $E_{l}=E_{\mathrm{m}} \sin \omega t$ and a capacitance $C$ :

$I_{t}=C E_{\mathrm{m}} \omega \cos \omega t$

$I_{\mathrm{m}}=E_{\mathrm{m}} /(1 / \omega C)$

$1 / \omega C$ is equivalent to a resistance for the a.c. circuit and is indicated by $Z_{C}$ (impedance of capacitance).

In this circuit $I_{t}=I_{\mathrm{m}} \sin (\omega t+\pi / 2): I$ leads $E$ by $90^{\circ}$ or $\pi / 2$.

\subsubsection{Resistance and capacitance.}

Suppose an alternating potential difference $E$ is applied across a resistance $R$ and a capacitance $C$ in series (fig. 2.1).

The vector sum of $E_{R}$ and $E_{C}$ equals the applied potential difference $E$ (fig. 2.2). $I$ leads $E$ by a phase angle $\operatorname{tg} \phi=-1 / \omega R C$.

For this circuit : $I_{\mathrm{m}}=E_{\mathrm{m}}\left(R^{2}+(1 / \omega C)^{2}\right)^{-1 / 2}=E_{\mathrm{m}} / Z$.

The quantity $\left(R^{2}+(1 / \omega C)^{2}\right)^{1 / 2}$ is called the impedance $(Z)$ of the circuit.

\subsubsection{Resistance, capacitance and inductance}

A $R$ - $L$-C-circuit is shown in fig. 2.3 .

The vector sum of $E_{R}, E_{L}$ and $E_{C}$ equals the applied potential difference (fig. 2.4).

In this example, $I$ lags $E$ by a phase angle $\phi$.

$\operatorname{tg} \phi=(\omega L-1 / \omega C) / R$.

Furthermore,

$I_{\mathrm{m}}=E_{\mathrm{m}}\left(R^{2}+(\omega L-1 / \omega C)^{2}\right)^{-1 / 2}$

The denominator is equal to the impedance of the circuit. $\omega L-1 / \omega C$ is the reactance of the circuit, $X$.

If the absolute values of $\omega L=1 / \omega C$ than the reactance equals zero. This is called electrical resonance. 


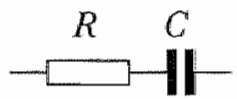

Fig. 2.1 .

$R C$ - circuit in series.

( $R$ : resistance; $C$ : capacitance)

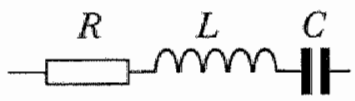

Fig. 2.3 .

RLC circuit in series.

( $L$ : inductance)

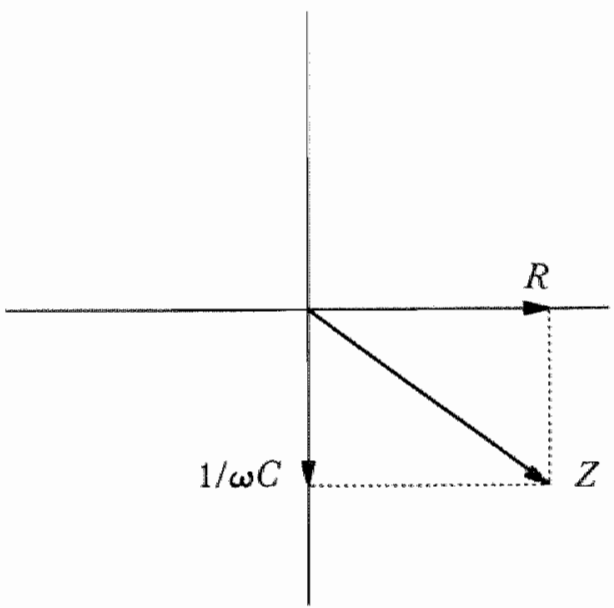

Fig. 2,2

Vector diagram of $R C$ in series.

$(Z$ : impedance; $\omega: 2 \pi /)$

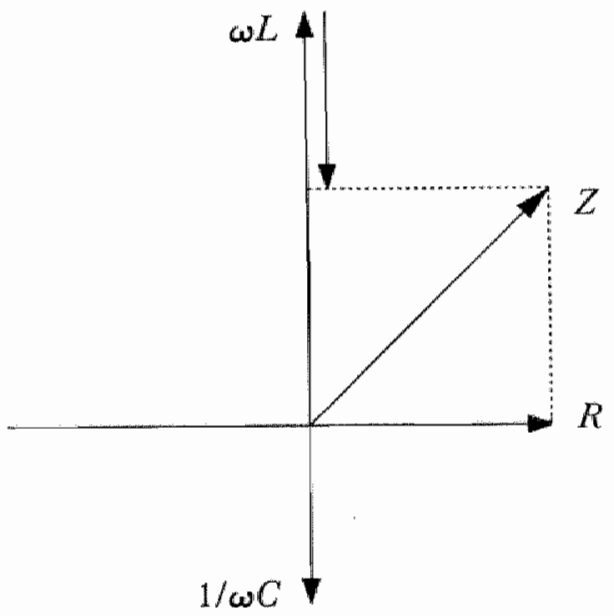

Fig. 2.4.

Vector diagram of $R L C$ in series. 
Searching for a possible mechanical basis for the phenomenon of uneven distribution of alveolar ventilation, Otis et al. (2) supposed that the lungs are composed of a population of elements or pathways which are not all similar mechanically and that because of the mechanical differences they operate asynchronously even when subjected to the same driving force.

They analyzed the behaviour of the respiratory system on the basis of a simple model with two parallel units, each unit consisting of a flow-resistive element and a volume-elastic element in series (fig. 2.5).
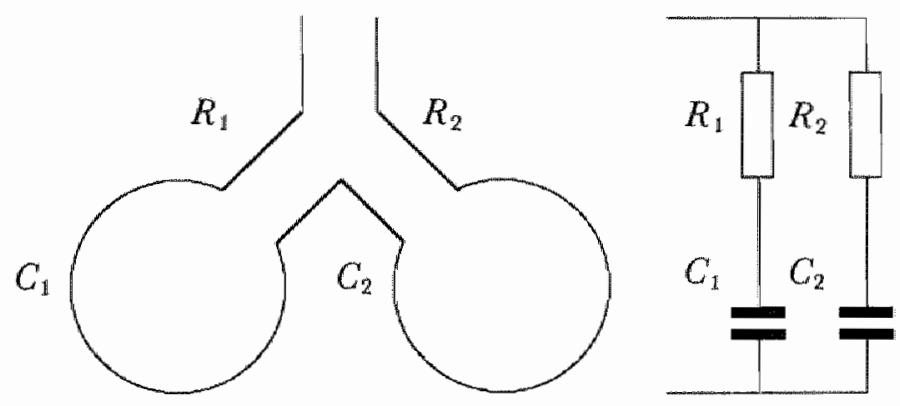

Fig. 2.5.

Two-compartment lung model of Otis and electrical analogue of the model. Each unit consists of a flow-resistive element $(R)$ and a volume-elastic element $(C)$ in series.

They further made the following assumptions :

1. Inertial factors are negligible up to a frequency of $2 \mathrm{~Hz}$.

2. The resistive and elastic characteristics of each pathway are linear.

3. The pressure changes to which the lungs are subjected may be approximated by sine waves.

4. The pressure changes to which the individual pathways are subjected are the same as, or directly proportional to, the overall pressure changes for the lungs. In such a network, the distribution of overall flow in the separate pathways and the timing of flow events depend on the distribution of the impedance $(Z)$ of the separate pathways.

If the separate impedances are identical, they will all operate exactly in phase with each other and the magnitude of the total admittance $(Y=1 / Z)$ will be the sum of the separate admittances:

$1 / Z=1 / Z_{1}+1 / Z_{2}$

$Y=Y_{1}+Y_{2}$ 
Otis et al. showed that the proportionate change of impedance with frequency is the same in different pathways if the products of the resistance and compliance of the separate pathways are equal.

For each pathway the magnitude of the impedance, $Z$, may be expressed: $Z=\left(R^{2}+(1 / \omega C)^{2}\right)^{1 / 2}=(1 / C)\left(T^{2}+1 / \omega^{2}\right)^{1 / 2}$ where $T=R C ; \omega=2 \pi f$.

The proportional change of $Z$ with changes in frequency from $\omega_{1}$ to $\omega_{2}$ may be expressed by the following equation :

$\frac{Z_{1}}{Z_{2}}=\frac{\frac{1}{C} \sqrt{T^{2}+\frac{1}{\left(\omega_{1}\right)^{2}}}}{\frac{1}{C} \sqrt{T^{2}+\frac{1}{\left(\omega_{2}\right)^{2}}}}=\sqrt{\frac{T^{2}+\frac{1}{\left(\omega_{1}\right)^{2}}}{T^{2}+\frac{1}{\left(\omega_{2}\right)^{2}}}}$

The product, $R C$, has the dimension of time and is called the time-constant $(T)$ of the system. The larger the time-constant, the smaller will be the phase angle between pressure and flow in a $R C$-circuit. The temporal behaviour of a single pulmonary element to a given sinusoidal driving pressure is therefore a function of its time-constant. If the separate pathways have different time-constants, the phase angles between flow and pressure will be different and the flows will be out of phase with each other.

The instants of zero flow in the separate pathways will not coincide and there will be gas flowing between the separate pathways at the instant of zero flow in the common pathway ("Pendelluft").

In this case the total admittance of the system must be expressed in the vector form :

$\bar{Y}=\bar{Y}_{1}+\bar{Y}_{2}$

Generally, in a two-pathway network, made up of known resistance and compliance elements, $R_{1}, C_{1}, R_{2}$ and $C_{2}$, the effective compliance, $C_{c}$ and the effective resistance, $R_{e}$, may be expressed as follows, according to Otis et al. :

$$
\begin{aligned}
& C_{\mathrm{e}}= \frac{\omega^{2}\left(T_{2} C_{1}+T_{1} C_{2}\right)^{2}+\left(C_{1}+C_{2}\right)^{2}}{\omega^{2}\left(T_{1}^{2} C_{2}+T_{2}^{2} C_{2}\right)+\left(C_{1}+C_{2}\right)} \\
& R_{\mathrm{e}}=\frac{\omega^{2} T_{1} T_{2}\left(T_{2} C_{1}+T_{1} C_{2}\right)+\left(T_{1} C_{1}+T_{2} C_{2}\right)}{\omega^{2}\left(T_{2} C_{1}+T_{1} C_{2}\right)^{2}+\left(C_{1}+C_{2}\right)^{2}}
\end{aligned}
$$

Where $\omega=2 \pi f, T_{1}=R_{1} C_{1}$ and $T_{2}=R_{2} C_{2}$. 
Otis et al. (2) suggested that the frequency dependence of lung compliance or flow resistance can be caused by a non-uniform distribution of the mechanical properties among parallel pulmonary units, determining spatial time-constant inequalities.

Furthermore, in considering the spatial distribution of time-constants in normal and diseased lungs, it is convenient to distinguish an interregional non-uniformity and an intraregional non-uniformity as reviewed by Cutillo and Renzetti ( 7 ). They further distinguished spatial time-constant inequalities due to differences in the intrinsic mechanical properties of the parallel pulmonary units and spatial time-constant inequalities reflecting the influence of factors extrinsic to the lung. In view of asymmetrical bronchial anatomy, spatial differences in elastic properties and the influence of gravitational forces, Cutillo and Renzetti concluded that the presence of interregional and intraregional time-constant inequality in normal lungs is predictable but that this degree of inequality existing in healthy subjects has generally little effect on the mechanical lung behaviour as a function of frequency. On the basis of the theoretical concepts of Otis et al, the marked frequency dependence of compliance and resistance in patients with pulmonary diseases suggests that spatial time-constant inequality is greater in these patients than in normal subjects.

Regional and intraregional ventilation inhomogeneity reported in patients with chronic obstructive pulmonary diseases supports this concept.

\subsection{Model of Mead}

Frequency dependence of compliance and resistance can be explained without assuming the presence of time-constant inequalities among parallell parenchymal lung units. This concept has been analyzed by Mead (3) by evaluating the contribution of compliance of airways to the frequency-dependent behaviour of the lungs.

Mead stated that airways are more than simply conduits : they are also compliant structures. As conduits, the airways are mechanically in series with the air spaces, which they supply; as expanding structures, they are mechanically in parallel with the air spaces. This expansion makes an entirely separate contribution to the total expansion of lungs from that of the air spaces.

Based on impedance and phase angle measurements at $6 \mathrm{~Hz}$ in normal subjects and COPD patients, Sobol (8) already suggested that there has to be a compliant element in parallel with the lung and chest wall and that this compliant element may be the airways themselves.

Mead developed a two-compartment lung model where the two parallel units are represented by the expansible airways (with compliance $C_{\mathrm{D}}$ ) and by the air spaces (with compliance $C_{\mathrm{p}}$ ). The resistance of the airway compartment $\left(R_{\mathrm{D}}\right)$ is considered to be pratically zero and the resistance of the air space compartment $\left(R_{\mathrm{p}}\right)$ is the equivalent of the peripheral resistance (fig. 2.6). 

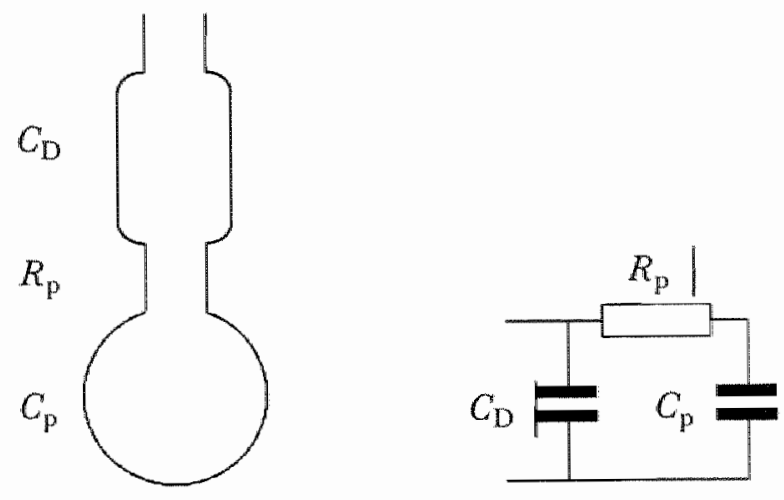

Fig. 2.6 .

Lung model of Mead and electrical analogue of the model. ( $C_{\mathrm{D}}$ : capacitance of expansible airways; $C_{\mathrm{p}}$ : capacitance of air spaces; $R_{\mathrm{p}}$ : peripheral resistance)

For $T_{1} \cong 0$ and $C_{1} \cong 0$, the equations of Otis for effective compliance and resistance can be re-expressed:
$C_{\mathrm{e}}=\frac{\omega^{2}\left(T_{2} C_{1}\right)^{2}+C_{2}^{2}}{\omega^{2}\left(T_{2}^{2} C_{1}\right)+C_{2}}$
$R_{\mathrm{e}}=\frac{T_{2} C_{2}}{\omega^{2}\left(T_{2} C_{1}\right)^{2}+C_{2}^{2}}$

The analysis of Mead has focused on the role of an increase in the resistance of the peripheral airways, effectively between the air spaces and the major part of the airway distensible volume, as a major determinant of the frequencydependent behaviour of effective compliance and resistance.

Although the frequency-dependent behaviour of the model of Otis et al. and that of Mead are qualitatively similar, they differ from a quantitative point of view. In the model of Otis et al., the decrease in compliance and resistance is virtually completed at 1-2 $\mathrm{Hz}$; in Mead's model compliance and resistance decrease over a much more extended frequency range.

Further modifications of the models of Otis et al. and Mead were made, as extensively reviewed by Cutillo and Renzetti ( 7 ).

\section{4 Model of Lewven}

In their theoretical analysis, Otis et al. and Mead had ignored inertial factors. Obviously, the effects of inertial forces on the mechanical behaviour of the respiratory system are important at the higher frequencies. This component was incorporated in the model, described by Nagels et al. (4). 
The model was composed of 7 components :

\begin{tabular}{|c|c|c|}
\hline 3 resistances & $R$ & $\begin{array}{l}\text { central airways } \\
\text { peripheral airways } \\
\text { chest wall }\end{array}$ \\
\hline 3 capacitances & C & $\begin{array}{l}\text { lungs } \\
\text { airways }\end{array}$ \\
\hline inductance & $L$ & $\begin{array}{l}\text { chest wall } \\
\text { air in airways }\end{array}$ \\
\hline
\end{tabular}

The model is graphically presented in figure 2.7 .

Nagels et al. stated that this model satisfactorily reproduces the values of total lung and chest wall resistance and reactance observed in healthy subjects and in COPD patients. The frequency dependence of $R_{\mathrm{rs}}$ depended critically on the value of peripheral resistance.

The resistance of the chest wall is similar in healthy subjects and in patients with COPD. The values measured at FRC by Nagels et al. (mean $0.054 \mathrm{kPa} . \mathrm{s} / \mathrm{L}$ ) are comparable to those found by Grimby et al. (9) $\left(0.6 ; 0.5 ; 0.5\right.$ and $0.4 \mathrm{cmH}_{2} \mathrm{O} . \mathrm{s} / \mathbb{L}$ for $3,5,7$ and $9 \mathrm{~Hz}$ respectively) and Sharp $(10)\left(0.51 \mathrm{cmH}_{2} \mathrm{O} . \mathrm{s} / \mathrm{L}\right)$ but lower than the value found by Aronsson et al. (11) $\left(0.9 \mathrm{cmH}_{2} \mathrm{O} . \mathrm{s} / \mathrm{L}\right)$.

The value of chest wall compliance, used in the model, is $0.5 \mathrm{~L} / \mathrm{kPa}$. This value is lower than those found in most publications. Naimark and Cherniack (12)

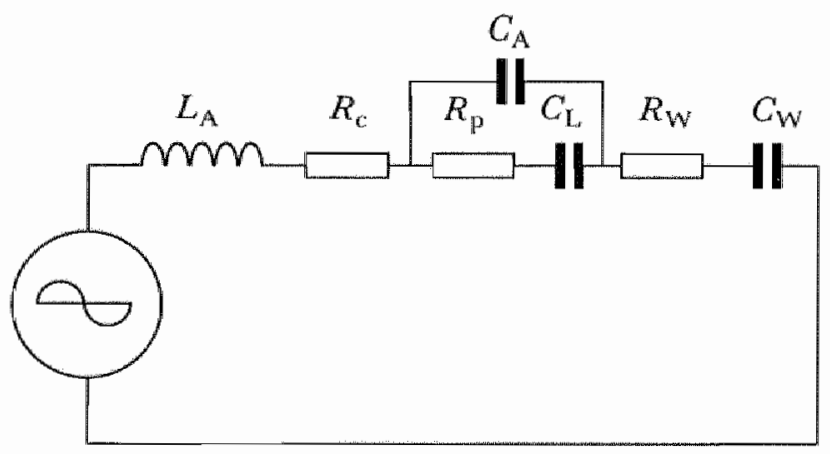

Fig. 2.7 .

Lung model of Nagels. ( $L_{\mathrm{A}}$ : inductance of air in airways $0.001 \mathrm{kPa} /\left(\mathrm{L} / \mathrm{s}^{2}\right) ; R_{\mathrm{C}}$; resistance of central airways $0.127 \mathrm{ka} /(\mathrm{L} / \mathrm{s}) ; R_{\mathrm{p}}$; resistance of peripheral airways $0.014 \mathrm{kPa}(\mathrm{L} / \mathrm{s}) ; C_{\mathrm{A}}$ : airway capacitance $0.05 \mathrm{~L} / \mathrm{kPa} ; G_{\mathrm{L}}$ : lung capacitance $2 \mathrm{~L} / \mathrm{kPa} ; R_{W}$; chest wall resistance $0.05 \mathrm{kPa} /(\mathrm{L} / \mathrm{s})$ and $C_{W}$ : chest wall capacitance $0.5 \mathrm{~L} / \mathrm{kPa}$ ). 
measured a value of $0.245 \mathrm{~L} / \mathrm{cmH}_{2} \mathrm{O}$ in sitting position and $0.208 \mathrm{~L} / \mathrm{cmH}_{2} \mathrm{O}$ in supine position for chest wall compliance. This value is comparable with those found by Sharp et al. (10) $\left(0.2 \mathbb{4} \mathrm{L} / \mathrm{cmH}_{2} \mathrm{O}\right)$. In younger persons, Mittman (13) measured even higher values for chest wall compliance $\left(0.475 \mathrm{~L} / \mathrm{cm} \mathrm{H}_{2} \mathrm{O}\right)$ and found a significamt decrease of chest wall compliance with age $\left(0.196 \mathrm{~L} / \mathrm{cmH}_{2} \mathrm{O}\right.$ for persons aged $70-79$ years).

As mentioned by Nagels et al., their value of chest wall elastance $(1.51 \mathrm{kPa} / \mathrm{L})$ is markedly larger than those determined by other investigators: Van Lith et al. (14) found values for thoracic elastance of $3.7 \mathrm{cmH}_{2} \mathrm{O} / \mathrm{L}$ for normal, paralyzed subjects in the supine position and $5.9 \mathrm{cmH}_{2} \mathrm{O} / \mathrm{L}$ during voluntary relaxation. As suggested by Peslin et al. (15), Nagels et al. believed that this discrepancy can be explained if the chest behaves as a two-compartment system, consisting of a low compliance-low inertance rib cage and a high compliance-high inertance abdomen. Then the compliance measured at low frequencies will primarily reflect that of the abdomen, whereas the compliance value measured between 4 and 20 $\mathrm{Hz}$ will be mainly that of the rib cage.

A low value of capacitance was also calculated by Dubois et al. (16) $(C=0.018$ $\mathrm{L} / \mathrm{cm} \mathrm{H}_{2} \mathrm{O}$ ). They evenso mentioned that this may be an indication that the chest exhibits a non-homogeneous response at higher frequencies.

Using surface velocity measurements of different regions of the chest wall they concluded, that the abdomen probably responds at lower frequency and that the chest responds at higher frequency.

Michaelson et al. (17) calculated that the average chest wall compliance has to be about $0,031 \mathrm{~L} / \mathrm{cmH}_{2} \mathrm{O}$, assuming a static lung compliance of $0.2 \mathrm{~L} / \mathrm{cmH}_{2} \mathrm{O}$.

The impedance $(Z)$ of this circuit can be considered at each frequency as consisting of a resistance, capacitance and inductance in series.

$Z_{\mathrm{rs}}=R_{\mathrm{rs}}+1 / j \omega C_{\mathrm{rs}}+j \omega L_{\mathrm{rs}}$

where $\omega=2 \pi f, f=$ frequency, $\mathrm{j}=\sqrt{-1}, \mathrm{rs}=$ respiratory system.

Also, at each $f$ the total resistance can be considered as the sum of three resistances in series.

$R_{\mathrm{rs}}=R_{\mathrm{c}}+R_{\mathrm{L}}+R_{\mathrm{W}}$

$R_{\mathrm{L}}$ represents the real part of the peripheral impedance $\left(Z_{\mathrm{p}}\right)$.

$R_{\mathrm{L}}=R_{\mathrm{p}} C_{\mathrm{L}}^{2} /\left(\left(\omega R_{\mathrm{p}} C_{\mathrm{A}} C_{\mathrm{L}}\right)^{2}+\left(C_{\mathrm{A}}+C_{\mathrm{L}}\right)^{2}\right)$

$R_{\mathrm{L}}$ is frequency dependent. 
Reactance can be represented as :

$X_{\mathrm{rs}}=\omega L_{\mathrm{A}}+X_{\mathrm{L}}-1 / \omega C_{\mathrm{W}}$

$X_{L}$ is the imaginary part of the peripheral impedance $Z_{\mathrm{p}}$.

$X_{\mathrm{L} .}=\frac{-1}{\omega} \cdot \frac{\left(C_{\mathrm{A}}+C_{\mathrm{L}}\right)+\left(\omega R_{\mathrm{p}} C_{\mathrm{A}} C_{\mathrm{L}}\right)^{2 / C_{\mathrm{A}}}}{\left(\omega R_{\mathrm{p}} C_{\mathrm{A}} C_{\mathrm{L}}\right)^{2}+\left(C_{\mathrm{A}}+C_{\mathrm{L}}\right)^{2}}$

$R_{\mathrm{p}}$ is a major determinant of the frequency dependent behaviour of this circuit. Supposing $R_{\mathrm{p}}$ equals zero, $C_{\mathrm{L}}$ and $C_{\mathrm{A}}$ are in parallel (fig. 2.8). The capacitance of the respiratory system is determined by the sum of $C_{\mathrm{L}}$ and $C_{\mathrm{A}}$ in series with $C_{W}$.

Otherwise, supposing high values of $R_{p}, C_{L}$ is excluded and the capacitance of the respiratory system is determined by $C_{\mathrm{A}}$ and $C_{\mathrm{W}}$ in series (fig. 2.9).

\subsection{Electrical analogon of mechanical systems.}

The analogy between analogous quantities in respiratory mechanics and in electrical systems is clearly illustrated in the next table, according to Cutillo and Renzetti (7).

Mechanical quantities

\begin{tabular}{|c|c|c|c|c|c|c|}
\hline Quantity & Symbol & $\begin{array}{l}\text { Symboll } \\
\text { for } \\
\text { Unit }\end{array}$ & Quantity & Symbol & Unit & $\begin{array}{l}\text { Symool } \\
\text { for } \\
\text { Unit }\end{array}$ \\
\hline Volume & $V$ & $\mathbb{L}$ & Charge & $Q$ & coulomb & $\mathrm{C}$ \\
\hline Flow & $\dot{V}$ & $\mathrm{~L} / \mathrm{s}$ & Current & $\vec{I}$ & ampère & $\mathrm{A}$ \\
\hline Pressure & $p$ & $\mathrm{cma}_{2} \mathrm{CPa}_{2} \mathrm{O}$ & Potential & $E$ & volt & $\mathrm{V}$ \\
\hline Resistance & $R$ & $\begin{array}{l}\mathrm{cmH}_{2} \mathrm{O} \cdot \mathrm{s} / \mathrm{L} \\
\mathrm{kPa} \mathrm{s} / \mathrm{L}\end{array}$ & Resistance & $R$ & ohm & $\Omega$ \\
\hline Compliance & $C$ & $\begin{array}{l}\mathrm{L} / \mathrm{cmH}_{2} \mathrm{O} \\
\mathrm{L} / \mathrm{kPa}\end{array}$ & Capacitance & $C$ & farad & $\mathrm{F}$ \\
\hline Inertance & $l$ & $\begin{array}{l}\mathrm{cmH}_{\mathrm{g}} \mathrm{O} \cdot \mathrm{s}^{2 / \mathrm{L}} \\
\mathrm{kPa} \mathrm{s}^{2} / \mathrm{L}\end{array}$ & Inductance & $L$ & henry & $\mathrm{H}$ \\
\hline Impedince & $Z$ & see resistance & Impedance & $Z$ & ohm & $\Omega$ \\
\hline Total reactance & $X$ & see resistance & $\begin{array}{l}\text { Total } \\
\text { reactance }\end{array}$ & $X$ & ohm & $\Omega$ \\
\hline Compliant reactance & $X_{C}$ & see resistance & $\begin{array}{l}\text { Capacitive } \\
\text { reactance }\end{array}$ & $X_{C}$ & ohm & $\Omega$ \\
\hline Inertial reactance & $X_{I}$ & see resistance & $\begin{array}{l}\text { Inductive } \\
\text { reactance }\end{array}$ & $X_{L}$ & ohm & $\Omega$ \\
\hline Frequency & $f$ & $\begin{array}{l}\text { cycles/s } \\
\text { hertz }\end{array}$ & Frequency & $f$ & hertz & $\mathrm{Hz}$ \\
\hline
\end{tabular}


To evaluate the partitioning of airway resistance and inertance along the bronchial tree, calculations of $R$ and $I$ were performed using the symmetric model of the bronchial tree of Weibel $(5,18)$.

\section{6. I Airway resistance}

Supposing a laminar flow in the airways and no pressure drops at bifurcations, resistance can be calculated using the Poiseuille formula:

$R=8 \eta / / \pi r^{4}$,

where $\eta=$ viscosity of air, $l=$ length, $\pi=3.14159, r=$ radius.

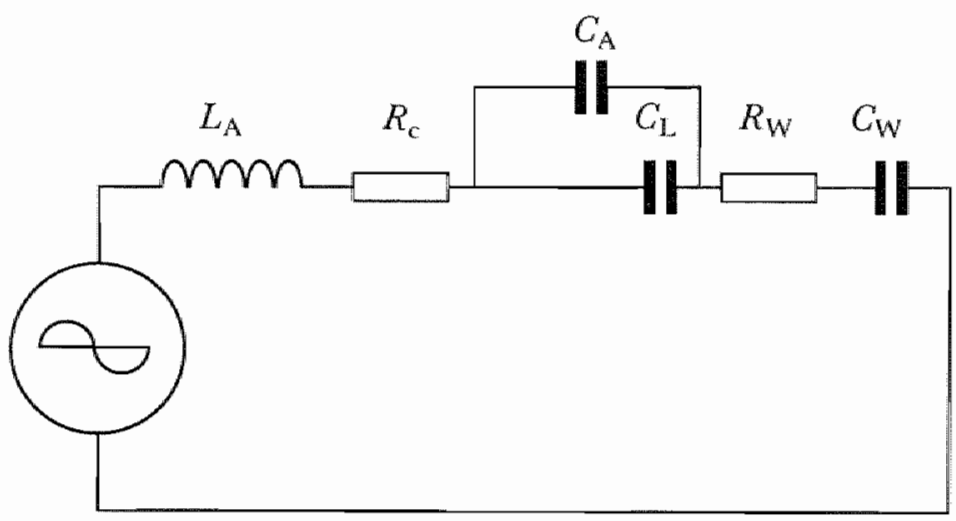

Fig. 2.8.

Lung model of Nagels $\left(R_{\mathrm{p}} \cong 0\right)$.

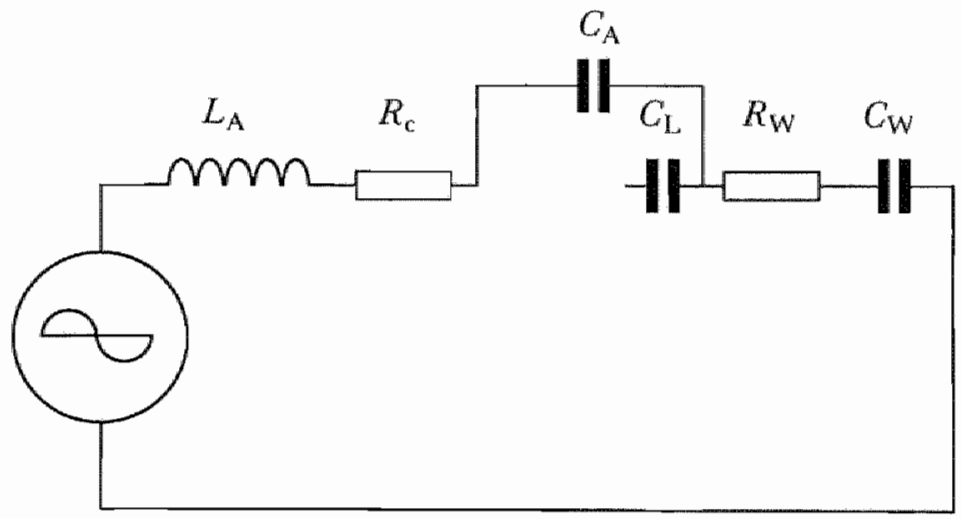

Fig. 2.9.

Lung, model of Nagels $\left(R_{\mathrm{p}}=\infty\right)$. 
Results are illustrated in fig. 2.10: highest resistance occurs at the sixth generation. Cumulatively, $90 \%$ of total resistance walue is reached at the 12 th bronchial generation (internal diameter $0.95 \mathrm{~mm}$ ) (fig. 2.11). This is in accordance with the partitioning of airway resistance, as described in the model of Leuven (4).

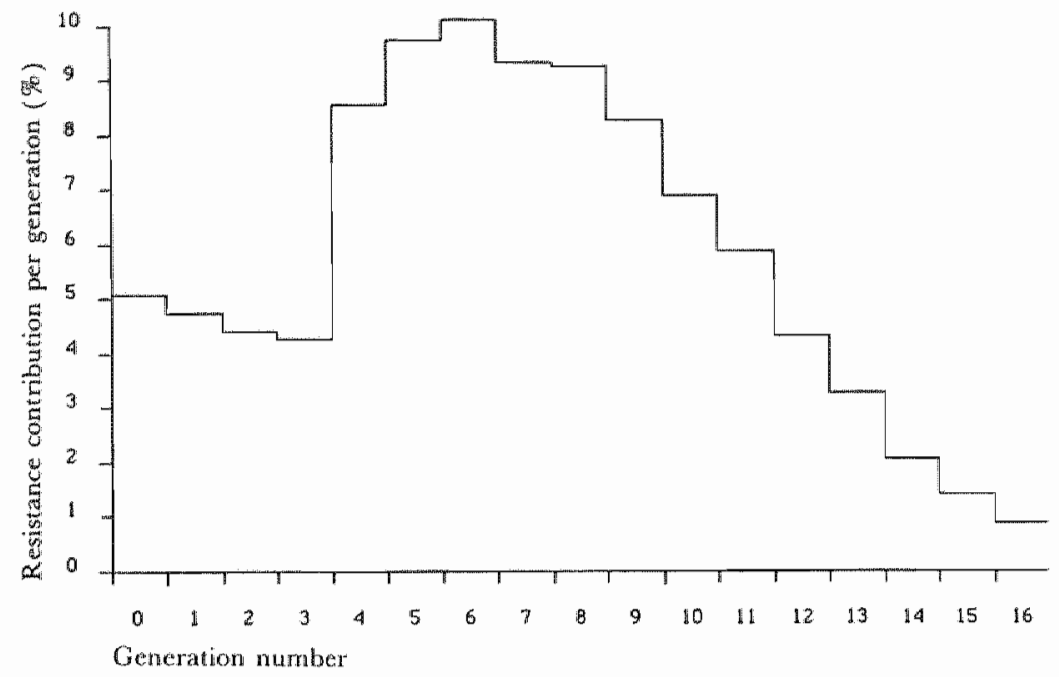

Fig. 2.10.

Distribution of airway resistance along the tracheobroncheal tree. (trachea: generation number 0 ).

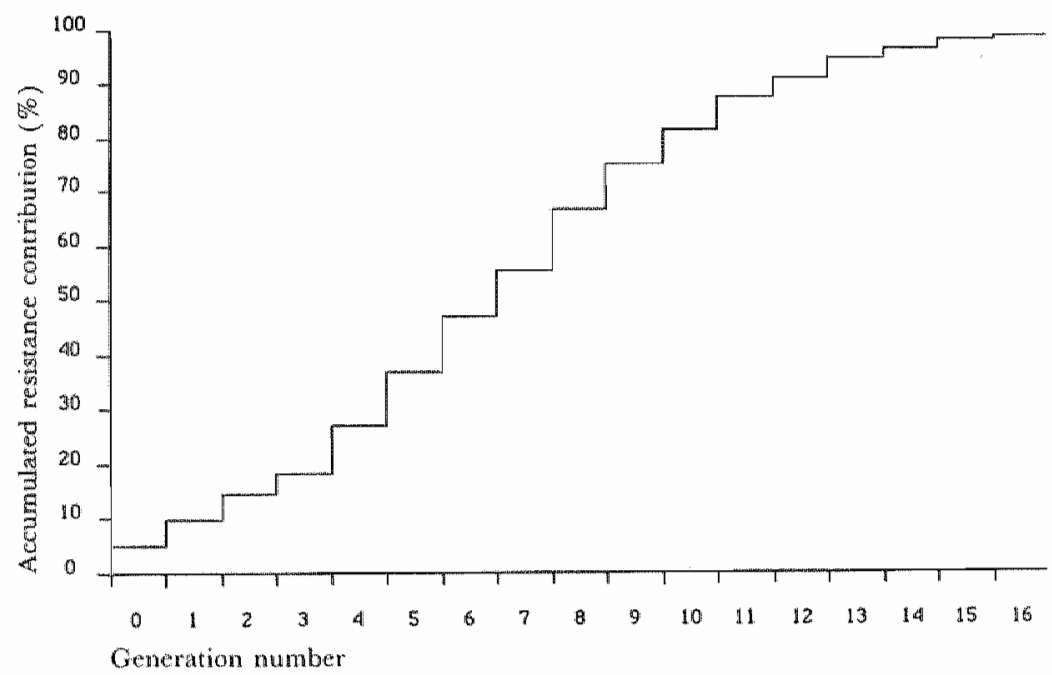

Fig. 2.11.

Cumulative presentation of airway resistance. 
2.6.2 Inertance of air in the airways.

Supposing a square front factor, inertance can be calculated by the formula : $I=\rho l / A$,

where $\rho=$ density, $l=$ length, $A=$ total cross section.

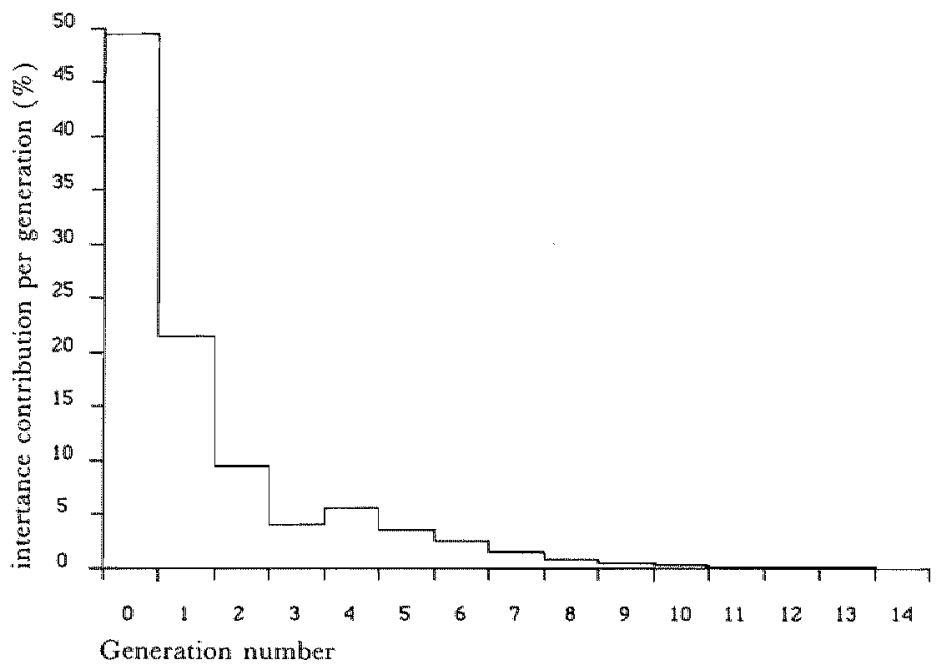

Fig. 2.12 .

Distribution of inertance of air along the tracheobroncheal tree. (trachea: generation number 0 )

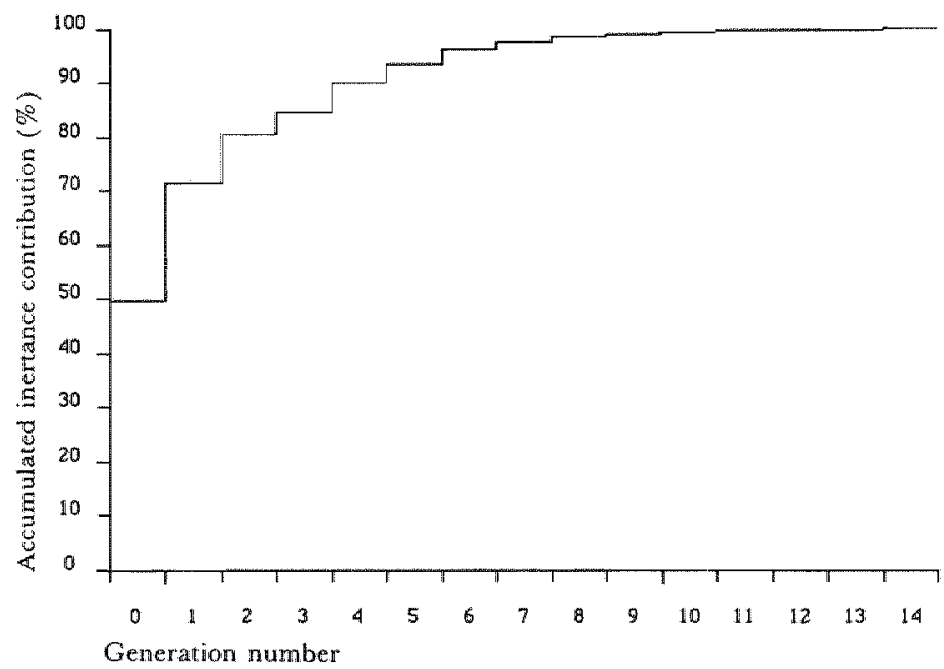

Fig. 2.13.

Cumulative presentation of inertance of air in the airways. 
As illustrated in fig. 2.12 most inertance is localized in the trachea and decreases quickly in the following generations. Cumulatively, $90 \%$ of total inertance is reached at the fourth generation (fig. 2.13).

Total calculated inertance is $0.001045 \mathrm{kPa}^{2} / \mathrm{L}$ and this value is comparable to the value of $L$ used in the model of Leuven $\left(L=0.001 \mathrm{kPa} \cdot \mathrm{s}^{2} / \mathrm{L}\right)$.

These calculations are based on the values of the symmetrical model of Weibel. However, Horsfield and Cumming (19) have found an asymmetrical structure of the airways and branching in the bronchial tree by asymmetrical dichotomy. Remarkably, these authors concluded that their measurements are in agreement with the symmetrical model of Weibel taking into account that generation 16 representing the terminal bronchioles in Weibel's model corresponds with generation 15 in the model of Horsfield and Cumming. Assuming laminar flow, these authors found that from their measurements of airways geometry pressure gradients most steeply fall at branches between 1 and $4 \mathrm{~mm}$ diameter. This is in accordance with our calculations, using Weibel's model.

The other assumption used in our calculations was a laminar flow regime across the tracheobronchial tree. By determining the magnitude of the Reynolds number, according to the formula:

$R e=V D \rho / \eta$ the potential flow regime can be obtained.

Where $V=$ average velocity of fluid across one cross section $(\mathrm{cm} / \mathrm{s}), D=$ diameter of tube $(\mathrm{cm}), \rho=$ density, $\eta=$ viscosity.

For values of the Reynolds number from 0 to about 2000 the flow is laminar, from about 2000 to 4000 the flow is critical, from 4000 to 10000 the flow is transition turbulent and above 10000 the flow is fully turbulent (20).

Olson et al. (20) have calculated Reynolds number, pressure drop and cumulative pressure drop for different inspiratory flow rates. Their data and their calculated values using Weibel's model are presented in table 2.1.

Furthermore, the entrance length, the distance for air to establish the parabolic velocity profille normally associated with the laminar flow regime, is tabulated. Inspection of the tables shows that very little development of the velocity profile has occurred until after the fifth order bronchi. This is in accordance with our assumption of a square shape of the velocity profile in the more central airways, as used for calculation of inertance values.

The results of Olson et al. showed that the location of the predominant position of pressure drop occurs in the central airways and that at least $80 \%$ of the total pressure drop is attained by order 6 ( $3.6 \mathrm{~mm}$ bronchi). 
Table 2.1.

Reynolds number, entrance length, tube length and total predicted pressure drop for each order of branching at different flow rates, according to Olson and the same data using Weibel's data. (reprinted with permission, J Appl Physiol 1970; 28: 485-86).

\section{INSPIRATORY FLOW RATE - $0.5 \mathrm{~L} / \mathrm{s}$ (Olson)}

\begin{tabular}{|c|c|c|c|c|c|c|}
\hline \multicolumn{2}{|c|}{ Order } & \multirow{2}{*}{$\begin{array}{l}\text { Actual } \\
\text { Tube } \\
\text { Length } \\
\text { cm } \\
7 .\end{array}$} & \multirow{2}{*}{$\begin{array}{l}\text { Entrance } \\
\text { Length } \\
\mathrm{cm} \\
42.93\end{array}$} & \multirow{2}{*}{$\begin{array}{l}\text { Reynolds } \\
\text { No. } \\
1,493 .\end{array}$} & \multirow{2}{*}{$\begin{array}{l}\text { Pressure } \\
\text { Drop } \\
\mathrm{cmH}_{\mathrm{g}} \mathrm{O} \\
0.0491\end{array}$} & \multirow{2}{*}{$\begin{array}{l}\text { Cumularive } \\
\text { Pressute } \\
\text { Drop } \\
\text { cmH }_{2} \mathrm{O} \\
0.049\end{array}$} \\
\hline 00 & (Mouth) & & & & & \\
\hline 0 & (Trachea) & 12 & 50.50 & 1,757 & 0.0718 & 0.121 \\
\hline 1 & $\begin{array}{l}\text { (Primary } \\
\text { bronchi) }\end{array}$ & 4.22 & 42.12 & 1,465 & 0.0383 & 0.159 \\
\hline 2 & & 3.03 & 29.03 & 1,010 & 0.0401 & 0.199 \\
\hline 3 & & 2.34 & 21.69 & 754 & 0,0467 & 0.246 \\
\hline 4 & & 1.84 & 9.67 & 336. & 0.0217 & 0.268 \\
\hline 5 & & 1.46 & 7.36 & 256. & 0.0227 & 0.290 \\
\hline 6 & & 1.07 & 3.44 & 120 & 0.0108 & 0.301 \\
\hline 7 & & 0.975 & 2.54 & 88.6 & 0.0107 & 0.312 \\
\hline 8 & & 0.780 & 1.97 & 68.4 & 0.0121 & 0.324 \\
\hline 9 & & 0.650 & 0.824 & 28.7 & 0.00558 & 0.330 \\
\hline 10 & (Bronchiole) & 0.530 & 0.679 & 23.6 & 0.00678 & 0.336 \\
\hline 11 & & 0.432 & 0.318 & 11.1 & 0.00434 & 0.341 \\
\hline 12 & & 0.357 & 0.238 & 8.3 & 0.00464 & 0.345 \\
\hline 13 & & 0.283 & 0.179 & 6.2 & 0.00496 & 0.350 \\
\hline 14 & & 0.251 & 0.083 & 2.9 & 0.00361 & 0.354 \\
\hline 15 & & 0.197 & 0.063 & 2.2 & 0.00381 & 0.358 \\
\hline 16 & $\begin{array}{l}\text { (Term } \\
\text { bronchiole) }\end{array}$ & 0.162 & 0.046 & 1.6 & 0.00416 & 0.362 \\
\hline 17 & $\begin{array}{l}\text { (Resp } \\
\text { bronchiole) }\end{array}$ & 0.080 & 0.018 & 0.6 & 0.00080 & 0.363 \\
\hline 18 & & 0.080 & 0.009 & 0.3 & 0.00017 & 0.363 \\
\hline 19 & & 0.100 & 0.003 & 0.1 & 0.00005 & 0.363 \\
\hline
\end{tabular}

Total $\Delta P=0.363\left(\mathrm{~cm} \mathrm{H} \mathrm{H}_{2} \mathrm{O}\right) \pm 0.06$ 


\begin{tabular}{|c|c|c|c|c|c|c|}
\hline \multicolumn{2}{|c|}{ Order } & \multirow{2}{*}{$\begin{array}{l}\text { Actual } \\
\text { Tube } \\
\text { Lengeh } \\
\text { cm } \\
\frac{7}{}\end{array}$} & \multirow{2}{*}{$\begin{array}{l}\begin{array}{l}\text { Entrance } \\
\text { Length } \\
\mathrm{cm}\end{array} \\
48 .\end{array}$} & \multirow{2}{*}{$\begin{array}{l}\text { Reynolds } \\
\text { No. } \\
2,986 .\end{array}$} & \multirow{2}{*}{ 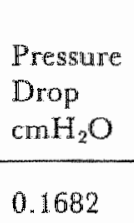 } & \multirow{2}{*}{$\begin{array}{l}\text { Cumulative } \\
\text { Pressure } \\
\text { Drop } \\
\mathrm{cmH}_{2} \mathrm{O} \\
0.168\end{array}$} \\
\hline 00 & (Mouth) & & & & & \\
\hline 0 & (Trachea) & 12 & 50 & 3,513 & 0.2238 & 0.393 \\
\hline 1 & $\begin{array}{l}\text { (Prinary } \\
\text { bronchi) }\end{array}$ & 4.22 & 75.0 & 2,930 & 0.1252 & 0.518 \\
\hline 2 & & 3.03 & 58.06 & 2,019 & 0.1271 & 0.645 \\
\hline 3 & & 2.34 & 43.38 & 1,509 & 0.1468 & 0.792 \\
\hline 4 & & 1.84 & 19.32 & 672 & 0.0584 & 0.851 \\
\hline 5 & & 1.46 & 14.72 & 512. & 0.0641 & 0.915 \\
\hline 6 & & 1.07 & 6.88 & 239. & 0.0287 & 0.943 \\
\hline 7 & & 0.975 & 5.09 & 177 & 0.0309 & 0.974 \\
\hline 8 & & 0.780 & 3.93 & 137 & 0.0324 & 1.007 \\
\hline 9 & & 0.650 & 1.65 & 57.3 & 0.0132 & 1.020 \\
\hline 10 & (Bronchiole) & 0.530 & 1.36 & 47.2 & 0.0157 & 1.036 \\
\hline 11 & & 0.432 & 0.637 & 22.2 & 0.00936 & 1.045 \\
\hline 12 & & 0.357 & 0.476 & 16.5 & 0.00984 & 1.055 \\
\hline 13 & & 0.283 & 0.359 & 12.4 & 0.01049 & 1.065 \\
\hline 14 & & 0.251 & 0.167 & 5.8 & 0.00738 & 1.073 \\
\hline 15 & & 0.197 & 0.126 & 4.4 & 0.00774 & 1.080 \\
\hline 16 & $\begin{array}{l}\text { (Tenm } \\
\text { bronchiole) }\end{array}$ & 0.162 & 0.093 & 3.2 & 0.00844 & 1.089 \\
\hline 17 & $\begin{array}{l}\text { (Resp } \\
\text { bronchiole) }\end{array}$ & 0.080 & 0.035 & 1.2 & 0.00158 & 1.090 \\
\hline 18 & & 0.080 & 0.017 & 0.6 & 0.00035 & 1.091 \\
\hline 19 & & 0.100 & 0.006 & 0.2 & 0.00009 & 1.091 \\
\hline
\end{tabular}

Total $\Delta P=1.091\left(\mathrm{~cm} \mathrm{H}_{2} \mathrm{O}\right) \pm 0.20$ 


\begin{tabular}{|c|c|c|c|c|c|c|}
\hline \multicolumn{2}{|c|}{ Order } & \multirow{2}{*}{$\begin{array}{l}\text { Actual } \\
\text { Tube } \\
\text { Length } \\
\mathrm{cm} \\
7 .\end{array}$} & \multirow{2}{*}{$\begin{array}{l}\begin{array}{l}\text { Entrance } \\
\text { Length } \\
\mathrm{cm}\end{array} \\
43 .\end{array}$} & \multirow{2}{*}{$\begin{array}{l}\begin{array}{l}\text { Reynollds } \\
\text { No. }\end{array} \\
2,986 .\end{array}$} & \multirow{2}{*}{$\begin{array}{l}\text { Pressure } \\
\text { Drop } \\
\mathrm{cmH}_{2} \mathrm{O} \\
0.1682\end{array}$} & \multirow{2}{*}{$\begin{array}{l}\text { Cumulative } \\
\text { Pressure } \\
\text { Drop } \\
\mathrm{cmH}_{2} \mathrm{O} \\
0.168\end{array}$} \\
\hline 0 & (Mouth) & & & & & \\
\hline 00 & (Trachea) & 12.2 & 50.5 & 3,500 & 0.240 & 0.408 \\
\hline 1 & $\begin{array}{l}\text { (Primary } \\
\text { bronchi) }\end{array}$ & 4.76 & 45 & 3,114 & 0.2183 & 0.626 \\
\hline 2 & & 1.90 & 65.7 & 2,295 & 0.1787 & 0.805 \\
\hline 3 & & 0.76 & 48.8 & 1,698 & 0.2091 & 1.014 \\
\hline 4 & & 1.27 & 30.4 & 1,058 & 0.1816 & 1.181 \\
\hline 5 & & 1.07 & 19.5 & 679. & 0.1465 & 1.342 \\
\hline 6 & & 0.90 & 12.2 & 424 & 0.1098 & 1.452 \\
\hline 7 & & 0.76 & 7.44 & 259 & 0.0867 & 1.539 \\
\hline 8 & (Bronchiole) & 0.64 & 4.60 & 160. & 0.0674 & 1.606 \\
\hline 9 & & 0.54 & 2.77 & 96.4 & 0.0484 & 1.640 \\
\hline 10 & & 6.46 & 1.64 & 57.1 & 0.0332 & 1.688 \\
\hline 11 & & 0.39 & 0.98 & 34.1 & 0.0252 & 1.719 \\
\hline 12 & & 0.33 & 0.56 & 19.6 & 0.0170 & 1.730 \\
\hline 13 & & 0.27 & 0.33 & 11.3 & 0.0119 & 1.742 \\
\hline 14 & & 0.23 & 0.18 & 6.3 & 0.00737 & 1.749 \\
\hline 15 & & 0.20 & 0.10 & 3.6 & 0.00313 & 1.752 \\
\hline 16 & $\begin{array}{l}\text { (Term } \\
\text { bronchiole) }\end{array}$ & 0.165 & 0.056 & $\mathbb{1 . 9}$ & 0.00296 & 1.755 \\
\hline 17 & $\begin{array}{l}\text { (Resp } \\
\text { bronchiolle) }\end{array}$ & 0.141 & 0.031 & 1.1 & 0,00192 & 1.75 .7 \\
\hline 18 & & 0.119 & 0.017 & 0.6 & 0.00108 & 1.758 \\
\hline
\end{tabular}

Total $\Delta P=1.758\left(\mathrm{~cm} \mathrm{H}_{2} \mathrm{O}\right) \pm 0.30$ 


\section{References}

1. Mead J, Lindgren I, Gaensler EA. The mechanical properties of the lungs in emphysema. J Clin Invest $1955 ; 34: 1005-16$.

2. Ous AB, McKerrow CB, Bartlett RA, Mead J, Mclloy MB, Selverstone NJ, Radford EP. Mechanical factors in distribution of pumonary ventilation. J Appl Physiol 1956:8:427 - 43.

3. Mead J. Contribution of compliance of airways to frequency-dependent behavior of lungs. J Appl Physiol 1969;26:670-73.

4. Nagels I, Lándsér $\mathbb{F}^{\mathrm{J}} \mathrm{J}$, Van der Linden L, Clément J, Van de Woestijne KP. Mechanical properties of lungs and chest wall during spontaneous breathing. I Appl Physiol $1980: 49: 408-16$.

5. Weibel ER. Morphometry of the haman lung. Academic Press New York, 1963.

6. d'Olieslager J, Verhaegen L. Experimentele Natuurkunde. Ed. Wouters Leuven, 1968.

7. Cutillo AG, Renzetti Jr AD. Mechanical behavior of the respiratory system as a function of frequency in health and disease. Bull Europ Physiopath Respir 1983;19:293 - 326 .

8. Sobol JB. Test of ventilatory function not requiring maximal subject effort. Am Rev Respir Dis $1968 ; 97: 868-79$.

9. Grimby G, Takishima T, Graham W, Macklem P, Mead J. Frequency dependence of flow resistance in patients with obstructive lung disease. J Clin Invest 1968;47:1455--65.

10. Sharp JT, Henry JP, Sweany SK, Meadows WR, Pietras RJ. The total work of breathing in normal and obese men. J Clin Invest 1964;43:728-39.

11. Aronsson EI, Solymar L, Dempsey J, Bjure J, Olsson, Bake B. A modified forced oscillation technique for measurements of respiratory resistance. J Appl Physiol 1977;42:650-55.

12. Naimark A, Cherniack RM. Compliance of the respiratory system and its components in thealth and obesity. J Appl Physiol 1960;15:377-82.

13. Mittman C, Edelman NH, Norris AH, Shock NW. Relationship between chest wall and pulmonary compliance and age. I Appl Physiol 1965;20:1211-16.

14. Var Lith P, Johnson FN, Sharp JT. Respiratory elastances in relaxed and paralyzed states in normal and abnormal men. J Appl Physiol 1967;23:475-86.

15. Peslin $R$, Papon J, Duvivier $C$, Richalet $J$. Frequency response of the chest: modeling and parameters estimation. I Appl Physiol 1975;39:523-34.

16. Dubois AB, Brody AW, Lewis DH, Burgess BF. Oscillation mechanics of lungs and chest in man. J Appl Physiol 1956;8:587-94.

17. Michaelson ED, Grassman ED, Peters WR. Pulmonary mechanics by spectral analysis of for ced random noise. IJ Clin Invest 1975;56:1210-30.

18. Visser BF. Personal communications.

19. Horsheld $K$, Cumming $G$. Morphology of the bronchial tree in man. J Appl Physiol $1968 ; 24: 373-83$.

20. Olson DE, Dart GA, Filley GF. Pressure drop and fluid flow regime of air inspired into the human lung. J Appl Physiol $1970 ; 28: 482-94$. 


\section{CHAPTER 3 \\ FORCED OSCILLOMETRY OF THE RESPIRATORY SYSTEM}

\subsection{Historical review}

Most of the experimental data on the behaviour of the respiratory system as a function of frequency have been obtained by measurements of total respiratory resistance using various methods derived from the forced oscillation technique described by Dubois et al. in $1956(\mathbb{1})$. The frequency response characteristics of the airways, lungs and chest were measured as the pressure-flow response to a sine wave, produced by a pump over the frequency range from 1 to $35 \mathrm{~Hz}$. Sinusoidal oscillations were applied at the mouth or at the chest. Total respiratory resistance was measured at resonant frequency, at which the net reactance of the respiratory system is zero and pressure and flow are in phase.

Mead (2) showed that the forced oscillations can be superimposed on the breathing pattern.

Ferris et al. (3) measured total respiratory flow resistance by rapid oscillations of pressure at the mouth produced by a loudspeaker at a frequency corresponding to the resonant frequency of the respiratory system and superimposed upon the flow variations associated with breathing.

Fisher et al. (4) measured total respiratory resistance by the application of a sine wave of airflow to the mouth at the resonant frequency of the respiratory system. Oscillating air flows were produced at the mouth with a variable frequency pump that delivered a sine wave of fixed stroke volume of approximatively $30-40 \mathrm{ml}$. The oscillations were superimposed upon the normal respiratory pattern of the subject. However, the subjects were instructed to relax the muscles of the chest wall and upper airways at the end of expiration and to prolong the pause between breaths. They measured total respiratory resistance in normal subjects and in COPD patients. Where in normal subjects resonant frequency is between 5 and $8 \mathrm{~Hz}$, they found that in many of the COPD patients the phase angle between mouth pressure and airflow is not zero at any frequency between 2 and $10 \mathrm{~Hz}$. Nevertheless, they measured total respiratory resistance in a frequency range from 3.7 to $7.0 \mathrm{~Hz}$.

Grimby et al. (5) found that an equipment, consisting of a single loudspeaker connected directly to the flowmeter with a long tube and incorporating a bias flow system, produces adequate pressure oscillations. This equipment is still the basis of the present techniques (fig. 3.1). These authors were the first to apply the forced oscillation technique to the study of behaviour of resistance as a function of frequency. 


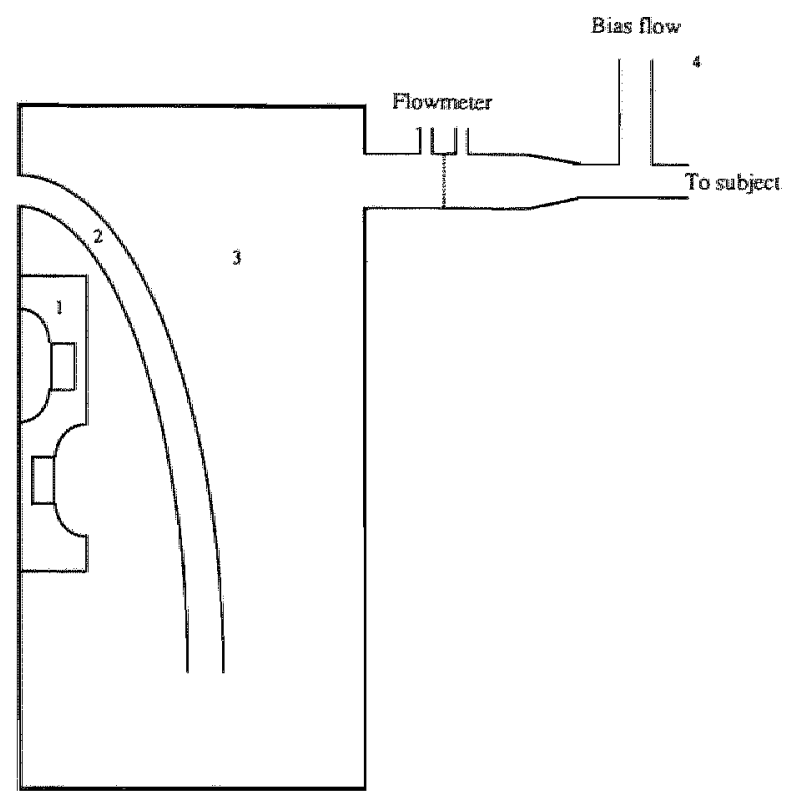

Fig. 3.1.

Forced oscillation apparatus according to Grimby. 1: loudspeaker; 2: tubing from the atmosphere to the box; 3 : volume of gas in the box; 4: bias flow.

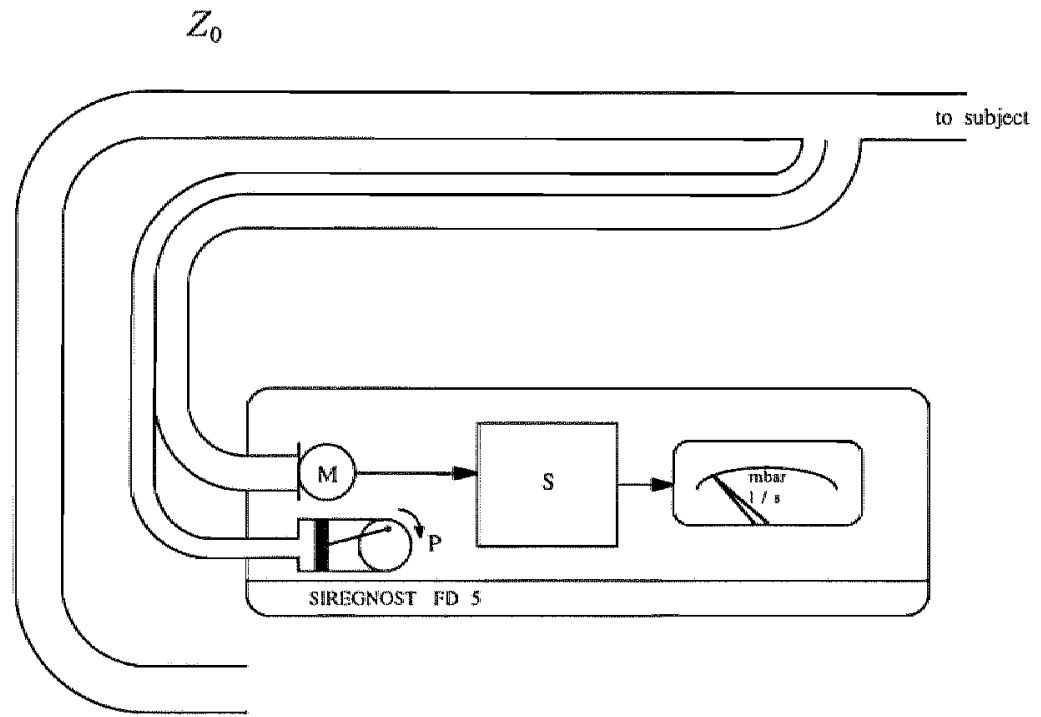

Fig. 3.2

Respiratory impedance apparatus according to Korn. ( $Z_{0}$ : reference resistance; $\mathrm{M}$ : microphone; $\mathrm{S}$ : signal processing; $\mathrm{P}$ : oscillation generator.) 
Total respiratory, pulmonary and chest wall flow resistances were determined by means of forced pressure and flow oscillations (at $3 ; 5 ; 7$ and $9 \mathrm{~Hz}$ ) in a group of patients with varying degrees of obstructive lung disease. They found increased total respiratory and pulmonary resistances, whereas the chest wall resistance was normal or subnormal. The total respiratory and pulmonary resistances decreased with increasing frequencies. Furthermore, they found that patients who exhibit frequency dependence of compliance also exhibit frequency dependence of resistance, according to Otis et al. (6). Resistance could be measured by achieving an artificial resonance at different frequencies by adding to the pressure signals ones proportional to the instantaneous volume or to volume acceleration. Supposing a linear behaviour: of the respiratory system, Goldman et al. (7) published a simplified method to measure total respiratory resistance by utilizing two specific instants in the induced cycle where the components of the applied pressure difference due to elastic and inertial impedance are both equal to zero. This method is commercially applied in the Astrograph ${ }^{\circledR}$. Initially, sine waves of $3 \mathrm{~Hz}$ were applied. The commercial apparatus now measures at 3,5 and $7 \mathrm{~Hz}$. Hyatt et al. (8) also had developed equipment that computed total respiratory resistance from consecutive points of zero flow acceleration.

Another simplified method for measurement of the respiratory impedance was presented by Korn et. al. (9). Respiratory impedance was determined at a fixed frequency of $10 \mathrm{~Hz}$. This method is commercially applied in the Siregnost FD $5^{(}$. The measuring principle is shown in figure 3.2 . The subject breathes normally through a defined flow impedance $Z_{0}$, which is called the reference impedance. Near the mouthpiece a known oscillating flow $V_{0}$ enters the system. This will make its way to ambient pressure partly through the respiratory impedance $Z_{\text {rs }}$, partly through the reference impedance $Z_{0}$. Therefore, $Z_{\text {rs }}$ and $Z_{0}$ are connected in parallel with respect to $\dot{V}_{0}$. This can be expressed by the equation :

$\bar{V}_{0} / p=1 / Z_{\mathrm{rs}}+1 / Z_{0}$

$Z_{\mathrm{rs}}=1 /\left(\mathscr{V}_{0} / p-1 / Z_{0}\right)$

As $\dot{V}_{0}$ and $Z_{0}$ are known and constant, $Z_{\mathrm{r} s}$ is determined by the pressure $p$. By measuring the amplitude and phase angle of $p, Z_{\text {rs }}$ can be calculated.

The reference impedance $Z_{0}$ is a virtually inductive impedance in the form of a tube. By estimating the phase angle at a certain resistance value, only the pressure amplitude has to be processed. This value is called oscillatory resistance $\left(R_{\text {os }}\right)$.

Modifications of the forced oscillation technique have been developed to remove the distorting influence of spontaneous breathing on the forced oscillations (10, 11). 
a.

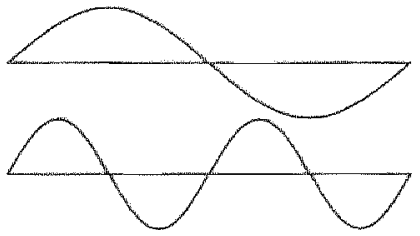

c. HMAHHHAHAHAMH

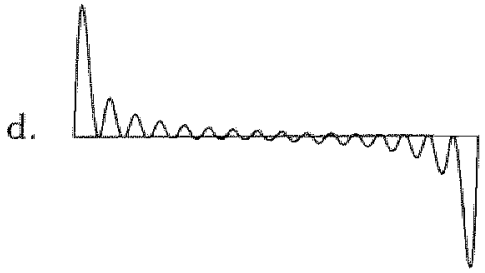

Fig. 3.3.

Computer simulation of a composed signal: all frequencies start at the same moment. (a: ground frequency; b: doubling of ground frequency; c: ground frequency times 16 ; $\mathrm{d}$ : composed signal). a.

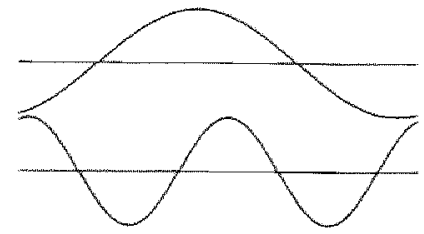

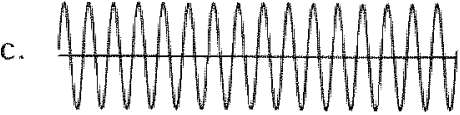

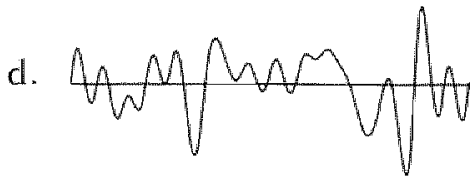

Fig. 3.4.

Computer simulation of a pseudo-random noise signal: $a, b, c$ and $d$ as in fig. 3.3 .

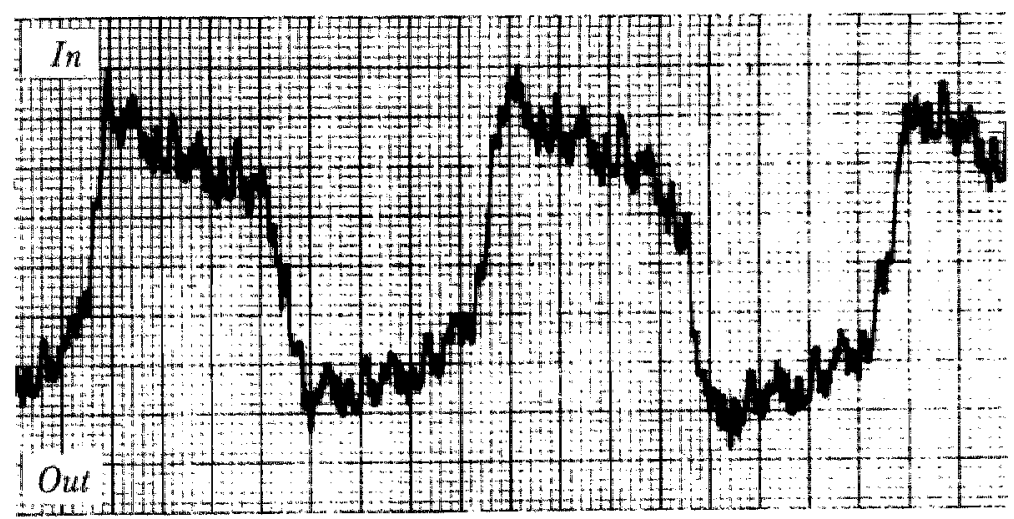

Fig. 3.5

A pseudo-random noise signal superimposed on the normal breathing pattern. 
The advent of fast computer techniques for frequency analysis had promoted the use of non-periodic waveforms with appropriate frequency spectra.

The analysis of these waveforms allowed rapid measurement of total respiratory impedance and its components as functions of frequency over an extended frequency range.

In the technique developed by Michaelson et al. (12) a random noise pressure signal was applied at the mouth during spontaneous breathing and the resulting pressure and flow signals were resolved into their frequency spectra by Fourier analysis. Total respiratory impedance and its components were obtained as functions of frequency between 3 and $45 \mathrm{~Hz}$.

In a further development of the forced oscillation technique, a signal composed of known frequencies is applied at the respiratory system.

However, the application of such a signal can have some disadvantages. As illustrated in figure 3.3, when all frequencies start at the same moment, the positive amplitude at the start and the negative amplitude at the end are great, introducing the possibility of alinearity of the system. Furthermore, amplitudes in the middle part are so small that the signal-to-noise ratio is unfavourable. To avoid this problem, Lándsér et al. (13) had introduced the pseudo-random noise technique, using a complex signal containing the fundamental frequency of $2 \mathrm{~Hz}$ and all harmonics of $2 \mathrm{~Hz}$ up to $32 \mathrm{~Hz}$.

Each frequency starts at a different, randomly selected moment (fig. 3.4). The advantages of such a technique are that all amplitudes can be made equal and that all applied frequencies are known.

The forced oscillation technique has been used for measurement of respiratory resistance or impedance in preschool children by many investigators $(14-21)$.

\subsection{Forced pseudo-random noise oscillation technique.}

\subsubsection{Methads}

Frequency characteristics of the respiratory system were investigated by Lándser et al. (13) using a complex signal consisting of a $2 \mathrm{~Hz}$ signal with its harmonics up to $32 \mathrm{~Hz}$.

This impulse was applied at the mouth during spontaneous breathing (fig. 3.5). Initially, measurements were performed over a period of $16 \mathrm{~s}$ or over several breathing cycles.

Impedance $(Z)$ of the respiratory system $(\mathrm{rs})$ was calculated at each frequency according to the formula $Z_{\mathrm{r} s}=p / V$. Supposing a $R-L-C$ model of the respiratory system, $Z_{\mathrm{rs}}$ can be defined as $: Z_{\mathrm{rs}}=R+1 / \mathrm{j} \omega C+\mathrm{j} \omega L$

where $R=$ resistance, $Z-R=X=$ reactance $=\omega L-1 / \omega C, \mathrm{j}=\sqrt{-1}$, $\omega=2 \pi f, f=$ frequency. 
That impedance is partitioned into a real part, or resistance, and an imaginary part, or reactance. Simultaneously, resonant frequency, $f_{0}$, is measured.

At $f_{0}$, reactance equals zero and therefore $f_{0}$ can be calculated according to the formula: $f_{0}=(L C)^{-1 / 2 / 2 \pi}$.

The method of Lándsér is commercially applied in the Oscillaire ${ }^{\circledR}$. This commercial apparatus used impulses containing all harmonics of $2 \mathrm{~Hz}$ up to $26 \mathrm{~Hz}$. Frequencies below $2 \mathrm{~Hz}$ are not used because even by averaging over $16 \mathrm{~s}$, the

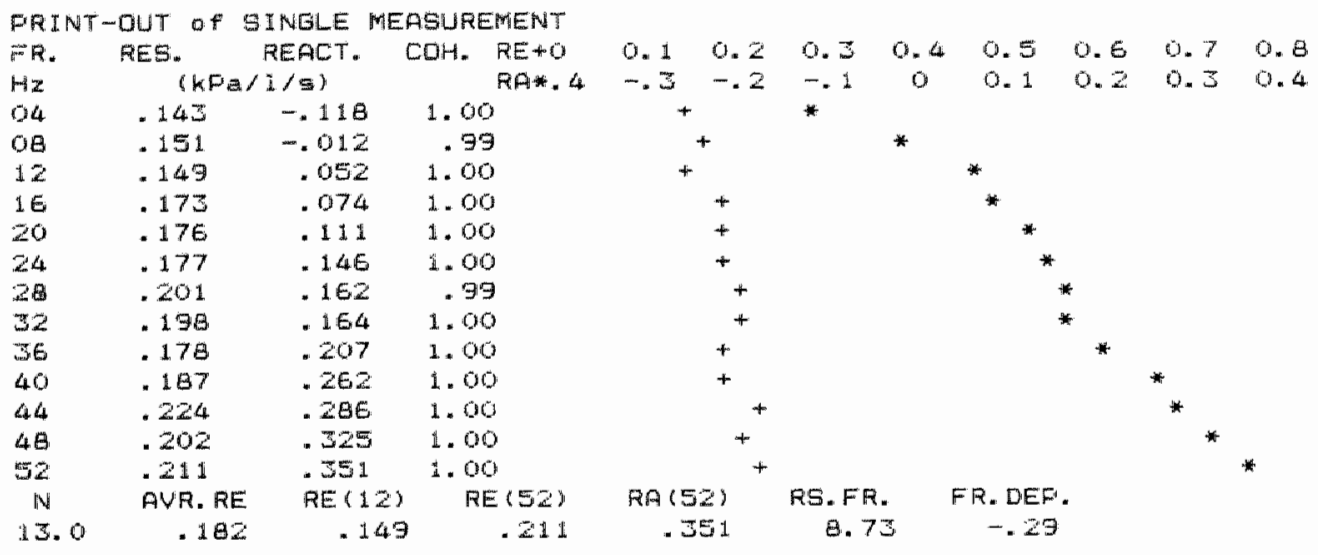

Table 3.1.

Print-out of impedance measurement with FOT according to Lándsér in a normal subject.

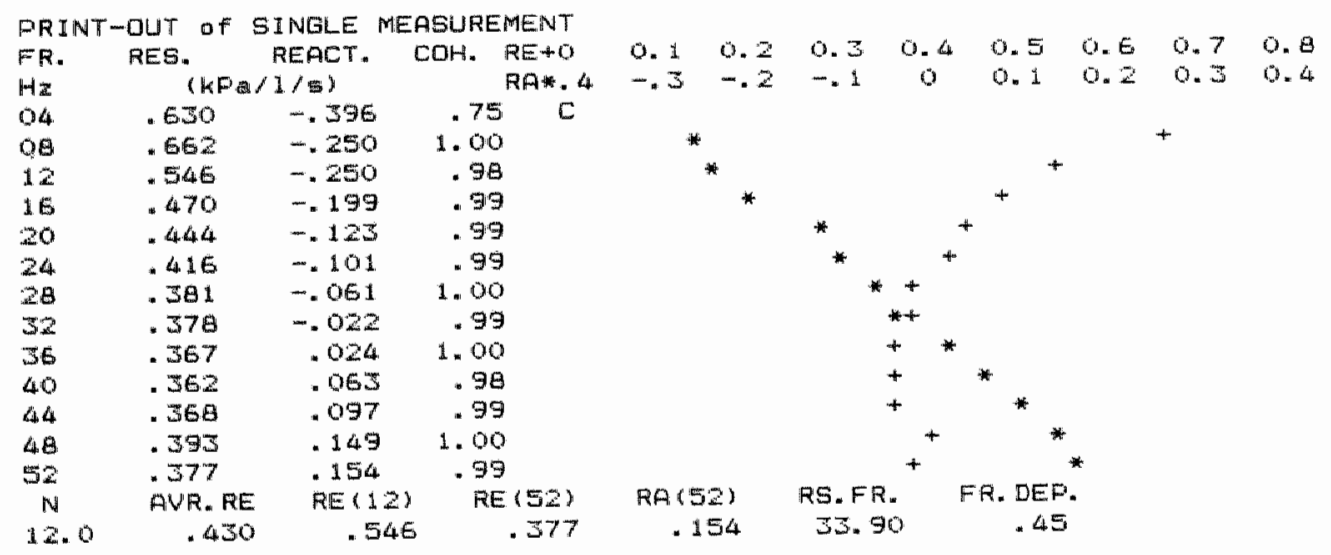

Table 3.2 .

Print out of impedance measurement with FOT according to Laándsér in a COPD patient. 
influence of the high frequency components, present in the spontaneous breathing pattern, becomes too important.

The frequency spectrum is extented to $52 \mathrm{~Hz}(22)$. Sine waves of $4,8,12 \ldots 52$ $\mathrm{Hz}$ are applied at the mouth as a pseudo-random noise signal. The measuring time is reduced to $8 \mathrm{~s}$.

For each frequency a coherence value is calculated to assess the interference of the noise signal with the signal of breathing. A perfect coherence is indicated by 1; its value decreases in the presence of noise and of an alinearity in the relation of the investigated signals. Only values with a coherence function equal to or larger than .95 were retained (13).

The on-line use of a microprocessor system facilitates the calculations. In addition, measured values can be compared instantaneously with predicted values.

\subsubsection{Results of measurements}

Table 3.1 represents a print-out of an impedance measurement of the respiratory system in a normal subject.

Resistance values slightly increase with frequency. At lower frequencies, the reactance is negative: this means that the capacitive part of the reactance predominates. At higher frequencies the influence of the inertance becomes larger and the reactance grows positive. The resonant frequency, at which the influence of capacitance and inertance cancels out, is $8.73 \mathrm{~Hz}$.

Table 3.2 represents a print-out of an impedance measurement of the respiratory system in a COPD patient.

Resistance values are increased at lower frequencies and values of resistance markedly decrease with increase of frequency: there is frequency dependence of resistance. At $28-32 \mathrm{~Hz}$, no further decrease of resistance values occurs. Reactance values are negative up to $32 \mathrm{~Hz}$. Resonant frequency is reached at $34 \mathrm{~Hz}$.

\subsubsection{Frequency dependence of resistance}

According to Cutillo and Renzetti (24) the expression "frequency dependence" is used to indicate a decrease of resistance statistically significant or exceeding conventional limits of the normal range.

A considerable amount of information on the relationship between resistance and frequency has been obtained by many investigators on the basis of measurements of total resistance by the forced oscillation technique.

Grimby et al. (5) have demonstrated frequency dependence of inspiratory resistance using frequencies from 3 to $9 \mathrm{~Hz}$ in a group of COPD patients.

Hyatt et al. (8), measuring total respiratory resistance at 3 and $5 \mathrm{~Hz}$ in normal subjects and in COPD patients, found in the latter group lower values of $R_{\mathrm{rs}}$ at $5 \mathrm{~Hz}$ than at $3 \mathrm{~Hz}$.

Frank and co-workers (25), measuring oscillatory resistance during quiet breathing in normal subjects at $3 ; 6$ and $10 \mathrm{~Hz}$, found in every subject a decrease of respiratory resistance with increasing frequency. 

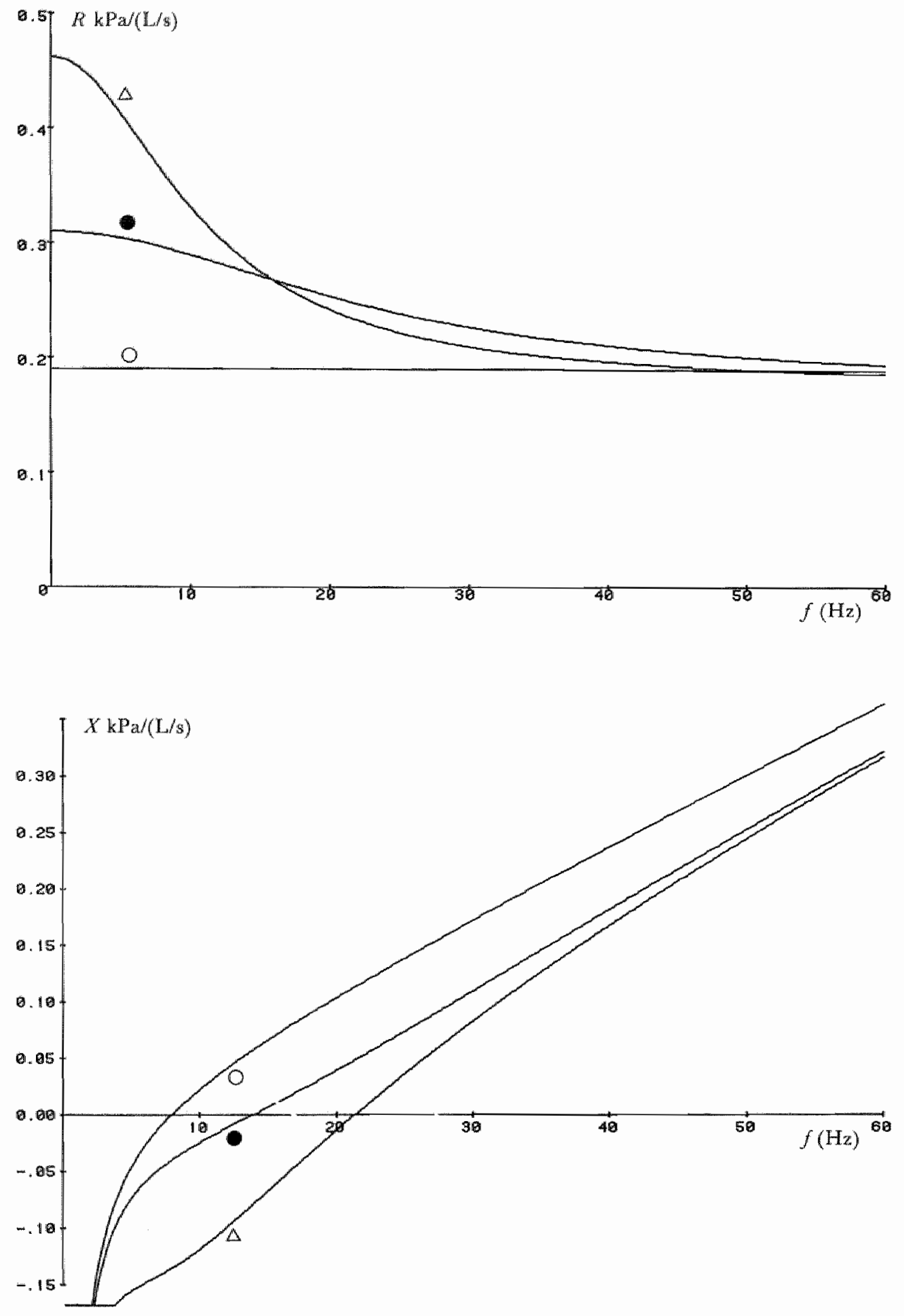
Stanescu et al. (10) found a qualitatively similar pattern of frequency dependence as observed by Grimby et al. in a group of COPD patients over a range of 3 to $9 \mathrm{~Hz}$. These authors found no change of resistance values at 3 and $9 \mathrm{~Hz}$ in a group of normal subjects.

Michaelson et al. (12), measuring the impedance of the respiratory system from 3 to $45 \mathrm{~Hz}$, demonstrated in COPD patients that impedance of the respiratory system is quite high at low frequencies and decreases to a minimum at much higher frequencies compared to normal subjects and smokers.

Kjeldjaard and co-workers (26), comparing the frequency dependence of lung compliance and of pulmonary resistance, found a close correlation between both measurements. Respiratory resistance was measured at $3 ; 5 ; 7$ and $9 \mathrm{~Hz}$. Healthy non-smokers, asymptomatic smokers and COPD patients were studied by these authors.

Hayes et al. (27), using a forced random noise signal from 5 to $19 \mathrm{~Hz}$, demonstrated a marked decrease of respiratory resistance at increased frequencies.

Lándsér et al. (13), using a pseudo-random noise signal from 2 to $32 \mathrm{~Hz}$, made the same observations in COPD patients.

Clément et al. (28), comparing the frequency dependence of total respiratory resistance and reactance by a forced oscillation technique in healthy subjects and in patients with respiratory complaints, demonstrated that $R_{\mathrm{rs}}$ and $X_{\mathrm{rs}}$ data of patients, measured between 8 and $24 \mathrm{~Hz}$, differ from those of healthy subjects primarily by a decrease of $R_{\mathrm{rs}}$ with frequency associated with more negative $X_{\mathrm{rs}}$ and thus with an increase of resonant frequency. Frequency dependence could accurately be described using the first derivative of $R_{\mathrm{rs}}$.

\subsubsection{Extended spectrum model analysis.}

\subsection{Peripheral resistance.}

Results of an increase of peripheral resistance with constant values of other components of the model of Leuven (23) are illustrated in fig. 3.6.

Peripheral resistance values of $0.014 ; 0.14$ and $0.30 \mathrm{kPa} /(\mathrm{L} / \mathrm{s})$ are used.

Supposing $R_{\mathrm{p}}$ equals zero, the real part of the peripheral impedance $\left(R_{\mathrm{L}}\right)$ equals zero and resistance of the respiratory system is determined by $R_{\mathrm{c}}$ and $R_{\mathrm{W}}$ in series. $R_{\text {rs }}$ is frequency independent.

\section{Fig. 3.6.}

Computer simulation of an increase of peripheral resistance in the model of Leuven

Open circles $R_{\mathrm{p}}=0.014 \mathrm{kPa} /(\mathrm{L} / \mathrm{s})$; closed circles $R_{\mathrm{p}}=0.14 \mathrm{kPa} /(\mathrm{L} / \mathrm{s})$ and open triangles $R_{\mathrm{p}}=$ $0.3 \mathrm{kPa} /(\mathrm{L} / \mathrm{s})$. Other components are unchanged. 

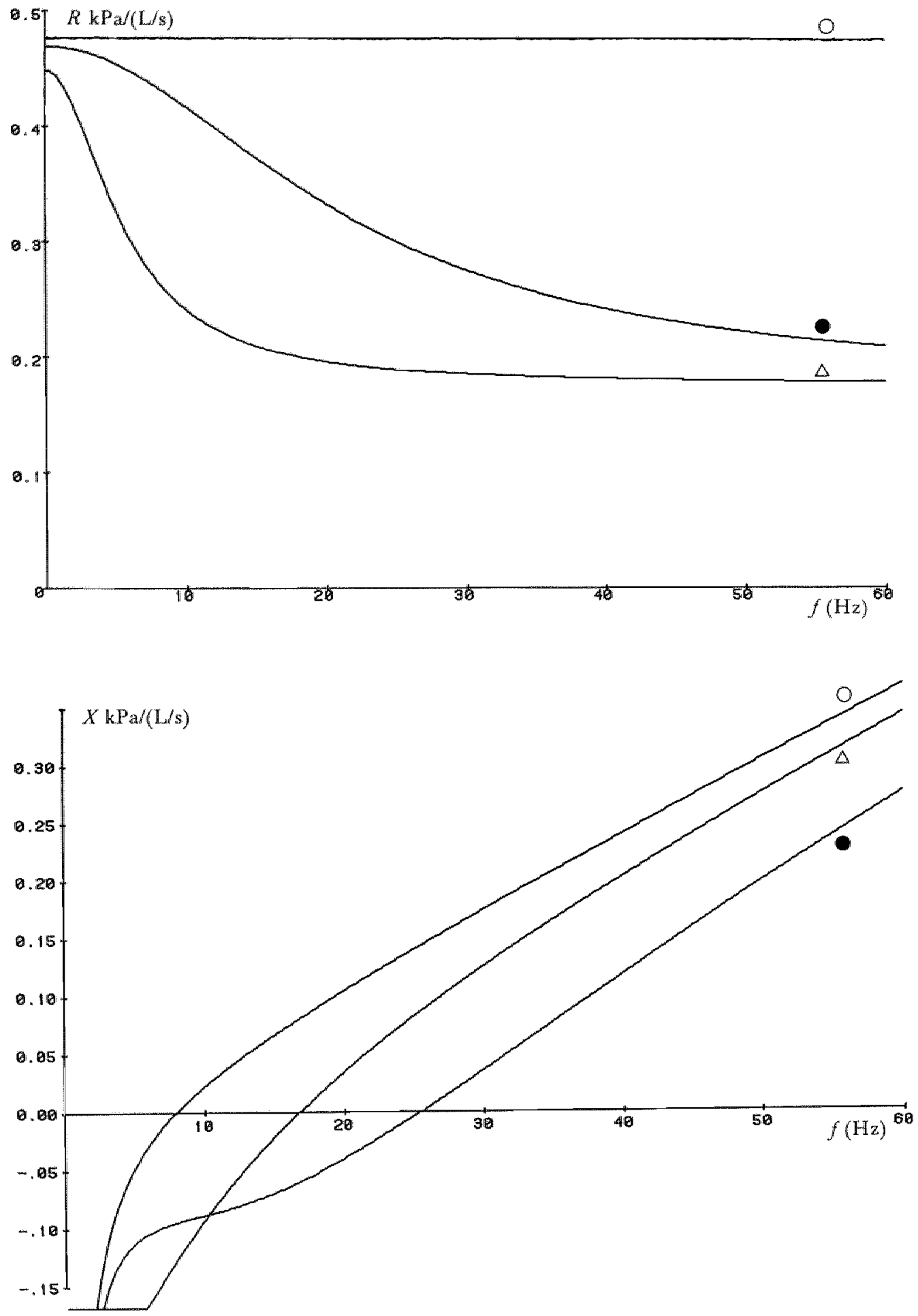
Increasing $R_{\mathrm{p}}$ values, resistance becomes frequency dependent, reactance decreases and the course of $X_{\mathrm{rs}}$ with frequency is less concave i.e. more linear than at lower values of $R_{\mathrm{p}}$. By increasing $R_{\mathrm{p}}$ values, the capacitance of the respiratory system is determined by $C_{\mathrm{A}}$ and $C_{W}$ in series, resulting in an increase of $f_{0}$.

\subsection{Influence of ainway compliance.}

Frequency dependence of the real part of impedance is only possible by including airway compliance in the model. Supposing $C_{\mathrm{A}}$ to be zero, the equation of the real part of the peripheral impedance $\left(R_{\mathrm{L}}\right)$ can be simplified :

$R_{\mathrm{L}}=R_{\mathrm{p}} C_{\mathrm{L}}{ }^{2} / C_{\mathrm{L}}{ }^{2}$

$R_{\mathrm{L}}=R_{\mathrm{p}}$

$R_{\mathrm{rs}}$ is determined by $R_{\mathrm{c}}, R_{\mathrm{p}}$ and $R_{\mathrm{W}}$ in series and is frequency independent.

Fig. 3.7 illustrates the changes of $R_{\mathrm{rs}}$ and $X_{\mathrm{rs}}$ using different values of $C_{\mathrm{A}}(0.000$; 0.025 and $0.1 \mathrm{~L} / \mathrm{kPa}$ ) when $R_{\mathrm{p}}$ is $0.3 \mathrm{kPa} /(\mathrm{L} / \mathrm{s})$ and other components are constant.

When $C_{\mathrm{A}}$ is zero, resistance is frequency independent.

In this case, the equation of the imaginary part of the peripheral impedance can be simplified :

$X_{\mathrm{L}}=-\mathrm{j} / \omega C_{\mathrm{L}}$

According to the equation of $R_{\mathrm{L}}$, increase of $C_{\mathrm{A}}(0.1 \mathrm{~L} / \mathrm{kPa})$, results in a steeper curve of resistance with frequency, higher reactance values and a decrease of $f_{0}$ in comparison with the results of $C_{\mathrm{A}}=0.05 \mathrm{~L} / \mathrm{kPa}$ (fig. 3.6). Opposite changes are observed with lower values of $C_{\mathrm{A}}=0.025 \mathrm{~L} / \mathrm{kPa}$.

Fig. 3.7 .

Computer simulation of respiratory impedance at different values of airway compliance at increased $R_{\mathrm{p}}$ value $0.3 \mathrm{kPa} /(\mathrm{L} / \mathrm{s})$.

Open circles $C_{\mathrm{A}}=0.00 \mathrm{~L} / \mathrm{kPa}$; closed circles $C_{\mathrm{A}}=0.025 \mathrm{~L} / \mathrm{kPa}$ and open triangles $C_{\mathrm{A}}$ - 0.1 $\mathrm{L} / \mathrm{kPa}$. Other components are unchanged. 

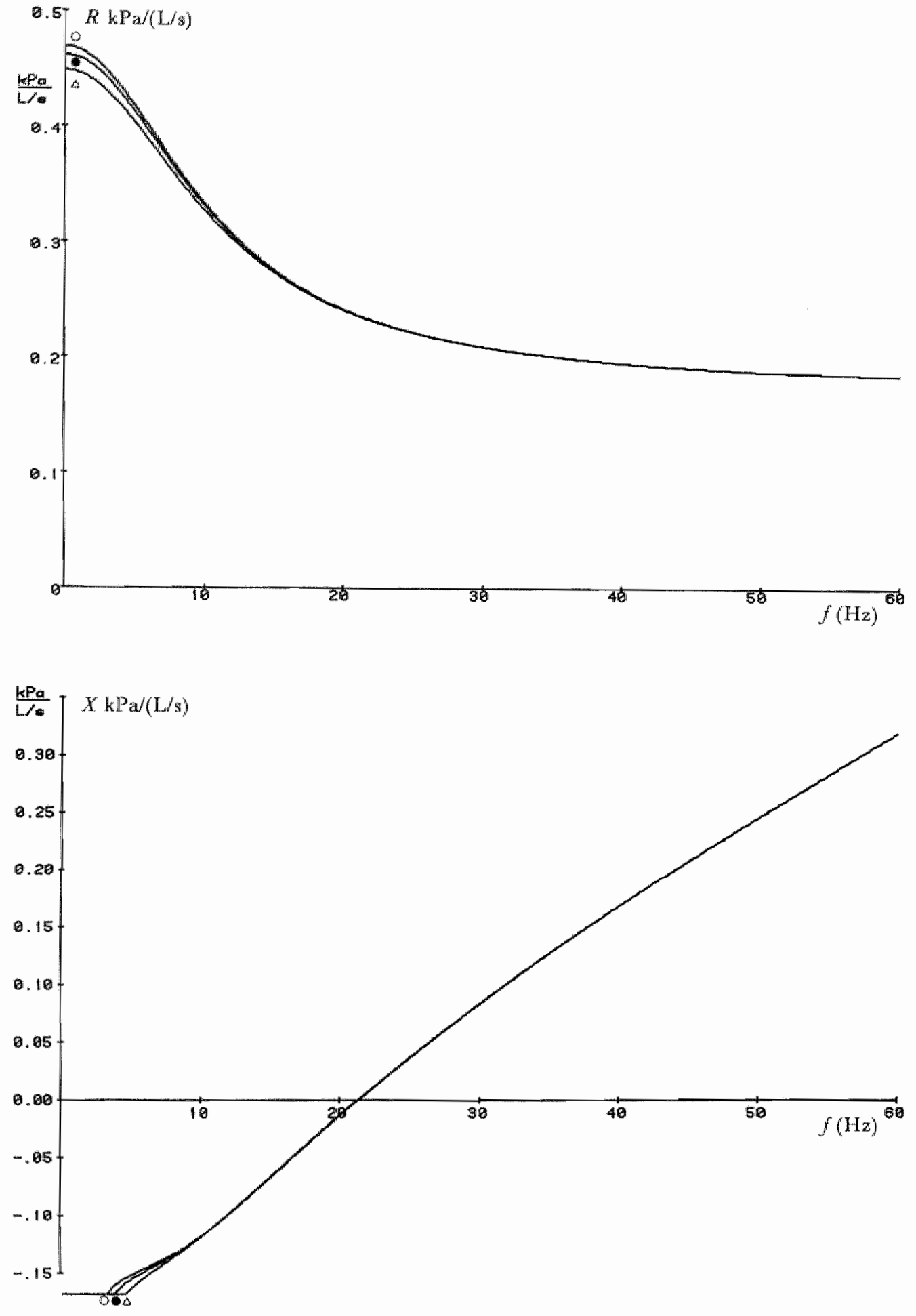


\subsection{Influence of lung compliance.}

Results of calculations using different values of $C_{\mathrm{L}}$ are presented in figure 3.8 . As can be expected, changing values of $C_{\mathrm{L}}$ have no effect on the frequency dependent behaviour of the respiratory system.

\subsubsection{Influence of age.}

Earlier studies have reported a decrease of respiratory resistance as a function of height in children $(14,15,20)$.

Stanescu and co-workers (19) measured respiratory resistance in 130 children aged 3-14 years with the oscillation technique between 4 and $9 \mathrm{~Hz}$. They found a statistically significant decrease of respiratory resistance at both 4 and $9 \mathrm{~Hz}$ as a function of height. No statistically significant difference was found between boys and girls of 3-14 years. Frequency dependence of resistance $\left(R_{\mathrm{rs}(4)}\right.$ $R_{\mathrm{rs}(9)}>0$ ) was found in children at all ages.

Frequency dependence was maximal at the age of 3-4 years and decreased progressively to reach a minimum at the age of $12-13$ years. Frequency dependence decreased with increasing height. These authors suggested that frequency dependence of resistance in children can be explained on the basis of an increased peripheral resistance.

The results of Duiverman et al. (21) were quite different from the observations of Stanescu et al. (19).

Duiverman et al. have studied 255 healthy Caucasian children of Dutch descent between 2.3 and 12.5 years, using a forced pseudo-random noise technique measuring $R_{\mathrm{rs}}$ and $X_{\mathrm{rs}}$ at frequencies from 4 to $26 \mathrm{~Hz}$.

Stanescu et al. found a decrease of $R_{\mathrm{rs}(6)}$ values as a function of height. However, the results of Duiverman indicated a constant $R_{\mathrm{rs}(6)}$ when the height is $150 \mathrm{~cm}$. Data of Stanescu suggested a further decrease of $R_{\mathrm{rs}(6)}$ from $150 \mathrm{~cm}$ to about $165-170 \mathrm{~cm}$.

Duiverman et al. found that $R_{r s}$ and $X_{r s}$ are influenced by sex, height, weight and age. Overweight was associated with higher values of $R_{\mathrm{r} s}$ but virtually no change of $X_{\mathrm{rs}}$. They further found that in children at 4 years of age $R_{\mathrm{rs}}$ is significantly higher in boys than in girls, in children at about 8 years of age $R_{\mathrm{rs}}$ values do not differ significantly in the two sexes, and at about 12 years, $R_{\mathrm{rss}}$ is again significantly higher in boys than in girls.

Fig. 3.8.

Computer simulation of respiratory impedance at different values of lung compliance at increased $R_{\mathrm{p}}$ value $0.3 \mathrm{kPa} /(\mathrm{L} / \mathrm{s})$.

Open circles $C_{\mathrm{L}}=4 \mathrm{~L} / \mathrm{kPa}$; closed circles $C_{\mathrm{L}}=2 \mathrm{~L} / \mathrm{kPa}$ and open triangles $C_{\mathrm{L}} \approx 1 \mathrm{~L} / \mathrm{kPa}$. Other components are unchanged. 

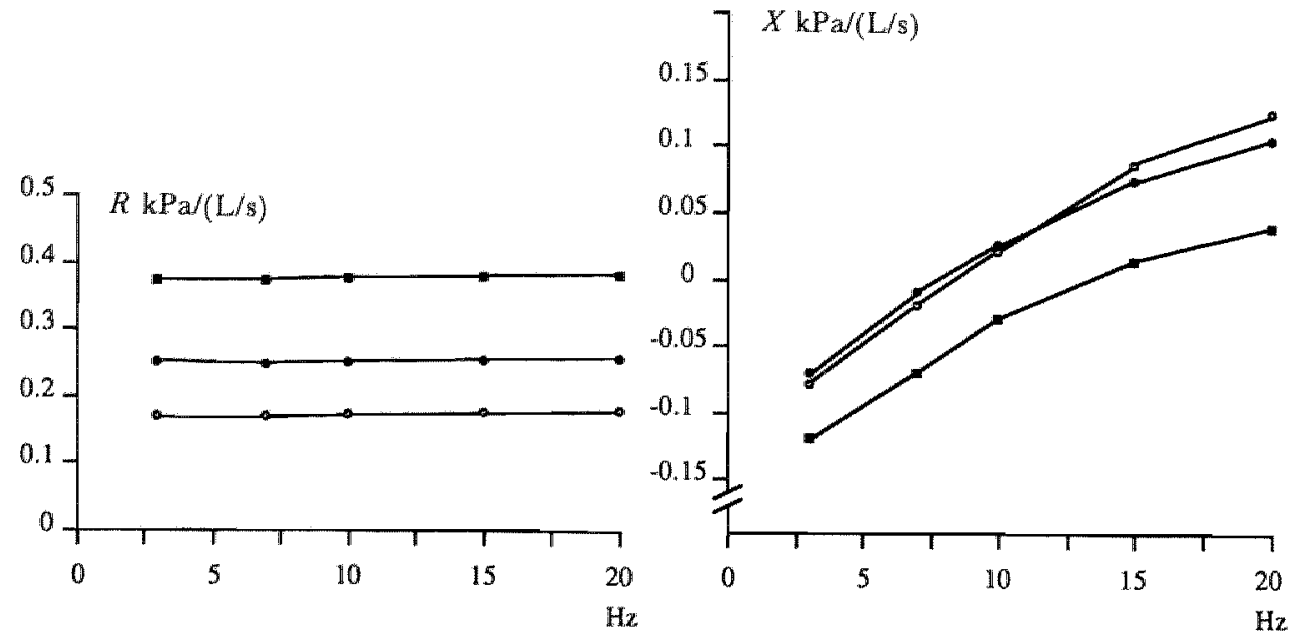

Fig. 3.9.

Influence of lung volume on respiratory impedance in normal subjects according to Nagels. (Open circles $70 \% \mathrm{VC}$; closed circles $40 \% \mathrm{VC}$ and closed squares $25 \% \mathrm{VC}$ ).

(J Appl Physiol 1980; 49:408-16; reprinted with permission).
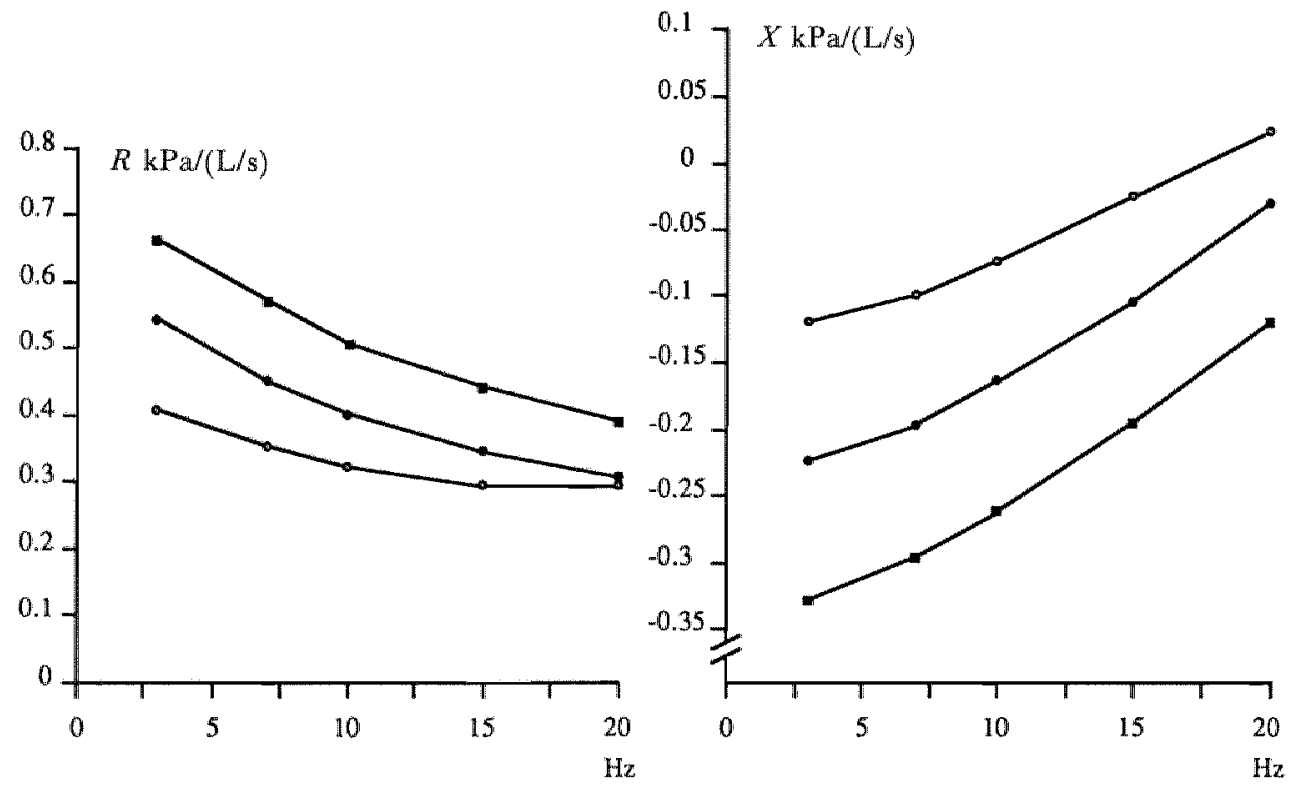

Fig. 3.10.

Influence of lung volume on respiratory impedance in COPD patients according to Nagels. (Open circles $70 \% \mathrm{VC}$; closed circles $40 \%$ and closed squares $25 \% \mathrm{VC}$ ).

(J Appl Physiol 1980; $49: 408-16$; reprinted with permission). 
Furthermore, frequency dependence of $R_{\mathrm{rs}}$ was only found in young boys up to the age of approximatively 5 years.

$X_{\text {rs }}$ values were significantly lower in boys than in girls at all ages.

Duiverman et al. suggested that the differences in $R_{\mathrm{rs}}$ found between boys and girls below the age of about 8 years are compatible with differences in airway diameter and the differences at the age of 12 years were explained by the fact that at age 12 many girls but not boys have reached their puberty and that the growth spurt is accompanied by an increase in airway diameter. However, Stanescu had not found this sex difference extending their measurements to children of 16 years of age.

According to the model of Mead (29), Duiverman et al. suggested that the frequency dependence of $R_{\mathrm{rs}}$ in healthy boys under the age of five can be explained by an increase of peripheral airway obstruction. However, resonant frequencies of boys and girls at the age of 4 were about the same $(20 \mathrm{~Hz})$.

The increase of resonant frequency suggests an increase of peripheral resistance in both sexes. Therefore, also in girls a frequency dependence of resistance will be expected.

The lower $R_{\mathrm{rs}}$ and higher $X_{\mathrm{rs}}$ values in children with an increased height for age were explained by a larger airway diameter for age. However, increase of airway diameter will decrease inertance and therefore, supposing compliance is constant, will increase resonant frequency. The opposite effect was measured by Duiverman et al..

\subsubsection{Influence of lung volumes.}

Fisher et al. (4) demonstrated that total respiratory $\left(R_{\mathrm{rs}}\right)$ resistance varies inversely with lung volume measured plethysmographically. As evidenced by a high correlation between volume and the reciprocal of total respiratory resistance, they concluded that the relationship between $R_{\mathrm{rs}}$ and lung volume is hyperbolic. Slightly higher mean $R_{\mathrm{rs}}$ values in the female group than in the male group were attributed by these authors to the smaller lung volume present in females. Michaelson et al. (12) mentioned the effects of changing lung volumes on the components of total respiratory impedance. They found that by increasing lung volume, $R_{\mathrm{rs}}$ falls and the system appears less damped. At lung volumes above FRC, $f_{0}$ was slightly higher than at FRC. Below FRC, $R_{\mathrm{rs}}$ values were higher and $f_{0}$ increased. Furthermore, at low lung volumes, $R_{\mathrm{rs}}$ was frequency dependent.

Nagels et al. (23) measured resistance and reactance of the respiratory system at various lung volumes in 15 healthy subjects and in 7 patients with COPD. In healthy subjects, these authors found that $R_{\mathrm{rs}}$ and $X_{\mathrm{rs}}$ depend on lung volume. At higher lung volumes, $R_{\mathrm{rs}}$ decreased and $X_{\mathrm{rs}}$ increased, resulting in a decrease of fo (fig. 3.9).

In obstructive patients (fig. 3.10) $R_{r s}$ was higher and $X_{\mathrm{rs}}$ was lower than in healthy subjects. 

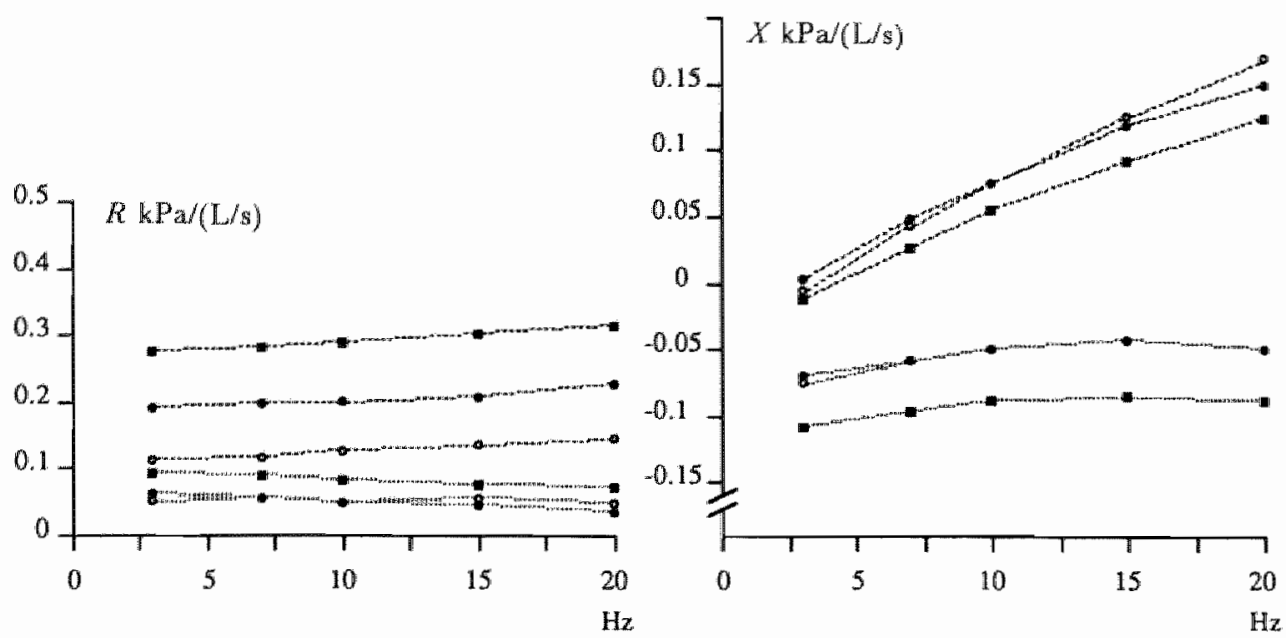

Fig. 3.11.

Intluence of Jung volume on different, components of respiratory impedance in normal subjects according to Nagels. (Lungs-airways: dashed lines; chest wall: dotted lines; open circles $70 \% \mathrm{VC}$; closed circles $40 \% \mathrm{VC}$; closed squares $25 \% \mathrm{VC}$ ).

(J Appl Physiol 1980; 49:408 - 16; reprinted with permission).

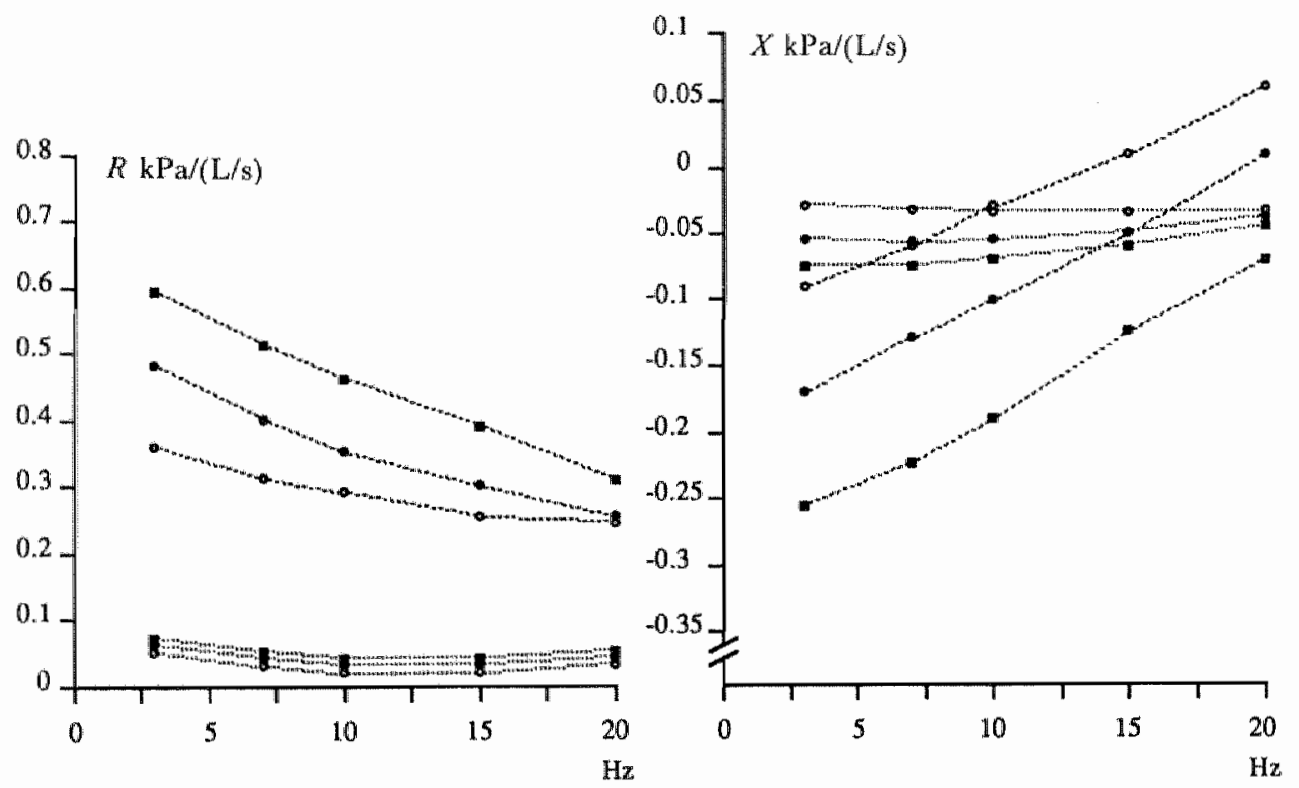

Fig. 3.12 .

Influence of lung volume on different components of respiratory impedance in COPD patients according to Nagels. (symbols see fig. 3.11).

(J Appl Physiol 1980; $49: 408-16$; reprinted with permission). 
As in healthy subjects, $R_{\mathrm{rs}}$ decreased and $X_{\mathrm{rs}}$ increased at higher lung volumes. Remarkably, frequency dependence of $R_{\mathrm{rs}}$ decreased at higher lung volumes and the increase of $X_{\mathrm{rs}}$ with frequency was less pronounced at $70 \%$ than at $25 \% \mathrm{VC}$.

\subsubsection{Frequency dependence of pulmonary resistance, chest wall resistance and resistance of the total respiratory system.}

Total respiratory resistance, pulmonary (airway plus lung tissue) resistance and chest wall flow resistance were measured by Grimby et al. (5) at different frequencies. They found in COPD patients a fall in total respiratory and pulmonary resistance with increasing oscillatory frequencies.

Chest wall resistance comprised only a minor fraction of the total respiratory resistance in most of the patients and no marked frequency dependence could be observed.

Resistance and reactance of the lungs $\left(R_{\mathrm{L}}\right.$ and $\left.X_{\mathrm{L}}\right)$ and chest wall $\left(R_{\mathrm{W}}\right.$ and $\left.X_{\mathrm{W}}\right)$ at various lung volumes were measured by Nagels et al. (23) in healthy subjects and in COPD patients. In healthy subjects (fig. 3.11), $R_{\mathrm{L}}$ decreased and $X_{\mathrm{L}}$ increased at higher lung volumes. Variations of $R_{\mathrm{W}}$ and $X_{\mathrm{W}}$ with changing lung volumes were much smaller: $R_{W}$ and $X_{W}$, respectively, increased and decreased with decreasing lung volume. The resonant frequency of the lungs was on the average $3 \mathrm{~Hz}$ and the resonant frequency of the chest was not reached at $20 \mathrm{~Hz}$. In obstructive patients (fig. 3.12), the variations of $R_{\mathrm{rs}}$ and $X_{\mathrm{rs}}$ with volume were determined by those of $R_{\mathrm{L}}$ and $X_{\mathrm{L}}$, since the changes of the impedance of the chest wall did not reach the level of statistical significance. $X_{L}$ increased with frequency, more at lower than at higher volumes. $R_{\mathrm{L}}$ decreased with frequency but this decrease was less pronounced at 70 than at $25 \% \mathrm{VC}$. These observations of Nagels in COPD patients were in accordance with the earlier results of Grimby et all..

\subsubsection{Impedance of the cheeks and upper airways.}

If the cheeks are sufficiently compliant, they represent an alternative pathway for the forced oscillations : part of the flow measured at the mouth will be lost in a movement of the cheeks. To reduce this source of error, the subjects support their cheeks by means of their hands.

Michaelson et al. (12) demonstrated that supporting the cheeks does not completely eliminate the error induced by a possible loss of flow in a movement of the cheeks. Therefore, impedance of the mouth $\left(Z_{\mathrm{m}}\right.$ '), including oral cavity, cheeks, pharynx and larynx and mouthpiece was determined by spectral analysis of the induced pressure and flow during a Valsalva manoeuvre. Supposing that $Z_{\mathrm{m}}$ ' was acoustically in parallel with the remainder of the respiratory system $\left(Z_{\mathrm{rs}}\right)$, this measurement was used to correct the impedance measurements obtained during quiet breathing $\left(Z_{\mathrm{rs}}{ }^{\prime}\right)$ for the characteristics of the mouth to obtain the true $Z_{\mathrm{rs}}$ according to the formula:

$Z_{\mathrm{rs}}=Z_{\mathrm{m}} \cdot Z_{\mathrm{rs}} \cdot /\left(Z_{\mathrm{m}}{ }^{\prime}-Z_{\mathrm{rs}}{ }^{\prime}\right)$ 
Since $Z_{\mathrm{m}}$ ' is large compared to $Z_{\mathrm{rs}}$, and the variability about $Z_{\mathrm{m}}$ ' is small, these authors routinely corrected $Z_{\mathrm{rs}}$ ' by the mean $Z_{\mathrm{m}}$ '.

Peslin et al. (30) introduced a method for upper airway walls impedance measurement using a head plethysmograph. They compared closed-glottis upper airway walls input impedance, closed-glottis upper airway walls transfer impedance and open-glottis upper airway walls transfer impedance. The term "input" indicates that flow and pressure are measured at the same place; the term "transfer" indicates that flow and pressure are measured at different places.

They found larger upper airway impedance values during Valsalva manoeuvres. Therefore, they concluded that respiratory impedance values are undercorrected when using the Valsalva method, promoting in normal subjects positive frequency dependence of the respiratory resistance i.e. an increase of resistance values with increasing frequency.

Influence of upper airway wall motion was studied by Peslin et al. (31) in patients with chronic obstructive pulmonary disease by measuring respiratory impedance with the cheeks unsupported, with the cheeks supported and when upper airway wall motion was simultaneously measured with a head plethysmograph and corrected for. They found that in patients average resistance from 4 to $30 \mathrm{~Hz}$ is significantly lower when the cheeks are not supported than when they are and when the data are corrected. Moreover, resistance increased with increasing frequency when wall motion was corrected for and decreased when it was not.

Upper airway wall motion also tended to increase the resonant frequency in patients.

Nagels et al. (23) mentioned that the impedance measured during the Valsalva manoeuvre is determined not only by the parallel impedance of the cheeks but also by the impedance of the upper airways, between mouth and glottis, in series with the lower airways. Therefore, $Z_{\mathrm{m}}$ can not be substracted from the impedance of the respiratory system as if it is totally in parallel. They concluded that the influence of the shunt characteristics of the upper airways on $R_{\mathrm{rw}}$ and $X_{\mathrm{rs}}$ depends on the value of the peripheral resistance. If the value of the peripheral resistance was small, $R_{\mathrm{r} s}$ increased and $X_{\mathrm{rs}}$ decreased at higher frequencies. When the value of the peripheral resistance was large, $R_{\mathrm{rs}}$ was reduced at lower frequencies, whereas $X_{\text {rs }}$ decreased at higher frequencies.

Cauberghs et al. (32) evaluating the series and shunt components of the impedance of the upper airway, found that the shunt properties of the upper airway have a rather minor influence on the absolute values of resistance in healthy adults and that this influence results in an increase of the resistance of the respiratory system with frequency between 2 and $32 \mathrm{~Hz}$. In patients with obstructive lung diseases, they found that the shunt properties cause a marked underestimation of resistance, mainly at lower frequencies. In children, they found that resistance is markedly underestimated also at higher frequencies. 


\section{References}

1. Dubois AB, Brody AW, Lewis DH, Burgess BF, Oscillation mechanics of lungs and chest in man. J Appl Physiol 1956;8:587-94.

2. Mead J. Control of respiratory frequency. J Appl Physiol 1960;15:325-36.

3. Ferris FG, Mead J, Opie LH. Partitioning of respiratory flow resistance in man. J Appl Physiol 1964;19:653-58.

4. Fisher $A B$, Dubois $A B, H y d e$ RW. Evalnation of the forced oscillation technique for the deter" mination of resistance to breathing. $\mathbb{J}$ Clin Invest 1968;47:2045-57.

5. Grimby G, Takishima T, Graham W, Macklem P, Mead J. Frequency dependence of flow resistance in patients with obstructive lung disease. J Clin Invest 1968;47:1455-65.

6. Otis AB, McKerrow CB, Bartlett RA, Mead J, Mcllroy MB, Selverstone NJ, Radford EP. Mechanical factors in distribution of pulmonary ventilation. J Appl Physiol 1956;8:427-43.

7. Goldman M, Knudson RJ, Mead J, Peterson N, Schwaber JR, Wohl ME.

A simplified measurement of respiratory resistance by forced oscillation. J Appl Physiol $1970 ; 28: 113-16$.

8. Hyatt RE, Zimmerman IR, Peter GM, Sullivan WJ. Direct write-out of total respiratory resistance. J Appl Physiol 1970;28:675-78.

9. Korn V, Franetzki M, Prestele K. A simplified appraach to the measurement of respiratory impedance. Prog Resp Res 1979;11:144-61.

10. Stanescu DC, Fesler R, Veriter $C_{n}$ Frans A, Brasseur L. A modified measurement of respiratory resistance by forced oscillation during normal breathing. J Appl Physiol $1975 ; 39: 305-11$.

11. Aronsson H, Solymar L, Dempsey J, Bjure J, Olsson, Bake B.

A modified forced oscillation technique for measurements of respiratory resistance. J Appl Physiol 1977;42:650-55.

12. Michaelson ED, Grassman ED, Peters WR. Pulmonary mechanics by spectral analysis of forced random noise. J Clin Invest 1975; 56:1210-30.

13. Lándsér FJ, Nagels J, Demedts M, Billiet L, Van de Woestijne KP. A new method to determine frequency characteristics of the respiratory system. J Appl Physiol 1976; 4:101-06.

14. Mansell A, Levison $H$, Kruger $M$, Tripp $T L$. Measurement of respiratory resistance in children by forced oscillations.

Am Rev Respir Dis 1972;106:710 - 14.

15. Cogswell JJ. Forced oscillation technique for determination of resistance to breathing in children. Arch Dis Childhood 1973; 48:259-66.

16. Cogswell JI, Hull D, Milner AD, Norman AP, Taylor B. Lung function in Childhood. III. Measurement of airflow resistance in healthy children. Brit J Dis Chest 1975;69:177-87.

17. Luenney $W$, Milner AD. Recurrent wheezing in the preschool child. Arch Dis Childhood $1978 ; 53: 468-73$

18. Lenney $W$, Milner AD. At what age do bronchodilator drugs work? Arch Dis Childhood $1977 ; 53: 532-35$

19. Stanescu D, Moavero NE, Veriter C. Brasseur L. Frequency dependence of respiratory resistance in healthy children. J Appl Physiol 1979,47:268 - 71.

20. Williams SP, Fullon JM, Tsai MJ, Pimmel RL, Collier AM, Respiratory impedance and derived parameters in young children by forced random noise. J Appl Physiol $1979 ; 47: 169-74$

21. Duiverman $\mathbb{E} J$, Clếment J, Van de Woestijne KP, Neijens HJ, Van den Bergh ACM, Ker* rebijn KF. Forced oscillation technique, reference values for resistance and reactance over a. frequency spectrum of $2-26 \mathrm{~Hz}$ in healthy children aged $2.3-12.5$ years.

Bull Europ Physiopath Resp 1985;21:171 - 78 . 
22. Lấndsér FJ, Polko AH, Visser BF. Oxcillatory measurement of total respiratory impedance with extended spectrum up to $52 \mathrm{~Hz}$.

Arch Internat Physiol Biochim 1983,91:12.

23. Nagels J, Lándsér FJ, Van der Linden L, Clément J, Van de Woestijne KP. Mechanical properties of Jungs and chest wall during spontaneous breathing. J Appl Physiol $1980 ; 49: 408$ - 16 .

24. Cutillo $\mathrm{AC}$, Renzett $\mathrm{AD}$. Mechanical behavior of the respiratory system as a function of frequency in health and disease. Bull Europ Physioparh Resp 1983;19:293 - 326.

25. Frank $N R$, Mead $J$. Whittenberger JL. Comparative sensitivity of four methods for measuring changes in respiratory flow resistance in man. J Appl Physiol 1971;31:934-38.

26. Kjeldgaard JM, Hyde RW, Speers DM, Reichert WW. Frequency dependence of total respiratory resistance in early airway disease. Am Rev Respir Dis 1976;114:501-08.

27. Hayes DA, Pimmel RL, Fullton JM, Bromberg PA. Detection of respiratory mechanical dysfunction by forced random noise impedance parameters. Am Rev Respir Dis $1979 ; 120: 1095-1100$.

28. Clément J. Lándsếr FJ, Van de Woestijne KP. Total resistance and reactance in patients with respiratory complaints with and without airways obstruction. Chest $1983 ; 83: 215-20$.

29. Mead J. Contribution of compliance of airways to frequency dependent behavior of lungs. J Appl Physiol 1969;26:670-73.

30. Peslin R, Duvivier $\mathrm{C}$, Jardin P. Upper airways walls impedance measured with head plethysmograph. J Appl Physiol 1984;57:596-600.

31. Peslin $R$, Duvivier $C$, Gallina $C$, Cerwantes $P$. Upper airway artifact in respiratory impedance measurements. Am Rev Respir Dis 1985;132:712-14.

32. Cauberghs M, Van de Woestijne KP. Mechanical properties of the upper airway. J Appl Physiol $1983,55: 335-42$. 


\title{
CHAPTER 4
}

\section{EXTENDED SPECTRUM OSCILLOMETRY IN CLINICAL PRACTICE}

\author{
WOUTERS E.F.M., LANDSER F.J., POLKO A.H., \\ BEUNEN H.J.A., VISSER B.F.
}

DEPARTMENT OF PULMONARY DISEASES, UNIVERSITY LIMBURG, MAASTRICHT, THE NETHERLANDS.

Submitted for publication.

Key words: Forced oscillations, normal subjects, COPD, respiratory system, impedance, resistance, reactance, resonant frequency, gas compressibility, gas compliance, ainway wall compliance. 
Using a forced oscillation technique, the resistance and reactance of the respiratory system were measured between 4 and $52 \mathrm{~Hz}$ in 20 healthy subjects and in 9 patients with severe chronic airway obstruction. In normal subjects, resistance values increased at higher frequencies. As compared to the results in normal subjects, resistance values were much higher and decreased with frequency in COPD patients. Reactance values were more negative resulting in an increase of resonant frequency. Using matrix network topography, these findings were analyzed in a modified Mead's model. Compressibility of alveolar gas was incorporated in the model calculations. Resistance and reactance values decreased by adding gas compliance in the model calculations.

\section{INTRODUCTION}

The technique of forced oscillations was first described by Dubois et al. (6): measurements were performed during breathholding at one frequency only. To determine the variations of resistance with frequency, the subject had to be forced at various frequencies. Michaelson et al. (13) introduced the random noise oscillation technique: a random noise pressure was forced on the respiratory system and compared to the induced flow using a Fourier analysis. Measurements of the magnitude and frequency dependence of the impedance of the respiratory system at frequencies from 3 to $45 \mathrm{~Hz}$ were obtained by this technique.

Lándsêr et al. (10) described the technique of forced pseudo-random noise oscillations, by which the resistance and reactance of the respiratory system can be measured simultaneously at various fixed frequencies by means of a pseudorandom noise pressure signal superimposed at the mouth during spontaneous quiet breathing. Originally, the impulses contained all harmonics of $2 \mathrm{~Hz}$ up to $30 \mathrm{~Hz}$ with intervals of $2 \mathrm{~Hz}$. Usually, a pseudo-random noise pressure signal containing all harmonics of 2 to $26 \mathrm{~Hz}$ in steps of $2 \mathrm{~Hz}$ is applied at the mouth. Lándsér et al. extended the frequency range to $52 \mathrm{~Hz}$ (11).

The results of applying this extended frequency signal containing all the harmonics in steps of $4 \mathrm{~Hz}$ in the range of 4 to $52 \mathrm{~Hz}$ are described.

The contribution of the compressibility of air in the lungs is evaluated by model analysis.

\section{METHODS}

The technique was similar to the one originally described by Lándsér et al. (10). Briefly, a signal consisting of a $4 \mathrm{~Hz}$ sinusoidal oscillation with its harmonics up to $52 \mathrm{~Hz}(4,8 \ldots 52 \mathrm{~Hz})$ was imposed at the mouth of a spontaneously breathing subject. A pseudo-random noise impulse was used, containing the various harmonics in steps of $4 \mathrm{~Hz}$ appearing with random phase shift repeated every $0.25 \mathrm{~s}$. 
The measuring set-up was that described by Grimby et al. (9). The seated subject supported the cheeks and floor of the mouth with his hands and breathed quietly via a screen pneumotachograph through a high impedance side tube; a bias flow reduced the $\mathrm{CO}_{2}$ build-up at the mouth. The pseudo-random noise impulse was generated by an oscillator, amplified and transmitted by a loudspeaker. Mouth pressure relative to athmospheric pressure and air flow, transduced to a pressure signal, were recorded by two identical differential transducers with equal frequency characteristics (Validyne MP $45^{\circledR}$ ). Pressure and flow signals were fed directly without filtering into a Fourier analyzing system, dividing pressure by flow: the system calculated an impedance value for each of the investigated frequencies. To filter out the disturbing signals produced by the breathing of the subject, an ensemble averaging was performed during $8 \mathrm{~s}$. Accordingly, the obtained impedance values were averaged over the same period, covering several breathing cycles. That impedance was partitioned into a real and an imaginary part. The real part or resistance, $R_{r s}$, is the equivalent of a total resistance in a resistanceinductance-capacitance $(R-L-C)$ circuit. The imaginary part or reactance, $X_{\mathrm{rs}}$, depends on the elastic and inertial properties of the system: at lower frequencies, the reactance is negative because it is influenced mainly by the capacitance of the system. At higher frequencies, the inertial properties dominate $X_{\mathrm{rs}}$; the latter is then positive. The frequency at which $X_{\mathrm{rs}}$ equals zero is called the resonant frequency $\left(f_{0}\right)$ : in a $R-L-C$ circuit, the influences of capacitance and inductance on $X_{\text {rs }}$ cancel out at the resonant frequency.

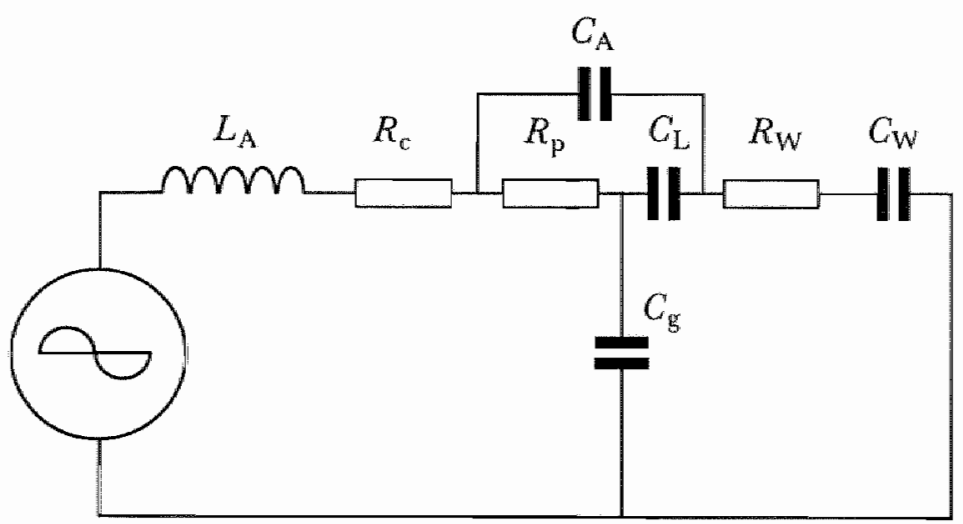

Figure 1: Model of the respiratory system.

Values and symbols used for the different components in healthy subjects:

airway inductance $\left(L_{\mathrm{A}}=0.001 \mathrm{kPa} /\left(\mathrm{L} / \mathrm{s}^{2}\right)\right)$, intrathoracic resistance $\left(R_{\mathrm{A}}\right)$ partitioned into a central part $\left.\left(R_{\mathrm{C}}=0.127 \mathrm{kPa} / \mathrm{L} / \mathrm{s}\right)\right)$ and a peripheral part $\left(R_{\mathrm{p}}=0.014 \mathrm{kPa} /(\mathrm{L} / \mathrm{s})\right)$, chest wall resistance $\left(R_{\mathrm{W}}=0.05 \mathrm{kPa} /(\mathrm{L} / \mathrm{s})\right)$, compliance of the lungs $\left(C_{\mathrm{L}}=2 \mathrm{~L} / \mathrm{kPa}\right)$, chest wall compliance $\left(C_{\mathrm{W}}\right.$ $0.5 \mathrm{~L} / \mathrm{kPa})$, airway compliance $\left(C_{\mathrm{A}}=0.05 \mathrm{~L} / \mathrm{kPa}\right)$ and gas compliance $\left(C_{\mathrm{g}}=0.04 \mathrm{~L} / \mathrm{kPa}\right)$. 
As a criterium for the validity of all measurements, a coherence function was calculated for each frequency. This indicated the amount of noise, generated by the subject's spontaneous breathing, present in the measured signals. Only impedance values with a coherence function equal to or greater than 0.95 were retained.

Mathematical analysis was performed using a modified Mead's model $(12,14)$ (figure 1).

In order to evaluate the contribution of the compressibility of air in the lungs, this compliance was added to the model. The compressibility was considered as isothermic: the isothermic compliance $\left(C_{\mathrm{g}}\right)$ of $1 \mathrm{~L}$ of air is $0.01 \mathrm{~L} / \mathrm{kPa}$.

Using matrix network topography the impedance $Z$ of the model was calculated for different values of $C_{\mathrm{g}}$ and $R_{\mathrm{p}}$ to evaluate the effects of these parameters.

\section{MATERIAL}

Impedance measurements were performed in 20 healthy subjects without any pulmonary complaint and in 9 patients with severe chronic airway obstruction. In this latter group of patients forced expiratory volume in one second was lower than $50 \%$ of the reference values, as defined by the European Community for Coal and Steel (16). In every subject, 3 successive measurements, each lasting $8 \mathrm{~s}$, were performed.

Results of 3 impedance measurements were averaged at each frequency,

Figure 2.

Results of respiratory resistance $\left(R_{\mathrm{rs}}\right)$ and reactance $\left(X_{\mathrm{rs}}\right)$ measurements in 20 healthy subjects.

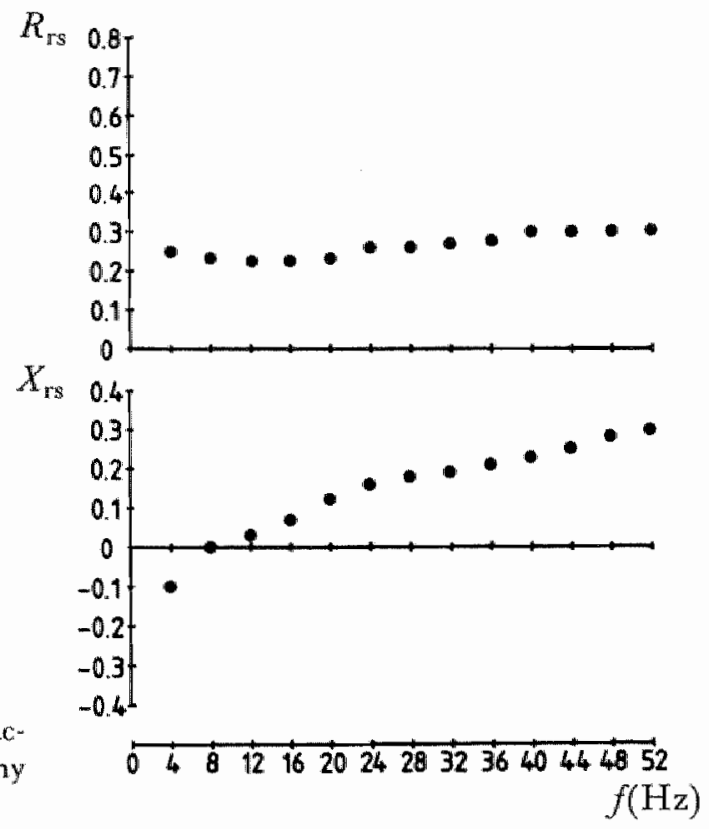



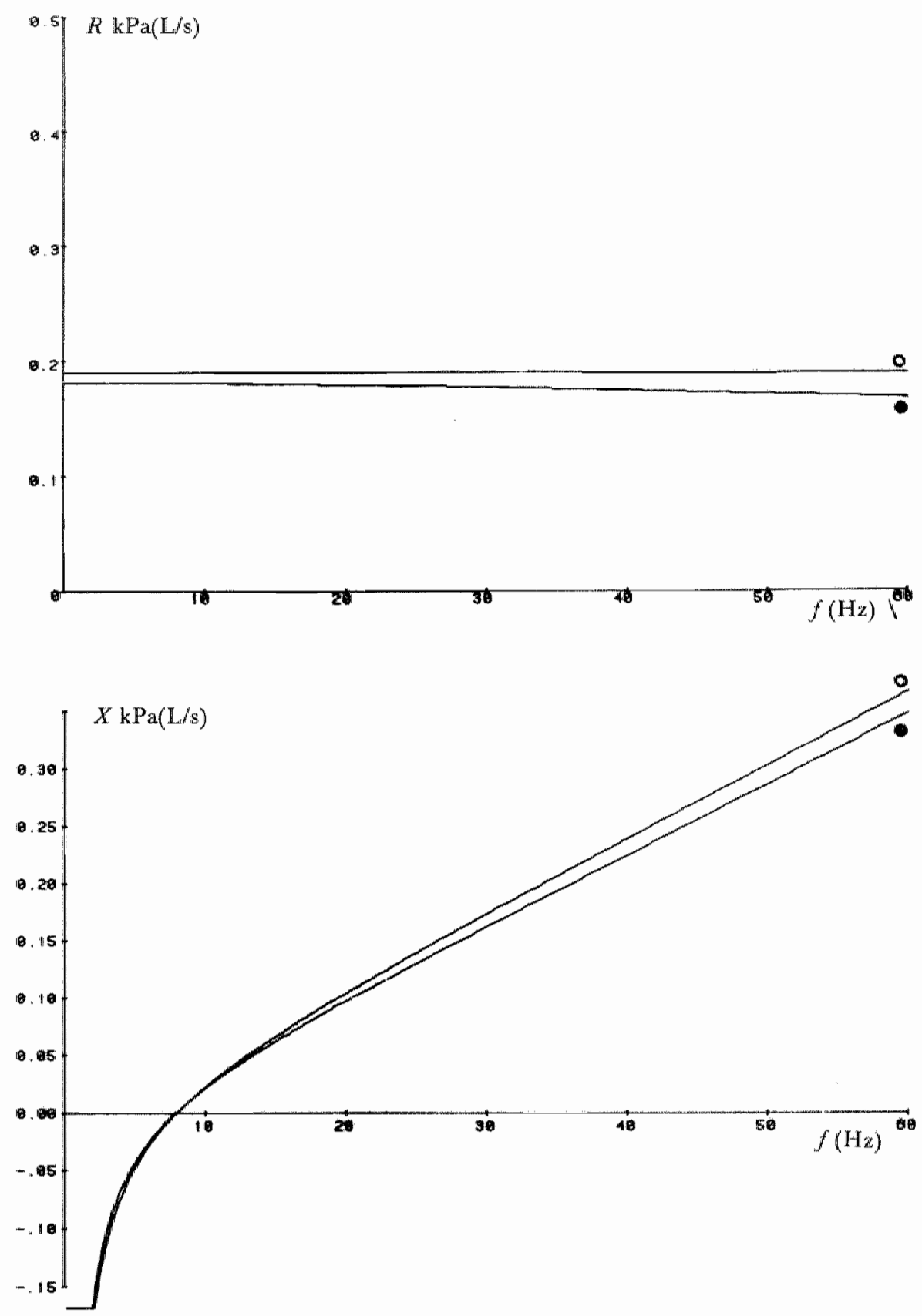

Figure 3.

Behaviour of respiratory resistance $(R)$ and reactance $(X)$ as a function of frequency supposing low values of peripheral resistance $\left(R_{\mathrm{p}}=0.014 \mathrm{kPa} /(\mathrm{L} / \mathrm{s})\right)$; open circles represent calculations without gas compliance, closed circles represent calculations including gas compliance $\left(C_{\mathrm{g}}-0.04 \mathrm{~L} / \mathrm{kPa}\right)$. Values of other components are mentioned in figure 1. 
The impedance measurements of the normal subjects are illustrated in figure 2. Average resistance value was $0.235 \mathrm{kPa} /(\mathrm{L} / \mathrm{s})$. Resonant frequency was about 9 $\mathrm{Hz}$. At higher frequencies, $R_{\mathrm{rs}}$ slightly increased.

Figure 3 shows the results of mathematical analysis of $R$ and $X$ using values given in the legend of figure $1 . R_{\mathrm{p}}$ value was fixed at $0.014 \mathrm{kPa} /(\mathrm{L} / \mathrm{s})$. Calculations were performed using alveolar volumes of 0 and $4 \mathrm{~L}$ with corresponding values of gas compliance: $C_{\mathrm{g}}=0.0 \mathrm{~L} / \mathrm{kPa}$ and $C_{\mathrm{g}}=0.04 \mathrm{~L} / \mathrm{kPa}$. The real and imaginary part of impedance showed a slight decrease by adding gas compliance in the model calculations.

The impedance measurements of patients with COPD are illustrated in figure 4. As compared to the results in normal subjects, resistance values were much higher, resistance decreased with frequency and $X_{\mathrm{rs}}$ values were more negative resulting in an increase of $f_{0}(31 \mathrm{~Hz})$.

The results of mathematical analysis at increased value of peripheral resistance are illustrated in figure 5 . When $R_{\mathrm{p}}=0.3 \mathrm{kPa} /(\mathrm{L} / \mathrm{s})$, there was a marked increase of $R_{\mathrm{rs}}$ value at lower frequencies but always lower than $R_{\mathrm{c}}+R_{\mathrm{p}}+R_{\mathrm{W}}$ and $R_{\mathrm{rs}}$ became frequency dependent: $R_{\mathrm{rs}}$ values decreased with increasing frequencies.

Reactance markedly decreased and became a linear function of frequency at higher values of $R_{\mathrm{p}}$. Resonant frequency increased because $f_{0}$ in this case is mainly determined by airway compliance and airway inertance.

Figure 4.

Results of respiratory resistance $\left(R_{\mathrm{rs}}\right)$ and reactance $\left(X_{\mathrm{rg}}\right)$ measurements in 9 COPD patients.

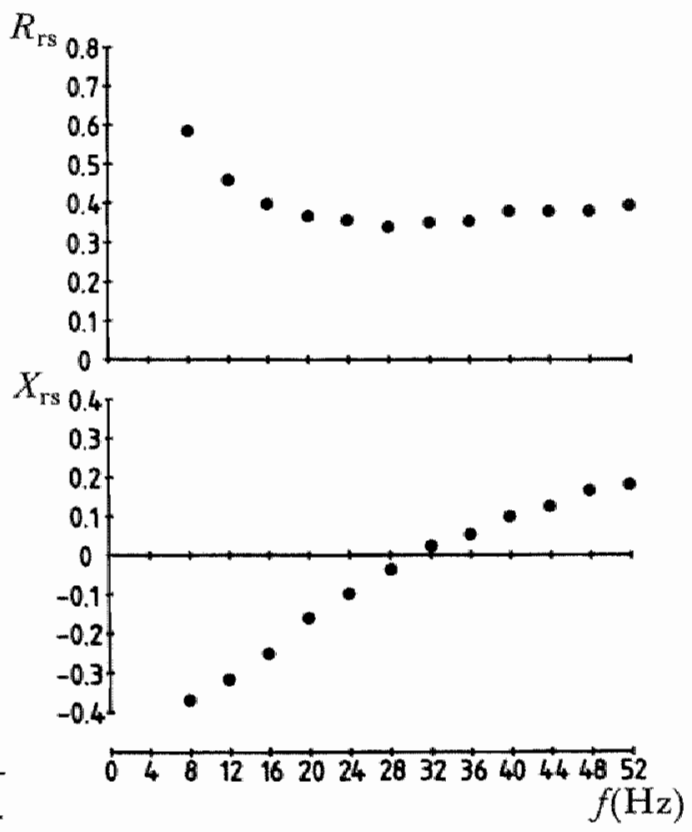



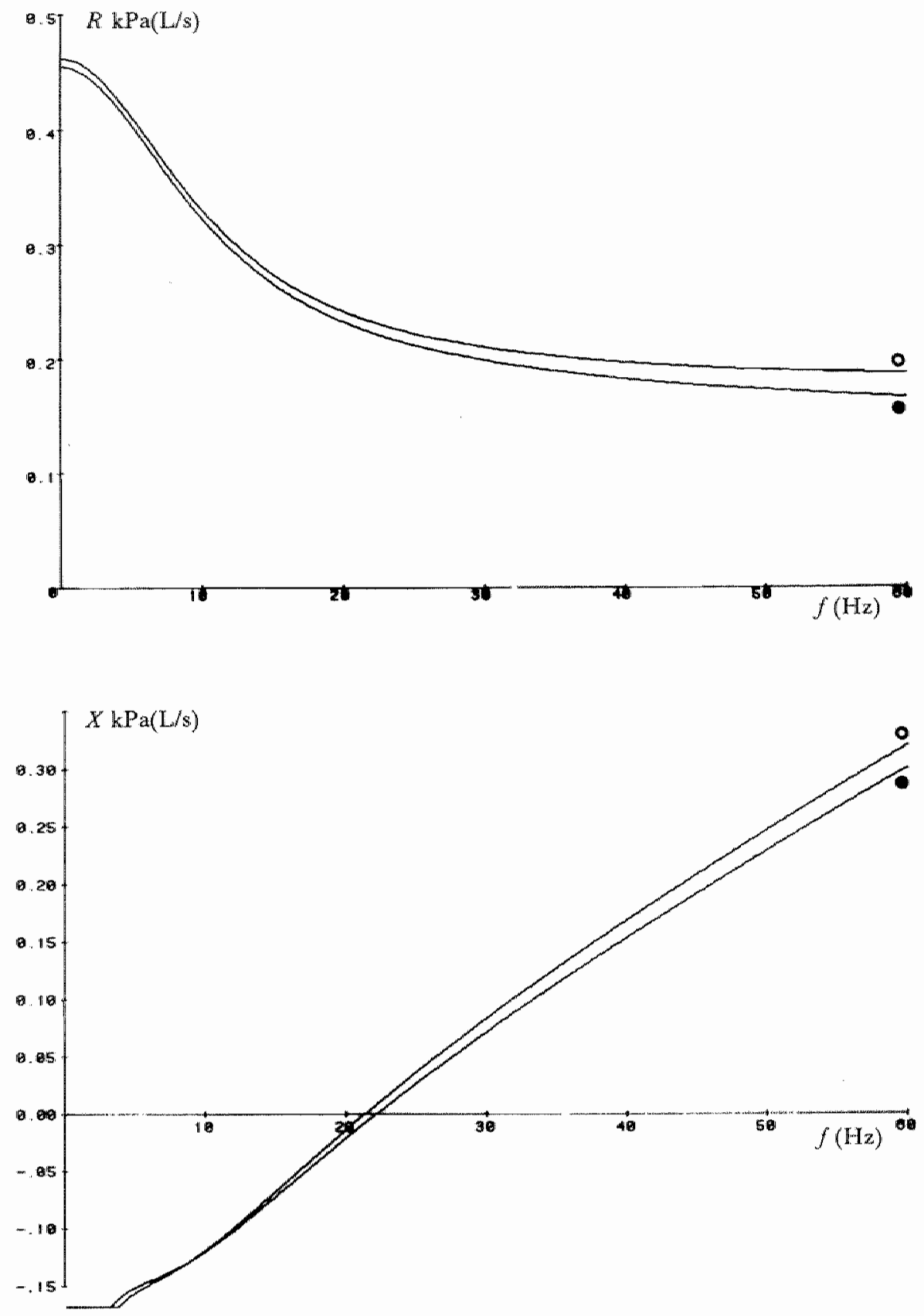

Figute 5.

Behaviour of respiratory resistance $(R)$ and reactance $(X)$ as a function of frequency at increased values of peripheral resistance $\left(R_{\mathrm{p}}=0.3 \mathrm{kPa} /(\mathrm{L} / \mathrm{s})\right)$. Open circles represent calculations without gas compliance, closed circles represent calculations including gas compliance $\left(C_{\mathrm{g}}=0.04 \mathrm{~L} / \mathrm{kPa}\right)$. Values of other components are mentioned in figure $\mathbb{1}$. 
Lándsér et al. (10) first described the technique of forced pseudo-random noise oscillations to measure the impedance of the respiratory system at various frequencies simultaneously. Originally, a pseudo-random noise signal containing all the harmonics of $2 \mathrm{~Hz}$ up to $30 \mathrm{~Hz}$ was used. Routinelly, a signal containing all harmonics of 2 to $26 \mathrm{~Hz}$ in steps of $2 \mathrm{~Hz}$ is applied to the mouth.

Clément et al. (3), comparing a sample of healthy subjects with one of patients, found that patients demonstrate larger resistance values, a decrease of resistance with frequency, a lower average $X_{\mathrm{rs}}$ value, resulting in an increase of resonant frequency and a course of $X_{\mathrm{rs}}$ with frequency which is less concave i.e. more linear than in healthy subjects.

These authors showed that in patients with chronic obstructive lung diseases resonant frequency is not reached at $24 \mathrm{~Hz}$. A similar observation was made by Decramer et al. (5) after cold air provocation in asthmatics.

Therefore, in our study the frequency spectrum was extended and a pseudorandom noise pressure signal containing all the harmonics of 4 up to $52 \mathrm{~Hz}$ in steps of $4 \mathrm{~Hz}$ was applied to the mouth.

As clearly illustrated in our group of normal subjects, a small increase in total respiratory resistance with increasing frequency could be observed. This finding had been attributed to several factors, including inhomogeneous distribution of inertance-resistance time-constants among parallel lung pathways, inertial distortion of velocity profiles associated with periodic breathing, gas compressibility, interference of the shunt characteristics of the mouth and airway distensibility (4). To evaluate the effect of gas compressibility on the increase of resistance values at higher frequencies, model analyses were performed after incorporating a capacitance, simulating the compressibility of alveolar gas, in the electrical model. As illustrated in the model calculations, the effect was opposite. $R_{\mathrm{rs}}$ and $X_{\text {rs }}$ decreased. This finding was found at low and higher values of peripheral resistance.

Bobbaers et al. (1), analyzing the frequency dependence of effective compliance, concluded that gas capacity has a small but definite effect acting to increase effective compliance with frequency. Nagels et al. (14) concluded that the introduction of a capacitance simulating the compressibility of alveolar gas does not noticeably modify the results of resistance and reactance of the chest by computing these values from the air flow at the mouth and from the plethysmographic air flow. Measurements were done in normal subjects and in one patient with advanced airway obstruction and ventilation unevenness.

Finucane et al. (7), measuring the resistance and reactance of intrathoracic airways during periodic flow, found consistent increases in resistance with frequency between 1 and $10 \mathrm{~Hz}$. They supposed that the increases reflect changes in the distribution of flow with frequency, probably explained by changes in the distribution of flow over the different airway pathways due to differences in air- 
way impedance and changes in flow distribution arising from displacements of the airway walls.

Fredberg et al. (8), simulating the measurements of Finucane, stated that the most important source of frequency dependence of resistance is change in the distribution of flow among inhomogeneous parallel airways, and that inertial velocity profile distortion in a lesser manner contributes to the increase of resistance with frequency. They found that gas compressibility causes a small increase of resistance below $10 \mathrm{~Hz}$ and that airway wall distensibility has a very small effect. However, in the studies of Finucane and Fredberg stroke volumes, varying between $130 \mathrm{ml}$ and $16 \mathrm{ml}$ according to the frequency and peak flow rate, were applied: this is different from the measurement procedure in forced oscillation techniques.

The shunt characteristics of the cheeks were omitted in our model analysis. Michaelson et al. (13) stated that impedance measurements of the respiratory system have to be corrected for the influence of the cheeks. Therefore, they determined the impedance of the mouth $\left(Z_{\mathrm{m}}\right)$ separately during a Valsalva manoeuvre and substracted it from the impedance of the respiratory system $\left(Z_{\mathrm{rs}}\right)$ considering $Z_{\mathrm{m}}$ as an impedance placed in parallel with $Z_{\mathrm{rs}}$.

These corrections resulted in only minor changes in healthy subjects during quiet breathing at FRC or at higher respiratory level: minimal increase of $R_{\mathrm{rs}}$ at low frequencies and slight increase of $X_{\mathrm{rs}}$ at higher frequencies.

However, Nagels et al. (14) demonstrated that $R_{\mathrm{rs}}$ and $X_{\mathrm{rs}}$ values markedly increase after correction for $Z_{\mathrm{m}}$ in healthy subjects breathing below functional residual capacity. They also found that the increase of $R_{\mathrm{rs}}$ with frequency, often observed in healthy subjects, disappears or is reversed following the correction. These authors stated that the impedance measured during a Valsalva manoeuvre is determined not only by the parallel impedance of the cheeks but also by that of the upper airways, between mouth and glottis, in series with the lower airways. They found that the influence of the shunt characteristics of the upper airways on $R_{\mathrm{rs}}$ and $X_{\mathrm{rs}}$ depends on the value of the peripheral resistance and that if the latter is small, $R_{\mathrm{rs}}$ and $X_{\mathrm{rs}}$ increase and decrease, respectively, at higher frequencies when shunt impedance of upper airways is taken into account.

Cauberghs et al . (2) concluded that the shunt properties of the upper airways appear to have a minor influence on the absolute values of $R_{\mathrm{rs}}$ in healthy adults and that this influence varies with frequency resulting in an increase of $R_{\text {rss }}$ with frequency.

Peslin et al. (15) found that in normal subjects upper airway wall motion has little influence on $R_{\mathrm{rs}}$ but increases $f_{0}$ and respiratory compliance and decreases respiratory inertance.

Our findings in patients with COPD are in agreement with observations of Michaelson et al. (13) and Clément et al. (3). They observed in patients larger resistance values, a decrease of resistance with frequency, a lower average $X_{\mathrm{rs}}$ and a less concave course of $X_{\mathrm{rs}}$ with frequency. However, by extended spectrum 
oscillometry $f_{0}$ could be measured even in severely obstructive patients in this study.

These findings can be explained by Mead's model of the lungs (14). Mead (12) had developed a two-compartment lung model where the two parallel units are represented by the expansible airways and by the airspaces.

Mead's analysis focused on the role of an increase of the resistance of the peripheral airways as a major determinant of the frequency-dependent behaviour of effective compliance and resistance. The effect of an increase of peripheral resistance on $R_{\mathrm{rs}}$ and $X_{\mathrm{rs}}$ is clearly illustrated in the model simulation. In case of high peripheral resistance, resonant frequency is predominantly determined by airway compliance and airway inertance.

Airway wall compliance has a definite role in frequency dependence of $R_{\mathrm{rs}}$ and this factor can not be neglected by assuming that the bronchi behave as stiff structures, as proposed by Bobbaers et al. (1). When airway compliance equals zero, there is no frequency dependence of the resistance of the respiratory system. The shunt characteristics of the cheeks in patients with COPD were omitted in the present model analysis.

Michaelson et al. (12) found that $R_{\mathrm{rs}}$ and $X_{\mathrm{rs}}$ values increase markedly after correction for the impedance of the mouth in patients with COPD.

Nagels et al. (13) concluded that if the peripheral resistance is large as in COPD, $R_{\text {rs }}$ is reduced at low frequencies whereas $X_{\text {rs }}$ decreases at high frequencies when the shunt impedance of the upper airways is taken into account.

Cauberghs et al. (2) found that in patients with COPD, the shunt properties of the upper airway cause a marked underestimation of resistance, mainly at lower frequencies. However, Peslin et al. (15) concluded that in patients with COPD correction of the data for upper airway wall motion results in a significant increase of $R_{\mathrm{rs}}$ with increasing frequency, a decrease of $f_{0}$ and an increase of $X_{\mathrm{rs}}$. They stated that the errors are not such as to obscure differences between normal subjects and patients and that therefore the forced oscillation technique retains its diagnostic value.

It can be concluded that extended spectrum oscillometry can contribute important information in the analysis of the mechanical behaviour of the respiratory system. 


\section{References}

1. Bobbaers $\mathrm{H}$, Clément J, Pardaens J, Van de Woestijne KP:

Simulation of frequency dependence of compliance and resistance in healthy man.

J Appl Physiol 38:427-435 (1975)

2. Cauberghs $M$, Van de Woestijine KP:

Mechanical properties of the upper airway.

J Appl Physiol 55:335-342 (1983)

3. Clément J, Lándsér FJ, Van de Woestijne KP:

Totall resistance and reactance in patients with respiratory complaints with and without airways obstruction.

Chest 2:215-220(1983)

4. Cutillo AG, Renzetti AD:

Mechanical behavior of the respiratory system as a function of frequency in health and diseast.

Bull Europ Physiopath Resp 19:293 - 326 (1983)

5. Decramer M, Demedts $M$, Van de Woestijne KP:

Isocapnic thyperventilation with cold air in healthy non-smokers, smokers and asthmatic subjects.

Bull Europ Physiopath Resp 20:237 - 243 (1984)

6. Dubois AB, Brody AW, Lewis DH, Burgess BF:

Oscillation mechanics of lungs and chest in man.

I Appl Physiol 8:587 - 594 (1956)

7. Finucane KE, Dawson SV, Phelan PD, Mead J:

Resistance of intrathoracic airways of healthy subjects during periodic flow.

J Appl Physiol 38:517-530 (1975)

8. Fredberg JJ, Mead J:

Impedance of intrathoracic airway models during low-frequency periodic flow.

J Appl Physiol 47:347 - 351 (1979)

9. Grimby G, Takishima T, Graham W, Macklem P, Mead J:

Frequency dependence of flow resistance in patients with obstructive lung disease.

J Clin Invest 47:1455-1465 (1968)

10. Lándsér FJ, Nagels J, Demedts M, Billiet L, Van de Woestijne KP:

A new method to determine frequency characteristics of the respiratory systern.

J Appl Physiol 41:101-106 (1976)

11. Laándsér FJ, Polko AH, Visser BF:

Oscillatory measurement of total respiratory impedance with extended spectrum up to $52 \mathrm{~Hz}$.

Arch Int Physiol Biochem 91:12 (1983)

12. Mead J:

Contribution of compliance of airways to frequency-dependent behavion of lungs.

J Appl Physiol 26:670-673 (1969)

13. Michaelson ED, Grassman ED, Peters WR:

Pulmonary mechanics by spectral analysis of forced random noise.

J Clin Invest $56: 1210-1230(1975)$

14. Nagels J, Lándsér FJ, Van der Linden L, Clément J, Van de Woestijne KP:

Mechanical properties of lungs and chest wall during spontaneous breathing.

J Appl Physiol 49.408-416 (1980)

15. Peslin R, Duwivier C, Gallina C, Cervantes P:

Upper airway artifact in respiratory impedance measurements.

Am Rev Respir Dis 132:712 - 714 (1985)

16. Quanjer PH. (ed.):

Standarized lung function resting.

Bull Europ Physiopath Resp 10:1-95 (1983) 


\section{CHAPTER 5}

\section{FORCED EXPIRATORY FLOW AND OSCILLOMETRIC IMPEDANCE}

MEASUREMENT IN EVALUATING AIRWAY OBSTRUCTION

WOUTERS E.F.M., MOSTERT R., POLKO A.H., VISSER B.F.

DEPARTMENT OF PULMONARY DISEASES, UNIVERSITY LIMBURG, MAASTRICHT, THE NETHERLANDS.

Presented at the SEP-congres "The lung and environment", Amsterdam, 1987. Submitted for publication.

Key words: Forced oscillations, impedance, resistance, resonant frequency, frequency dependence, forced expiratory flow. 
The forced pseudo-random noise oscillation technique for measuring resistance and reactance of the respiratory system was compared with maximal forced expiratory spirometry in 100 patients.

Resonant frequency and frequency dependence of resistance correlated significantly with selected parameters of the forced expiratory flow-volume curve: correlation coefficient values ranged from 0.492 to 0.688 .

No correlation between average resistance and spirometric parameters reached a statistically significant level.

The low degree of correlation is a reflection of the different but characteristic information about the mechanical behaviour and properties of the respiratory system obtained by both measurement procedures.

\section{INTRODUCTION}

Dubois et al. (1) were the first to describe the forced oscillation technique to estimate total respiratory resistance.

Michaelson et al. (2) introduced the random-noise oscillation technique: measurements of the magnitude and phase angle of the impedance of the respiratory system were obtained at frequencies from 3 to $45 \mathrm{~Hz}$.

Lándsér et al. (3) described the technique of forced pseudo-random noise oscillations, by which the resistance and reactance of the respiratory system can be measured simultaneously at various fixed frequencies by means of complex oscillations superimposed at the mouth during spontaneous quiet breathing. Originally, the impulses contained all harmonics of 2 up to $30 \mathrm{~Hz}$ with intervals of $2 \mathrm{~Hz}$. Recently, an extended frequency signal containing all the harmonics in steps of $4 \mathrm{~Hz}$ in the range of 4 to $52 \mathrm{~Hz}$ was used (4).

Generally, comparison of results obtained by a new measuring device with a more standardized method is recommended. Therefore, impedance measurements are compared with parameters obtained from maximal expiratory flow-volume curves in one hundred non-selected patients.

\section{METHODS}

Impedance of the respiratory system was determined by the forced pseudorandom noise oscillation technique. This technique is described in chapter 4 (3). Three successive impedance measurements were performed in each subject and the results were averaged. Average resistance values $\left(a R_{\mathrm{rs}}\right)$ were computed using 4 to $52 \mathrm{~Hz}$ data. $R_{\mathrm{rs}(12)}$ represented the resistance value at a frequency of $12 \mathrm{~Hz}$. Resonant frequency was measured in the extended oscillation spectrum. Frequency dependence $\left(\Delta R_{\mathrm{rs}} / R_{\mathrm{rs}(52)}\right)$ was defined as the $R_{\mathrm{rs}}$ vallue at $12 \mathrm{~Hz}$ minus 
the $R_{\mathrm{rs}}$ value at $52 \mathrm{~Hz}$ divided by $R_{\mathrm{rs}}$ at $52 \mathrm{~Hz}$. Resistance at $12 \mathrm{~Hz}$ was choosen for the presence of good coherence function in all measurements.

Maximum forced expiratory spirometric data were obtained using a computerized spirometric system (Jaeger Transferscreen ${ }^{\circledast}$ ). Each subject performed at least three acceptable manoeuvres and the system computed and printed out the standard spirometric parameters from the envelope curve of the performed measurements: FVC, FEV $, V_{\text {Emax }} 75, V_{\text {Emax }} 50, V_{\text {Emax } 25}, V_{\text {Emax }} 75-25, V_{\text {Emax }}$ and $\mathrm{FEV}_{1} / \mathrm{FVC}$ ratio were used. Except $\mathrm{FEV}_{1} / \mathrm{FVC}$ ratio all values were expressed as percentage of the reference values as defined by the European Coal and Steel Community (5).

Impedance parameters and spirometric parameters were correlated using a linear regression analysis.

\section{MATERIAL}

The stucly involved one hundred out-patients aged 18-70 years, who performed both lung function tests. From January to March 1986 all data were collected. The studied group consisted of 36 women and 64 men. The mean age of the total group was 46.7 years. Eighty two patients were suffering from COPD, one patient had cystic fibrosis and 15 patients performed the measurements to evalluate pulmonary function : these patients were not suffering from interstitial lung diseases. Only 2 patients were known with interstitial lung disease.

The spirometric data are summarized in table 1.

TABLE 1.

Spirometric parameters of the study group $(n=100)$.

\begin{tabular}{lccc}
\hline FVC & M pred & 96.7 & S.D. \\
FEVi & $\%$ pred & 74.1 & 21.3 \\
$V_{\text {Emax } 75}$ & $\%$ pred & 56.2 & 27.6 \\
$V_{\text {Emax } 50}$ & $\%$ pred & 46.9 & 34.2 \\
$V_{\text {Emax } 25}$ & $\%$ pred & 41.1 & 30.6 \\
$V_{\text {Emax }}$ & $\%$ pred & 80.9 & 26.7 \\
$V_{\text {Emax } 75-25}$ & $\%$ pred & 4.5 .1 & 28.5 \\
FEV $/ F V C$ ratio & $\%$ & 62.1 & $\mathbb{2}$ \\
\hline
\end{tabular}


The results of correlation analysis between random noise impedance parameters and maximum forced expiratory spirometric parameters are summarized in table 2. All correlations using $f_{0}$ and $\Delta R_{\mathrm{rs}} / R_{\mathrm{rs}(52)}$ as impedance parameters were statistically significant at the $p<0.001$ level for all the studied forced expiratory spirometric parameters. Correlation coefficients ranged from 0.492 (between $\Delta R_{\mathrm{rs}} / R_{\mathrm{rg}(52)}$ and $\mathrm{FVC}$ ) to 0.668 (between $f_{0}$ and $\mathrm{FEV}$ ).

Correlations of random noise average resistance values and forced expiratory spirometric parameters showed a very low correlation coefficient.

No correlation coefficient with the average resistance values reached a statistically significant level. Except the correlation between $R_{\mathrm{rs}(12)}$ value and $\mathrm{FEV}_{\mathbb{1}} / \mathrm{FVC}$ ratio, all others were statistically significant but correlation coefficients were very low. A marked difference between spirometric parameters depending on the early portion of the maximum forced expiration and spirometric parameters depending on the late portion of this manoeuvre was not observed.

\section{TABLE 2.}

Correlation coefficients between random noise impedance parameters and forced expiratory spirometric parameters.

$$
\begin{array}{lllll}
\mathrm{FVC} & \mathrm{FEV}_{1} \quad \dot{V}_{\operatorname{Emax} 75} \dot{V}_{\operatorname{Emax} 50} \dot{V}_{\mathrm{Emax} 25} \dot{V}_{\mathrm{Emax}} \quad \dot{V}_{\operatorname{Emax} 75-25} & \mathrm{FEV} / \mathrm{FVC}
\end{array}
$$

\begin{tabular}{|c|c|c|c|c|c|c|c|c|}
\hline$f_{00}$ & $\begin{array}{c}-0.548 \\
* * * *\end{array}$ & $\begin{array}{c}-0.668 \\
\text { w }\end{array}$ & $\begin{array}{c}-0.644 \\
* * *\end{array}$ & $\begin{array}{c}-0.638 \\
* *\end{array}$ & $\begin{array}{c}-0.587 \\
* * *\end{array}$ & $\begin{array}{c}-0.641 \\
* * *\end{array}$ & $\begin{array}{c}-0.595 \\
* * * *\end{array}$ & $\begin{array}{c}-0.591 \\
*\end{array}$ \\
\hline $\begin{array}{l}\Delta R_{\mathrm{rs}} \\
R_{\mathrm{rs}(52)}\end{array}$ & -0.492 & $\begin{array}{c}-0.635 \\
*\end{array}$ & $\begin{array}{r}.0 .641 \\
* *\end{array}$ & $\begin{array}{c}-0,641 \\
* * *\end{array}$ & $\begin{array}{c}-0.593 \\
*\end{array}$ & $\begin{array}{c}-0.594 \\
*\end{array}$ & $\begin{array}{c}-0.586 \\
* *\end{array}$ & $\begin{array}{c}-0.597 \\
* \text { * }\end{array}$ \\
\hline$R_{\mathrm{rs}}$ & -0.030 & 0.016 & -0.017 & 0.044 & 0.081 & -0.096 & -0.001 & 0.113 \\
\hline$R_{\text {rs(12) }}$ & $\begin{array}{c}-0.215 \\
*\end{array}$ & -0.24 .4 & -0.271 & -0.236 & $\begin{array}{c}-0.208 \\
*\end{array}$ & -0.303 & -0.246 & -0.156 \\
\hline $\begin{array}{r}0.01 \leq \\
0.001 \leq\end{array}$ & $\begin{array}{l}<0.05 \\
<0.01 \\
<0.001\end{array}$ & & & & & & & \\
\hline
\end{tabular}


Forced expiratory flow manoeuvres are a generally accepted method for measuring airway obstruction. The instantaneous air flow recorded during this breathing manoeuvre is plotted against the lung volume which yields a maximal expiratory flow-volume curve.

Fry and Hyatt (6) had shown that this curve is composed of an effort-dependent portion, which extends from total lung capacity through about the first third of the expired vital capacity, and an effort-independent portion which extends from this point to residual volume.

The early part of forced expiration (the effort-dependent section) reflects the rapidity of expiratory muscle contraction, the high elastic recoil pressure at full inflation and the degree of patency of the large central airways. The effortindependent portion reflects the resistance from the point of flow limitation toward the alveoli and the recoil pressure of the lung in the mid-vital capacity range $(7,8)$.

Once the airways have narrowed, flow is a reflection of the mechanical properties of the lungs and intrathoracic airways (7).

Clément et al. (9), comparing the forced oscillation impedance data of a sample of healthy subjects with one of patients, found that patients demonstrate larger resistance values, a decrease of resistance with frequency, a lower average $X_{\mathrm{rs}}$ value, resulting in an increase of $f_{0}$ and a course of $X_{\mathrm{rs}}$ with frequency which is more linear than in healthy subjects.

They formulated a discriminant function to separate normal subjects and obstructive patients made up by the first derivative of $R_{r s}$, the average reactance value, $\mathrm{a} X_{\mathrm{rs}}$, and the second derivative of $X_{\mathrm{rs}}$.

A decrease of $R_{\mathrm{rs}}$ with frequency and an overall decrease of $X_{\mathrm{rs}}$ are features considered as typical for obstructive lung disease and can be simulated by Mead's model of the lung (10).

Peslin et al. (11), studying the correlation between impedance and forced expiratory flow-volume parameters, found significant correlations between these two types of measurement. The best correlation was found between resonant frequency and $\mathrm{FEV}_{\mathrm{i}}$.

Kabiraj et al. (12) compared the values of resistance obtained at $10 \mathrm{~Hz}$ with an oscillatory method and $\mathrm{FEV}_{1}$ measured by spirometer and peak expiratory flow rate measured with a Wright peak flow meter. They found a significant correlation between respiratory resistance measurements and the spirometric parameters. However, the degree of correlation was low between these two different measurement procedures.

König et al. (13) correlated forced pseudo-random noise measurements with more standard spirometric parameters in asthmatic children over three years of age. They compared resistance values at 6 and $26 \mathrm{~Hz}$ and average resistance using 6 to $26 \mathrm{~Hz}$ data with $\mathrm{FEV}_{1}, V_{\text {Emax }} 75, V_{\text {Emax } 50}, V_{\text {Emax } 25}$, and $V_{\text {Emax }} 75-2.5$. 
They found that all correlations are statistically significant at the 0.0001 level except that between $\mathrm{R}_{\mathrm{rs}(26)}$ and $\hat{V}_{\mathrm{Emax}} 25$, which is statistically significant at the 0.005 level. Correlation coefficient values ranged from 0.50 to 0.89 .

Furthermore, they concluded that all three impedance parameters correlate better with spirometric parameters depending on the early portion of the maximal forced expiration than with these spirometric parameters depending on the late portion of this manoeuvre.

However, correlations were performed using impedance measurements and absolute spirometric parameters. It can therefore be supposed that the good correlation is a reflection of the age-dependent decrease of resistance values and age-dependent increase of spirometric parameters in children. Correlating bronchodilator-induced changes in impedance and spirometric parameters, these authors found a poor correlation and most correlation coefficient values fell below 0.60 .

In our study, a statistically significant correlation at the 0.001 level is found between the resonant frequency and frequency dependence as impedance parameters and eight selected parameters of the forced expiratory flow-volume curve.

The lowest correlation values are found between average resistance values and spirometric measurements: no correlation reachs a statistically significant level. Using resistance values at $12 \mathrm{~Hz}$, correlation coefficient values reach a significant level, except with the FEV $/$ FVC ratio. Coefficients are markedly lower than those published by Peslin et al. (11), comparing resistance at $10 \mathrm{~Hz}$ and flowvolume parameters.

Correlation coefficients are low: for resonant frequency and frequency dependence the values ranged from $0.492\left(\Delta R_{\mathrm{rs}} / R_{\mathrm{rs}(52)}\right.$ vs $\left.\mathrm{FVC}\right)$ to $0.668\left(f_{0} v \mathrm{FEV}_{1}\right)$. The highest correlation was found between resonant frequency and $\mathrm{FEV}_{1}$.

Correlation coefficients between average resistance and spirometric parameters are very low. This is in accordance with the observations of Clement et al. (9), comparing normal subjects and COPD patients: they found that $a R_{\mathrm{r} s}$ has a negative contribution to the total discriminative power.

Many factors can be supposed to explain this lack of correlation between the changes in these two groups of parameters.

Firstly, our data of the impedance of the respiratory system are not corrected for the shunt properties of the upper airway impedance.

According to Cauberghs and Van de Woestijne (14), these shunt properties of the upper airway cause a marked underestimation of resistance, mainly at lower frequencies, in patients with obstructive lung diseases.

Secondly, spirometric values are expressed as a percentage of reference values (6). However, the maximal expiratory flow-volume curve shows a considerable intersubject variability (15), which may be largely due to between-individual differences in lung anatomy, called dysanapsis by Mead (16).

Thirdly, the technique of maximal expiratory flow-volume curve requires a max- 
imum inspiration; this manoeuvre itself can cause reflex changes in airway smooth muscle tone $(17,18,19)$.

Fourthly, the lung volume at which the impedance of the respiratory system is measured, is unknown. As mentioned by Nagels (20), impedance measurements of the respiratory system depend on lung volume.

Finally, each impedance measurement represents an ensemble averaging over a time interval of $8 \mathrm{~s}$ and the recorded resistance and reactance values are averages calculated over several breathing cycles.

Especially in older COPD patients with increased closing volume, changing airway obstruction during a breathing cycle can be supposed.

As concluded by Kabirai et al. (12) the low degree of correlation reflects the two different ways of measurement: forced breathing with dynamic compression of airways and quiet breathing reflecting airway narrowing without dynamic compression and without high flows.

Each measurement has its own characteristics and limitations and both give - each by there own - information about the mechanical behaviour and properties of the respiratory system.

\section{References}

1. Dubois $\mathrm{AB}$, Brody $\mathrm{AW}$, Lewis $\mathrm{DH}$, Burgess $\mathrm{BF}$. Oscillation mechanics of lungs and chest in man.

J App\Physiol 1955; 26:587-594

2. Michaelson ED, Grassman ED, Peters WR. Pulmonary mechanics by spectral analysis of forced random noise.

J Clin Invest $1975 ; 56: 1210-1230$

3. Líndsér FJ, Nagels J, Demedts M, Billiet L, Van de Woestijne KP. A new method to determine frequency characteristics of the respiratory system.

JAppl Physiol 1976; $41: 101-106$

4. Lándsér FJ, Polko AH, Visser BF. Oscillatory measurement of total respiratory inpedance with extended spectrum up to $52 \mathrm{~Hz}$.

Arch Internat Physiol Biochem 1983; $91: 12$

5. Quamjer PH. (Ed.) Standardized lung function testing.

Bull Europ Physiol Resp Suppl 1983; 19:7-10

6. Fry DL, Hyatt RE. Pulmonary mechanics: a unified analysis of the relationschip between pressure, volume and gas flow in the lungs of normal and diseased human subjects.

Am J Med 1960; 29:672-689

7. Ingram RH, Mc Fadden ER. Localization and mechanisms of airway responses. New Eng J Med 1977; 15:596-601

8. Mead J, Turner JM, Macklem PT. Significance of the relationship between lung recoil and maximum expiratory flow.

J Appl Physiol 1967; 22:95 108 
9. Clément J. Lắndsér FJ, Van de Woestijne KP. Total resistance and reactance in patients with respiratory complaints with and without airways obstruction.

Chest $1983: 2.215-220$

10. Mead J. Contribution of compliance of airways to frequency-dependent behaviour of lungs. J Appl Physiol 1969; 26:670-673

11. Pélin R, Hannhart B. Pino J. Impédance mécanique thoraco-pulmonaire chez des sujets fumeurs et non-fumeurs.

Bull Europ Physiopath Resp 1981; 17:93-105

12. Kabiraj MU, Rolf $\mathrm{C}$, Simonsson $\mathrm{BG}$. Drug-induced changes in airway obstruction reflected by forced expiratory flows and airway resistance measured with an oscillometric method using quiet breathing.

Respiration $1981 ; 41.90-95$

13. König $P$, Hordwik NL, Pimmel RL. Forced random noise resistance determination in child diood asthma.

Chest $1984 ; 6: 884-890$

14. Gaberghs M, Van de Woestine KP. Mechanical properties of the upper airway. J App Physiol 1983; 55:335-342

15. Knudson RJ, Slatin RC, Lebowitz MD, Burrows B. The maximal expiratory flow-volume curve.

Am Rew Resp Dis 1976; 113:587-600

16. Mead J. Dysanapsis in normal lungs assessed by the relationship between maximal flow, static recoil, and vital capacity.

Am Rev Resp Dis $1980 ; 121: 339.342$

17. Gayrard $P$, Orehek $J$, Grimaud $C$. Charpin $J$. Bronchoconstrictor effects of a deep inspiration in patients with asthma.

Am Rev Resp Dis 1975; 111:433-439.

18. Higenbottam T, Clark TJH. Practical importance of a preceding full inhalation or exhalation upon the measurement of airway resistance.

Clin Science 1980; $58.249-253$

19. Orehek J, Nicoli MM, Delpierre S, Beaupré A. Influence of the previous deep inspiration on the spirometric measurement of provoked bronchoconstriction in asthma.

Am Rew Respir Dis 1981; 123:269-272

20. Nagels J, Lándsér FJ, Van Der Linden L, Clément J, Van de Woestijne KP. Mechanical properties of lungs and chest wall during spontaneous breathing.

J Appl Plinysiol 1980; 43:408:416 


\section{CHAPTER 6}

\section{IMPEDANCE MEASUREMENT OF THE RESPIRATORY SYSTEM DURING AIR AND HELIUM-OXYGEN BREATHING IN NORMAL SUBJEGTS.}

WOUTERS E.F.M., LANDSER F.J., POLKO A.H., VISSER B.F. DEPARTMENT OF PULMONARY DISEASES, UNIVERSITY LIMBURG. MAASTRICHT, THE NETHERLANDS.

Submitted for publication

Key words: Oscillatory impedance, $\mathrm{He}+\mathrm{O}_{2}$ breathing, resistance, inductive reactance, resonant frequency, turbulence, gas density, forced oscillation 
Impedance of the respiratory system, determined by the forced pseudo-random noise oscillation technique, was measured in 15 healthy male subjects during air and helium $80 \%+$ oxygen $20 \%$ breathing. Resistance and reactance values were calculated at frequencies from 4 to $52 \mathrm{~Hz}$.

During $\mathrm{He}+\mathrm{O}_{2}$ breathing, a significant decrease of resistance values at all frequencies was observed and resonant frequency was 1.88 times higher than during air breathing.

Impedance measurement of the respiratory system permitted to observe in normal subjects a density dependent decrease of the real part of impedance and a density dependent decrease of inductive reactance reflected in an increase of resonant frequency.

\section{INTRODUCTION}

Respiratory impedance measurements by means of the forced oscillation technique allow the determination of total respiratory resistance and reactance during spontaneous breathing at several frequencies. Reactance values depend on the elastic and inertial properties of the respiratory system.

The effect of gas physical properties on resistance and reactance of the respiratory system was evaluated by impedance measurement in healthy subjects.

\section{MATERIAL AND METHODS.}

Impedance measurements during air and $\mathrm{He}+\mathrm{O}_{2}$ breathing were performed in 15 healthy male subjects without pulmonary complaints and with normal pulmonary function (table 1 ).

Impedance $(Z)$ of the respiratory system (rs) was determined by the forced pseudo-random noise oscillation technique.

This technique is described in detail in chapter $4(4,5)$. A coherence function was obtained to evaluate the accuracy of the computations at each frequency : only $R_{\mathrm{rs}}$ and $X_{\mathrm{rs}}$ values with a coherence function greater than or equal to 0.95 were retained.

Three successive measurements were performed in each subject during air breathing and during breathing a mixture of $80 \%$ helium (He) and $20 \%$ oxygen $\left(\mathrm{O}_{2}\right)$.

The equipment for $\mathrm{He}+\mathrm{O}_{2}$ breathing is illustrated in fig. 1. Subjects breathed quietly until the alveolar concentration of helium reached a plateau. He concentrations were measured by a katapherometer. The $\mathrm{He}+\mathrm{O}_{2}$ mixture used is 0.33 times as dense and 1.13 times as viscous as air. The resistance and reactance measurements were averaged at each frequency. Means were compared using a paired t-test. All values represented in the text are means $\pm 1 . \mathrm{SD}$. 
Table 1.

Spirometric and impedance measurements of the patient group.

\begin{tabular}{|c|c|c|c|c|c|c|}
\hline \multirow[b]{2}{*}{$\begin{array}{l}\text { Patient } \\
\text { number }\end{array}$} & \multicolumn{4}{|c|}{ Air } & \multicolumn{2}{|c|}{$\mathrm{He}+\mathrm{O}_{2}$} \\
\hline & $\begin{array}{l}\text { IVG } \\
\mathrm{L}\end{array}$ & $\begin{array}{l}\mathrm{FEV}_{1} \\
\mathrm{~L}\end{array}$ & $\begin{array}{l}\mathrm{a} R_{\mathrm{rs}} \\
\mathrm{kPa} /(\mathbb{L} / \mathrm{s})\end{array}$ & $\begin{array}{l}f_{0} \\
\mathrm{~Hz}_{z}\end{array}$ & $\begin{array}{l}\mathrm{a}_{\mathrm{Ts}} \\
\mathrm{kPa}(\mathrm{L} / \mathrm{s})\end{array}$ & $\begin{array}{l}f_{0} \\
\mathrm{H}_{2}\end{array}$ \\
\hline 1 & 6.13 & 4.45 & 0.202 & 6.93 & 0.149 & 12.87 \\
\hline 2 & 5.43 & 3.58 & 0.329 & 7.56 & 0.275 & 16.50 \\
\hline 3 & 6.03 & 4.72 & 0.160 & 10.72 & 0.134 & 16.37 \\
\hline 4 & 6.13 & 5.43 & 0.274 & 6.70 & 0.177 & 11.08 \\
\hline 5 & 5.97 & 4.72 & 0.314 & 7.65 & 0.266 & 19.60 \\
\hline 6 & 5.16 & 4.07 & 0.254 & 9.61 & 0.228 & 19.63 \\
\hline 7 & 5.59 & 4.34 & 0.350 & 10.24 & 0.326 & 18.45 \\
\hline 8 & 6.84 & 4.94 & 0.266 & 12.91 & 0.206 & 18.03 \\
\hline 9 & 3.69 & 2.82 & 0.350 & 10.74 & 0.285 & 19.29 \\
\hline 10 & 5.32 & 5.10 & 0.313 & 8.28 & 0.209 & $16 . \mathbb{1}$ \\
\hline 11 & 4.67 & 3.96 & 0.275 & 10.92 & 0.211 & 22.02 \\
\hline 12 & 5.43 & 3.96 & 0.241 & 9.04 & 0.175 & 17.80 \\
\hline 13 & 5.85 & 5.16 & 0.203 & 9.93 & 0.156 & 16.19 \\
\hline 14 & 4.89 & 3.69 & 0.281 & 8.37 & 0.196 & 16.43 \\
\hline 15 & 6.03 & 4.67 & 0.246 & 6.95 & 0.194 & 12.68 \\
\hline Mean & 5.54 & 4.37 & 0.271 & 9.10 & 0.212 & 16.87 \\
\hline S.D. & 0.75 & 0.70 & 0.056 & 1.82 & 0.055 & 2.94 \\
\hline
\end{tabular}

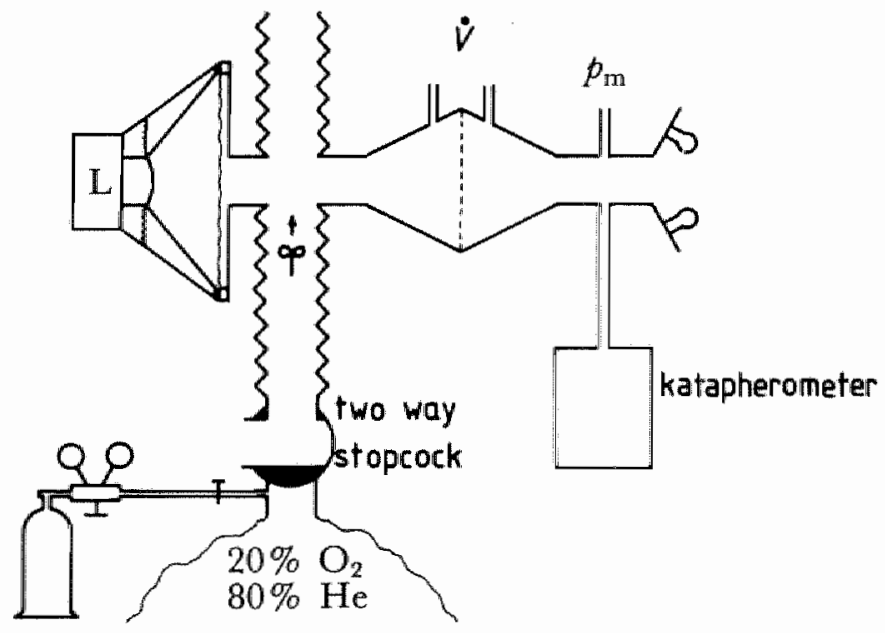

Fig. 1 .

Schematic diagram of experimental apparatus.

A pseudo-random noise signal of 4 to $52 \mathrm{~Hz}$ is applied at the mouth by means of a loudspeaker (L). Mouth pressure $\left(\phi_{\mathrm{m}}\right)$ and flow signal $(\dot{V})$ are recorded. Wash-in of the helium-oxygen mixture is measured by a katapherometer. 
The calibrating problem of the forced oscillation equipment for helium-oxygen breathing is discussed elsewhere (9). As mentioned before, an apparatus for the application of forced oscillations to the human respiratory system and the measurement of its impedance consists of a loudspeaker (L), a pneumotachograph and a differential manometer, measuring the pressure ( $p)$ at the entrance of the respiratory system relative to atmospheric $\left(p_{\mathrm{B}}\right)$ (fig. 2). The pneumotachograph incorporates a screen type resistance $(S)$, showing a linear relation between pressure difference $\left(\Delta p_{1}\right)$ and volume flow rate $\left(V_{1}\right)$. The differential manometer to measure $\Delta p_{1}$ is identical with the one measuring $p-p_{B}$. The ratio $\left(p-p_{\mathrm{B}}\right) / \Delta p_{1}$ is proportional to $Z_{r 8}$. Therefore, an absolute calibration of the two pressure transducers is not necessary, but the proportionality factor has to be determined.

To do so, a calibrating device (c) of known resistance $(R)$ is connected to the measuring device $(m)$ and amplification of one of the two manometers is adjusted until the real part of the measured $Z$ equals the known $R$.

Intending to measure $Z_{\mathrm{rs}}$ during He breathing, a conventional calibration can be performed after filling the whole system $(m+c)$ with pure He. Due to the influence of viscosity ( $\eta$ ), a $6 \%$ increase of $R$ can be expected. However, measurements in pure $\mathrm{He}$ and in air show no difference.

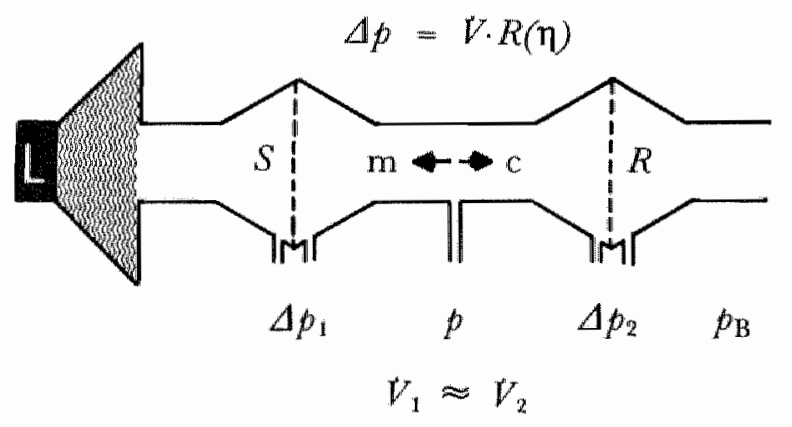

Fig. 2.

Calibration of the forced oscillation equipment.

The measuring device (m) consists of a loudspeaker (L), a pneumotachograph, incorporating a screen type resistance $(S)$ and a differential manometer measuring the pressure $(p)$ at the entrance of the respiratory system relative to atmospheric $\left(p_{\mathrm{B}}\right)$.

The calibrating device (c) has a known resistance $(R)$. 
This observation can be explained as follows. The system is open to atmospheric pressure, compression is negligible and $\vec{V}_{1}$ passing the screen $S$ equals $\vec{V}_{2}$ through $R$. Both $\Delta p_{1}$ and $\Delta p_{2}$ are proportional to $\vec{V}$ and to $\eta: \Delta p_{2}$ is the real part of $p-p_{\mathrm{B}}, \Delta p_{1}$ is interpreted as the flow signal. The ratio $\Delta p_{2} / \Delta p_{1}$ is proportional to $R$, independent of $\eta$.

Therefore, calibration can not be performed in the conventional way but by using a known volume of the mixture and adjusting the integrated signal of the pneumotachograph to that known volume.

\section{RESULTS}

The results are summarized in fig. 3 .

During air breathing, respiratory resistance was, on the average, between 0.20 and $0.27 \mathrm{kPa} /(\mathrm{L} / \mathrm{s})$ at lower frequencies. Resistance values slightly increased with frequency. Resonant frequency was $9.1 \mathrm{~Hz}$.

After breathing $80 \%$ helium $+20 \%$ oxygen, there was a significant decrease of resistance values at all frequencies.

The differences of resistance values during air and $\mathrm{He}+\mathrm{O}_{2}$ breathing were statistically significant at $8 \mathrm{~Hz}(\mathrm{p}<0.05)$. At all other frequencies, these differences were significant at a $\mathrm{p}<0.001$ level.
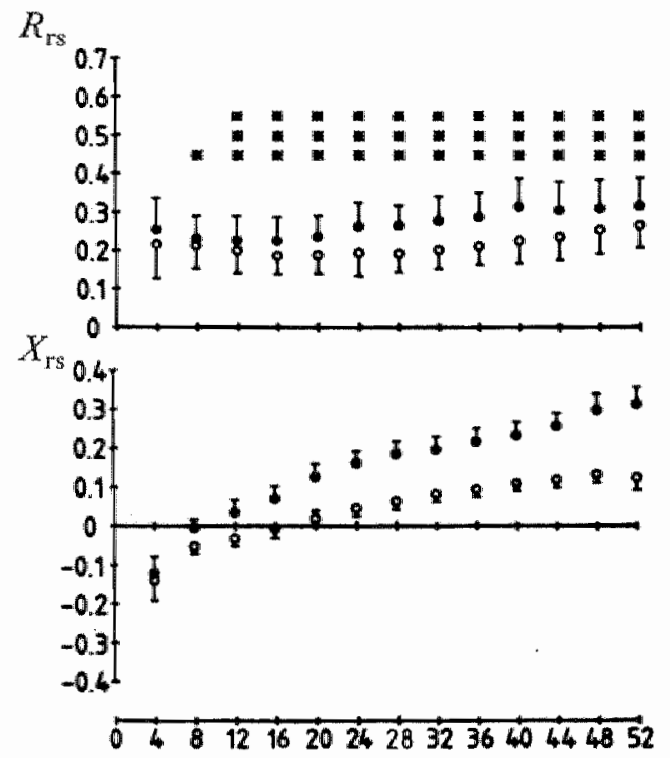

$f(\mathrm{~Hz})$

Fig. 3.

Mean values for resistance $\left(R_{\mathrm{rs}}\right)$ and reactance $\left(X_{\mathrm{rs}}\right)$ during air breathing (closed circles) and helium + oxygen breathing (open circles).

$\left({ }^{*} \mathrm{p}<0.05 ; * * \mathrm{p}<0.001\right)$. 
There was still an increase of resistance with frequency during $\mathrm{He}+\mathrm{O}_{2}$ breathing. Resonant frequency increased to $16.9 \mathrm{~Hz}$.

Changes of the imaginary part of the impedance were simulated using a modified Mead"s model (see Chapter 4). As illustrated in fig. 4, a decrease of inertance of air in the airways caused a decrease of reactance and an increase of the resonant frequency. These changes were compatible with our observations in normal subjects (fig. 3).

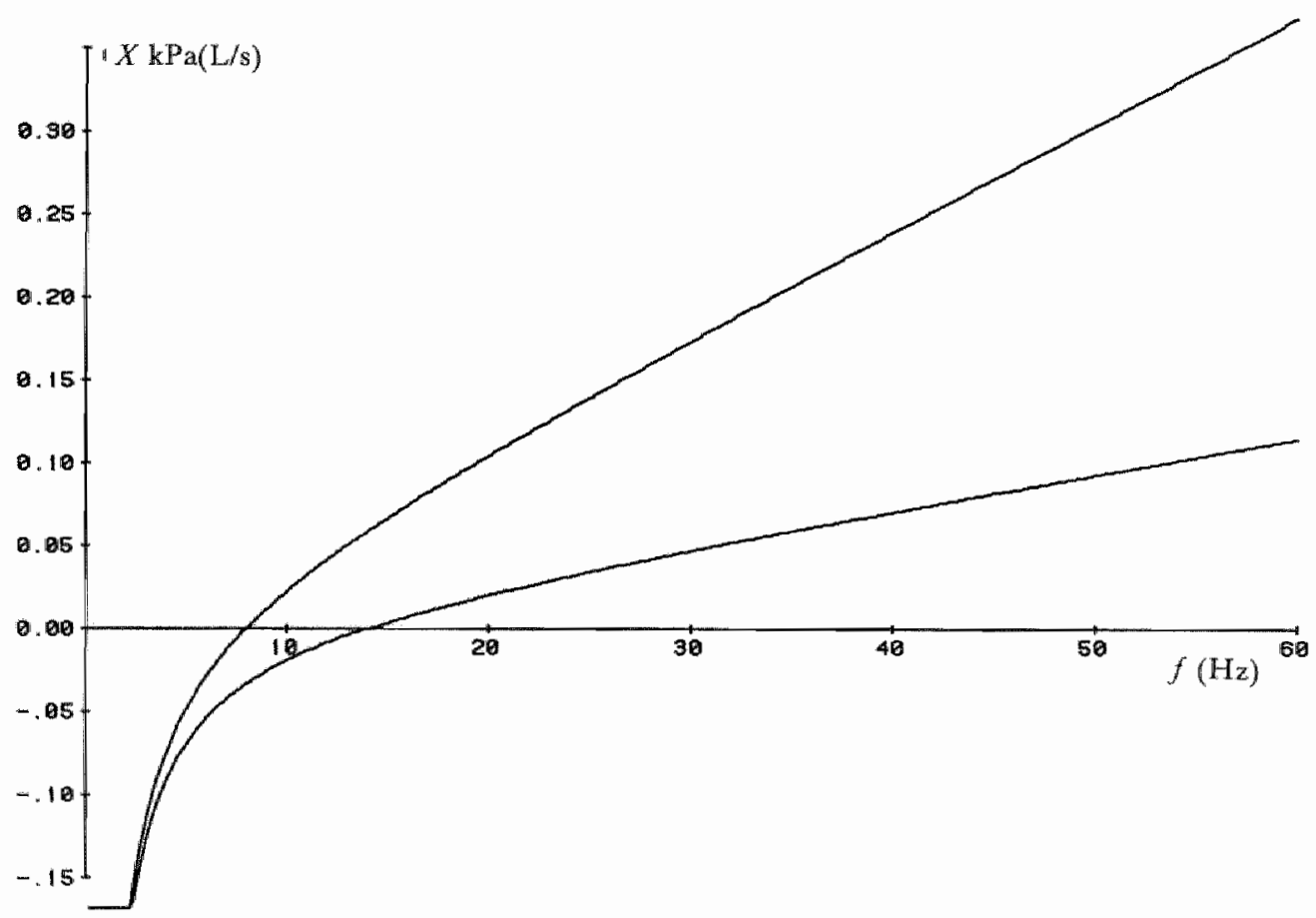

Fig. 4.

Model simulation of reactance for $L=0.001 \mathrm{kPa} /\left(\mathrm{L} / \mathrm{s}^{2}\right)$ (upper curve) and $L=0.0003 \mathrm{kPa} /\left(\mathrm{L} / \mathrm{s}^{2}\right)$ (lower curve) at constant value of $R_{\mathrm{p}}=0.014 \mathrm{kPa} /(\mathrm{L} / \mathrm{s}) . L=0.0003 \mathrm{kPa} /\left(\mathrm{L} / \mathrm{s}^{2}\right)$ represents inductance during helium + oxygen breathing. Other parameters are unchanged. 
The forced pseudo-random noise oscillation technique is a method by which the resistance and reactance of the respiratory system can be measured simultaneously at various frequencies by means of complex oscillations.

In the present study, impulses containing all the harmonics of $4 \mathrm{~Hz}$ up to $52 \mathrm{~Hz}$ were applied to the respiratory system (5) during air and helium-oxygen breathing.

In human lungs, theoretical predictions and experimental measurements have demonstrated that most of the pulmonary resistance is in airways larger than 2 $\mathrm{mm}$ internal diameter. As mentioned by Drazen et al. (2), the resistance to gas flow through a conduit is a function of conduit geometry, flow rate, flow direction, gas density and gas viscosity. Under steady flow conditions, there is a unique relationship between the degree of turbulence - as indicated by the Reynolds' number at a specified location - and the ratio of viscous pressure loss to gas kinetic energy within a conduit.

Because Reynolds' number progressively decreases from trachea to bronchioles (7), flow will be turbulent in the trachea and large airways and the degree of turbulence will decrease as one proceeds towards the smaller peripheral airways (10). Drazen et al. (2) supposed that the distribution of inspiratory pressure loss can be altered by changing flow regime. They demonstrated in canine lungs that when the Reynolds' number in the trachea is high by breathing a dense gas such as a $80 \%$ sulfurhexafluoride $+20 \%$ oxygen $\left(\mathrm{SF}_{6}+\mathrm{O}_{2}\right)$ mixture at a higher flow (1 L/s) the fraction of the total pulmonary resistance in the large airways is significantly greater than the fraction of pulmonary resistance in the same airways when Reynolds' number is low during breathing a $80 \%$ helium $+20 \%$ oxygen $\left(\mathrm{He}+\mathrm{O}_{2}\right)$ mixture at a lower flow $(0.25 \mathrm{~L} / \mathrm{s})$. In the latter case, the contribution of peripheral airways to total pulmonary resistance is increased.

Bhansali et al. (1), evaluating the effect of different gases by comparing pulmonary resistance and respiratory resistance at the same flow $(0.5 \mathrm{~L} / \mathrm{s})$, did not observe any difference in pulmonary resistance and respiratory resistance at $4 \mathrm{~Hz}$ between air and $\mathrm{He}+\mathrm{O}_{2}$ but did observe an increase for $\mathrm{SF}_{6}+\mathrm{O}_{2}$. They concluded that flow is laminar or near laminar for air and $\mathrm{He}+\mathrm{O}_{2}$ during quiet breathing, and that $\mathrm{SF}_{6}+\mathrm{O}_{2}$ breathing induces turbulence which makes pulmonary and respiratory resistance gas density dependent.

Tsai et al. (8), measuring the frequency dependence of the magnitude and phase angle of total respiratory impedance in apneic dogs at functional residual capacity during forced oscillation, found only a $8 \%$ decrease in mean resistance. They concluded that the constant influence of the chest wall minimizes the effects of He $+\mathrm{O}_{2}$ on average resistance.

They also observed with $\mathrm{He}+\mathrm{O}_{2}$ that the inertance value is greater than the value predicted from the inertance with air and the ratio of the densities of the gas mixtures. 
Holle et al. (3), measuring the oscillatory impedance at $10 \mathrm{~Hz}$ during air and $\mathrm{He}$ $+\mathrm{O}_{2}$ breathing, found in normal subjects a decrease of the real part of impedance during $\mathrm{He}+\mathrm{O}_{2}$ breathing. Due to the decrease of the inertial factor, the observed phase angle was negative during $\mathrm{He}+\mathrm{O}_{2}$ breathing.

We observed a statistically significant difference of the real part of the impedance at all frequencies between 8 and $52 \mathrm{~Hz}$. There was no difference between velocity profile and concentration profile, because all measurements during $\mathrm{He}+\mathrm{O}_{2}$ breathing were performed in steady state after complete wash-in of the gas mixture, as checked by a katapherometer.

Our measurements are in agreement with theoretical and experimental results of Olson et al. (7) and Wood et al. (10).

Olson et al. (7) presented a theoretical analysis to predict the fluid flow regime and pressure drop of air inspired into the lung. They concluded that on the basis of the calculated value of Reynolds' number, entrance length, tube length and total predicted pressure drop for each order of bronchi at different flow rates, very little development of the velocity profile occurs until after the fifth generation of bronchi and that turbulent llow prevails in several generations in the bronchial tree.

Turbulence induced into the fluid by the bifurcations and the waviness of the tubes, the pulsation of the heart and the geometry of the larynx are other factors that will tend to decrease the stability of the laminar velocity profile (7). Wood et al. (10) suggested that flow patterns undergo a continuous metamorphosis as Reynolds" number decreases between trachea and alveoli. Based on the results of Olson et al. (7), they found that frictional pressure losses produced by flow in tubes may be explained by the general equation, $p=\mathrm{K} V \mathrm{~V} \eta^{2-\mathrm{a}} \rho^{\mathrm{a}-1}$, where a reflects the proportion of inertial to viscous pressure losses and varies between 1 and 2 according to Reynolds' number. At flow rates between 0.5 and $1 \mathrm{~L} / \mathrm{s}$ they calculated a decrease of a from 1.75 in the trachea to 1.25 in the 9 th generation of the bronchial tree.

The observed increase of resonant frequency can be explained by the decrease of inductive reactance according to the formula $L=\rho / / A(l=$ length, $A=$ diameter). The $\mathrm{He}+\mathrm{O}_{2}$ mixture is 0.33 times as dense as air. According to the formule $2 \pi f_{0}=(L C)^{-1 / 2}$ resonant frequency wil] be 1.73 times higher during $\mathrm{He}+\mathrm{O}_{2}$ breathing. The mean ratio in our study was 1.88 . Differences between the measured results and the calculated increase were not statistically significant. Our results are in accordance with earlier published data (6).

In conclusion, impedance measurement of the respiratory system by forced oscillation technique permits to observe in normal subjects during $\mathrm{He}+\mathrm{O}_{2}$ breathing a density dependent decrease of the real part of impedance due to decreased turbulence in the larger airways and a density dependent decrease of inductive reactance reflected in an increase of resonant frequency. 


\section{References}

1. Bhansali PV, Irvin CG, Dempsey JA, Bush R, Webster JG. (1979)

Human pulmonary resistance: effect of frequency and gas physical properties.

IAppl Physiol 47:161-168

2. Drazen MJ. Stephen HL, Roland HI. (1976)

Distribution of pulmonary resistance: effects of gas density, viscosity and flow rate.

J Appl Physiol 41:388:-395

3. Holle JP, Magnussen H, Hartmann V. (1979)

Die Messung der Oszillatorischen Impedanz während Luft-und $\mathrm{He}_{2} \mathrm{O}_{2}$-Atmung.

Atemw- Lungenkrkh 3:117-119

4. Lándsếr FJ, Nagels J, Demedts M, Billiet L, Van de Woestijne KP.(1976)

A new method to determine frequency characteristics of the respiratory system.

J Appl Physial 41:101-106

5. Lándsér FJ. Polko AH, Visser BF. (1983)

Oscillatory measurement of total respiratory impedance with extended spectrum up to 52 $\mathrm{Hz}$.

Arch Intern Physiol Biochem 91:12

6. Ländsề $\mathrm{FJ}$, Polko AH, Visser BF. (1984)

Infuence of helium breathing on impedance measurement by the forced oscillation techni. que up to $52 \mathrm{~Hz}$.

Bull Europ Physiopathol Resp 20:34A

7. Olson DE, Gladys AD, Giles FF. (1970)

Pressure drop and fluid regime of air inspired into the human lung.

J Appl Physiol 28:482-494:

8. Tsai MI, Pimmel RL, Stiff EJ, Bromberg PA, Hamlin RL. (1977)

Respiratory parameter estimation using forced oscillatory impedance data.

J Appl Physiol 43:322-330

9. Visser BF. (1987)

Tautometry: How to calibrate forced oscillation equipment.

Pfügers Archiv 408:56

10. Wood LDH, Engel LA, Griffin P, Despas P, Macklem PT'. (1976)

Effect of the gas physical properties and flow on lower pulmonary resistance.

J Appl Physiol 41:234-244 



\section{CHAPTER 7}

\section{IMPEDANCE MEASUREMENT DURING AIR AND HELIUM-OXYGEN BREATHING BEFORE AND AFTER SALBUTAMOL IN NORMAL SUBJECTS}

WOUTERS E.F.M., LANDSER F.J., POLKO A.H., VISSER B.F.

DEPARTMENT OF PULMONARY DISEASES, UNIVERSITY LIMBURG. MAASTRICHT, THE NETHERLANDS.

Presented at the SEP congres "Bronchitis and emphysema", Milano Stresa, Italy, September 23-29, 1985. Published as an abstract in Eur. J. Resp. Dis., 1986, Suppl. 146, 69, A183.

Complete paper submitted for publication.

Key-words: Impedance, respiratory system, resistance, reactance, resonant frequency, helium + oxygen breathing, salbutamol, normal subjects, forced oscillations. 
Using a forced pseudo-random noise pressure signal, impedance measurements of the respiratory system were performed in 20 healthy male subjects during air or helium and oxygen breathing before and after inhalation of $0.200 \mathrm{mg}$ salbutamol.

During air breathing, there was a statistically significant decrease of resistance values at lower frequencies after inhalation of salbutamol. By equilibrating the subject with a mixture of $80 \%$ helium $(\mathrm{He})$ and $20 \%$ oxygen $\left(\mathrm{O}_{2}\right)$ the real part of impedance markedly decreased at all frequencies. After inhalation of salbutamol resistance values further decreased during $\mathrm{He}+\mathrm{O}_{2}$ breathing.

The density-dependent decrease of the real part of impedance can be explained by turbulence in the larger airways. The bronchodilating effect of salbutamol was not influenced by changing physical properties of the inhaled gas. During He + $\mathrm{O}_{2}$ breathing, reactance values significantly decreased resulting in an increase of resonant frequency due to a decrease of inductive reactance.

After inhalation of salbutamol, reactance values increased during air and during $\mathrm{He}+\mathrm{O}_{2}$ breathing.

\section{INTRODUCTION}

The technique of the forced oscillation, first described by Dubois et al. (6), was developed as a simple method to determine the resistance of the respiratory system by imposing sinusoidal oscillations at the mouth. Lándsér et al. (12), using a forced pseudo-random noise pressure signal, described a technique allowing the simultaneous determination of resistance and reactance of the totall respiratory system at various frequencies. In this study, a signal of $4 \mathrm{~Hz}$ and the harmonics up to $52 \mathrm{~Hz}$ is applied (14).

The influences of beta-adrenergic stimulation on pulmonary mechanics were extensively studied in normal subjects $(1,2,5,8,9,11,15,18-20,22,24)$.

These studies consistently pointed out a large decrease in airway resistance $\left(R_{\text {aw }}\right)$ and a comparatively modest increase in maximal expiratory flow ( $\tilde{V}_{\text {Emax }}$ ).

This $R_{\text {aw }}-V_{\text {Emax }}$ dichotomy has been attributed to decreased lung recoil pressure $(5,15,22)$, increased compressibility of the flow-limiting airways $(1,2$, $15,20,22)$, volume- and time-dependent behaviour of airway smooth muscle tone (8) and non-uniform distribution of inhaled aerosols within the tracheobronchial tree (20).

In the present study, we investigated the influences of inhalation of salbutamol, a beta-2-sympaticomimetic drug, on the impedance of the respiratory system in normal subjects during breathing gases with different physical properties. 
The technique of forced oscillations is described in chapter 4 (12). Three successive measurements, each lasting $8 \mathrm{~s}$, were performed in every subject during air breathing and after equilibrating the subject with a mixture of $80 \%$ helium (He) $+20 \%$ oxygen $\left(\mathrm{O}_{2}\right)$. Equilibration was checked by rapid katapherometry (see chapter 6). After wash-out of the $\mathrm{He}+\mathrm{O}_{2}$ mixture, $0.200 \mathrm{mg}$ salbutamol was inhaled using an inhalation device.

Ten minutes later, impedance measurements during air breathing and after equilibration with the $\mathrm{He}+\mathrm{O}_{2}$ mixture were repeated. The $\mathrm{He}+\mathrm{O}_{2}$ mixture used was 0.33 times as dense as air as calculated from molar masses.

Calibration was performed using a known volume of the mixture and adjusting the integrated signal of the pneumotachograph to that known volume. It was shown that the $\mathrm{He}+\mathrm{O}_{2}$ mixture is 1.13 times as viscous as air (23).

Twenty male subjects without pulmonary complaints participated in the study. Anthropometric and spirometric data are summarized in table 1.

Table 1 .

Anthropometric and spirometric data of studied subjects.

\begin{tabular}{lllllll}
\hline $\mathrm{n}$ & Age & Height & Weight & IVG & FEV & FEV $/ \mathrm{IVC}$ \\
& years & $\mathrm{cm}$ & $\mathrm{kg}$ & $\%$ pred $^{*}$ & $\%$ pred & $\%$ \\
1 & 36 & 175 & 60 & 122 & 112 & 73 \\
2 & 35 & 172 & 73 & 112 & 92 & 66 \\
3 & 31 & 187 & 82 & 102 & 101 & 78 \\
4 & 22 & 182 & 71 & 105 & 116 & 88 \\
5 & 29 & 189 & 85 & 98 & 98 & 79 \\
6 & 36 & 175 & 77 & 103 & 102 & 79 \\
7 & 39 & 165 & 70 & 129 & 125 & 78 \\
8 & 39 & 184 & 95 & 125 & 115 & 72 \\
9 & 34 & 174 & 60 & 74 & 70 & 76 \\
10 & 37 & 177 & 90 & 104 & 105 & 80 \\
11 & 27 & 161 & 52 & 106 & 109 & 85 \\
12 & 31 & 180 & 65 & 99 & 91 & 73 \\
13 & 26 & 181 & 79 & 103 & 114 & 88 \\
14 & 24 & 185 & 63 & 82 & 77 & 76 \\
15 & 31 & 185 & 78 & 104 & 102 & 77 \\
16 & 40 & 182 & 68 & 115 & 95 & 65 \\
17 & 36 & 184 & 65 & 111 & 109 & 77 \\
18 & 30 & 179 & 75 & 109 & 106 & 78 \\
19 & 28 & 178 & 74 & 99 & 107 & 87 \\
20 & 38 & 180 & 70 & 109 & 99 & 72 \\
mean & 33 & 179 & 73 & 106 & 102 & 77 \\
SD & 5 & 7 & 11 & 13 & 13 & 6 \\
\hline
\end{tabular}

* reference values of European Community for Coal and Steel 
Means of impedance parameters were compared using a paired t-test. $\mathbb{P}$-values lower than 0.05 were retained as statistically significant. Comparison of means was not possible at $4 \mathrm{~Hz}$ : coherence function was too often lower than 0.95 at this frequency. All values presented in the text are means $\pm 1 \mathrm{SD}$.

\section{RESULTS}

Resistance values are summarized in table 2. $R_{\mathrm{rg}}$ slightly increased with frequency during air breathing. After inhalation of salbutamol, there was a slight but statistically significant decrease of resistance values between 8 and $24 \mathrm{~Hz}$. At frequencies higher than $24 \mathrm{~Hz}$ there was no significant difference between both measurements.

By equilibrating the subject with a mixture of $\mathrm{He}+\mathrm{O}_{2}$, the real part of impedance markedly decreased : p-values are smaller than 0.001 at all frequencies

Table 2.

Mean values of $R_{\mathrm{rs}}(\mathrm{kPa} /(\mathrm{L} / \mathrm{s}))$ during air and $\mathrm{He}+\mathrm{O}_{2}$ breathing before and after inhatation of salbutamol (salb).

\begin{tabular}{|c|c|c|c|c|c|c|c|c|c|c|c|c|}
\hline Freq. $(\mathrm{Hz})$ & 8 & 12 & 16 & 20 & 24 & 28 & 32 & 36 & 40 & 44 & 48 & 52 \\
\hline air & .230 & .224 & .223 & .232 & .260 & .257 & .271 & .278 & .303 & .297 & .298 & .304 \\
\hline $\mathrm{He}+\mathrm{O}_{2}$ & .203 & .193 & .181 & .179 & .183 & .182 & .193 & .201 & .221 & .232 & .247 & .258 \\
\hline$a i+s a l b$ & .205 & .198 & .203 & .214 & .241 & .246 & .263 & .275 & .302 & .299 & .295 & .303 \\
\hline $\mathrm{He}+\mathrm{O}_{\mathfrak{a}}+\mathrm{salb}$ & .177 & .166 & .158 & .157 & .160 & .162 & .174 & .182 & .204 & .215 & .232 & .242 \\
\hline \multicolumn{13}{|c|}{ Level of significance } \\
\hline air ys $\mathrm{He}+\mathrm{O}_{2}$ & 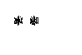 & * * * * & $* * *$ & $* * *$ & * * * * & $* *$ & $* * *$ & $* * *$ & $* *$ & $* *$ & $* * *$ & is \\
\hline air as air + salb & $* *$ & * * * * * & ** & $*$ & $*$ & n.s. & n.s. & n.s. & n.s. & n.s. & n.s. & n.s. \\
\hline \multicolumn{13}{|l|}{$\mathrm{He}+\mathrm{O}_{2}$ os } \\
\hline $\mathrm{He}+\mathrm{O}_{2}+\mathrm{salb}$ & $* *$ & $* *$ & $* *$ & $* *$ & ** & $* *$ & $* *$ & $* *$ & $*$ & $*$ & n.s. & n.s. \\
\hline $\begin{array}{l}\text { not significant } \\
\text { p-value } 0.01 \leq \\
0.001 \leq\end{array}$ & $\begin{array}{l}0.05 \\
0.01 \\
0.001\end{array}$ & & $\begin{array}{l}\text { n.s. } \\
* \\
* * \\
* * *\end{array}$ & & & & & & & & & \\
\hline
\end{tabular}


between 12 and $52 \mathrm{~Hz}$. After inhalation of salbutamol, resistance values further decreased during $\mathrm{He}+\mathrm{O}_{2}$ breathing. Between 8 and $44 \mathrm{~Hz}$ these differences reached a statistically significant level.

Mean values of $X_{\mathrm{rs}}$ at each frequency during air and $\mathrm{He}+\mathrm{O}_{2}$ breathing before and after inhalation of salbutamol are summarized in table 3 .

After equilibration of the subject with the $\mathrm{He}+\mathrm{O}_{2}$ mixture reactance values significantly decreased at all frequencies. After inhalation of the beta-2-sympaticomimetic drug reactance values slightly increased.

During air breathing the increase of reactance was statistically significant between 16 and $40 \mathrm{~Hz}$. During $\mathrm{He}+\mathrm{O}_{2}$ breathing, the differences were statistically significant at all frequencies between 8 and $44 \mathrm{~Hz}$. Resonant frequency values were influenced by salbutamol neither during air nor during $\mathrm{He}+\mathrm{O}_{2}$ breathing.

Table 3

Mean values of $X_{\mathrm{rs}}(\mathrm{kPa} /(\mathrm{L} / \mathrm{s}))$ during air and $\mathrm{He}+\mathrm{O}_{2}$ breathing before and after inhalation of salbutamol (salb).

\begin{tabular}{|c|c|c|c|c|c|c|c|c|c|c|c|c|}
\hline Freq. $(\mathrm{Hz})$ & 8 & 12 & 16 & 20 & 24 & 28 & 32 & 36 & 40 & 44 & 48 & 52 \\
\hline air & -.005 & .033 & .067 & .118 & .154 & .174 & .189 & .208 & .224 & .248 & .281 & .294 \\
\hline $\mathrm{He}+\mathrm{O}_{2}$ & $-.047-$ & $.030-$ & .008 & .020 & .044 & .064 & .081 & .093 & .111 & .118 & .132 & .123 \\
\hline $\mathrm{air}+\mathrm{salb}$ & -.002 & .040 & .079 & .133 & .171 & .194 & .207 & .226 & .243 & .259 & .290 & .305 \\
\hline $\mathrm{He}+\mathrm{O}_{2}+\mathrm{salb}$ & $-.041-$ & .020 & $.00 \mathbb{1}$ & .029 & .053 & .072 & .090 & .103 & .120 & .127 & .136 & 126 \\
\hline \multicolumn{13}{|c|}{ Level of significance } \\
\hline air os $\mathrm{He}+\mathrm{O}_{2}$ & $* * *$ & $* * *$ & ***m & $* * *$ & * * * & **** & $* * *$ & *** & $* * *$ & $* * *$ & $* 4$ & $* *$ \\
\hline air os air + salb & n.s. & $\mathrm{nu} . \mathrm{s}$ & $*$ & ** & $*$ & \# & $*$ & $* *$ & * * & n.s. & n.s & n.s. \\
\hline \multicolumn{13}{|l|}{$\mathrm{He}+\mathrm{O}_{2}$ os } \\
\hline $\mathrm{He}+\mathrm{O}_{2}+$ salb & * & *** & $*$ & $* *$ & * & " & * & $*$ & $*$ & $*$ & n. 5. & n.s. \\
\hline
\end{tabular}

mot significant

$\mathrm{p}^{\text {-value }} 0.01 \leq \mathrm{p}<0.05$

$0.001 \leq \mathrm{p}<0.01$

$p<0.001$

n.s.

$*$

*

*** * 
The forced pseudo-random noise technique allows the simultaneous determination of the impedance of the total respiratory system for various frequencies during spontaneous, quiet breathing. The impedance of the respiratory system is partitioned into a real part, $R_{\mathrm{rs}}$, or resistance, and an imaginary part, $X_{\mathrm{rs}}$, or reactance. Nagels et al. (17) showed that it is not necessary to partition $Z_{\mathrm{rs}}$ into the impedance of the lungs and the impedance of the chest wall and that valid conclusions can be drawn for resistance and reactance of the lungs from the values of $R_{\text {ris }}$ and $X_{\text {rs. }}$.

Lándsêr et al. (13), evaluating the usefulness of the forced oscillation technique to evaluate the influence of bronchoactive drugs, demonstrated in one normal subject that after inhalation of salbutamol, all resistance values were decreased but that the shape of the resistance curve was not changed.

This observation is in accordance with our results, showing a significant decrease of resistance values at frequencies from 8 to $24 \mathrm{~Hz}$. In accordance with Mead's analogon of the lung (16), this parallel decrease of the resistance curve can be explained by bronchodilation of the larger airways.

At higher frequencies, the increase of total respiratory resistance observed in normal subjects is not changed. This increase of resistance reflects the influences of several factors, including inhomogeneous distribution of inertance - resistance time-constants among parallel lung pathways, inertial distortion of velocity profiles associated with periodic breathing, gas compressibility, interference of the shunt characteristics of the upper airways and airway distensibility (3).

The decrease of airway resistance after inhalation of beta-2-sympaticomimetics as found by several authors is in accordance with these changes of the real part of impedance after inhalation of salbutamol $(1,2,5,15,18,19,22,24)$.

Based on the reported perihilar disposition of aerosols (4), Stamm et al. (20) supposed a preferential dilation of lobar and segmental airways after inhalation of beta-2-sympaticomimetic drugs. Other authors $(9,11)$ reported a predominant effect of beta-2-agonists on smaller airways in normal subjects. By studying density dependence of maximal expiratory flow to assess the relative contributions of large versus small airways to flow limitation, Ingram et al. (11) found that isoproterenol has its predlominant effects on smaller airways of the upstream segment as reflected by an increase in density dependence, defined as the ratio of $\vec{V}_{\mathrm{Emax},} \mathrm{HeO}_{2}$ to $\vec{V}_{\text {Emax, air }}$ at the same lung volume.

Using changes in anatomical dead space as a measure of larger airway effects and differences in the volume at which phase IV of the single-breath nitrogen washout curve occurs as indices of peripheral airway effects after inhalation of isoetharine, a beta-adrenergic stimulant, Hensley et al. (9) found a significant increase of closing volume after isoetharine inhalation and concluded that betaadrenergic stimulants have a greater effect on peripheral airways.

During breathing a $\mathrm{He}+\mathrm{O}_{2}$ mixture, there is a significant decrease of 
resistance. This density-dependent decrease of the real part of impedance can be explained by decreased turbulence in the larger airways (25).

During breathing of this low density gas mixture, salbutamol further decreases the resistance values.

Our results clearly illustrate the decrease in reactance during $\mathrm{He}+\mathrm{O}_{2}$ breathing. These changes are caused by the decrease of inductive reactance and are reflected in an increase of resonant frequency (25).

During air breathing and more markedly during $\mathrm{He}+\mathrm{O}_{2}$ breathing, salbutamol increases reactance values. In normal subjects reactance value is determined by inertance of air in the airways, compliance of the lungs and chest wall compliance in series.

Chest wall compliance is not modified by inhalation of even higher doses of beta-2-agonists as used in this study (5).

The influence of inhalation of beta-2-sympaticomimetic drugs on the elastic recoil of the lung is more conflicting. The elastic recoil pressure has been found to be unchanged $(1,2,11,20)$ or decreased $(5,10,15,21,22)$.

De Troyer et al. (5) found that the decrease in lung recoil pressure after betaadrenergic stimulation depends on the dose of the drug administered. Dilation of alveolar duct smooth muscle was supposed by De Troyer et al. (5) as the most likely cause of the observed change in lung pressure-volume characteristics. Doses of beta-2-agonists as used in this study failed to induce any change in the pressure-volume relationship.

Furthermore, because of the much lower value of chest wall compliance $(0.05$ $\mathrm{L} / \mathrm{kPa})$ in comparison with lung compliance $(2 \mathrm{~L} / \mathrm{kPa})$, capacitive reactance in normal subjects is mainly determined by chest wall compliance (17). To explain the observed increase of reactance values after inhalation of salbutamol, it can be hypothesized that due to an influence on the interregional and intraregional timeconstant inequalities in normal lungs, as reviewed by Cutillo and Renzetti (3), values of capacitive reactance will decrease, resulting in a net increase of total reactance according to the formula $X_{\mathrm{r} s}=\omega L-1 / \omega C(L=$ inductance; $C=$ capacitance; $\omega=2 \pi f ; f=$ frequency).

However, analyzing the parallel decrease of the real part of impedance after inhalation of salbutamol, a decrease of inductive reactance due to an increased central airway diameter has to be considered.

However, the decrease of capacitive reactance has to be greater than the decrease of inductive reactance according to the observed net increase of total reactance. It has to be pointed out that the observed changes of salbutamol on the real and imaginary part of impedance are obtained after administration of much lower doses of beta-2-sympaticomimetic drugs than generally reported in the literature $(2,8,11,15,20,22)$.

It can therefore be concluded that impedance measurements are useful to follow resistance and reactance changes in subjects under the influence of bronchoactive drugs and during breathing gases with different physical properties. Further- 
more, impedance measurements are performed during quiet breathing. Therefore, the bronchomotor effect, observed during maximal inspiratory manoeuwres ( 7 ) is negligible using the forced oscillation technique.

By simultaneous measurement of resistance and reactance, it is not only possible to quantify the effect of bronchoactive drugs but also to localize these effects along the tracheobroncheal tree, using Mead's analogon of the respiratory system (16).

\section{References}

1. BOBBAERS (H.), STANESCU (D.C), DEMEDTS (M.), CLEMENT U.), PARDAENS (J.), VAN DE WOESTIJNE (K.P.). - Action of isoprenaline on the mechanical properties of lungs and airways in healthy people and patients with obstructive lung diseases. Bull. Europ. Physiopath. Resp., 1976, 12, 515-31.

2. BOUHUYS (A.), VAN DE WOESTIJNE (K.P.). - Mechanical consequences of airway smooth muscle relaxation. J. Appl. Physiol. $1971,30,670-76$.

3. CUTILLO (A.G), RENZETTI (A.D.). - Mechanical behavior of the respiratory system as a function of frequency in health and disease. Bull. Europ. Physiopath. Resp., 1983, 19, 293-326.

4. DASHE (C.K.), PONTS (R.A.), GANAPES (C.M.), DRAGE (C.W.), KRONENBERG (R.S.) - The distribution of nebulized isoproterenol and its effect on regional ventilation and perfusion. Am. Rew. Respir. Dis., 1974, 110, 293-300.

5. DE TROYER (A.), YERNAULT (J.C.), RODENSTEIN (D). - Influence of beta-2-agonist aerosols on pressure-volume characteristics of the lungs. Am. Rev. Respir. Dis., 1978, 118, $987-95$.

6. DUBOIS (A.B.), BRODY (A.W.), LEWIS (D.H.), BURGESS (B.F.). - Oscillation mechanics of lungs and chest in man. J. Appl. Physiol., 1956, 8, 587-94.

7. GAYRARD (P.), OREHEK (J), GRIMAUD (C.), CHARPIN (J.). - Bronchoconstrictor effects of a deep inspiration in patients with asthma. An. Rev. Respir. Dis, 1975, 111, 433-39.

B. GREEN (M.), MEAD (J.). - Time dependence of flow-volume curves. J. Appl. Physiol., $1974,37,793-97$.

9. HENSLEY (MJ.), O'CAIN (G.F.), McFADDEN (E.R.), INGRAM (R.H.). - Distribution of bronchodilation in normal subjects : beta agonist versus atropine. J. Appl. Physiol., 1978, $45,778-82$.

10. INGRAM (R.H.), O'CAIN (C.F.). - Frequency dependence of compliance in apparently healthy smokers versus non-smokers. Bull. Europ. Physiopath. Resp., 1971, 7, 195-210.

11. INGRAM (R.H.), WELLMAN U.J.), MCFADDEN (E.R.), MEAD (J). - Relative contributions of large and small airways to low limitation in normal subjects before and after Atropine and Isoproterenol. J. Clin. Invest., 1977, 59, 696-703.

12. LÁNDSER (F.J), NAGELS (J.), DEMEDTS (M.), BILLIET (L.) VAN DE WOESTIJNE. $\left(K . P^{*}\right)$. - A new method to determine frequency characteristics of the respiratory system. $J$. Appl. Physiol., 1976, 41, 101 6.

13. LÁNDSER (F.J.), NAGELS O.), VAN DE WOESTIJNE (K.P.). - Implementation by means of microprocessor techniques for the measurement of total respiratory impedance during spontaneous breathing. Prog Respir. Res., 1979, 11, 135-43. 
14. LANDSER (F.J.), POLKO (A.H.), VISSER (B.F.). Oscillatory measurement of total respiratory impedance with extended spectrum up to $52 \mathrm{~Hz}$. Arch. Internat. Physiol. Biochim, 1983, 91,12 .

15. MCFADDEN (E.R.), NEWTON-HOWES U.), PRIDE (N.B.) - Acute effects of inhaled isoproterenol on the mechanical characteristics of the lungs in nomal man. J. Clin. Invest." $1970,49,779-90$.

16. MEAD (J.). - Comtribution of compliance of airways to frequency-dependent behavior of lungs. J. Appl. Physiol., 1969, 26, 670-73.

17. NAGELS (I.), LANDSER (F.J.), VAN DER LINDEN (L.), CLEMENT O), VAN DE WOESTIJNE (K.P.). - Mechanical properies of lungs and chest wall during spontaneous breathing. J. Appl. Physiol., 1980, 49, 408-16.

18. SKINNER (C.), PALMER (K.N.V.). - Changes in specific airways conductance and forced expiratory volume in one second after a bronchodilator in nomal subjects and patients with airways obstruction. Thorax, 1974, 29, 574-77.

19. SOBOL (B.J.), EMIRGL (G.), WALDIE U.R.), REED (A.). - The response to isoproterenol in normal subjects and subjects with asthma. Am. Rev. Respir. Dis., 1974, 109, $290-92$.

20. STAMM (A.M.), CLAUSEN U.L.), TISI (G.M.) - Effect of aerosolized isoproterenol on resting myogenic tone in normals. J. Appl. Physiol., 1976, 40, 525-32.

21. STANESCU (D.C.), CLEMENT U.), VAN DE WOESTIJNE (K.P.). - Influence of isoprenaline on static elastic properties of lungs in chronic obstructive lung diseases and normals. Bull. Europ. Physiopath. Resp., 1972, 8, $868-70$.

22. TATTERSFIELD (A.E.), LEAVER (D.G.), PRIDE (N.B.). - Effects of beta-adrenergic blockade and stimulation on normal human airways. J. Appl. Physiol., 1973, 35, 613-19.

23. VISSER (B.F.), POLKO (A.H.), LANDSÉR (F.J.). - Compressibility in cylindrical models analyzed by the forced oscillation technique up to $52 \mathrm{~Hz}$. Bull. Europ. Physiopath. Resp., $1984,20,32 a-33 a$.

24. WATANABE (S.), RENZETTT (A.D.), BÉGIN (R.), BIGLER (A.H.). - Airway responsiveness to a bronchodillator aerosol. Am. Rev. Respir. Dis., 1974, 109, $530-37$.

25. WOUTERS (E.F.M.), POLKO (A.H.), LÁNDSÉR (F.J.), VISSER (B.F.). - Impedance measurement during air and helium breathing before and after Salbutamol in normal subjects. Eur. J. Respir. Dis., 1986, 69, Suppl. 146, A 183. 


\section{CHAPTER 8}

\section{IMPEDANCE MEASUREMENT OF THE RESPIRATORY SYSTEM DURING AIR AND HELIUM-OXYGEN BREATHING BEFORE AND AFTER IPRATROPIUM BROMIDE IN NORMAL SUBJEGTS.}

WOUTERS E.F.M., POLKO A.H., VISSER B.F.

DEPARTMENT OF PULMONARY DISEASES, UNIVERSITY LIMBURG, MAASTRICHT, THE NETHERLANDS.

Submitted for publication.

Key words: Impedance, respiratory system, resistance, reactance, capacitance, resonant frequency, helium + axygen, ipratropium bromide, normal subjects. 
Using a forced pseudo-random noise pressure signal, impedance measurement of the respiratory system was performed in 15 normal subjects during air or helium + oxygen breathing before and after inhalation of $0.040 \mathrm{mg}$ ipratropium bromide.

During air breathing, neither resistance nor reactance values changed significantly after ipratropium bromide. During $\mathrm{He}+\mathrm{O}_{2}$ breathing, ipratropium caused a significant decrease of resistance values from 8 to $48 \mathrm{~Hz}$ and a significant increase of reactance values from 12 to $44 \mathrm{~Hz}$.

It can be assumed that breathing gases with decreased kinematic viscosity is preferable for measuring the effects of low doses ipratropium on the tracheobronchial tree in normal subjects.

\section{INTRODUCTION}

Impedance measurement of the respiratory system by a forced pseudo-random noise signal allows to determine simultaneously the resistance and reactance of the respiratory system at various frequencies (1).

In normal subjects, impedance of the respiratory system is mainly determined by inertance of air in the larger airways, central airway resistance and compliance of the lungs and chest wall in series (2).

This study is performed to evaluate the acute effect of an inhaled atropinelike agent, ipratropium bromide, on impedance parameters during breathing gases with different physical properties.

\section{METHODS}

The technique of forced oscillations is described in chapter $4(1,3)$.

Three successive measurements, each lasting $8 \mathrm{~s}$, were performed in every subject during air breathing and after equilibration of the subject with a mixture of $80 \%$ helium ( $\mathrm{He}$ ) and $20 \%$ oxygen $\left(\mathrm{O}_{2}\right)$. Equilibration was checked by rapid katapherometry (chapter 6). After wash-out of the $\mathrm{He}+\mathrm{O}_{2}$ mixture, $0.040 \mathrm{mg}$ ipratropium bromide was inhaled using a metered dose inhaler.

Ten minutes later, impedance measurements during air breathing and after equilibration with the $\mathrm{He}+\mathrm{O}_{2}$ mixture were repeated.

The used $\mathrm{He}+\mathrm{O}_{2}$ mixture is 0.33 times as dense as air, calculated from molar masses. Callibration was performed using a known volume of the mixture and adjusting the integrated signal of the pneumotachograph to that known volume. It was shown that the $\mathrm{He}+\mathrm{O}_{2}$ mixture is 1.13 times as viscous as air (4).

Means were compared using a paired t-test. P-values lower than 0.05 were retained as statistically significant. Comparison of means was not possible at $4 \mathrm{~Hz}$ : coherence function was too often lower than 0.95 at this frequency. All values presented in the text are means $\pm 1 \mathrm{SD}$. 
Fifteen subjects without pulmonary complaints participated in the study, 6 women and 9 men. Anthropometric data and some basal impedance parameters during air breathing are summarized in table 1.

\section{RESULTS}

Mean values of $R_{\mathrm{rs}}$ and $X_{\mathrm{rs}}$ at all frequencies between 8 and $52 \mathrm{~Hz}$ are summarized in tables 2 and 3 .

During breathing the $\mathrm{He}+\mathrm{O}_{2}$ mixture, values of the real and imaginary part of impedance significantly decreased at all frequencies. Resonant frequency significantly increased: $7.5 \mathrm{~Hz}$ during air breathing and $15.9 \mathrm{~Hz}$ during $\mathrm{He}+$ $\mathrm{O}_{2}$ breathing $(\mathrm{p}<0.001)$.

After inhalation of ipratropium bromide neither $R_{\mathrm{rs}}$ nor $X_{\mathrm{rs}}$ changed significantly during air breathing.

No significant decrease of $f_{0}$ was observed after ipratropium bromide during air breathing: values of $f_{0}$ were resp. 7.5 and $7.4 \mathrm{~Hz}$ before and after ipratropium. However, during $\mathrm{He}+\mathrm{O}_{2}$ breathing, ipratropium bromide caused a significant. decrease of $R_{\mathrm{rs}}$ and a significant increase of $X_{\mathrm{rs}}$ except at 8,48 and $52 \mathrm{~Hz}$. Resonant frequency slightly decreased after ipratropium: $15.9 \mathrm{~Hz}$ before and 15.1 $\mathrm{Hz}$ after ipratropium $(\mathrm{p}<0.05)$.

Table 1.

Anthropometric and basal impedance parameters of the studied subjects.

\begin{tabular}{|c|c|c|c|c|c|c|c|}
\hline $\begin{array}{l}\text { Patient } \\
\text { number }\end{array}$ & Sex & $\begin{array}{l}\text { Age } \\
\text { years }\end{array}$ & $\begin{array}{l}\text { Height } \\
\mathrm{cm}\end{array}$ & $\begin{array}{l}\text { Weight } \\
\mathrm{kg}\end{array}$ & $\begin{array}{l}R_{\mathrm{rs}(12)} \\
\mathrm{k}_{\mathrm{Pa} /(\mathrm{L} / \mathrm{s})}\end{array}$ & $\begin{array}{l}\mathrm{a} R_{\mathrm{rs}} \\
\mathrm{kPa}(\mathrm{L} / \mathrm{s})\end{array}$ & $\begin{array}{l}f_{0} \\
H_{z}\end{array}$ \\
\hline 1 & $m$ & 32 & 182 & 67 & .195 & .252 & 9.09 \\
\hline 2 & f & 28 & 173 & 59 & .167 & .257 & 8.95 \\
\hline 3 & $\mathrm{~m}$ & 37 & 182 & 73 & .226 & .313 & 7.40 \\
\hline 4 & $f$ & 22 & 166 & 57 & 300 & .432 & 8.78 \\
\hline 5 & f & 22 & 156 & 53 & .470 & .562 & 8.54 \\
\hline 6 & f & 24 & 174 & 71 & .360 & 416 & 8.45 \\
\hline 7 & f & 29 & 163 & 53 & .285 & .365 & 8.57 \\
\hline 8 & $\mathrm{~m}$ & 32 & 186 & 81 & .171 & .211 & 9.55 \\
\hline 9 & $\mathrm{~m}$ & 27 & 185 & 70 & .185 & .224 & 11.76 \\
\hline 10 & $\mathrm{~m}$ & 32 & 185 & 71 & .173 & 241 & 6.97 \\
\hline 11 & $\mathrm{~m}$ & 41 & 184 & 90 & .201 & .219 & 7.61 \\
\hline 12 & $\mathrm{~m}$ & 30 & 178 & 72 & .227 & .304 & 7.90 \\
\hline 13 & $f$ & 26 & 166 & 52 & .448 & .571 & 9.22 \\
\hline 14 & $\mathrm{~m}$ & 31 & 187 & 86 & .202 & .283 & 6.68 \\
\hline 15 & $\mathrm{~m}$ & 23 & 176 & 64 & .184 & .281 & 7.16 \\
\hline Mean & & 29 & 176 & 68 & .253 & .329 & 8.44 \\
\hline S.D. & & 5 & 9 & $\mathbb{1}$ & .096 & .114 & 1.23 \\
\hline
\end{tabular}

$m=$ male $f=$ female. 
Table 2.

Mean values of $R_{\mathrm{rs}}(\mathrm{kPa} /(\mathrm{L} / \mathrm{s}))$ during air and $\mathrm{He}+\mathrm{O}_{2}$ breathing before and after inhalation of ipratropium bromide (ipr).

\begin{tabular}{|c|c|c|c|c|c|c|c|c|c|c|c|c|}
\hline Freq. $(\mathrm{H} w)$ & 8 & 12 & 16 & 20 & 24 & 28 & 32 & 36 & 40 & 44 & 48 & 52 \\
\hline air & .249 & .255 & .264 & .283 & .322 & .327 & .356 & .369 & .405 & .398 & .401 & .409 \\
\hline $\mathrm{He}+\mathrm{O}_{2}$ & .203 & .194 & .188 & .187 & .194 & .198 & .209 & 223 & .241 & .255 & .275 & .283 \\
\hline air $+\mathrm{ipr}$ & .235 & .233 & .240 & .266 & .304 & .311 & .332 & .343 & .372 & .361 & .356 & .353 \\
\hline $\mathrm{He}+\mathrm{O}_{2}+\mathrm{ipr}$ & .176 & .166 & .161 & .161 & .168 & .172 & .183 & .197 & .217 & .231 & .251 & .258 \\
\hline \multicolumn{13}{|c|}{ Level of significance } \\
\hline air ws $\mathrm{He}+\mathrm{O}_{2}$ & $* *$ & $*: *$ & $* * *$ & *** & $* *$ & $*$ * * & *** & *** * * & \#*** & $* *$ & $* * *$ & * \\
\hline air ws air + ipr & n.s. & n.s. & n.s. & $\mathrm{m}, \mathrm{s}$. & $n . s_{.}$ & n.s. & n.s. & n. s. & n.s. & n.s. & * & $*$ \\
\hline \multicolumn{13}{|l|}{$\mathrm{He}+\mathrm{O}_{2}$ ws } \\
\hline $\mathrm{He}+\mathrm{O}_{2}+\mathrm{ipr}$ & $*$ & $* *$ & $*$ & $* *$ & $* *$ & $* *$ & $* *$ & $*$ & $*$ & * & * & n.s. \\
\hline
\end{tabular}

Table 3.

Mean values of $X_{\mathrm{rs}}(\mathrm{kPa} /(\mathrm{L} / \mathrm{s}))$ during air and $\mathrm{He}+\mathrm{O}_{2}$ breathing before and after inhalation of ipratropinm bromide (ipr).

\begin{tabular}{lrrrrrrrrrrrrr}
\hline Freq. (Hz) & 8 & 12 & 16 & 20 & 24 & 28 & 32 & 36 & 40 & 44 & 48 & 52 \\
air & -.001 & .055 & .095 & .151 & .186 & .216 & .218 & .235 & .234 & .256 & .272 & .310 \\
$\mathrm{He}+\mathrm{O}_{2}$ & -.058 & -.025 & -.001 & .027 & .053 & .072 & .089 & .101 & .113 & .121 & .131 & .134 \\
air $+\mathrm{ipr}$ & .003 & .062 & .102 & .159 & .196 & .217 & .215 & .231 & .237 & .258 & .282 & .331 \\
$\mathrm{He}+\mathrm{O}_{2}+\mathrm{ipr}$ & -.053 & -.020 & .003 & .032 & .059 & .080 & .097 & .109 & .121 & .128 & .138 & .143
\end{tabular}

Level of significance

$\operatorname{air}$ or $\mathrm{He}+\mathrm{O}_{2}$

air vs air $+\mathrm{ipr}$

n.s. n.s. n.s. n.s. n.s. n.s. n.s. n.s. n.s. n.s. n.s. n.s.

$\mathrm{He}+\mathrm{O}_{2} \mathrm{us}$

$\mathrm{He}+\mathrm{O}_{2}+\mathrm{ipr}$

n.s.

n.s.

not significant :

$0.01 \leq \mathrm{p}<0.05$

$0.001 \leq \mathrm{p}<0.01$

$p<0.001$ 
Reported studies on the effects of cholinergic receptor blockade on lung and airway function in man appear somewhat discrepant.

Vincent et al. (5) reported a reduction of total pulmonary and lower pulmonary resistance and a highly significant change in the maximum expiratory flow-volume curve after intravenous injection of $1.2 \mathrm{mg}$ atropine sulphate, a parasympaticolytic agent. A significant shift to smaller recoil pressure after atropine was found in their study.

Ingram et al (6) compared bronchodilation produced in normal subjects by the inhalation of atropine and isoproterenol, a beta-adrenergic stimulator. They found that after atropine maximal expiratory flow ( $V_{\text {Emax }}$ ) increases, elastic recoil pressure does not change and density dependence, defined as the ratio of $V_{\mathbb{E} \max }$, $\mathrm{HeO}_{2}$ to $V_{\text {Emax, air }}$ at the same lung volume, decreases. After isoproterenol, $V_{\text {Emax }}$ increases, elastic recoil pressure does not change and density dependence increases. Utilizing the equal pressure point analysis, they suggested a greater relative dilation of the larger airways after atropine such that more of the driving pressure is dissipated across the smaller airways in which flow is less dependent upon gas density. After isoproterenol, a preferential dilation of the smaller and more peripheral airways with less density-dependent flow regimens should occur such that more of the driving pressure will be dissipated in the larger airways in which flow is more dependent upon gas density.

Hensley et al.(7), using changes in anatomical dead space as a measure of larger airway effects and differences in the volume at which phase IV of the $\mathrm{N}_{2}$ wash-out curve occurs as indices of peripheral airway effects, showed that atropine causes a greater increase in anatomical dead space than isoetharine, a beta-adrenergic agent, whereas - unlike isoetharine - atropine induces no change in closing volume.

They concluded that the predominant site of action of atropine is in the larger central airways and of isoetharine in the smaller peripheral airways. These authors suggested that the anatomical dead space reflects the volume of all airways having an internal larger than $1.0 \mathrm{~mm}$.

Francis et al. (8) demonstrated in normal subjects a statistically significant fall in specific airway resistance $1,2,3$ and 6 hours after inhalation of ipratropium bromide, a synthetic anticholinergic agent, chemically a quaternary ammonium compound. No dose effect was observed in this study.

Douglas et al. (9) demonstrated in normal subjects after inhalation of $0.080 \mathrm{mg}$ ipratropium bromide an increased specific conductance and increased flow rates during maximal and partial forced expiratory manoeuvres at all volumes from 50 to $10 \%$ vital capacity. Ipratropium produced no change in quasistatic or dynamic compliance, closing volume, or the slope of phase III of the closing volume trace, but there was an increase in the height of phase IV. When specific conductance reflected central airway caliber and flow rates at low lung volume in the absence 
of alteration in static recoil pressure reflected the caliber of more peripheral airways, these authors concluded that inhibition of yagal tone results in dilation of large and small airways.

De Troyer et al. (10) tested the possibility that the observed discrepancies in man in the site of action of anticholinergic agents may be due to differences in the way of administration of the drugs. Therefore, they compared the effects of intravenous atropine administration on the lung mechanical properties in normal subjects with those of inhalation of ipratropium bromide.

They found that intravenous atropine induces a reduction in lung recoil pressure with an increase in FRC, in VC and in lung compliance, whereas inhalation of large doses of ipratropium does not modify the static elastic properties of the lung.

Furthermore, both procedures caused a similar decrease in airway resistance and a similar increase in maximal expiratory flow at high lung volumes but only intravenous atropine increased maximal expiratory flow at lower lung volumes.

These authors believed that the differences in the mechanical consequences of the two experimental procedures can be explained on the basis that intravenous atropine produces relaxation of resting bronchomotor tone in every part of the tracheobronchial tree, including alveolar ducts whereas ipratropium inhalation causes relaxation of bronchomotor tone in the central airways exclusively. The reduction in lung elastic recoil after intravenous atropine was confirmed by Woodrow Weiss et al. (11).

Analyzing our results, we found no significant decrease of the real part of impedance after inhalation of $0.04 \mathrm{mg}$ ipratropium bromide in normal subjects during air breathing. Furthermore, reactance values did not increase significantly under these conditions after ipratropium bromide.

According to the model of Weibel (12) and supposing a laminar flow pattern it can be calculated that $90 \%$ of resistance in normal subjects is reached at the 12 th bronchial generation. Internal diameter of these bronchioli is about $0.95 \mathrm{~mm}$. Supposing an effect on central airways as described before, a parallel decrease of resistance values at all frequencies has to occur, according to Mead's analogon of the lungs (13).

Furthermore, a dilation of the intrathoracic and central, mainly extrapulmonary, bronchi after inhalation of ipratropium as discussed by De Troyer et al. (10), will decrease inertance values of the central airways and therefore, a decrease of reactance values resulting in an increase of $f_{0}$ will occur. However, neither reactance values nor resonant frequency changed in our study material. It can be hypothesized that larger doses are needed to show these effects on central airways.

Remarkably, after equilibration of the subject with the $\mathrm{He}+\mathrm{O}_{2}$ mixture, resistance values significantly decreased at all frequencies except at $52 \mathrm{~Hz}$ after inhalation of ipratropium bromide.

Furthermore, reactance values increased significantly except at 8,48 and $52 \mathrm{~Hz}$ causing a slight decrease of $f_{0}$. $\mathrm{He}+\mathrm{O}_{2}$ cause a significant fall in resistance due to altered gas physical properties. Reynolds" number is lowered because the low 
density of this gas mixture and flow becomes more laminar. Therefore, according to Drazen (14), central airway contribution to total pulmonary resistance decreases and contribution of peripheral airways increases. It can be assumed that the significant decrease of resistance after ipratropium bromide during $\mathrm{He}+\mathrm{O}_{2}$ breathing is caused by effects on more distal airways.

Furthermore, reactance values significantly increased after ipratropium during $\mathrm{He}$ $+\mathrm{O}_{2}$ breathing. $\mathrm{He}+\mathrm{O}_{2}$ cause a significant decrease of inductive reactance (15). Under these circumstances, reactance is determined by central airway inductance, lung compliance and chest wall compliance.

Chest wall compliance can be considered constant, according to Nagels et al. (2). Inhalation of ipratropium, even in much higher doses as used in this study, did not modify static mechanical properties of the lung $(9,10,11)$. It can be hypothesized that the observed increase of reactance is caused by influencing interregional and intraregional time-constant inequalities (16). This is in accordance with the increase in the height of phase IV of argon wash-out tests, as observed by Douglas et al. (9). This decrease of capacitive reactance is not counterbalanced by a decrease of inductive reactance. The net effect will be an increase of reactance.

Further studies using higher doses $(9,10)$ and during a longer period of measurement $(8,17)$ are needed for assessing further effects of anticholinergic agents on impedance parameters of the respiratory system and for evaluation the distribution of vagal tone along the tracheobronchial tree in man.

\section{References}

1. Lándsér FJ, Nagels J, Demedts M, Billiet L, Van de Woestijne KP. A new method to determine frequency characteristics of the respiratory system. J Appl Physiol 1976; 41: $101-106$.

2. Nagels J, Lándser FJ, Van der Linden L, Clêment J, Van de Woestijne KP. Mechanical proper. ties of lungs and chest wall during spontaneous breathing. J Appl Physiol 1980; 49: 408 - 4:16.

3. Lándsér FJ, Polko AH, Visser BF. Oscillatory measurement of total respiratory impedance with extended spectrum up to $52 \mathrm{~Hz}$. Arch Internat Physiol Biochim 1983; 91:2:12.

4. Visser $\mathrm{BF}$, Polko AH, Lándsế FJ. Compressibility in cylindrical models analyzed by the forced oscillation technique up to $52 \mathrm{~Hz}$. Bull Europ Physiopath Resp 1984; 20:32A - 33A.

5. Vincent $\mathbb{N J}$, Knudson $\mathbb{R}$, Leith DE, Macklem PT', Mead J. Factors influencing pulmonary resistance. J Appl Physiol 1970; 29:236-243.

6. Ingram RH, Wellman JJ, Mc Fadden ER, Mead J. Relative contributions of large and small airways to how limitation in normal subjects before and after atropine and isoproterenol. J Clin Invest $1977 ; 59: 696-703$.

7. Hensley MJ, O' Cain ChF, Mc Fadden ER, Ingram RH. Distribution of bronchodilatution in normal subjects : beta agonist versus atropine. J Appl Physiol 1978; 45: 778 - 782.

8. Francis RA, Thomson ML, Pavia D, Douglas RB. Ipratropium bromide : mucociliary clearance rate and airway resistance in normal subjects. Br J Dis Chest 1977; $71: 173-178$.

9. Douglas $\mathbb{N J}$, Sudlow MF, Flenley DC. Effect of an inhaled atropinelike agent on normal airway function. J Appl Physiol 1979; 46: $256-262$. 
10. De Troyer A, Yernault JC, Rodenstein D. Effects of vagal blockade on lung mechanics in rormal man. J Appl Physiol 1979; 46:217-226.

11. Woodrow Weiss J, Mc Fadden ER, Ingram RH. Parenteral vs. inhaled atropine: density dependence of maximal expiratory llow. J Appl Physiol 1982; 53:392-396.

12. Weibel ER. Morphomety of the human lung. Academic Press New York 1963.

13. Mead J Contribution of compliance of airways to frequency dependent behavior of lungs. I Appl Physiol 1969: 26:670-673.

14. Drazen $J M$, Loring $S H$, Ingram RH. Distribution of pulmonary resistance : effects of gas density, wiscosity, and llow rate. J Appl Physiol 1976; 41:388-395.

15. Wouters EFM, Polko AH, Lándsér FJ, Visser BF. Impedance measurement during air and helium breathing before and after salbutamol in normal subjects. EurJ Resp Dis 1986; 69 (suppl. 146): A 183 .

16. Cutillo $A G$, Renzeti $A D$. Mechanical behavior of the respiratory system as a function of frequency in health and disexse. Bull Europ Physiopath Resp 1983; 19: $293-326$.

17. Mclntyre E, Alpers JH, Ruffin RE. Bronchial smooth muscle tone in normal subjects. Chest $1981 ; 33: 396$. 


\section{CHAPTER 9}

\section{IMPEDANCE MEASUREMENT OF THE RESPIRATORY SYSTEM BEFORE AND AFTER SALBUTAMOL IN COPD PATIENTS.}

WOUTERS E.F.M., VERSCHOOF A.G., POLKO A.H., VISSER B.F.

DEPARTMENT OF PULMONARY DISEASES, UNIVERSITY LIMBURG. MAASTRICHT, THE NETHERLANDS

Submitted for publication.

Key words: Forced oscillations, impedance, resistance, reactance, resonant frequency, airway compliance, frequency dependence, COPD, salbutamol, bronchadilation. 
Impedance measurements of the respiratory systern by means of the forced oscillation technique were performed in a group of 20 COPD patients before and after inhalation of $0.400 \mathrm{mg}$ salbutamol. A slight, but statistically not significant decrease of resistance was observed at all frequencies from 12 to $52 \mathrm{~Hz}$. Increase of reactance values reached a statistically significant level at all frequencies except at 24 and $52 \mathrm{~Hz}$.

It is hypothesized that the increase of reactance in these patients can be explained by an increase of capacitance due to an increase of airway compliance or a decrease of peripheral resistance according to Mead's analogon of the lungs.

\section{INTRODUCTION}

Respiratory impedance measurements by means of the forced oscillation technique allow the determination of total respiratory resistance $\left(R_{\mathrm{rs}}\right)$ and reactance $\left(X_{\mathrm{rs}}\right)$ during spontaneous, quiet breathing simultaneously at several oscillatory frequencies. To evaluate the effect of a bronchodilating drug on the behaviour of the total respiratory impedance and its components, measurements by this technique were performed before and after inhalation of salbutamol in a group of COPD patients during air breathing.

\section{METHODS}

The technique of forced oscillations is described in detail in chapter $4(4,6)$. To avoid the influence of a deep inspiration on the bronchial tone during impedance measurements (9), three successive impedance measurements, each lasting $8 \mathrm{~s}$, were performed in every subject in basal conditions before the inspiratory vital capacity (IVC) and forced expiratory volume in $1 \mathrm{~s}\left(\mathrm{FEV}_{1}\right)$ were measured by a wet spirometer. The highest value of three spirometric manocuvres, performed by each patient, was retained.

Ten minutes after inhalation of $0.400 \mathrm{mg}$ salbutamol, delivered by rotahaler, all measurements were repeated in the same order.

\section{MATERIAL}

Twenty patients were investigated: 17 male and 3 female subjects. All patients were suffering from chronic airway obstruction, defined as a baseline $F E V$, value lower than the reference value minus 1.6 times the residual standard deviation as predicted by the European Community for Coal and Steel (10). The anthropometric data of the investigated patient group are summarized in table 1. 


\section{DATA ANALYSIS}

Three impedance measurements were performed in every subject before and after inhalation of salbutamol. Resistance and reactance values of the 3 manoeuvres were averaged at each frequency.

Means were compared using a paired t-test. P-values lower than 0.05 were retained as statistically significant. Values at 4 and $8 \mathrm{~Hz}$ were not analyzed because of low coherence functions in too many observations.

\section{RESULTS}

Spirometric data before and after inhalation of $0.400 \mathrm{mg}$ salbutamol are summarized in table 2. Baseline $F E V_{1}$ value for the total group was $1.36 \pm 0.51 \mathrm{~L}$; mean IVC value was $3.34 \pm 0.88 \mathrm{~L}$. After inhalation of salbutamol, mean $F_{E V}$ value increased to $1.61 \pm 0.78 \mathrm{~L}$ and mean $I V C$ value to $3.59 \pm 0.88 \mathrm{~L}$. Changes of IVC and FEV 1 after inhalation of sallbutamol were statistically significant (IVC $\mathrm{p}<0.001 ; \mathrm{FEV}_{1} \mathrm{p}<0.01$ ).

Table 1 .

Anthropometric data of studied patients.

\begin{tabular}{|c|c|c|c|c|}
\hline Number & Sex & $\begin{array}{l}\text { Age } \\
\text { Years }\end{array}$ & $\begin{array}{l}\text { Height } \\
\mathrm{cm}\end{array}$ & $\begin{array}{l}\text { Weight } \\
\mathrm{kg}\end{array}$ \\
\hline $\mathbb{1}$ & $\mathrm{m}$ & 66 & 159 & 53 \\
\hline 2 & $\mathrm{~m}$ & 60 & 168 & 67 \\
\hline 3 & $\mathrm{~m}$ & 73 & 168 & 78 \\
\hline 4 & $\mathrm{~m}$ & 52 & 169 & 59 \\
\hline 5 & $\mathrm{~m}$ & 73 & 175 & 91 \\
\hline 6 & $\mathrm{~m}$ & 70 & 164 & 60 \\
\hline 7 & $\mathrm{~m}$ & 57 & 169 & 65 \\
\hline 8 & f & 53 & 162 & 63 \\
\hline 9 & $m$ & 41 & 173 & 69 \\
\hline 10 & f & 70 & 154 & 72 \\
\hline 11. & $\mathrm{~m}$ & 65 & 167 & 81 \\
\hline 12 & $\mathrm{~m}$ & 53 & 175 & 60 \\
\hline 13 & $\mathrm{~m}$ & 70 & 168 & 68 \\
\hline 14 & $\mathbb{f}$ & 65 & 163 & 55 \\
\hline 15 & $\mathrm{~m}$ & 55 & 163 & 54 \\
\hline 16 & $\mathrm{~m}$ & 65 & 174 & 65 \\
\hline 17 & $\mathrm{~m}$ & 47 & 176 & 74 \\
\hline 18 & $\mathrm{~m}$ & 59 & 170 & 81 \\
\hline $\mathbb{1 9}$ & $\mathrm{m}$ & 59 & 160 & 58 \\
\hline 20 & $\mathrm{~m}$ & 48 & 179 & 79 \\
\hline Mean & & 60 & 168 & 68 \\
\hline $\mathrm{SD}$ & & 9 & 6 & 10 \\
\hline Range & & $41-73$ & $154-179$ & $53-91$ \\
\hline
\end{tabular}

$\mathrm{m}=$ male; $\mathrm{f}=$ female. 
Mean resistance and reactance values of the patient group before and after salbutamol are summarized in tables 3 and 4 .

In basal conditions, there was a marked decrease of resistance values with increasing frequency up to $32 \mathrm{~Hz}$. Resonant frequency was about $28 \mathrm{~Hz}$.

After inhalation of salbutamol there was a slight, statistically not significant decrease of resistance values. However, reactance values increased at all frequencies and these changes reached a statistically significant level except at 24 and 52 $\mathrm{Hz}$. Therefore, resonant frequency decreased.

When only the results of patients with an increase of $\mathrm{FEV}_{\Perp}$ greater than $10 \%$ of the baseline values were observed, the changes of impedance measurement were more pronounced (tables 5 and 6). Resistance values significantly decreased especially at lower frequencies.

Table 2.

Spirometric data before and after $0.400 \mathrm{mg}$ salbutamol for each patient.

\begin{tabular}{|c|c|c|c|c|}
\hline \multirow[b]{2}{*}{ Number } & \multicolumn{2}{|c|}{ Before } & \multicolumn{2}{|c|}{ After } \\
\hline & $\mathrm{IVC}^{*}$ & $\mathrm{FEV}_{1}^{*}$ & $\mathbb{I V C}^{*}$ & $\mathrm{FEV}_{1}^{*}$ \\
\hline 1 & 2.77 & 0.87 & 3.15 & 1.14 \\
\hline 2 & 3.15 & 0.76 & 3.20 & 0.81 \\
\hline 3 & 3.58 & 1.68 & 3.69 & 1.74 \\
\hline 4 & 4.13 & 1.47 & 4.07 & 1.57 \\
\hline 5 & 3.47 & 1.85 & 3.58 & 1.90 \\
\hline 6 & 2.93 & 1.03 & 3.26 & 1.25 \\
\hline 7 & 2.17 & 1.30 & 2.55 & 1.52 \\
\hline 8 & 2.99 & 1.36 & 2.93 & 1.52 \\
\hline 9 & 4.18 & 2.33 & 4.72 & 4.02 \\
\hline 10 & 1.90 & 0.87 & 2.12 & 0.92 \\
\hline $\mathbb{1}$ & 3.53 & 1.57 & 4.29 & 2.12 \\
\hline 12 & 4.34 & 1.85 & 4.67 & 2.06 \\
\hline 13 & 2.77 & 1.03 & 2.82 & 1.09 \\
\hline 14 & 1.95 & 0.83 & 2.01 & 0.76 \\
\hline 15 & 2.33 & 0.71 & 3.04 & 0.76 \\
\hline 16 & 3.09 & 0.76 & 3.69 & 0.92 \\
\hline 17 & 4.94 & 2.28 & 4.83 & 2.82 \\
\hline 18 & 3.53 & 1.47 & 3.91 & 1.74 \\
\hline 19 & 402 & 0.98 & 3.96 & 1.1 .4 \\
\hline 20 & 494 & 2.12 & 5.32 & 2.33 \\
\hline Mean & 3.34 & 1.36 & 3.59 & 1.61 \\
\hline $\mathrm{SD}$ & 0.88 & 0.51 & 0.88 & 0.78 \\
\hline
\end{tabular}

* expressed in L. B'TPS 
Table 3.

Mean resistance values $(\mathrm{kPa} /(\mathrm{L} / \mathrm{s})$ ) of the parient group before and after salbutamol.

\begin{tabular}{lrrrrrrrrrrr}
\hline Frequency & 12 & 16 & 20 & 24 & 28 & 32 & 36 & 40 & 44 & 48 & 52 \\
Before & .471 & .425 & .375 & .374 & .354 & .352 & .358 & .372 & .376 & .354 & .369 \\
After & .436 & .397 & .354 & .352 & .346 & .345 & .353 & .354 & .357 & .347 & .348 \\
\hline
\end{tabular}

* no difference is significant

Table 4

Mean reactance values $(\mathrm{kPa} /(\mathrm{L} / \mathrm{s}))$ of the patient group before and after salbutamol.

\begin{tabular}{lrrrrrrrrrrr}
\hline Frequency & 1.2 & 16 & 20 & 24 & 28 & 32 & 36 & 40 & 44 & 48 & 52 \\
Before & -.196 & -.160 & -.077 & -.033 & .023 & .076 & .081 & .131 & 164 & .195 & .218 \\
After & -109 & -.070 & -.009 & .016 & .069 & .129 & .122 & .163 & 193 & .230 & .238 \\
p-value & $* *$ & $* *$ & $* *$ & n.s. & $*$ & $*$ & $*$ & $*$ & $*$ & $* *$ & n.s. \\
\hline
\end{tabular}

Table 5.

Mean resistance values $(\mathrm{kPa} /(\mathrm{L} / \mathrm{s}))$ of the reversible patient group before and after salbutamol

\begin{tabular}{lrrrrrrrrrrr}
\hline Frequency & 12 & 16 & 20 & 24 & 28 & 32 & 36 & 40 & 44 & 48 & 52 \\
Before & .478 & .428 & .387 & .385 & .366 & .377 & .357 & .368 & .376 & .358 & .365 \\
After & .398 & .355 & .333 & .338 & .315 & .340 & .311 & .336 & .343 & .343 & .304 \\
p-value & n.s. & $*$ & $*$ & $*$ & n.s. & $*$ & n.s. & n.s. & $*$ & n.s. & n.s. \\
\hline
\end{tabular}

Table 6 .

Mean reactance values $(\mathrm{kPa} /(\mathrm{L} / \mathrm{s}))$ of the reversible patient group before and after salbutamol.

\begin{tabular}{|c|c|c|c|c|c|c|c|c|c|c|c|}
\hline Frequency & 12 & $\mathbb{1 6}$ & 20 & 24 & 28 & 32 & 36 & 40 & 44 & 48 & 52 \\
\hline Before & -.177 & -.133 & -.063 & -.020 & .037 & .070 & .086 & .131 & .160 & .182 & .214 \\
\hline After & -.050 & -.011 & .034 & .055 & .096 & 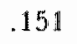 & .142 & .177 & .195 & .234 & .230 \\
\hline$p$-value & * & * & * & n.s. & n.s. & * & n.s. & n.s. & n.s. & ". & $\mathbb{\pi} .8$. \\
\hline
\end{tabular}

not significant

$0.01 \leq \mathrm{p}<0.05$

$0.001 \leq p<0.01$

n.s.

$+$

*: 
The forced pseudo-random noise oscillation technique is a method by which total respiratory resistance and reactance can be measured simultaneously at various frequencies during spontaneous quiet breathing.

In normal subjects, frequency dependence of resistance is not observed and the resonant frequency, at which the influence of capacitance and inductance cancels out, lies between 5 and $10 \mathrm{~Hz}(4,5)$.

Clérnent et al. (1), comparing the frequency dependence of total respiratory resistance and reactance determined by a forced oscillation technique in healthy subjects and in patients with respiratory complaints, concluded that patients demonstrate larger resistance values, a decrease of resistance with frequency, a lower average reactance value, resulting in an increase of resonant frequency, and a course of reactance with frequency which is more linear than in healthy subjects.

The changes, occurring during bronchoconstriction, are clearly illustrated by Decramer et al. (2) in a group of asthmatics before and after isocapnic hyperventilation with cold air.

Analyzing the observations of many authors $(1,2,3,4)$, it can be concluded that for exact measurement of resonant frequency, a pseudo-random noise pressure signal containing the harmonics of 2 to $24 \mathrm{~Hz}$ is too limited.

Therefore, the spectrum is extended by applying a pseudo-random noise signal containing sine waves of $4,8,12$ up to $52 \mathrm{~Hz}$ to the respiratory system (6).

Results of the effect of bronchodilators on total respiratory impedance and its components in COPD patients are limited. Michaelson et al. (8), measuring respiratory impedance before and after inhalation of isoproterenol in one subject with COPD, observed a marked change in frequency dependent behaviour of respiratory resistance, characterized by a reversal towards the normal pattern. Reactance values increased, resulting in a decrease of resonant frequency. The same observations were made by Lándsér et al. (5) in one patient with chronic obstructive lung disease, before and after inhalation of salbutamol.

Holle et al. (3), measuring the respiratory resistance at $10 \mathrm{~Hz}$ by means of a forced oscillation method (Siregnost FD $5^{3}$ ) during application of salbutamol, observed a significant decrease of resistance in patients with bronchial asthma and patients with chronic bronchitis and emphysema.

Our results show no significant decrease of resistance values between 12 and 52 $\mathrm{Hz}$ for the total group of COPD patients. However, there is a significant increase of reactance values resulting in a decrease of resonant frequency. According to the lung model of Mead (7), the increase of observed reactance values after inhalation of salbutamol can be explained by an increase of the capacitance of the respiratory system. Increase of the capacitance can be explained by assuming an increase of airway compliance or in combination with a decrease of frequency dependence by assuming a decrease of peripheral resistance. Indeed, inductive 
reactance will only decrease when also a bronchodilating effect of salbutamol on central airways is supposed.

More pronounced effects of salbutamol on impedance measurements were observed when the patient group with an increase of $\mathrm{FEV}_{1}$ greater than $10 \%$ of the baseline values was observed.

However, by estimating total respiratory impedance and its real and imaginary parts in a frequency range where the influence of inertial factors is significant, the forced pseudo-random noise technique contributes additional information on the mechanical characteristics of the respiratory system and on the effects of bronchodilating drugs upon this system.

Moreover, impedance measurement is a non-invasive method for measuring these mechanical properties of the respiratory system and is performed during quiet breathing. Therefore, influences upon bronchial tone are avoided (9).

\section{ACKNOWLEDGEMENT}

We will thank GLAXO LTD for the supply of salbutamol rotacaps and rotahalers.

\section{References}

1. Clément, J., Lándsèr, F.J., Van de Woestijne, K.P. (1983) Total resistance and reactance in patients with respiratory complaints with and without airways obstruction. Chest 83 , $215-220$.

2. Decramer, M., Demedts, M., Van de Woestijne, K.P. (1984) Isocapnic hyperventilation with cold air in healthy non-smokers, smokers and asthmatic subjects. Bull. Europ. Physiopath. Resp. 20, $237-243$.

3. Holle, J.P., Hartmann, V., Heer, G., Magnussen, H. (1978) Die kontinulerliche Messung des oszillatorischen Atemwiderstandes unter Salbutamol-, Aminophyllin- und Ipratropiumbromid - Gabe. Atemw. Lungenkrkh, 6, 418-420.

4. Lándsér, F.J., Nagels, J., Demedts, M, Billet, L Van de Woestijne, K.P. (1976) A new method to determine frequency characteristics of the respiratory system. I. Appl. Physiol. 41, $101-106$.

5. Lándsér, F.J., Nagels, J., Van de Woestijne, K.P. (1979) Implementation by means of microprocessor techniques for the measurement of total respiratory impedance during spontaneous breathing. Prog. Resp. Res. 11, 135-143.

6. Lándsér, F.J., Polko, A.H., Visser B.F. (1983) Oscillatory measurement of total respiratory impedance with extended spectrum up to $52 \mathrm{~Hz}$. Arch. Internat. Physiol. Biochim. 91, 12.

7. Mead, J. (1969) Contribution of compliance of airways to frequency dependent behavior of lungs. J. Appl. Physiol. 26, 670-673.

8. Michaelson, E.D., Grassman, E.D., Peters, W.R. (1975) Pulmonary mechanics by spectral analysis of forced random noise. J. Clin. Invest. 56, 1210-1230.

9. Gayrard, P., Orehek, J., Grimaud, C., Charpin, J. (1975). Bronchoconstrictor effects of a deep inspiration in patients with asthma. Am. Rev. Respir. Dis. 111, 133-439.

10. Quanjer, P.H. (1983) Standardized lung function testing. Bull. Europ. Physiopath. Resp. 19, $7-10$. 


\section{CHAPTER 10}

\section{IMPEDANCE MEASUREMENT DURING AIR AND HELIUM-OXYGEN BREATHING BEFORE AND AFTER SALBUTAMOL IN GOPD PATIENTS.}

WOUTERS E.F.M., LANDSER F.J., POLKO A.H., VISSER B.F.

DEPARTMENT OF PULMONARY DISEASES, UNIVERSITY LIMBURG, MAASTRICHT, THE NETHERLANDS.

Presented at the meeting of Lung mechanics working group of the SEPCR congres: 'The lung in growth and ageing".

The Hague, The Netherlands, June 1985.

Published as an abstract in : Bull. Europ. Physiopathol. Resp. 1985; 21: 55 m.

Complete paper submitted for publication.

Key words: Forced oscillation, impedance, resistance, reactance, inductive reactance, airway compliance, resonant frequency, helium +oxygen, salbutamol, COPD. 
During air breathing and after equilibration with a mixture of $80 \%$ helium ( $\mathrm{He}$ ) and $20 \%$ oxygen $\left(\mathrm{O}_{2}\right)$ impedance of the respiratory system was measured in 21 COPD patients by means of a forced pseudo-random noise pressure signal over a frequency spectrum of 4 to $52 \mathrm{~Hz}$ before and after inhalation of $0.400 \mathrm{mg}$ salbutamol.

During air breathing, inhalation of salbutamol caused a marked increase of reactance values from 8 up to $40 \mathrm{~Hz}$. He $+\mathrm{O}_{2}$ breathing caused a significant decrease of reactance from 16 to $52 \mathrm{~Hz}$ without marked changes of resistance. After equilibration with the $\mathrm{He}+\mathrm{O}_{2}$ mixture, salbutamol caused a significant decrease of resistance and a significant increase of reactance at all frequencies. It can be supposed that a distribution of pulmonary resistance with minimal losses in the larger airways is more sensitive to measure the effects of salbutamol on impedance of the respiratory system in COPD patients. The results during $\mathrm{He}+$ $\mathrm{O}_{2}$ breathing are in accordance with a more peripheral airway obstruction in COPD patients and a density dependent decrease of inductive reactance.

\section{INTRODUCTION}

The forced pseudo-random noise oscillation technique is a method by which the resistance and reactance of the respiratory system can be measured simultaneously at various frequencies by means of complex oscillations (1).

The resistance is the equivalent of a total resistance in a series resistanceinductance - capacitance $(R-L-C)$ circuit. The reactance or imaginary part of the impedance depends on the elastic and inertiall properties of the system. Oscillatory impedance measurement during breathing gases of different physical properties is very suitable to evaluate effects on the real part of the impedance and on the density dependent inertial part of the reactance. Impedance of the respiratory system over a frequency spectrum of 4 to $52 \mathrm{~Hz}(2)$ is measured in COPD patients during breathing air and a mixture of helium and oxygen before and after administration of salbutamol.

\section{METHODS AND MATERTAL}

The technique of forced oscillations is described in detail in chapter 4 (1). Three successive measurements were performed in every subject during air breathing and after equilibrating the subject with a mixture of $80 \%$ helium ( $\mathrm{He}$ ) and $20 \%$ oxygen $\left(\mathrm{O}_{2}\right)$. Equilibration was checked by rapid katapherometry (chapter 6). After washout of the $\mathrm{He}+\mathrm{O}_{2}$ mixture each patient inhaled $0.400 \mathrm{mg}$ salbutamol by rotahaler. Ten minutes later, impedance measurements during air breathing and after equilibration with the $\mathrm{He}+\mathrm{O}_{2}$ mixture were repeated. The used $\mathrm{He}+\mathrm{O}_{2}$ mixture was 0.33 times as dense as air as calculated from molar masses. 
Calibration was performed using a known volume of the mixture and adjusting the integrated signal of the pneumotachograph to that known volume.

It was shown that the $\mathrm{He}+\mathrm{O}_{2}$ mixture is 1.13 times as viscous as air (3).

\section{INVESTIGATED SUBJECTS}

Twenty-one patients were studied: 18 male and 3 female subjects. All patients were suffering from $\mathrm{COPD}$. Baseline $\mathrm{FEV}_{1}$ values were lower than the reference values minus 1.6 times the residual standard deviation as predicted by the European Community for Coal and Steel (4). Anthropometric and spirometric data of the patient group are summarized in table 1 .

Table 1 .

Anthropometric and spirometric data of studied patients.

\begin{tabular}{|c|c|c|c|c|c|c|c|c|c|}
\hline Number & Sex & $\begin{array}{l}\text { Age } \\
\text { Years }\end{array}$ & $\begin{array}{l}\text { Meigth } \\
\mathrm{cm}\end{array}$ & $\begin{array}{l}\text { Weight } \\
\mathrm{kg}\end{array}$ & $\begin{array}{l}\text { IVC } \\
\text { LBTPS }\end{array}$ & $\begin{array}{l}\text { FEV } \\
\text { L BTPS }\end{array}$ & $\begin{array}{l}\text { IVG } \\
\% \text { pred }\end{array}$ & $\begin{array}{l}\text { FEV, } \\
\text { o pred }\end{array}$ & $\begin{array}{l}\text { FEV } / \text { IVC } \\
\text { Ratio }\end{array}$ \\
\hline 1 & $\mathrm{~m}$ & 48 & 179 & 79 & 5.81 & 2.50 & 118 & 66 & 43 \\
\hline 2 & $\mathrm{~m}$ & 65 & 169 & 80 & 4.02 & 1.90 & 105 & 66 & 47 \\
\hline 3 & $\mathrm{~m}$ & 59 & 160 & 58 & 4.29 & 1.25 & 124 & 47 & 29 \\
\hline 4 & $\mathrm{~m}$ & 59 & 170 & 81 & 3.04 & 1.09 & 75 & 35 & 36 \\
\hline 5 & $\mathrm{~m}$ & 53 & 175 & 60 & 4.61 & 1.90 & 101 & 54 & 41 \\
\hline 6 & $f$ & 53 & 162 & 63 & 2.55 & 1.25 & 85 & 51 & 49 \\
\hline 7 & $\mathrm{~m}$ & 47 & 176 & 74 & 4.94 & 2.77 & 104 & 75 & 56 \\
\hline 8 & $\mathrm{~m}$ & 64 & 174 & 65 & 2.66 & 0.54 & 64 & 17 & 20 \\
\hline 9 & $\mathrm{~m}$ & 54 & 163 & 54 & 3.04 & 0.81 & 80 & 27 & 27 \\
\hline 10 & $\mathrm{~m}$ & 73 & 175 & 91 & 2.44 & 1.25 & 61 & 43 & 51 \\
\hline 11 & $\mathrm{~m}$ & 62 & 175 & 69 & 3.75 & 1.52 & 87 & 47 & 41 \\
\hline 12 & $\mathbb{f}$ & 65 & 163 & 55 & 2.06 & 0.92 & 75 & 42 & 45 \\
\hline 13 & $\mathrm{~m}$ & 70 & 168 & 68 & 2.50 & 0.76 & 69 & 28 & 30 \\
\hline 14 & $f$ & 70 & 154 & 72 & 1.90 & 0.71 & 86 & 41 & 37 \\
\hline 15 & $\mathrm{~m}$ & 73 & 168 & 78 & 3.42 & 1.63 & 96 & 62 & 48 \\
\hline 16 & $\mathrm{~m}$ & 39 & 165 & 66 & 3.69 & 1.68 & 85 & 48 & 46 \\
\hline 17 & $\mathrm{~m}$ & 56 & 169 & 65 & 2.61 & 1.52 & 64 & 48 & 58 \\
\hline 18 & $\mathrm{~m}$ & 70 & 164 & 60 & 2.88 & 1.09 & 85 & 43 & 38 \\
\hline 19 & $\mathrm{~m}$ & 66 & 159 & 53 & 2.93 & 1.14 & 92 & 47 & 39 \\
\hline 20 & $\mathrm{~m}$ & 60 & 168 & 60 & 2.28 & 0.60 & 58 & 20 & 26 \\
\hline 21 & $\mathrm{~m}$ & 70 & 170 & 86 & 3.15 & 1.19 & 84 & 43 & 38 \\
\hline Mean & & 61 & 168 & 68 & 3.27 & 1.33 & 86 & 45 & 40 \\
\hline $\mathrm{SD}$ & & 9 & 6 & $\mathbb{1} \mathbb{1}$ & 0.99 & 0.57 & 18 & 14 & 10 \\
\hline
\end{tabular}

$\mathrm{m}=$ male $\mathrm{f}=$ female 
Tabe 2.

Mean resigtance values $\left(\mathrm{kPa} /(\mathrm{L} / \mathrm{s})\right.$ ) during air and $\mathrm{He}+\mathrm{O}_{2}$ breathing before and after salbutamol (salb).

\begin{tabular}{|c|c|c|c|c|c|c|c|c|c|c|c|c|}
\hline Freq. $\left(\mathrm{Hz}_{z}\right)$ & 8 & 12 & 16 & 20 & 24 & 28 & 32 & 36 & 40 & 44 & 48 & 52 \\
\hline air & .570 & .456 & .392 & .372 & .370 & .343 & .345 & .347 & .375 & .369 & .379 & .387 \\
\hline $\mathrm{He}+\mathrm{O}_{2}$ & .497 & .423 & .366 & .339 & .331 & .319 & .326 & .336 & .363 & .373 & .395 & 411 \\
\hline air + saib & .496 & .433 & 374 & .357 & .354 & .328 & .333 & .336 & .367 & .363 & .371 & .377 \\
\hline $\mathrm{He}+\mathrm{O}_{2}+$ salb & .428 & .368 & .324 & .305 & .299 & .287 & .290 & .299 & .324 & .333 & .356 & .367 \\
\hline \multicolumn{13}{|c|}{ Level of significance } \\
\hline air os $\mathrm{He}+\mathrm{O}_{2}$ & ** & $\mathrm{n}_{\mathrm{n}} \mathrm{s}$. & n.s. & * & $* *$ & n.s. & n.s. & n.s. & n..s. & $n+s$. & n.s. & n.s. \\
\hline air os air + salb & $* *$ & n.s. & n.s. & n.s. & n.s. & n.s. & n.s. & M.s. & n.s. & n.s. & n.s. & n.s. \\
\hline \multicolumn{13}{|l|}{$\mathrm{He}+\mathrm{O}_{2}$ os } \\
\hline $\mathrm{He}+\mathrm{O}_{2}+\mathrm{salb}$ & 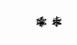 & * & * & * & $*$ & $*$ & * & $*$ & * & $*$ & $* * *$ & $* *$ \\
\hline
\end{tabular}

Table 3.

Mean reactance values $(\mathrm{kPa} /(\mathrm{L} / \mathrm{s}))$ during air and $\mathrm{He}+\mathrm{O}_{2}$ breathing before and after salbutamol (salb).

\begin{tabular}{lrrrrrrrrrrrr}
\hline Freq. (Hz) & 8 & 12 & 16 & 20 & 24 & 28 & 32 & 36 & 40 & 44 & 48 & 52 \\
air & -.326 & -.267 & -.191 & -.108 & -.058 & -.009 & .036 & .079 & .112 & .143 & .184 & .205 \\
$\mathrm{He}+\mathrm{O}_{2}$ & -.301 & -.273 & -.222 & -.160 & -.123 & -.080 & -.049 & -.024 & -.007 & .002 & .014 & .004 \\
$\mathrm{air}+\mathrm{salb}$ & -.204 & -.176 & -.120 & -.055 & -.013 & .092 & .074 & .113 & .139 & .166 & .207 & .225 \\
$\mathrm{He}+\mathrm{O}_{2}+\mathrm{salb}$ & -.213 & -.192 & -.155 & -.107 & -.078 & -.043 & -.015 & .008 & .029 & .036 & .052 & .046
\end{tabular}

Level of significance

at in ws $\mathrm{He}+\mathrm{O}_{2}$ n.s. n.s.

air $v s$ air + salb

$\mathrm{He}+\mathrm{O}_{2} \mathrm{sis}$

$\mathrm{Hc}+\mathrm{O}_{2}+$ sallb

not significant

$0.01 \leq \mathrm{p}<0.05$

$0.001 \leq \mathrm{p}<0.01$

$p<0.001$

r.s.

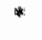

*** 
Means were compared using a paired $t$-test. P-values lower than 0.05 were retained as statistically significant. Comparison of means was not possible at $4 \mathrm{~Hz}$ : coherence function was too often lower than 0.95 at this frequency. All values represented in the text are means $\pm 1 \mathrm{SD}$.

\section{RESULTS}

The mean values of resistance during air and $\mathrm{He}+\mathrm{O}_{2}$ breathing before and after inhalation of salbutamol are summarized in table 2.

During air breathing, resistance values at lower frequencies were increased and a marked decrease of resistance values with increasing frequency was observed up to $32 \mathrm{~Hz}$. After equilibration of the patients with the $\mathrm{He}+\mathrm{O}_{2}$ mixture, no significant decrease of resistance values was observed except at 8, 20 and $24 \mathrm{~Hz}$. During air breathing, after inhalation of salbutamol, only at $8 \mathrm{~Hz}$ a significant decrease of resistance values was observed. However, during $\mathrm{He}+\mathrm{O}_{2}$ breathing, salbutamol caused a significant decrease of resistance values at all frequencies.

The mean reactance values of the patient group during air and $\mathrm{He}+\mathrm{O}_{2}$ breathing before and after inhalation of salbutamol are summarized in table 3 .

After equilibration of the patients with the $\mathrm{He}+\mathrm{O}_{2}$ mixture, reactance values

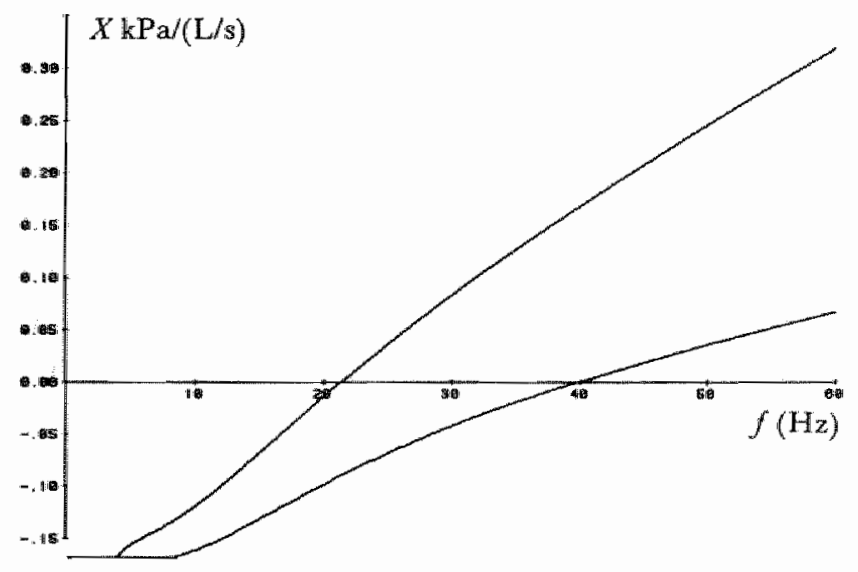

Fing. 7 :

Model analysis of reactance by changing inductance value at a constant peripheral resistance $\left(R_{\mathrm{p}}=\right.$ $0.3 \mathrm{kPa} /(\mathrm{L} / \mathrm{s}))$. The upper curve represents reactance $\mathrm{L}=0.001 \mathrm{kPa} /\left(\mathrm{L} / \mathrm{s}^{2}\right)$, the lower curve reactance $\mathrm{L}=0.00033 \mathrm{kPa} /\left(\mathrm{L} / \mathrm{s}^{2}\right)$. Other parameters are constant. 
decreased and these changes were statistically significant at all frequencies between 16 and $52 \mathrm{~Hz}$. During air breathing, after inhalation of salbutamol, there was a marked increase of reactance values at all frequencies except at 44 and $52 \mathrm{~Hz}$. During $\mathrm{He}+\mathrm{O}_{2}$ breathing, the effect of salbutamol on reactance was even more pronounced and was statistically significant at all frequencies. Using matrix network topography, the influence of a decrease of inductance on the imaginary part of impedance was simulated at a constant value of peripheral resistance $\left(R_{\mathrm{p}}=0.3\right.$ $\mathrm{kPa} /(\mathrm{L} / \mathrm{s}))$. As found in our patient group, there is a marked decrease of reactance and an increase of resonant frequency up to $40 \mathrm{~Hz}$ when inductance is supposed 0.33 times the value as expected during air breathing (fig. 1).

\section{DISCUSSTON}

By means of the forced oscillation technique, resistance and reactance are measured simultaneously over a frequency spectrum of 4 to $52 \mathrm{~Hz}$ in COPD patients. The changes of the functional indices of impedance observed in COOPD patients are described by Clément at al. (5). They found in this group of patients larger $R_{\mathrm{rs}}$ values, a decrease of $R_{\mathrm{rs}}$ with frequency, a lower average $X_{\mathrm{rs}}$ value, resulting in an increase of $f_{0}$ and a more linear course of $X_{\mathrm{rs}}$ with frequency . The results during air breathing in our study are compatible with these findings. The mechanical behaviour of the respiratory system as a function of frequency using extended frequency spectra can be explained by Mead's model of the respiratory system (6).

When factors other than the physical properties of the inspired gas are unchanged, the distribution of turbulence and hence the respiratory resistance is dependent on the kinematic viscosity (viscosity/density) of the gas mixture (7). The tendency for turbulence to occur increases with the linear velocity, with the diameter of the tube and with the density of the fluid. This tendency varies inversely with the viscosity. This relationship can be expressed in the dimensionless Reynolds' number (8). The alteration of the kinematic viscosity by substituting helium for nitrogen in the air will lower this Reynolds' number. In normal subjects, Reynolds' number progressively decreases from trachea to bronchioles (9) and during breathing of air most turbulent flow will be in the trachea and larger airways and the degree of turbulence will decrease as one proceeds toward the peripheral airways (10).

A statistically significant decrease of the real part of the impedance at all frequencies between 8 and $52 \mathrm{~Hz}$ can be observed in normal subjects during breathing a helium + oxygen mixture (11). In COPD patients, obstruction is generally localized in small airways. In this case, factors other than the physical properties of the respired gas are such as to keep the Reynolds' number below the critical value for turbulence and alteration of the kinematic viscosity by substituting helium for nitrogen in the air will be expected to alter resistance and non-elastic work very little. 
Barnett (12), studying the effect of breathing helium + oxygen mixtures upon pulmonary mechanics in dogs with airways constricted by various methods, concluded that helium + oxygen breathing reverses the effects on airway resistance of proximal airway constriction but has little influence upon that resulting from distal airway constriction.

These results are confirmed and extended by the work of Drazen et al. (13). In dogs, they demonstrated that the distribution of pulmonary resistance is altered by changing the pulmonary flow regime without altering airway dimensions. Supposing that a distribution of pulmonary resistance with minimal losses in the large airways should be more sensitive to peripheral airway constriction and a more turbulent flow regime more sensitive to changes in the large airways, they observed that in case of peripheral airway contriction, the change in pulmonary resistance measured while breathing helium is greater than the change measured while breathing sulphurhexafluoride $\left(\mathrm{SF}_{6}\right)$. In each case of central airway constriction, the change in pulmonary resistance measured while breathing $\mathrm{SF}_{6}$ is greater than the changes while breathing helium. It has to be noted that the experiments of Barnett and Drazen et al. were performed after intubation of the dogs. However, Grapé et al.(14) measuring pulmonary resistance in subjects with emphysema during breathing a mixture of $80 \%$ helium and $20 \%$ oxygen, observed a decrease of approximatively $20 \%$ of the value obtained with air during slow breathing, and a decrease of about $18 \%$ during rapid breathing.

Holle et al.(15), measuring respiratory impedance by a forced oscillation technique, observed a marked decrease of the resistance values during tidal breathing and at end-inspiratory apnea during $\mathrm{He}+\mathrm{O}_{2}$ breathing in asthmatics and in a group of patients with emphysema.

In the frequency spectrum, used in our study, no statistically significant decrease of resistance values is observed after equilibration with the helium + oxygen mixture except at 8,20 and $24 \mathrm{~Hz}$. Supposing a peripheral airway constriction in COPD patients, our data are in accordance with the experimental results of Barnett and Drazen et al.. It has to be noted that in our study the larynx and trachea are not bypassed by intubation. However during $\mathrm{He}+\mathrm{O}_{2}$ breathing, reactance values markedly decrease between 16 and $52 \mathrm{~Hz}$ resulting in an increase of resonant fre quency due to a decrease of inductive reactance: the helium + oxygen mixture is 0.33 times as dense as air. The observed changes can be confirmed by model analysis.

Impedance measurements during air breathing before and after inhalation of salbutamol show a slight, statistically not significant decrease of resistance values, except at $8 \mathrm{~Hz}$. However, there is a significant increase of reactance values resulting in a decrease of resonant frequency. According to the lung model of Mead the increase of observed reactance values after inhalation of salbutamoll can be explained by an increase of the capacitance of the respiratory system. Remarkably, there is a significant decrease of the real part of impedance measurement during helium + oxygen breathing before and after inhalation of salbutamol over the whole fre- 
quency spectrum. Therefore, it can be supposed that a distribution of pulmonary resistance with minimal losses in the larger airways is more sensitive to measure the effects of salbutamol on impedance parameters of the respiratory system.

It can be concluded that impedance measurements of the respiratory system are useful to follow changes of resistance and reactance in COPD patients under the influence of broncho-active drugs and during breathing of gases with different physical properties.

\section{References}

1. Lắndsér FJ, Nagels J, Demedts M, Billiet L, Van de Woestijne KP. A new method to determine frequency characteristics of the respiratory system.

J Appl Physiol 1976,41:101 - 106.

2. Lả̉ndsér $\mathbb{F J}$, Polko AH, Visser BF. Oscillatory measurement of total respiratory impedance with extended spectrum up to $52 \mathrm{~Hz}$. Arch Internat Physiol Biochem 1983;91:12.

3. Visser BF, Polko AH, Lándsér FJ. Compressibility in cylindrical models analyzed by the forced oscillation technique up to $52 \mathrm{~Hz}$. Bull Europ Physiopathol Resp 1984;20:32a-33a.

4. Quanjer PH (ed.) Standardized lung function testing. Bull Europ Physiopath Resp $1983 ; 19: 7-10$

5. Clément J, Lándsér FJ, Van de Woestijne KP. Total resistance and reactance in patients with respiratory complaints with and without airway obstruction.

Chest $1983 ; 83: 215-220$.

6. Mead J. Contribution of compliance of airways to frequency-dependent behavior of lungs. J Appl Physiol 1969;26;670-73.

7. Mclllroy MB, Mead J, Selverstone NJ, Radford E.P. Measurement of lung tissue viscous resistance using gases of equal kinematic viscosity. J Appl Physiol 1955;7:485-490.

8. Reynolds $O$. An experimental investigation of the circumstances witch determine whether the motion of water will be direct or sinuous, and of the law of resistance in parallel channels. Phil Trans Roy Soc 1883;174:935-982.

9. Olson DE, Dart GA, Filley GF. Pressure drop and fluid flow regime of air inspired into the human lung. I Appl Physiol 1970;28:482-494.

10. Wood LDH, Engel LA, Griffin P, Despas P, Macklem PT. Effect of gas physical properties and llow on lower pulmonary resistance. J Appl Physiol 1976;41:234-244.

11. Wouters EFM, Lándsër FJ, Polko AH, Visser BF. Impedance measurement during air and helium-oxygen breathing before and after salbutamol in normal subjects. Eur J Resp Dis $1986 ; 69:$ Suppl 146:A183.

12. Bamett TB. Effects of helium and oxygen mixtures on pulmonary mechanics during airway constriction. J Appl Physiol 1967;22:707-713.

13. Drazen JM, Loring $\mathbf{S H}$, Ingram $\mathbb{R}$ H. Localization of airway constriction using gases of varying density and viscosity. J Appl Physiol 1976;41:396-399.

14. Grape B, Channin E, Tyler JM. The effect of helium and oxygen mixtures on pulmonary resistances in emphysema. Am Rev Resp Dis 1960;81:823-829.

15. Holle JP, Magnussen H, Hartmann V. Die Messung der oszillatorischen Impedanz während Luft - und $\mathrm{He} / \mathrm{O}_{2}$ - Atmung. Atemw Lungenkr 1979;3:117 - 119. 


\section{CHAPTER 11}

\section{INFLUENCE OF TWO REGIMENS OF SALBUTAMOL ON IMPEDANCE PARAMETERS AFTER HISTAMINE INDUCED BRONCHOCONSTRICTION}

WOUTERS E.F.M., POLKO A.H., VISSER B.F.

DEPARTMENT OF PULMONARY DISEASES, UNIVERSITY LIMBURG MAASTRICHT, THE NETHERLANDS

Submitted for publication

Key words: Impedance, resistance, reactance, resonant frequency, histamine, salbutamol, dose effects, histamine induced bronchoconstriction, bronchodilation. 
The bronchodilating effect of $1.0 \mathrm{mg}$ and of $0.4 \mathrm{mg}$ salbutamol on the impedance of the respiratory system was studied in 25 ambulatory subjects after histamine induced bronchoconstriction.

Histamine caused an increase of respiratory resistance $\left(R_{\mathrm{rs}}\right)$ at lower frequencies and a frequency dependence of $R_{\mathrm{rs}}$.

Respiratory reactance $\left(X_{\mathrm{rs}}\right)$ decreased at all frequencies after histamine challenge. These changes could be explained by peripheral airway obstruction. Impedance measurements performed 5 minutes after inhalation of $1.0 \mathrm{mg}$ and of $0.4 \mathrm{mg}$ salbutamol showed a decrease of $R_{\mathrm{ry}}$ values at lower frequencies, a disappearance of the frequency dependence of $R_{\mathrm{rs}}$ and a significant increase of $X_{\mathrm{rs}}$ values.

No significant difference in absolute changes of $R_{\mathrm{rs}}$ and $X_{\mathrm{rg}}$ was observed between both salbutamol regimens. These changes after inhalation of salbutamol could be explained by supposing a predominant action of salbutamol on the peripheral airways.

\section{INTRODUCTION}

Many investigators have studied the response of asthmatic subjects to bronchodilator drugs by means of different pulmonary function tests. Most studies were performed to evaluate the intensity and duration of bronchodilation induced by these drugs.

By forced oscillations, impedance of the respiratory system is measured at different frequencies. According to the model of Mead (1), modified by Nagels et al. (2), it should not only be possible to measure the effect of bronchodilating drugs, but also to localize these effects along the tracheobronchial tree.

Furthermore, the frequency response of the total respiratory system is determined almost instantaneously by the forced oscillation technique during spontaneous breathing without active co-operation of the patient (3). Interfering effects on bronchial tone as observed by forced expiration manoeuvres are therefore avoided (4).

The effects of two doses of salbutamol on impedance parameters of the respiratory system are evaluated after induced bronchoconstriction in asthmatic subjects.

\section{MATERIAL AND METHODS}

\section{Subjects}

Twenty-five ambulatory subjects, 14 females and 11 males, were studied . Mean age was 24 years, range 19 to $35 \mathrm{y}$. All patients had a baseline FEV 1 greater than $80 \%$ of the reference value of the European Community for Coal and Steel (5). Their $\mathrm{FEV}_{1} / \mathrm{IVC}$ ratios were greater than $70 \%$. These conditions were proposed by Eiser et al. (6) for ideal interpretation of the results. 
Bronchodilating agents were withheld for $8 \mathrm{~h}$ prior to the study. All measurements were performed in the morning.

\section{Study design}

Under basal conditions, three impedance measurements were performed, followed by spirometry. All patients were challenged with histamine, delivered by Wiesbadener doppelinhalators. Bronchial. responsiveness was assessed by $\mathrm{PC}_{20}$ $\mathrm{FEV}_{1}$ (the concentration of histamine responsible for a fall of $\mathrm{FEV}_{1}$ of $20 \%$ of its baseline value). Immediately after reaching this decrease of FEV pedance measurements were made. Thereafter patients received in a random order either $1.0 \mathrm{mg}$ or $0.4 \mathrm{mg}$ salbutamol, delivered by rotahaler. The study was of double-blind, double-dummy design.

In both groups of patients, impedance measurements were repeated at $5 \mathrm{~min}, 15$ min and 25 min after inhalation of the bronchodilating drug.

Patients of group A received $1.0 \mathrm{mg}$ salbutamol, patients of group B $0.4 \mathrm{mg}$. The anthropometric and spirometric data of both patient groups are summarized in table 1 .

\section{Impedance measurements}

Respiratory impedance was determined by means of the forced oscillation technique as described in chapter $4(3,7)$.

\section{Statistical methods}

The means and standard deviations were calculated by standard equations. The results of each set of three impedance measurements, obtained before and after histamine and $5 \mathrm{~min}, 15 \mathrm{~min}$ and $25 \mathrm{~min}$ after inhalation of salbutamol were averaged at each frequency.

\section{Table 1 .}

Anthropometric and spirometric data of studied patient groups.

\begin{tabular}{|c|c|c|c|c|c|}
\hline & & \multicolumn{2}{|c|}{$\begin{array}{l}\text { Group } A \\
(\mathrm{n}=12)\end{array}$} & \multicolumn{2}{|c|}{$\begin{array}{l}\text { Group } \mathbb{B} \\
(\mathrm{n}=13)\end{array}$} \\
\hline & & MEAN & $\mathrm{SD}$ & MEAN & $\mathrm{SD}$ \\
\hline age & $(y)$ & 23 & 4 & 24 & 4 \\
\hline height & $(\mathrm{cm})$ & 169 & 10 & 173 & 7 \\
\hline weight & $(\mathrm{kg})$ & 69 & 11 & 68 & 10 \\
\hline IVC & (\% predicted) & 103 & 8 & 101 & 9 \\
\hline $\mathrm{FEV}_{1}$ & (\% predicted) & 100 & 11 & 101 & 9 \\
\hline \multicolumn{2}{|c|}{$\mathrm{FEV}, / \mathrm{IVC}(\%)$} & 82 & 7 & 81 & 6 \\
\hline
\end{tabular}


Table 2

Mean resistance values $(\mathrm{kPa} /(\mathrm{L} / \mathrm{s})$ ) of group $\mathrm{A}$ before and after histamine and $5 \mathrm{~min}, 15 \mathrm{~min}$ and 25 min after inhalation of $1.0 \mathrm{mg}$ salbutamol (salb).

$\begin{array}{lrrrrrrrrrrrr}\text { Prequency }(\mathrm{Hz}) & 8 & 12 & 16 & 20 & 24 & 28 & 32 & 36 & 40 & 44 & 48 & 52 \\ \text { basal } & & & & & & & & & & & & \\ \text { histamine } & .544 & .341 & .349 & .368 & .394 & .399 & .425 & .434 & .464 & .451 & .455 & .456 \\ \text { salb 5 } & .302 & .302 & .313 & .329 & .370 & .369 & .404 & .415 & .450 & .446 & .450 & .446 \\ \text { salb } 15^{\prime} & .285 & .278 & .290 & .311 & .351 & .357 & .390 & .407 & .447 & .445 & .448 & .453 \\ \text { salb 25, } & .285 & .279 & .288 & .306 & .344 & .337 & .373 & .383 & .428 & .427 & .430 & .435\end{array}$

\section{Level of significance}

basal vs

histamine

hist. ws salb 5'

basal os salb 5'

salb 5' wa salb $15^{\circ}$

salb 5" salb 25"

\begin{tabular}{|c|c|c|c|c|c|c|c|c|c|c|}
\hline * & * & 中* & $* *$ & $* * *$ & * * & * & $\mathrm{m} . \mathrm{s}$ & $\mathrm{n}, \mathrm{si}$ & n.s. & n.s. \\
\hline ** & $\$$ & 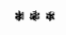 & $* *$ & $* *$ & 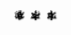 & ** & $*$ & n.s. & n.s. & n.s. \\
\hline$*$ & $*$ & * * & * & $\mathrm{n} . \mathrm{s}$ & * & n.s. & $\mathrm{n} . \mathrm{s}$ & n.s. & n.s. & n.s. \\
\hline n.s. & $*$ & * & ก. & n.s. & n.s. & n.s. & n.s. & n.s. & $\mathrm{n} \cdot \mathrm{s}$. & N.S. \\
\hline n.s. & n.s. & $\mathrm{n}, \mathrm{s}$. & n.s. & n.s. & *: & $\mathrm{M} s$ & n.s. & n.s. & $\mathrm{n} . \mathrm{s}$ & n.s. \\
\hline
\end{tabular}

Table 3 .

Mean reactance values $(\mathrm{kPa} /(\mathrm{L} / \mathrm{s}))$ of group $\mathrm{A}$ before and after histamine and $5 \mathrm{~min}, 15 \mathrm{~min}$, and $25 \mathrm{~min}$ after inhalation of $1.0 \mathrm{mg}$ salbutamol (sal.b).

\begin{tabular}{lrrrrrrrrrrrrr}
\hline Frequency (Hz) & 8 & 12 & 16 & 20 & 24 & 28 & 32 & 36 & 40 & 44 & 48 & 52 \\
& & & & & & & & & & & & \\
basal & -.021 & .035 & .083 & .136 & .173 & .191 & .204 & .228 & .231 & .252 & .285 & .311 \\
histamine & -.167 & -.122 & -.081 & -.030 & .011 & .036 & .069 & .103 & .126 & .156 & .200 & .231 \\
salb 5' & -.008 & .051 & .101 & .164 & .202 & .220 & .238 & .259 & .255 & .279 & .303 & .326 \\
salb 15, & -.001 & .057 & .108 & .176 & .220 & .242 & .256 & .277 & 275 & .300 & .316 & .344 \\
salb 25, & -.002 & .051 & .099 & .165 & .206 & .229 & .244 & .271 & .274 & .291 & .316 & .340
\end{tabular}

\section{Level of significance}

bissal whistamine

hist. os salb 5'

bassal wa salb $5^{\circ}$

salb 5' salb 15 "

salb $5^{\prime}$ us salb $25^{*}$

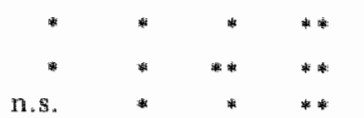

n.s. n.s. ri.s. n.s.

11. S.

n.s.

n.šs. n.s.
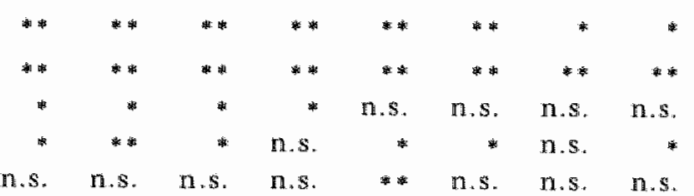

not significant:
$0.01 \leq p<0.05$
$0.001 \leq p<0.01$
$\quad p<0.001$


Student's t-test was used to compare mean results. Analyses of paired data were used where appropriate. A p-value less than 0.05 was considered statistically significant. Impedance values at $4 \mathrm{~Hz}$ were not evaluated because of frequently occurring low values of coherence function. All values represented in the text are means $\pm 1 \mathrm{SD}$.

\section{RESULTS}

The results of group A are summarized in tables 2 and 3 ; the results of group B in tables 4 and 5 .

a. Before inhalation of histamine, $R_{\mathrm{rs}}$ was, on the average, between 0.280 $\mathrm{kPa} /(\mathrm{L} / \mathrm{s})$ and $0.350 \mathrm{kPa} /(\mathrm{L} / \mathrm{s})$ at lower frequencies and increased slightly with frequency. $X_{\mathrm{rs}}$ values were negative in both groups at $8 \mathrm{~Hz}$ and became positive at $12 \mathrm{~Hz}$. Although mean spirometric data were similar in both groups, resistance values were lower in group $B$. These differences reached a significant level between 28 and $52 \mathrm{~Hz}$. Reactance values did not differ significantly between both groups.

b. After inhalation of histamine, $R_{\mathrm{rs}}$ values significantly increased between 8 and $32 \mathrm{~Hz}$ in group $\mathrm{A}$ and between 8 and $28 \mathrm{~Hz}$ in group $\mathrm{B}$. In the same frequency range, $R_{\mathrm{rs}}$ values decreased with increasing frequency.

$X_{\mathrm{rs}}$ values significantly decreased at all frequencies in both groups after histamine inhalation. $X_{\mathrm{rs}}$ values became positive between 20 and $24 \mathrm{~Hz}$ in group $\mathrm{A}$ and between 24 and $28 \mathrm{~Hz}$ in group $\mathrm{B}$.

At higher frequencies, between 32 and $48 \mathrm{~Hz}$, the significant differences of $R_{\mathrm{rs}}$ between group A and group B persisted. Changes of reactance after inhalation of histamine were similar in both groups.

c. Five minutes after inhalation of salbutamol, $R_{\mathrm{rs}}$ values significantly decreased between 8 and $36 \mathrm{~Hz}$ in group $A$ and between 8 and $52 \mathrm{~Hz}$ in group B. Furthermore, as observed before histamine challenge, $R_{\mathrm{rs}}$ values slightly increased with frequency in both groups. $X_{\mathrm{rs}}$ values significantly increased at all frequencies. Only at $8 \mathrm{~Hz}, X_{\mathrm{r} s}$ value still remained negative in both groups. The significantly higher values of $R_{\mathrm{rs}}$ from 32 to $48 \mathrm{~Hz}$ in group A persisted after inhalation of salbutamol. Reactance values did not differ significantly between both groups immediately after inhalation of salbutamol. Comparing the pre-challenge impedance parameters with the values obtained after inhalation of salbutamol, $R_{\mathrm{rs}}$ values were significantly lower after salbutamol inhalation between 8 and $20 \mathrm{~Hz}$ and at $28 \mathrm{~Hz}$ in group $A$ and between 12 and 24 . $\mathrm{Hz}$ in group $\mathrm{B} . X_{\mathrm{rs}}$ values were significantly higher after salbutamol inhalation between 12 and $36 \mathrm{~Hz}$ in group A. Remarkably, no significant difference between the pre-challenge measurements and the values after inhalation of the beta-2-agonist was observed in the $0.4 \mathrm{mg}$ salbutamol (B) group. 
Table 4.

Mean resistance values $(\mathrm{kPa} /(\mathrm{L} / \mathrm{s}))$ of group $\mathrm{B}$ before and after hüstamine and $5 \mathrm{~min}, 15 \mathrm{~min}$ and 25 min after inhalation of $0.4 \mathrm{mg}$ salbutamol (salb).

\begin{tabular}{|c|c|c|c|c|c|c|c|c|c|c|c|c|}
\hline Prequency $(\mathrm{H}, z)$ & 8 & 12 & 16 & 20 & 24 & 28 & 32 & 36 & 40 & 44 & 48 & 52 \\
\hline basal & .283 & .290 & .297 & .313 & .340 & .336 & .348 & .340 & .370 & .366 & .377 & .377 \\
\hline histamine & .515 & .458 & .415 & .400 & .402 & .378 & .378 & .374 & .392 & .387 & .398 & .410 \\
\hline salb 5 & .232 & .255 & .265 & .282 & .313 & .318 & .334 & .334 & .362 & .354 & .361 & .373 \\
\hline salb 15 & .228 & .230 & .239 & .256 & .291 & .300 & .321 & .321 & .349 & .344 & .348 & .359 \\
\hline salb 25 & .225 & .226 & 235 & .257 & .294 & .298 & .325 & .330 & .361 & .356 & .353 & .366 \\
\hline \multicolumn{13}{|c|}{ Level of significance } \\
\hline basal ys histamine & $* *$ & $*$ & $* * *$ & *** & $* *$ & $*$ & n.s. & n.s. & n.s. & n.s. & n.s. & n.s. \\
\hline hist. us salb 5" & $* * *$ & $* *$ & $* * *$ & $* *$ & $* * *$ & $* *$ & $* *$ & * * & $*$ & ** & $* *$ & ** \\
\hline basal ys salb 5 & n.s. & $*$ & $*$ & $*$ & $*$ & n.s. & n.s. & n.s. & $\mathrm{n} . \mathrm{s}$ & n.s. & n.s. & n.s. \\
\hline salb 5'v valb 15' & $*$ & $* *$ & $* * *$ & $* * *$ & $* * *$ & $*$ & n.s. & n.s. & n.s. & $\mathrm{n} . \mathrm{s}$ & n.s. & * \\
\hline salb 5'us salb 25' & a.s. & n.s. & $*$ & n.s. & n.s. & $\mathrm{n} . \mathrm{s}$ & $\mathrm{n} . \mathrm{s}$ & n.s. & n.s. & nis. & n.s. & n.s. \\
\hline
\end{tabular}

\section{Table 5.}

Mean reactance values $(\mathrm{kPa} /(\mathrm{L} / \mathrm{s}))$ of group $\mathrm{B}$ before and after histamine and 5 min, 15 min and 25 min after inhalation of $0.4 \mathrm{mg}$ salbutamol (salb).

\begin{tabular}{|c|c|c|c|c|c|c|c|c|c|c|c|c|}
\hline Frequency $(\mathrm{Hz})$ & 8 & 12 & 16 & 20 & 24 & 28 & 32 & 36 & 40 & 44 & 48 & 52 \\
\hline basal & -.001 & .045 & .080 & .129 & .150 & .172 & .183 & .209 & .226 & .255 & .285 & .317 \\
\hline histamine & -.183 & -151 & -.153 & -.050 & -.017 & .018 & .055 & .092 & .113 & .149 & .179 & .203 \\
\hline salb $5^{\prime}$ & -.012 & $.04 \%$ & .088 & .141 & .171 & .186 & .195 & .224 & .234 & .263 & .283 & .309 \\
\hline salb $15^{\prime}$ & -.001 & .056 & .099 & .154 & .182 & .205 & .213 & .240 & .249 & .276 & .291 & .321 \\
\hline salb $25^{\prime}$ & -.004 & .060 & .102 & .159 & .193 & .217 & .224 & .248 & .258 & .281 & .295 & .322 \\
\hline \multicolumn{13}{|c|}{ Level of significance } \\
\hline basal bs histamine & ** & $*$ & $* * *$ & $*$ & $* *$ & $* * *$ & $* *$ & $* *$ & $* * *$ & $* * *$ & $* * *$ & $* * *$ \\
\hline hist. vs salb 5' & ** * & * * & 央舟米 & * * * * & *** & $\cdots *$ & $* * *$ & $* * *$ & *** & $* * *$ & $* * *$ & $* *$ \\
\hline basal us salb $5^{3}$ & n.s. & $\mathrm{m}, \mathrm{s.}$ & n.s. & n.s. & n.s. & $\mathrm{n}, \mathrm{s}$. & $\mathrm{n} . \mathrm{s}$ & n.s. & n.s. & n.s. & n.s. & n.s. \\
\hline salb $5^{\prime}$ or salb $15^{\prime}$ & * & n.s. & $\mathrm{m} . \mathrm{s}$ & n.s. & n.s. & * & * * & $* *$ & $*$ & n.s. & n.s. & \\
\hline salb $5^{\prime}$ vs salb $25^{\prime}$ & * & n.s. & Tis. & n.s. & n.s. & $*$ & 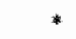 & $*$ & * & $*$ & n.s. & $n \times s$. \\
\hline
\end{tabular}

mot significant:
$0.01 \leq \mathrm{p}<0.05$
$0.001 \leq p<0.01$
p $<0.001$

n.s. 
d. Fifteen minutes after inhalation of the beta-2-sympacicomimetic drug, $R_{\mathrm{rs}}$ values were slightly lower in group $\mathrm{A}$, but in comparison with the values five minutes after inhalation only the differences at 12 and $16 \mathrm{~Hz}$ were statistically significant. Otherwise, $R_{\mathrm{rs}}$ values in group $\mathrm{B}$ significantly decreased between 8 and $28 \mathrm{~Hz}$ and at $52 \mathrm{~Hz} . X_{\mathrm{rs}}$ values further increased in both groups, most markedly at higher frequencies.

e. At 25 minutes, no marked changes of resistance and reactance values were observed in group A, in comparison with the values measured after 5 minutes. In group $B$ reactance values were significantly higher at $8 \mathrm{~Hz}$ and between 28 and $44 \mathrm{~Hz}$ in comparison with the values measured after 5 minutes.

f. Comparing the absolute changes of $R_{\mathrm{rs}}$ and $X_{\mathrm{rs}}$ in group $\mathrm{A}$ and group $\mathrm{B}$ after histamine challenge and 25 minutes after inhalation of salbutamol, no significant differences were observed between the decrease of $R_{\mathrm{rs}}$ and the increase of $X_{\text {rs }}$ (table 6).

Table 6 .

Absolute differences of $R_{\mathrm{rs}}$ and $\left.X_{\mathrm{rs}}(\mathrm{kPa} / \mathrm{L} / \mathrm{s})\right)$ between challenge values and values 25 min after inhalation of salbutamol.

\section{Resistance}

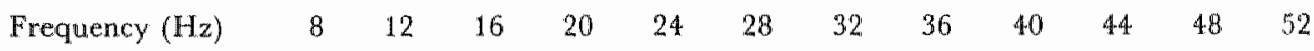

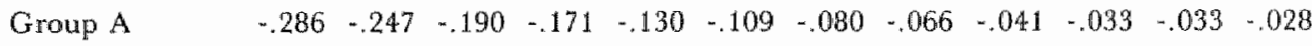

$\begin{array}{lllllllllllll}\text { Group B } & -.290 & -.232 & -.179 & -.143 & -.108 & -.080 & -.053 & -.044 & -.032 & -.032 & -.045 & -.044\end{array}$

Reactance

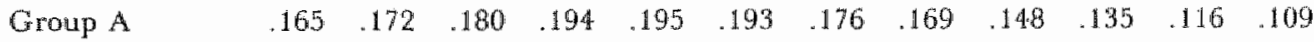

$\begin{array}{llllllllllllll}\text { Group B } & .182 & .210 & .205 & .209 & .210 & .198 & .169 & .156 & .145 & .132 & .116 & .120\end{array}$


The forced oscillation technique allows the evaluation of the impedance of the respiratory system over a wide range of frequencies by applying a composite pseudo-random noise signal at the mouth. The signal used in this study contains sine waves of $4,8,12$ up to $52 \mathrm{~Hz}(7)$.

The pre-challenge measurements of $R_{\mathrm{rs}}$ and $X_{\mathrm{rs}}$ obtained in both groups of subjects are compatible with the results obtained in normal subjects $(3,8,9) . R_{\mathrm{rs}}$ values increase slightly in both groups at higher frequency and $X_{\mathrm{rs}}$ values become positive between 8 and $12 \mathrm{~Hz}$.

Although spirometric data are similar in both groups, $R_{\mathrm{rs}}$ values are higher in group $A$. These differences in the real part of the impedance of the respiratory system can be explained by sex mismatch between our two patient groups (11). Three male subjects are studied in group A and 8 in group B. However, no significant differences are present in the imaginary part of the impedance between both groups.

After histamine challenge, $R_{\mathrm{rs}}$ values markedly increase at lower frequencies and decrease with increasing frequency. Furthermore, $X_{\mathrm{rs}}$ values markedly decrease at all frequencies in both groups. These changes are compatible with the results of impedance measurements obtained in patients with airway obstruction. According to Clément et al. (12), impedance measurements in these patients are characterized by larger resistance values, a decrease of resistance with frequency, a lower average reactance value resulting in an increase of resonant frequency and a more linear course of reactance with frequency. These changes can be reproduced in Mead's model of the lung (1) in the presence of an increased resistance of peripheral airways (2). Changes of reactance values are mainly due to the compliance of the airway walls, as a capacity in parallel with the alveolar capacity in case of increased peripheral resistance $(1,2)$.

When changes of reactance values are used as a parameter of peripheral airway obstruction, it can be concluded that in both groups a comparable degree of peripheral airway obstruction was present because $X_{r s}$ values do not differ significantly between both groups.

An increase of the peripheral resistance after histamine challenge as observed in our study, is in accordance with the results of Colebatch et al. (13) who found after intravenous injection of histamine in anaesthetized, vagotomized cats a decrease of pulmonary compliance and an increase of pulmonary resistance without a change of the anatomical dead space, indicating a peripheral airway response. This action of histamine was strengthened by a preferential small airway constriction after histamine exposure in frozen lung sections.

A difference in the sensitivity of smooth muscle from varying loci in the lung to the constrictive effect of histamine was also found by Drazen and Schneider (14), studying the comparative contractility of a tracheal spiral and an isolated parenchymal strip from a guinea pig lung. They found that a parenchymal strip is 
more sensitive and has a greater maximum response to histamine than to acetylcholine or carbachol and that a central airway strip responds similarly to equimolar concentrations of both of these agents. They further demonstrated that these differential responses to histamine and carbachol are not a result of prostaglandins, locall adrenergic mechanisms or differential populations of $\mathrm{H}_{1}$ and $\mathrm{H}_{2}$ receptors. Therefore, they concluded that the greater sensitivity of the parenchymal strip probably represents an intrinsic property of the contractile tissue itself.

Barnett (15) studied the effects of intravenous histamine on pulmonary mechanics during air and helium + oxygen breathing in dogs. He found after histamine injection an increase of pulmonary resistance and an associated decrease of pulmonary compliance. Based on the fact that a change to a gas mixture with greater kinematic viscosity failed to reverse this increased non-elastic respiratory work, he concluded that the main locus of the airway constriction was in the smaller terminal airways.

By comparing the change in inspiratory resistance measured while breathing gases of varying physical properties at different flow rates, Drazen et al. (16) also demonstrated in dogs that intravenous histamine infusion results in a predominant increase of peripheral resistance.

Our data are not corrected for the shunt characteristics of the cheeks. According to Cauberghs and Van de Woestijne (17), it can be assumed that the changes after histamine challenge are more pronounced because the shunt properties of the upper airway cause a marked underestimation of $R_{\text {rs }}$ mainly at lower frequencies when bronchoconstriction is present.

Eiser et al. (5) mentioned that impedance measurement has two disadvantages for evaluating airway calibre: forced oscillations measure total resistance, of which airway resistance is only one component and it should not be possible to standardize the resistance for lung size by this technique. However, according to Nagels et al. (2), chest wall resistance can be considered to behave similarly in healthy subjects and in patients with COPD. Furthermore, increase of lung volume as can be expected in case of bronchial obstruction will counteract the changes as observed after histamine challenge by decreasing $R_{\mathrm{rs}}$ and the frequency dependence of $R_{r s}$ and by increasing $X_{\mathrm{rs}}$.

Impedance measurements, performed 5 min after inhalation of salbutamol, a beta-2-sympaticomimetic drug, delivered by a rotahaler, show disappearance of the frequency dependence of $R_{\mathrm{rs}}$, a decrease of $R_{\mathrm{rs}}$ values especially at lower frequencies and a significant increase of reactance values. Similar patterns of action are found after inhalation of $1.0 \mathrm{mg}$ (group A) or $0.4 \mathrm{mg}$ (group B) salbutamol. Similar changes were observed by Michaelson et al (18) after isoproterenol inhalation in one COPD patient and by Lándsér et al. (8) in one patient after inhalation of salbutamol.

These changes after salbutamol inhalation can be explained by a decrease or normalization of peripheral resistance values (2). 
Furthermore, by comparing the pre-challenge impedance parameters with the values $5 \mathrm{~min}$ after salbutamol, there is a further parallel decrease of $R_{x \mathrm{~s}}$ values most markedly between 8 and $28 \mathrm{~Hz}$ in both groups. According to Mead's analogon of the lung (1), this parallel decrease of resistance values can be explained by an effect on the central airways and is compatible with the results of Landsér (8) observed in one normal subject after salbutamol inhalation and our previous results in a group of 20 normal subjects after inhalation of $0.2 \mathrm{mg}$ salbutamol (19). Furthermore, after inhalation of $1.0 \mathrm{mg}$ salbutamol, $X_{\mathrm{rs}}$ values are significantly higher between 12 and $36 \mathrm{~Hz}$ than the pre-challenge values. This effect can be explained by influencing the interregional and intraregional timeconstant inhomogeneity even found in normal subjects (20).

Conflicting results about the site of action of beta-2-agonists were previously reported. Chick and Jenne (21) concluded that terbutaline, a beta-2-sympaticomimetic drug, exerts its bronchodilatory action on small airways in patients with asthma. Ashutosh et al. (22), evaluating density dependence of expiratory flow and the bronchodilator response to isoproterenol in patients with asthma, concluded that these patients can be divided into two groups depending upon the changes in the degree of density dependence of the MEFV curve in response to isoproterenol: one group shows a decrease in density dependence and the other group an increase in density dependence after inhalation of isoproterenol. Increase in density dependence was explained by a mouthward movement of the equal pressure point (EPP) due to a preferential bronchodilation of the small airways; the decrease in density dependence was explained by a peripheral movement of the EPP due to a preferential dilation of the larger airways with isoproterenol. However, considering the peak flow at 50 percent of the vital capacity as a test for small airway function, increases after isoproterenol in both groups were similar. Fairhster and Wilson (23), performing a study comparable to Ashutosh et al. (22) for evaluation of density dependence of expiratory flow and bronchodilator response in asthmatics, found a significantly reduced change of expiratory flow at 50 percent of FVC $\left(V_{E} \max 50\right)$ compared to normal control subjects after inhalation of helium + oxygen in asthmatic subjects. After inhalation of beta-2-sympaticomimetic drugs, there was a significant increase of $V_{\text {Emax }}$ 50 in all asthmatic subjects. They concluded that the pre-bronchodilator response of asthmatics to the low density gas mixture indicates flow limitation in peripheral airways and the changes after bronchodilator use are in accordance with a predominant effect of beta-2-sympaticomimetic drugs on small airways in asthmatic subjects.

Elwood and Abboud (24), comparing specific airway conductance and $\vec{V}_{\mathrm{E} \text { max }} 50$ changes after inhalation of different doses of fenoterol, another beta-2-adrenergic agent, could not differentiate between possible predominant sites of action of these drugs.

Larsson and Svedmyr (25), evaluating the effects of salbutamol given by mouth and by inhalation, found that oral treatment has a better effect than inhalation 
treatment on the forced vital capacity (FVC) at the same effect on the FEV . They supposed that oral treatment may have a better effect on small airways due to a more even distribution of the drug through the bronchial tree and that beta-2-stimulants given by aerosol have a superior bronchodilating effect on large airways. On the other hand, Shim and Williams (26) comparing the bronchial response to oral versus aerosol metaproterenol in asthmatics, found a proportional increase of the FVC and $\mathrm{FEV}$, regardless of the route of administration. Inhalation of beta-2-sympaticomimetic drugs causes a rapid onset of bronchodilation (27). However, the time of onset is generally longer and the rate of dilation lower than found in this study after inhalation of 0.4 and $1.0 \mathrm{mg}$ salbutamol (24, $25,26,28-33$ ).

No significant differences in reactance values are observed between group $\mathrm{A}$ and group $B$ at $5 \mathrm{~min}, 15 \mathrm{~min}$ and $25 \mathrm{~min}$ after inhalation of salbutamol, suggesting a similar action of the two drug regimens on peripheral resistance. Furthermore, no significant difference in absolute changes of $R_{r s}$ and $X_{r s}$ is observed between both salbutamol regimens.

This is in accordance with earlier publications, demonstrating similar peak bronchodilator effects for different doses of beta-2-agonists $(30,31-35)$.

It can be concluded that impedance measurement of the respiratory system is useful to measure acute effects of bronchodilating agents and to localize these effects along the tracheobronchial tree.

\section{ACKNOWLEDGEMENTS}

The authors will thank Dr. J.J. Tamminga and Glaxo B.V. for delivering the study medication. 


\section{References}

1. Mead J. Contribution of compliance of airways to frequency-dependent behavior of lungs. J Appl Physiol 1969;26:670-73.

2. Wagels J. Lándsér $F$, Van der Linden L, Clëment J, Van de Woestijne KP. Mechanical properties of lungs and chest wall during spontaneous breathing. J Appl Physiol $1980 ; 49: 408-16$.

3. Lándsér FJ, Nagels J, Demedts M, Billiet L, Van de Woestijne KP. A new method to determine frequercy characteristics of the respiratory system. J Appl Physiol 1976;41:101-06.

4: Gayrard P, Orehek J, Grimaud C, Charpin J. Bronchoconstrictor effects of deep inspiration in patients with asthma. Am Rew Resp Dis 1975;111:433-39.

5. Quanjer PH (ed.) Standardized lung function testing. Bull Europ Physiopathol Resp 1983;19 suppl 5:7-44.

6. Eiser NM (ed.) Guidelines for standardization of bronchial challenges with (nonspecific) bronchoconstricting agents. Bull Europ Physiopathol Resp 1983;19:495-514.

7. Lảndsér FJ, Polko AH, Visser BF. Oscillatory measurement of total respiratory impedance with extended spectrum up to $52 \mathrm{~Hz}$. Arch Intern Physiol Biochim 1983;91:12.

8. Ländsér FJ, Nagels J, Van de Woestijne KP. Implementation by means of microprocessor techniques for the measurement of total respiratory impedance during spontaneous breathing. Prog Resp Res 1979;11:135-43.

9. Lấndsér FJ, Clément J, Van de Woestijne KP. Normal values of rotal respiratory resistance and reactance determined by forced oscillations. Chest 1982;81:586-91.

10. Fisher AB, Dubois AB, Hyde RW. Evaluation of the forced oscillation technique for the determination of resistance to breathing. J Clin Invest 1968;47:2045-57.

11. Peslin R, Hannhart B. Pino J. Mechanical impedance of the chest in smokers and nonsmokers. Bull Europ Physiopathol Resp 1981;17:93-105.

12. Clément J, Lándsér FJ, Van de Woestijne KP. Total resistance and reactance in patients with respiratory complaints with and without airways obstruction. Chest 1983;83:215-20.

13. Colebatch HJH, Olsen CR, Nadel JA. Effect of histamine, serotonin, and acetylcholine on the peripheral aiways. J Appl Physiol 1966;21:217-226.

14. Drazen JM, Schneider MW. Comparative responses of tracheal spirals and parenchymal strips to histamine and carbachol in vitro. J Clin Invest 1978;60:1441-47.

15. Barnet TB. Effects of helium and oxygen mixtures on pulmonary mechanics during airway constriction. 』Appl Physial 1967;22:707-13.

16. Drazen JM, Loring SH, Ingram RH jr. Localization of airway constriction using gases of varying density and viscosity. J Appl Physiol 1976;41:396-99.

17. Cauberghs M, Van de Woestijne KP. Mechanical properties of the upper airway. J Appl Physiol 1983;55:335-42.

18. Michadson ED, Grassman ED, Peters WR. Pulmonary mechanics by spectral analysis of forced random noise. J Clin Invest 1975;56:1210-30.

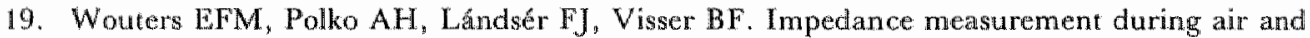
hellium breathing before and after salbutamol in normal subjects. Eur $\mathrm{J} \mathbb{R}$ espir Dis 1986;69 (146):A 183 .

20. Cutillo $A G$, Renzetti $\mathrm{AD}$. Mechanicall behavior of the respiratory system as a function of frequency in health and disease. Bull Europ Physiopathol Resp 1983;19:293-326.

21. Chick TW, Jenne JW. Comparative bronchodilator responses to atropine and terbutalline in asthma and chronic bronchitis. Chest $1977 ; 72: 719-23$.

22. Ashutosh $\mathrm{K}$, Mead G, Dickey JC jr, Berman P. Kuppinger M. Density dependence of expinatory now and bronchodiator response in asthma. Chest 1980;77:68-75.

23. Fairshter RD, Wilson AF. Response to inhaled metaproterenol and isoproterenol in asthmatic and normal subjects. Chest $1980 ; 78: 44-50$. 
24. Elwood RK, Abboud RT. The short-term bronchodilator effects of fenoterol and ipratropium in asthma. J Allergy Clin Immunol 1982;69:467 - 73.

25. Larsson S, Svedmyr N. Bronchodilating effect and side effects of beta-adrenoceptor stimulants by different modes of administration (tablets, metered acrosol, and combinations thereof). Am Rev Respir Dis 1977;116:861-69.

26. Shim $\mathrm{C}$, Williams MH jr. Bronchial response to oral versus aerosol metaproterenol in asthma. Ann Intern Med 1980;93:428-31.

27. Paterson JW, Woolcock AJ, Shenfield GM. State of the art. Bronchodilator drugs. Am Rev Respir Dis $1979 ; 120 ; 1149-88$.

28. Yeager $\mathrm{H} \mathrm{jr}$, Weinberg RM, Kaufman LV, Katz S. Asthma: comparative bronchodilator effects of ipratropium bromide and isoproterenol. J Clin Pharmacol 1979;141:198-204.

29. Hartley JPR, Nogrady SG, Gibby OM, Seaton A. Bronchodilator effects of dry salbutamol powder administered by rotahaler. Br J Pharmacol 1977;4:673-75.

30. Ruffin $\mathbb{R E}$, Obninski $G$, Newhouse MT. Aerosol salbutamol administration by IPPB: lowest effective dose. Thorax 1978;33:689-93.

31. Heimer D, Shim $\mathrm{C}$, Williams MH jr. The effect of sequential inhalations of metaproterenol aerosal in asthma. J Allergy Clin Immunol 1980;66:57 - 77.

32. Lenney $W, \mathbb{E}$ vans $A$ P. Nebulized salbutamol and ipratropium bromide in asthmatic childrem. Br J Dis Chest $1986 ; 80: 56-59$.

33. Williams $\mathrm{MH} \mathrm{jx}$, Kane $\mathrm{C}$. Dose response of patients with asthma to inhaled isoproterenol. Am Rev Respir Dis 1975;111:321-24.

34. Pennock BE, Rogers RM, Ryan BR, Ayers LN. Aenosol administmation of fenoterol hydrobromide (Th 1165a) in subjects with reversible obstructive airway disease. Chest $1977 ; 72: 731-37$

35. Sackner MA. Silva G. Effects of terbutaline aerosol in reversible airway obstruction. Chest $1978 ; 73: 802-06$. 



\section{CHAPTER 12}

\section{EFFEGTS OF IPRATROPIUM BROMIDE ON RESPIRATORY IMPEDANCE AFTER COLD AIR CHALLENGE IN ASTHMATIG SUBJECTS.}

WOUTERS E.F.M., QUAEDVLIEG M., MOSTERT R., POLKO A.H., VISSER B.F.

DEPARTMENT OF PULMONARY DISEASES, UNIVERSITY LIMBURG, MAASTRICHT, THE NETHERLANDS

Partly presented at the meeting of the lung mechanics working group of the SEPCR at the Congres "Mechanisms and management of respiratory symptoms", Antwerp, June 22-26, 1987.

Complete paper submitted for publication.

Key words: Respiratory system, impedance, resistance, reactance, frequency dependence, resonant frequency, airway compliance, cold air, ipratropium bromide, asthmatics. 
In 10 asthmatic subjects, the influence of $0.040 \mathrm{mg}$ ipratropium bromide on impedance $(Z)$ of the respiratory system $(\mathrm{rs})$ was determined after cold air challenge. Cold air inhalation caused a significant increase of respiratory resistance $\left(R_{\mathrm{rs}}\right)$ at frequencies between 8 and $32 \mathrm{~Hz}$.

This increase of $R_{\mathrm{rs}}$ was more pronounced at lower frequencies and, therefore, $R_{\mathrm{rs}}$ became frequency dependent.

Respiratory reactance $\left(X_{\mathrm{rs}}\right)$ decreased at all frequencies, resulting in an increase of resonant frequency.

These changes were compatible with a peripheral airway obstruction and a decrease of airway compliance, according to Mead's analogon of the respiratory, system.

Five minutes after inhalation of ipratropium bromide a significant decrease of $R_{\mathrm{rs}}$ between 8 and $28 \mathrm{~Hz}$ and a significant increase of $X_{\mathrm{rs}}$ at all frequencies, resulting in a decrease of resonant frequency, was observed.

Ipratropium bromide significantly reversed the bronchoconstriction induced by cold air challenge.

\section{INTRODUCTION}

A large number of therapeutical trials have been performed over the past 10 years to investigate the clinical efficacy of anticholinergic drugs. Most of these studies have been designed to compare the therapeutical effects of anticholinergics with placebo or beta-2-sympaticomimetic drugs. Generally, simple measurements of airway function have been used to assess therapeutic efficacy (1). More complex measurements have been occasionally used often in an attempt to define the site within the airways at which the drugs are effective.

The impedance of the respiratory system can easily be measured by the forced oscillation technique over a wide frequency range (2). Simultaneous determination of total respiratory resistance and reactance at different frequencies permits to localize a therapeutic effect of broncho-active drugs along the tracheobronchial tree, according to Mead's analogon of the lungs (3), modified by Nagels et al. (4). This study was developed to measure the possible acute effects of ipratropium bromide, a quaternary isopropyl derivative of atropine, on impedance parameters of the respiratory system after cold air challenge in asthmatic subjects.

\section{MATERIAL AND METHODS}

\section{Subjects}

Ten asthmatic subjects, 4 men and 6 women, were studied. Initial forced expiratory volume in one second $\left(\mathrm{FEV}_{1}\right)$ was greater than $80 \%$ of the reference value of the European Community for Coal and Steel (5). Their FEV 1 IVC 
ratios were greater than $70 \%$. These conditions were proposed by Eiser et al. to permit ideal interpretation of the results (6). Anthropometric and spirometric data are summarized in table 1.

\section{Cold air inhalation technique}

Cold air challenges were performed using the heat exchange system, developed by Jaeger ${ }^{\text {(i) }}$.

The subjects inhaled dry air, delivered from a cylinder. The temperature of the air leaving the cooling system was $-20^{\circ} \mathrm{C}$. The flow of dry air could be adjusted by a needle valve and measured by a rotameter.

The subjects were instructed to breathe at a predetermined ventilation rate by maintaining the size of a guide balloon. To avoid hypocapnia, $\mathrm{CO}_{2}$ was added at the entry of the system, at a rate of $5 \%$ of the predetermined minute ventilation.

Hyperventilation was sustained during $3 \mathrm{~min}$, after quiet breathing in the system for $1 \mathrm{~min}$. The subject kept his ventilation at about $60 \%$ of calculated maximal breathing capacity, defined as FEV, times 35.

\section{Measurements}

$\mathrm{FEV}_{1}$ was determined using a wet spirometer (Gould Pulmonet III ${ }^{\oplus}$ ). After performing these forced expiratory manoeuvres, subjects rested for $10 \mathrm{~min}$.

Thereafter, 5 impedance measurements were performed under basal conditions. Respiratory impedance was determined by means of the forced oscillation technique as described in chapter $4(2,7)$.

\section{Table 7 .}

Anthropometric and spirometric data of studied subjects.

\begin{tabular}{|c|c|c|c|c|c|c|}
\hline Patient & Sex & $\begin{array}{l}\text { Age } \\
\text { years }\end{array}$ & $\begin{array}{l}\text { IVC } \\
\text { L BTPS }\end{array}$ & $\begin{array}{l}\mathrm{FEV}_{\mathrm{a}} \\
\mathrm{L}, \mathrm{BTPS}\end{array}$ & $\begin{array}{l}\mathrm{FEV}_{1} \\
\% \text { pred }\end{array}$ & $\underset{\%}{\mathrm{FEV}}$ \\
\hline $\mathbb{1}$ & $\mathrm{m}$ & 25 & 6.13 & 4.99 & 108 & 81 \\
\hline 2 & f & 28 & 3.96 & 2.88 & 86 & 73 \\
\hline 3 & f & 26 & 4.02 & 3.20 & 96 & 80 \\
\hline 4 & $f$ & 12 & 2.82 & 2.23 & 91 & 79 \\
\hline 5 & $f$ & 38 & 3.75 & 3.53 & 116 & 94 \\
\hline 6 & f & 23 & 4.13 & 3.80 & 118 & 92 \\
\hline 7 & $\mathrm{~m}$ & 15 & 3.75 & 2.77 & 82 & 74 \\
\hline 8 & f & 47 & 4.40 & 3.53 & 117 & 80 \\
\hline 9 & $\mathrm{~m}$ & 19 & 6.57 & 5.37 & 120 & 82 \\
\hline 10 & $\mathrm{~m}$ & 24 & 5.32 & 3.85 & 107 & 72 \\
\hline mean & & 26 & 4.49 & 3.62 & 104 & 81 \\
\hline $\mathrm{SD}$ & & 10 & 1.11 & 0.92 & 14 & 7 \\
\hline
\end{tabular}

$\mathrm{m}=$ male $; \mathrm{f}=$ female 
After cold air challenge, three successive impedance measurements were performed.

Thereafter, subjects received $0.040 \mathrm{mg}$ ipratropium bromide, delivered by a metered dose inhaler. Five minutes later, again three impedance measurements were performed.

\section{Statistical methods}

The results of each set of impedance measurements, obtained before and after cold air challenge and $5 \mathrm{~min}$ after inhalation of ipratropium bromide were averaged at each frequency.

Students' t-test was used to compare mean results. A p-value less than 0.05 was considered as statistically significant.

Impedance values at $4 \mathrm{~Hz}$ were not evaluated because of frequently occurring low values of coherence function.

\section{RESULTS}

The results of $R_{\mathrm{rs}}$ and $X_{\mathrm{rs}}$ of the total group are summarized in tables 2 and 3 . The prechallenge values of $R_{\mathrm{rs}}$ showed a slight increase of $R_{\mathrm{rs}}$ with frequency. $X_{\mathrm{r} s}$ became positive between 8 and $12 \mathrm{~Hz}$.

After cold air challenge, there was a marked, statistically significant increase of $R_{\text {rs }}$ at all frequencies between 8 and $32 \mathrm{~Hz}$ : the increase of $R_{\mathrm{rs}}$ was most pronounced at lower frequencies. $R_{\mathrm{rs}}$ became highly frequency dependent after challenge. $X_{\mathrm{rs}}$ was markedly and significantly decreased at all frequencies and became positive between 28 and $32 \mathrm{~Hz}$.

Table 2.

Mean $R_{\mathrm{rs}}$ values $(\mathrm{kPa} /(\mathrm{L} / \mathrm{s}))$ before and after cold air challenge and after inhalation of ipratropium bromide (ipr).

\begin{tabular}{lrrrrrrrrrrrr}
\hline Frequency $(\mathrm{Hz})$ & 8 & 12 & 16 & 20 & 24 & 28 & 32 & 36 & 40 & 44 & 48 & 52 \\
Basal & .384 & .381 & .378 & .381 & .403 & .387 & .407 & .408 & .438 & .430 & .426 & .434 \\
Cold air & .648 & .592 & .539 & .500 & .489 & .440 & .436 & .427 & .458 & .456 & .459 & .471 \\
Ipratropium & .447 & .410 & .412 & .414 & .436 & .398 & .404 & .399 & .445 & .491 & .444 & .453
\end{tabular}

Level of significance

basal us cold ain

Cold air us ipr
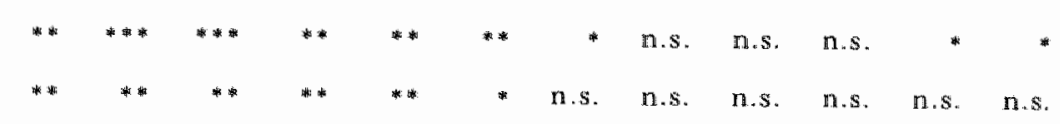

mot significant:"

$0.01 \leq p<0.05$

$0.001 \leq p<0.01$

n.s.

$p<0.001$ 
Five minutes after inhalation of ipratropium bromide, $R_{\mathrm{rs}}$ values significantly decreased between 8 and $28 \mathrm{~Hz} . X_{\mathrm{rs}}$ increased at all frequencies resulting in a decrease of $f_{0}$.

Neither for $R_{\mathrm{rs}}$ nor $X_{\mathrm{rs}}$ a statistically significant difference could be found between the prechallenge values and the measurements after ipratropium bromide. As illustrated in table 4, a highly significant increase of $f_{0}$ was observed after cold air challenge. The decrease of $f_{0}$ after ipratropium was evenso significant. No significant difference of $f_{0}$ was found between the prechallenge values and those after inhalation of the anticholinergic drug.

Table 3 .

Mean $X_{\mathrm{rs}}$ values $(\mathrm{kPa} /(\mathrm{L} / \mathrm{s}))$ before and after cold air challenge and after inhalation of ipratropium bromide (ipr).

\begin{tabular}{lrrrrrrrrrrrr}
\hline Frequency $(\mathrm{Hz})$ & 8 & 12 & 16 & 20 & 24 & 28 & 32 & 36 & 40 & 44 & 48 & 52 \\
Basal & -.025 & .004 & .038 & .091 & .122 & .140 & .163 & .185 & .198 & .225 & .261 & .286 \\
Cold air & -.167 & -.186 & -.145 & -.101 & -.068 & -.032 & .025 & .058 & .089 & .130 & .167 & .190 \\
Ipratropium & -.046 & -.023 & .012 & .067 & .092 & .102 & .132 & .158 & .186 & .214 & .265 & .278
\end{tabular}

Level of significance

Basal os cold air

Cold air vs ipr

$\begin{aligned} 0.01 \leq p & <0.05 \\ 0.001 \leq p & <0.01 \\ p & <0.001\end{aligned}$

Table 4.

Resonant frequency before and after cold air challenge and after inhalation of ipratropium bromide: (ipr).

\begin{tabular}{lrrr}
\hline Patient & Basal & Cold air & Ipr \\
1 & 7.48 & 34.18 & 14.79 \\
2 & 18.72 & 34.66 & 9.68 \\
3 & 8.24 & 37.62 & 31.66 \\
4 & 30.01 & 41.04 & 16.31 \\
5 & 6.40 & 29.70 & 19.93 \\
6 & 7.61 & 33.79 & 8.77 \\
7 & 7.92 & 18.02 & 9.92 \\
8 & 7.18 & 20.29 & 7.14 \\
9 & 9.54 & 15.45 & 10.90 \\
10 & 20.48 & 33.42 & 17.35 \\
Mean & 12.36 & 29.82 & 14.56 \\
SD & 7.97 & 8.78 & 7.37 \\
p- value & & & $<.001$ \\
\hline
\end{tabular}




\section{DISCUSSION}

The sensitivity of asthmatic patients to non-specific provocative stimuli is generally accepted. Cold air isocapnic hyperventilation has been introduced as a bronchial provocation test in patients with asthma (7-12).

By impedance measurement after cold air challenge in asthmatic subjects, Decramer et al. (13) found that $R_{r s}$ increases and becomes highly frequency dependent and that $X_{\mathrm{rs}}$ decreases resulting in an increase of resonant frequency. The observed changes persisted longer than $18 \mathrm{~min}$. Our results agree with these observations of Decramer et al. By extending the frequency spectrum up to 52 $\mathrm{H}_{z}$ it can be demonstrated that the changes of $R_{\mathrm{rs}}$ extend to $32 \mathrm{~Hz}$, that $X_{\mathrm{rs}}$ values are significantly decreased at all frequencies up to $52 \mathrm{~Hz}$ and that resonant frequency increases to about $30 \mathrm{~Hz}$.

As mentioned by Decramer et al., changes of resistance can be explained by an obstruction extending largely into the peripheral airways. Moreover, to explain the observed high resonant frequencies, a decrease of airway compliance has to be supposed according to Mead's analogon of the lungs (3).

Comparing our baseline measurements with those of Decramer et al, our resistance values are higher at all frequencies.

Partly, this difference can be explained by a sex difference between both study groups: Decramer et al. studied only male subjects. Resistance values are generally higher in women due to the lower lung volume (14). On the other hand, in spite of the strictly used spirometric selection criteria, a prechallenge increased resonant frequency and frequency dependence of resistance is observed in three of our patients.

After inhalation of $0.040 \mathrm{mg}$ ipratropium bromide a significant decrease of resistance values between 8 and $28 \mathrm{~Hz}$ and a significant increase of $X_{\mathrm{rs}}$ at all frequencies can be observed.

These changes can be explained by dilation of peripheral airways after inhalation of ipratropium bromide. The effect of this anticholinergic drug can be more pronounced because the post-challenge $R_{\mathrm{rs}}$ values were corrected neither for the shunt impedance of the cheeks as discussed by Cauberghs et al. (16), nor for a possible increase of lung volume (4) after' induced bronchoconstriction. Therefore, an underestimation of $R_{\mathrm{rs}}$ after cold air challenge is likely.

The results of earlier studies on the site of action of anticholinergic drugs are conflicting.

Storms et al. (17) concluded that the major effect of ipratropium bromide appears to be in the larger airways. Gross (18) found in the asthmatics a greater effect of the anticholinergic drug on maximal mid-expiratory flow than that of $\mathrm{FEV}_{1}$ and suggested that ipratropium has an effect on peripheral as well on large airways. Yeager et al. (19) confirmed in their study this supposition of Gross.

Chick and Jenne (20), comparing the bronchodilator responses to atropine and terbutaline in asthma, concluded that atropine exerts its bronchodilatory action 
predominantly on larger airways, evidenced by an equal improvement of the plethysmographically determined airway resistance after use of atropine and terbutaline and by a greater increase of flow at $50 \%$ exhaled volume, the chosen test for small airway caliber, after use of terbutaline. Snow (21) also concluded that atropine acts predominantly on large airways in asthmatic subjects.

Ashutosh et al. (22) also found a greater dilation of the large airways after atropine inhalation. Elwood and Abboud (23), determining specific airway conductance as well as flow from maximal expiratory flow volume curves, could not differentiate between sites of predominant action of fenoterol, a beta-2-sympaticomimetic agent, and ipratropium bromide.

Our results further illustrate the rapid onset of bronchodilation after inhalation of ipratropium. Some authors described this rapid effect of this anticholinergic drug $(17,24-28)$, others found a more gradual onset $(18,23,29,30)$.

It can be concluded that ipratropium bromide is an effective bronchodilator, showing a rapid effect on peripheral airway obstruction. Further studies are necessary to evaluate the duration of action and dose-effects of this drug on impedance of the respiratory system.

\section{References}

1. Mann J.; George C.: Anticholinergic drugs in the treatment of airways disease. Br. J. Dis. Chest 79: $209-228$ (1985).

2. Lándsér F.; Nagels M.; Demedts M.; Billiet L.; Van de Woestijne K.: A new method to determine frequency characteristics of the respiratorv system. J. Appl. Physiol. 41: 101-106 (1976).

3. Mead J.: Contribution of compliance of airways to frequency-dependent behavior of lungs. J. Appl. Physiol. 26: $670-673$ (1969).

4. Nagels J.; Lándsér F.; Van der Linden L.; Clément J.; Van de Woestijne K.: Mechanical properties of lungs and chest wall during spontaneous breathing. J. Appl. Physiol. 49: $408-416(1980)$.

5. Quanjer P.H. (ed.): Standardized lung function testing. Buil. Europ. Physiopath. Resp. 5: $7-44(1983)$.

6. Eiser N. (ed.): Guidelines for standardization of bronchial challenges with (nonspecific) bron" choconstricting agents. Bull. Europ. Physiopath. Resp. 19: 495 - 514 (1983).

7. Kivity S.; Souhrada J.: A new diagnostic test to assess airway reactivity in asthmatics. Bull. Europ. Physiopath. Resp. 17: 243-254 (1981).

8. Latimer K.; O'Byrne P.; Morris M.; Roberts R.; Hargreave F.: Bronchoconstriction stimulated by airway cooling. Am. Rev. Respir. Dis. 128: 4.40-443 (1983).

9. Heaton R.; Henderson A.; Gray B,; Costello J.: The bronchial response to cold air challenge: evidence for different mechanisms in normal and asthmatic subjects. Thorax 38:506-511 (1983).

10. Heaton R.; Henderson A.; Costello J.: Cold air as a bronchial provocation technique. Chest 86: $810-814(1984)$

11. Phillips Y.; Jaeger J.; Laube B.; Rosenthal R.: Eucapnic voluntary hyperventilation of compressed gas mixture. A simple system for bronchial challenge by respiratory heat loss. Am. Rev. Respir. Dis. 35: $31-35$ (1985). 
12. Assoufi B.; Dally M.; Newman Taylor A.; Denison D.: Cold air test: a simplified standard method for airway reactivity. Bull. Europ. Physioparh. Resp. 22: $349-357$ (1986).

13. Decramer M.; Demedts M.; Van de Woestijne $K$.: Isocapnic hyperventiation with cold air in healthy non-smokers, smokers and asthmatic subjects. Bull. Europ. Physiopath. Resp. 20: $237-243(1984)$.

14. Fisher A.; Dubois A.; Hyde $\mathbb{R}$. Evaluation of the forced oscillation techrique for the determination of ressistance to breathing. J. Clin. Invest. 47 : 2045-2057 (1968).

15. Peslin R.; Hannhart B.; Pino J.: Mechanical impedance of the chest in smakers and nonsmokers. Bull. Europ. Physiopath. Resp. 17: 93 - 105 (1981)

16. Cauberghs M.; Van de Woestine $\mathrm{K}$.: Mechanical properties of the upper airway. J. Appl. Physiol. 55: $335-342$ (1983).

17. Storms W.; Dopica G; Reed C.: Aerosol Sch 1000: an anticholinergic bronchodilator. Am. Rev. Resp. Dis. 111: $419-422$ (1975).

18. Gross J.: Sch 1000: a new anticholinergic bronchodilator. Am. Rev. Resp. Dis. 112: 823-828 $(1975)$.

19. Yeager H.; Weinberg R.; Kaufman L.; Katz M.: Asthma: comparative bronchodilator effects of ipratropium bromide and isoproterenol. J. Clin. Pharmacol.: 198-204 (1976).

20. Chick T.; Jenne J.: Comparative bronchodilator responses to atropine and terbutaline in asthma and chronic bronchitis. Chest 72: $719-723$ (1977).

21. Snow $\mathbb{R}$; Miller W.; Blair $\mathbb{H}$; Rice $D$ : Inhaled atropine in asthma. Ann. Allerg. 42: $286-289(1979)$.

22. Ashutosh K.; Mead G.; Dickey J. jr.; Berman P.; Kuppinger M.: Density dependence of expiratory Jow and bronchodilator response in asthma. Chest 77: 68-75 (1980).

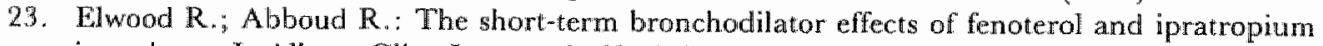
in asthma. J. Allerg. Clin. Immunol. 69: $467-473$ (1982).

24. Chervinsky P.: Double-blind study of ipratropium bromide, a new anticholinergic bronchodilator. J. Allerg. Clin. Immunol. 59: 22 - 30 (1977).

25. Barber $\dot{P}_{\text {; }}$, Chatterjee S.; Scott $\mathbb{R}$. A comparison of ipratropium bromide, detropine citrate and placebo in asthma and chronic bronchitis. Br. J. Dis. Chest 71: $101-104$ (1977).

26. Rebuck A.; Chapman K.; Braude A.: Anticholinergic therapy of asthma. Chest 82: $55 \mathrm{~S}-57 \mathrm{~S}$ (1982).

27. Hockley B.; Johnson M.: A comparison of three high doses of ipratropium bromide in chronic asthma. Br. J. Dis. Chest 79:379-384 (1985).

28. Lenney W.: Evans A.: Nebulized salbutamol and ipratropium bromide in asthmatic children. Br. J. Dis. Chest 80:59-65 (1986).

29. Ruffin R.; Fitzgerald J.; Rebuck A.: A comparison of the bronchodilator activity of Sch 1000 and salbutamol. J. Allerg. Clin. Immunol. 59: $136-141$ (1977).

30. Allen C.; Campbell A.: Dose response of ipratropium bromide assessed by two methods Thorax 34: $137-139(1979)$. 


\section{CHAPTER 13}

\section{CONTRIBUTION OF IMPEDANCE MEASUREMENT OF THE RESPIRATORY SYSTEM TO THE BRONCHIAL CHALLENGE TESTS.}

WOUTERS E.F.M., POLKO A.H., SCHOUTEN H.J.A.', VISSER B.F.

DEPARTMENT OF PULMONARY DISEASES AND MEDICAL INFORMATICS AND STATISTICS ${ }^{1}$, UNIVERSITY LIMBURG, MAASTRICHT, THE NETHERLANDS

Supported by a grant of the Dutch Asthma Foundation.

Paper submitted for publication.

Key words: Forced oscillations, respiratory system, impedance, resistance, conductance, reactance, bronchial challenge, spirometry. 
The contribution of impedance measurement of the respiratory system to bronchial challenge tests was studied in 64 asthmatics and 23 control subjects.

After histamine challenge, resistance values significantly increased at all frequencies but most markedly at the lower frequencies in the asthmatic group; reactance values significantly decreased at all frequencies.

In the control group, resistance significantly increased at 8 and $12 \mathrm{~Hz}$. However, reactance decreased significantly at all frequencies.

By multiple logistic model analysis a simple discriminant score was found with great discriminating power to differentiate asthmatics and non-asthmatics.

The discriminating score equals 9 times $\mathrm{FEV}_{1}$ after minus 7 times $\mathrm{FEV}_{1}$ before.

The addition of the forced oscillation technique to the equipment for measuring the bronchial response after challenging procedures can give information about the localization of the response to the challenge in the respiratory system.

\section{INTRODUCTION}

One of the characteristic features of asthma is the extreme sensitivity of the airways to physical, chemical and pharmacological stimuli (1). This increased response of airway smooth muscle to non-specific stimuli is so characteristic of asthma that it has been proposed as a criterion for the diagnosis of the disease (2). The response of smooth muscle to these non-specific stimuli can be assessed by different methods, indirectly reflecting airway caliber. Due to the simplicity and reproducibility, the forced expiratory volume in one second is generally used as an index for assessing the response to bronchial challenge (3).

However, forced expiratory flow measurements are effort dependent and need a prior deep inspiration, possibly influencing the bronchial tone (4-7).

The forced oscillatory method allows the simultaneous determination of the impedance of the respiratory system at various frequencies.

No active co-operation of the patient and no deep inspiratory manoeuvres are necessary for the measurement.

Furthermore, according to Mead's analogon of the respiratory system, it may not only be possible to measure the response, but also to localize this response in the respiratory system ( 8 ).

The purpose of this study is to evaluate the possible contribution of impedance measurement by forced oscillation to the determination of airway response after challenge with histamine. 


\section{Patients}

We studied 64 asthmatic patients and 23 control subjects. The diagnosis of bronchial asthma was based on a characteristic history of recurrent attacks of dyspnea with perceptible wheezing. The patients were asymptomatic at the time of the study and had not taken any medication for at least $8 \mathrm{~h}$ before challenge.

The control subjects denied any pulmonary complaint and were not suffering for rhinitis.

The anthropometric and spirometric parameters of both groups are summarized in table 1 .

The control subjects were older than the asthmatics and $\mathrm{FEV}_{\downarrow}$ and inspiratory vital capacity (IVC) values expressed as a percentage of the reference values of the European Community for Coal and Steel (9) were higher in the control population.

Forced pseudo-random noise oscillation technique

Respiratory impedance was determined by means of the forced oscillation technique as described in chapter $4(10,11)$.

\section{Challenge procedure}

Histamine diphosphate solution in isotonic phosphate buffer was used as the bronchoconstricting agent. It was delivered by a Wiesbadener Doppelinhalator at tidal breathing during $30 \mathrm{~s}$. The administered concentrations of histamine were $0.25,0.50,1,2,4,8$, and $16 \mathrm{~g} / \mathrm{L}$.

Table 1 .

Anthropometric and spirometric data of studied patients.

\begin{tabular}{|c|c|c|c|c|c|c|}
\hline & & \multicolumn{2}{|c|}{ Asthmatics $(n=64)$} & \multicolumn{3}{|c|}{ Non-asthmatics $(n=23)$} \\
\hline & & Mean & $\mathrm{SD}$ & Mean & $\mathrm{SD}$ & $\mathrm{p}$ \\
\hline Age & (years) & 25.7 & 9.6 & 41.6 & 12.6 & *** \\
\hline Height & $(\mathrm{cm})$ & 169.4 & 10.0 & 172.1 & 8.7 & n.s. \\
\hline Weight & $(\mathrm{kg})$ & 66.2 & 15.7 & 70.2 & 9.2 & n.s. \\
\hline$F E V_{1}$ & (L) & 3.3 & 0.8 & 3.6 & 0.8 & nis.s. \\
\hline IVC & (L) & 4.4 & 1.2 & 4.7 & 0.8 & n.s. \\
\hline $\mathrm{FEV}_{1}$ & (\% pred) & 87.4 & 15.3 & 101.3 & 13.5 & **** \\
\hline IVC & (\% pred) & 96.5 & 14.9 & 107.1 & 11.5 & $*$ \\
\hline $\mathrm{FEV}_{1} / \mathrm{TVC}$ & $\triangle \quad(\%)$ & 75.8 & 9.7 & 75.9 & 8.6 & n.s. \\
\hline
\end{tabular}

$\begin{aligned} \text { Not significant } & \text { n.s. } \\ 0.001 \leq \mathrm{p} & <0.01 \\ \mathrm{P} & <0.001\end{aligned}$


Isotonic phosphate buffer was inhaled before histamine in order to exclude nonspecific responses. At basal conditions, three impedance measurements were performed. Thereafter, baseline IVC and $\mathrm{FEV}_{\mathrm{I}}$ were measured using a wet spirometer. After each concentration of histamine, bronchial response was measured by determination of $\mathrm{FEV}_{\mathrm{l}}$. The challenge was stopped when the decrease of $\mathrm{FEV}_{1}$ was equal to or more than $20 \%$ of baseline $\mathrm{FEV}$ or when the maximal concentration of histamine $(16 \mathrm{~g} / \mathrm{L})$ was delivered.

Immediately after reaching the provocative concentration or the maximal concentration, three impedance measurements were performed.

\section{Data analysis}

Mean values of $R_{\mathrm{rs}}$ and $X_{\mathrm{rs}}$ of three impedance measurements were used in the statistical analysis. Mean values were compared by Students' two-sample and paired t-tests. P-values lower than 0.05 were defined as statistically significant. Stepwise discriminant and stepwise logistic regression analyses were used to find an optimal classification function that discriminates between the asthmatic and the non-asthmatic group.

Values of $R_{\mathrm{rs}}$ at 8 and $32 \mathrm{~Hz}$ and of average $R_{\mathrm{rs}}$, using 8 to $52 \mathrm{~Hz}$ data $\left(\mathrm{a} R_{\mathrm{rs}}\right)$ and their reciprocals $\left(1 / R_{\mathrm{rs}(8)}, 1 / R_{\mathrm{rs}(32)}\right.$ and $\left.1 / \mathrm{a} R_{\mathrm{rs}}\right)$ were compared.

The conductance at $8 \mathrm{~Hz}\left(G_{\mathrm{rs}(\theta)}\right)$ was calculated according the formula: $G_{\mathrm{rs}(8)}=R_{\mathrm{rs}(8)} /\left(R_{\mathrm{rs}(8)^{2}}+X_{\mathrm{rs}(8)^{2}}\right)$.

Frequency dependence was calculated according to the formula: $\left(R_{\mathrm{rs}(28)}-R_{\mathrm{rs}(8)}\right) / 20$.

To evaluate changes in the imaginary part of $Z_{\mathrm{rs}}$, average $X_{\mathrm{rs}}\left(\mathrm{a} X_{\mathrm{rs}}\right)$ was calculated, using data from 8 to $52 \mathrm{~Hz}$.

\section{RESULTS}

A. Impedance measurements before and after histamine in the asthmatic group.

Under basal conditions, no frequency dependence of $R_{\mathrm{rs}}$ was observed. $X_{\mathrm{rs}}$ values became positive between 12 and $16 \mathrm{~Hz}$ (fig. 1).

After histamine challenge, $R_{\mathrm{rs}}$ values significantly increased at all frequencies, but most markedly at the lower frequencies. $R_{\mathrm{rs}}$ values decreased with increasing frequencies between 8 and $28 \mathrm{~Hz} . X_{\mathrm{rs}}$ values decreased significantly at all frequencies. $X_{\mathrm{rg}}$ became positive between 28 and $32 \mathrm{~Hz}$.

Calculated reciprocal values of $R_{\mathrm{rs}}$ at 8 and $32 \mathrm{~Hz}$ and $G_{\mathrm{rs}}$ at $8 \mathrm{~Hz}$ changed significantly after challenge.

The differences of $\mathrm{a} R_{\mathrm{rs}}$ and the reciprocal, of $\mathrm{a} X_{\mathrm{rs}}$ and of frequency dependence were also highly significant in the asthmatic group (table 2).

B. Impedance measurements before and after histamine in the control group.

No decrease of $R_{\mathrm{rs}}$ with frequency was abserved and $X_{\mathrm{rs}}$ was positive at $8 \mathrm{~Hz}$ before histamine.

After histamine challenge, $R_{\mathrm{rs}}$ significantly increased at 8 and $12 \mathrm{~Hz}$. However, $X_{\text {rs }}$ significantly decreased at all frequencies (fig. 2). 

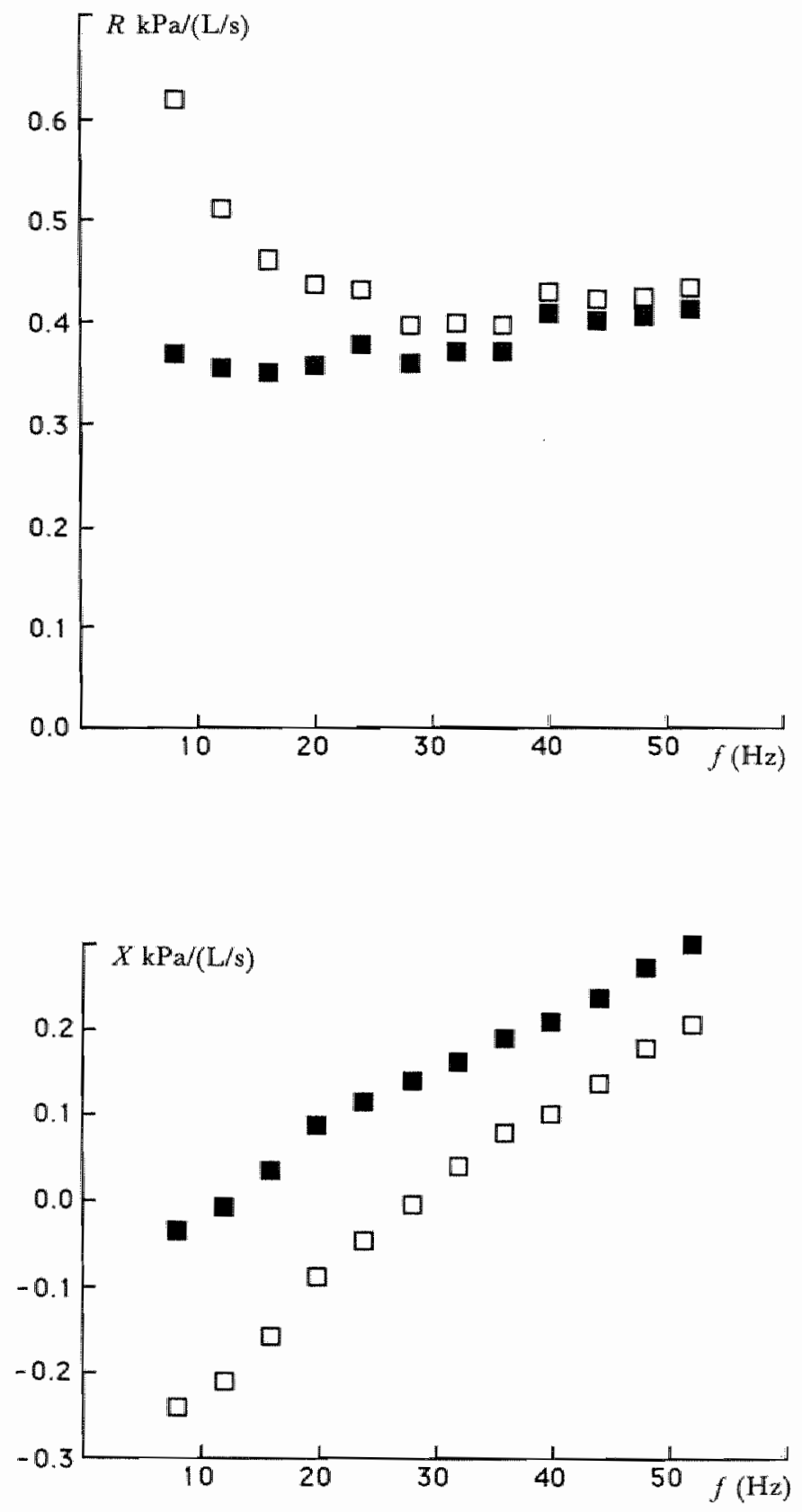

Fig. 13.1

Mean $R_{\mathrm{rs}}$ and $X_{\mathrm{rs}}$ values (kPa/(L/s)) before (closed squares) and after histamine challenge (open squares) in the asthmatic patient group. 

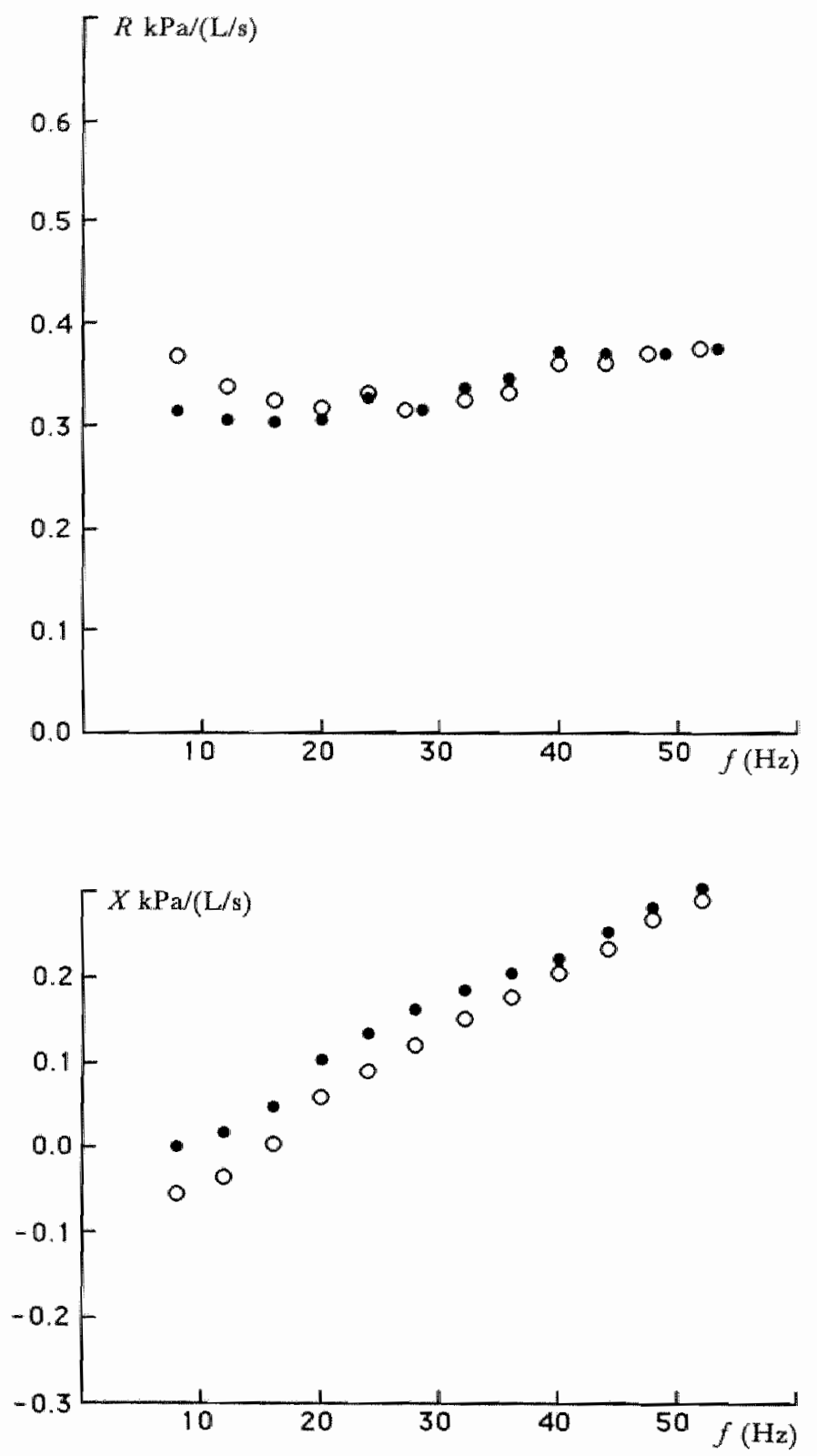

Fig. 13.2

Mean $R_{\mathrm{rs}}$ and $X_{\mathrm{rs}}$ values $(\mathrm{kPa} /(\mathrm{L} / \mathrm{s}))$ before (closed circles) and after histamine challenge (open circles) in the control group. 
Differences of calculated reciprocal values of $R_{\mathrm{rs}(8)}$ and $G_{\mathrm{rs}(8)}$ were also statistically significant.

Changes of the reciprocal of $R_{\mathrm{rs}(32)}$, of $\mathrm{a} R_{\mathrm{rs}}$ and the reciprocal were not significant. Differences of $a X_{\mathrm{rs}}$ and of frequency dependence however were statistically significant.

Table 1 .

Impedance parameters before and after histamine in the asthmatic (A) and non-asthmatic (NA) group.

\begin{tabular}{|c|c|c|c|c|}
\hline & & Before & After & $\mathrm{p}$ \\
\hline \multirow{3}{*}{$1 / R_{\mathrm{rs}(8)}$} & A & 3.060 & 1.885 & $* * * *$ \\
\hline & $\mathrm{NA}$ & 3.370 & 3.022 & ** \\
\hline & $\mathrm{p}$ & n.s. & $* * * *$ & \\
\hline \multirow[t]{3}{*}{$1 / R_{r s(32)}$} & $\mathrm{A}$ & 2.846 & 2.658 & $* *$ \\
\hline & NA & 3.139 & 3.186 & n.s. \\
\hline & $\mathrm{p}$ & n.s. & ** & \\
\hline \multirow[t]{3}{*}{$G_{\mathrm{rs}(B)}$} & A & 3.001 & 1.663 & $* * * *$ \\
\hline & NA & 3.323 & 2.907 & $* * * *$ \\
\hline & $\mathrm{p}$ & n.s. & $* * * *$ & \\
\hline \multirow[t]{3}{*}{$\mathrm{a} R_{\mathrm{rs}}$} & A & 0.380 & 0.448 & $* * * *$ \\
\hline & NA & 0.337 & 0.345 & n.s. \\
\hline & $\mathrm{p}$ & n.s. & $* * *$ & \\
\hline \multirow[t]{3}{*}{$1 / \mathrm{a} R_{\mathrm{rss}}$} & A & 2.813 & 2.381 & $* * * *$ \\
\hline & NA & 3.089 & 2.994 & n.s. \\
\hline & $\mathrm{p}$ & n.s. & $* * *$ & \\
\hline \multirow[t]{3}{*}{$a X_{\mathrm{rs}}$} & A & 0.143 & 0.0008 & $* * * *$ \\
\hline & NA & 0.159 & $0: 1249$ & ** \\
\hline & $\mathrm{p}$ & n. s. & $* * * *$ & \\
\hline \multirow[t]{3}{*}{ Fr. dep. } & A & 0.0005 & -0.011 & ***** \\
\hline & $\mathrm{NA}$ & 0.0000 & -0.003 & "** \\
\hline & $\mathrm{p}$ & n.s. & $* * *$ & \\
\hline
\end{tabular}

$0.01 \leq p<0.05$

$0.001 \leq \mathrm{p}<0.01$

$0.0001 \leq \mathrm{p}<0.001$

$\mathrm{p}<0.0001$ 
C. Comparison of calculated impedance parameters in both groups at basal conditions and after histamine challenge.

The results are summarized in table 2.

Before challenge, no significant differences of analyzed impedance parameters existed between the two groups.

After challenge, differences of impedance parameters between both groups were highly significant.

Table 3.

Results of the multiple logistic model analysis.

\begin{tabular}{lrrr}
\hline Factor & $\begin{array}{l}\text { Logistic } \\
\text { Coofficient }\end{array}$ & $\begin{array}{l}\text { Standard } \\
\text { Error }\end{array}$ & t-ratio \\
FEV, before & 5.89 & 1.54 & 3.81 \\
FEV & -7.52 & 1.69 & -4.46 \\
Constant & 2.40 & & \\
\hline
\end{tabular}

$p_{1}<.0001$ for each of the two t-ratios.

Table 4.

Performance of score $=9 \mathrm{FEV}_{1 \text { after }}-7 \mathrm{FEV}_{1}$ before.

\begin{tabular}{lccc}
\hline & Asthma & Non-asthrna & Total \\
Score $>2.7$ & 2 & 21 & 23 \\
Score $<2.7$ & 62 & 2 & 64 \\
Total & 64 & 23 & 87
\end{tabular}

Table 5 .

Detailed performance of score $9 \mathrm{FEV}_{1}$ after $-7 \mathrm{FEV}_{\text {, before }}$

\begin{tabular}{cccc}
\hline & Asthma & Non-asthma & Total \\
$7.00 \leq$ score & 0 & 9 & 9 \\
$3.00 \leq$ score $<\quad 7.00$ & 2 & 11 & 13 \\
$2.50 \leq$ score $<\quad 3.00$ & 2 & 1 & 3 \\
$-1.00 \leq$ score $<\quad 2.50$ & 21 & 2 & 23 \\
score $<-1.00$ & 39 & 0 & 39 \\
Total & 64 & 23 & 87 \\
\hline
\end{tabular}




\section{Linear discriminant and multiple logistic model analyses.}

The multiple logistic model was used to select a set of measurements, discriminating asthmatics and non-asthmatics. The significant contribution of the two FEV, measurements, expressed in L BTPS, is illustrated in table 3. Since the ratio $5.89 / 7.52$ of both logistic regression coefficients was about equal to $7 / 9$, the following discriminant score could be used :

$$
\begin{aligned}
\text { Score } & =9 \cdot \mathrm{FEV}_{1 \text { after }}-7 \cdot \mathrm{FEV}_{1 \text { before }} \\
& =2 \cdot \mathrm{FEV}_{1 \text { after }}+7\left(\mathrm{FEV}_{1 \text { after }}-\mathrm{FEV}_{1 \text { before }}\right) \\
& =9\left(\mathrm{FEV}_{1 \text { after }}-\mathrm{FEV}_{1 \text { before }}\right)+2 \mathrm{FEV}_{1 \text { before }}
\end{aligned}
$$

A great role was played by the change in $\mathrm{FEV}_{1}$. Tables 4 en 5 showed the great discriminating power of this very simple discriminant score.

The Fisher linear discriminant analysis was also used. A significant contribution of $G_{\mathrm{rs}(8)}$ after $\left(\mathrm{P}_{2}<.05\right)$, in addition to both $\mathrm{FEV}_{1}$ values was found by this analysis.

Stepwise logistic regression was also performed when only impedance parameters were investigated. It was shown that only $G_{\mathrm{rs}(8) \text { after }}$ is retained as a parameter discriminating between asthmatics and non-asthmatics after histamine challenge.

When $G_{\mathrm{rs}(8)}$ after value greater than 2.75 is compatible with non-asthma and a value lower than 2.75 with asthma, the sensitivity of $G_{\mathrm{rs}(8)}$ after in this study is $92 \%$, the specificity $61 \%$ and the accuracy $84 \%$.

\section{DISCUSSION}

Many methods can be used for the indirect measurement of airway response to bronchial stimuli. Forced expiratory volume in one second is a well-established. test for measurement of bronchial obstruction $(1,3)$.

Forced oscillometry allows the simultaneous determination of $R_{\mathrm{rss}}$ and $X_{\mathrm{rs}}$ at different frequencies. According to Mead's analogon of the respiratory system, modified by Nagels et al. (12), this method permits to distinguish between large and small intrathoracic airway obstruction and to evaluate possible changes of airway compliance during bronchial challenge.

Most of previous reports using forced oscillation techniques in bronchial provocation tests have measured at one or at a limited number of frequencies.

After methacholine provocation, Kabiraj et al.(13) found in ten patients a significant correlation between airway resistance, measured at $10 \mathrm{~Hz}$ and changes in $\mathrm{FEV}_{1}$ but coefficients of correlation were low. They concluded that the oscillometric method is best suited for provocation tests where abstruction is induced from normal resistance values.

Mitsuhashi et al. (14) measured $R_{\mathrm{rs}}$ by the forced oscillation technique at $7 \mathrm{~Hz}$ 
during methacholine challenge in asthmatic children. They distinguished five patterns of reaction after methacholine inhalation.

Solymar et al. (15) used total respiratory resistance and impedance at 2, 4 and $12 \mathrm{~Hz}$ and variables obtained with the forced vital capacity manoeuvre in the evaluation of the bronchial allergen challenge in asthmatic children. They found that $R_{\mathrm{rg}}$ at $4 \mathrm{~Hz}$ is the most sensitive variable obtained with the forced oscillation technique and respiratory resistance and impedance seem equivalent in detecting the bronchial response.

Tjwa et al. (16) monitored the airway reactivity during inhalation of histamine diphosphate by measuring the continuous response curve of the respiratory resistance by the oscillation method at 3,5 and $7 \mathrm{~Hz}$ and evaluated the correlation between the respiratory resistance and $\mathrm{FEV}_{1}$.

They were unable to make a differential diagnosis between normal subjects, patients with acute or chronic bronchitis and patients with asthma and they concluded that $R_{\mathrm{rs}}$ measurement by a forced oscillation method can not totally replace the conventional method of $\mathrm{FEV}_{1}$ determination due to the number of false negative tests. To note is the high number of positive tests even by $F E V_{1}$ as by $R_{\text {rs }}$ determination in their normal control group.

Decramer et al. (17), using a pseudo-random noise pressure signal containing all harmonics of 2 up to $26 \mathrm{~Hz}$ and using isocapnic hyperventilation with cold air as the non-specific stimulus, observed in asthmatics after challenge an increase of $R_{\mathrm{r}}$ by about $100 \%$ of the prechallenge value and a frequency dependence of $R_{\mathrm{rs}}$. They further found a decrease of $X_{\mathrm{rs}}$ resulting in an increase of the resonant frequency of the respiratory system.

Duiverman et al. (18) compared the dose of methacholine at which lung function indices obtained by forced pseudo-random noise oscillometry and expiratory flow-volume curves changed significantly from baseline (threshold dose) or reached a predetermined value (provocative dose). They found a close correlation between a $40 \%$ increase of $R_{\mathrm{rs}(6)}$ and of average $R_{\mathrm{rs}}$ and a $20 \%$ decrease of FEV Furthermore, they observed that the threshold dose of $X_{\mathrm{rs}}$ was the most sensitive index to detect methacholine induced bronchoconstriction.

Van Noord et al. (19) evaluated the response to bronchial challenge with histamine in 53 patients with asthmatic complaints by measuring $R_{\mathrm{rs}}$ and $X_{\mathrm{rs}}$ between 2 and $26 \mathrm{~Hz}$ by means of the pseudo-random noise method, by measuring forced vital capacity (FVC) and $\mathrm{FEV}_{1}$ and by measuring airway resistance $\left(R_{\mathrm{aw}}\right)$ and conductance $\left(G_{\mathrm{aw}}\right)$ using bodyplethysmography.

They found that the parameters with the best reproducibility and sensitivity to detect the effects of histamine are in decreasing order : the percentage changes of specific $G_{\mathrm{aw}}$ of the reciprocal of mean $R_{\mathrm{rs}}$, of $F E V_{11}$, of the reciprocal of thoracic gas volume and of FVC, the absolute changes of mean $X_{\mathrm{rs}}$ and of the average slope of the $R_{\mathrm{rs}}$ frequency relationship.

The changes of $R_{\mathrm{rs}}$ and $X_{\mathrm{rs}}$ observed in the asthmatics after histamine challenge in this study are compatible with the observations of Clement et al. (20) in pa- 
tients with airway obstruction. The increase of $R_{\mathrm{rs}}$ especially at lower frequencies, the decrease of $R_{\mathrm{rs}}$ with frequency and the more negative values of $X_{\mathrm{rs}}$ can be explained by an airway obstruction extending to the peripheral airways, accor* ding to Mead's analogon of the respiratory system, modified by Nagels et al.. Furthermore a decrease of airway compliance has to be considered to explain the observed changes of $f_{0}$.

It has to be noted that the results after histamine were not corrected for possible changes of lung volume (12) or for the mechanical properties of the upper airways (21). Therefore, underestimation of $R_{\mathrm{rs}}$ mainly at lower frequencies is possible (21).

As indicated by our results, changes in the peripheral airways have to be supposed to explain the observed changes of $R_{\mathrm{rs}}$ and $X_{\mathrm{rs}}$ in the control group.

However, changes are relatively small in comparison with the asthmatic group. Stepwise discriminant and stepwise logistic regression analysis were performed to find a classification function for the asthmatic and non-asthmatic patients. By the multiple logistic model analysis a simple discriminant score with a great discriminating power was found, made up by the $\mathrm{FEV}_{1}$ values after and before histamine challenge. The discriminating score equals 9 times $F E V_{1}$ after minus 7 times $\mathrm{FEV}_{1}$ before, expressed in L BTPS. Ninety one percent of non-asthmatics had score values greater than 2.7 ; ninety four percent of asthmatics had score values lower than 2.7 .

The sensitivity of this discriminant score in our study material was $97 \%$, the specificity $91 \%$ and the accuracy $95 \%$.

By the linear discriminant analysis, in addition to the spirometric values, only $G_{\mathrm{r}(8)}$ after histamine challenge contributed significantly to the classification function. Therefore, it can be concluded that, in addition to the spirometric values, the contribution of impedance parameters to discriminate between asthmatics and non-asthmatics is limited. However, the addition of the forced oscillation technique to the equipment for measuring the bronchial response after challenging procedures gives information about localization of the response in the respiratory system. 


\section{References}

1. Boushey HA, Holtzman MJ, Sheller JR, Nadel JA. State of the art: Bronchial Hyperreactivity. Am Rev Respir Dis 1980,121:389-405.

2. American Thoracic Socicty Committee on Diagnostic Standards for Non-Tuberculous Disease. Definitions and classification of chronic bronchitis, asthma and pulmonary emphysema. Am Rev Respir Dis 1962;85:762-69.

3. Eiser NM, Kerrebijn $\mathbb{K} F$, Quanjer PH. Guidelines for standardization of bronchial challenges with (nonspecific) bronchoconstricting agents. Bull Europ Physiopath Resp 1983;19:495 - 514.

4. Nadel JA. Tierney Dl". Effect of previous deep inspiration on airway resistance in man. J Appl Physiol $1961 ; 16 ; 717-19$.

5. Gimeno F, Berg WC, Sluiter HJ, Tammeling GJ. Spirometry-induced bronchial obstruction. Am Rev Respir Dis 1972;105:68-74.

6. Green M, Mead J. Time dependence of low-volume curves. J Appl Physiol 1974;37:793 - 97.

7. Gayrard P, Orehek J, Grimaud C, Charpin J. Bronchoconstrictor effects of a deep inspiration. in patients with asthma. Am Rev Respir Dis 1975;111:433-39.

8. Mead J. Contribution of compliance of airways to frequency-dependent behavior of lungs. J Appl Physiol 1969;26:670 - 73.

9. Quanjer PH (ed.) Standardized lung function testing. Bull Europ Physiopathol Resp 1983;19 suppl $5: \vec{\imath}-44$.

10. LaÁndsćr IJ, Nagels J, Demedts M, Billiet L, Van de Woestijne KP. A new method to determine frequency characteristics of the respiratory system. J Appl Physiol 1976;41:101-06.

11. Lándsér $\mathrm{FJ}, \mathrm{Polko}_{\mathrm{AH}} \mathrm{AH}$, Visser $\mathrm{BF}$. Oscillatory measurement of total respiratory impedance with extended spectrum up to $52 \mathrm{~Hz}$. Arch Intern Physiol. Biochim 1983;91:12.

12. Nagels J, Lándsếr FJ, Van der Linden I, Clément I, Van de Woestijne KP. Mechanical properties ol lungs and chest wall during spontaneous breathing. J Appl Physiol 1980;49:408-16.

13. Kabiraj MU, RolfC, Simonsson BG. Drug-induced changes in airways obstruction reflected by forced expiratory flows and airway resistance measured with an oscillometric method using quiet breathing. Respiration 1981;41:90-95.

14. Mitsuhashi M, Tajima K., Tokuyama K, Morkawa A, Kuroume T. Application of a new directwriting reconcler device, the "astrograph", to the evaluation of methacholine-induced bronchoconstriction in asthmatic children. Journal of Asthma 1984;21:89-95.

15. Solymar L, Aronsson PH, Engström I, Bake B, Bjure J. Fonced oscillation technique and maximum expiratory flows in bronchial provocation tests in children. Eur J Respir Dis $1984 ; 65: 486-95$.

16. Tjwa MKT, Smeets JJ, Janssen LPJ, Maesen FPV. Measurement of the non-specific threshold stimulus for the bronchial tree by contimuous monitoring of respiratory resistance using the oscillation method. Respiration 1985;48:1-11.

17. Decramer M, Demedts M, Wan de Woestijne KP. Isocapnic byperventilation with cold air in healthy non-smokers, smokers and asthmatic subjects. Bull Europ Physiopathol Resp $1984: 20: 237 \ldots 43$

18. Duwerman EJ, Neijens HJ, Van der Snee-Van Smaalen M, Kerrebijn KF. Comparison of forced oscillometry and forced expirations for measuring dose-related responses to inhalled methacholine in asthmatic children. Bull Europ Physiopathol Resp 1986;22:433-36.

19. Van Noord JA, Demedts M, Cilarysse I, Van de Woestijne KP. Total respiratory resistance and reactance in upper airway obstruction. Bull Europ Physiopath Resp 1986:22:54M.

20. Clément $\mathrm{J}$, Lándsér FJ, Van de Woestijne KP. Total resistance and reactance in patients with respiratory complaints with and without airways obstruction. Chest 1983;83:215-20.

21. Cauberghs M, Van de Woestijne KP. Mechanical properties of the upper airway.J Appl Physiol $1983 ; 55: 335-42$. 


\section{CHAPTER 14}

\section{SUMMARY}

Lándsér et al. described the technique of forced pseudo-random noise oscillations to measure simultaneously the impedance of the respiratory system at various frequencies. Originally, a pseudo-random noise signal containing all the harmonics of $2 \mathrm{~Hz}$ up to $30 \mathrm{~Hz}$ was used. The frequency spectrum was extended by Landser et al. and in our studies a pseudo-random noise pressure signal containing all the harmonics of 4 up to $52 \mathrm{~Hz}$ in steps of $4 \mathrm{~Hz}$ is applied to the mouth.

To analyse the frequency dependent behaviour of the respiratory system, different models were described, reviewed in chapter 2. To evaluate the partitioning of airway resistance and inertance along the bronchial tree, calculations were performed using the symmetrical model of the bronchial tree, described by Weibel. According to this model, it can be demonstrated that $90 \%$ of total resistance value is reached at the 12 th bronchial generation and that $90 \%$ of total inertance is reached at the 4th generation, when a laminar flow pattern is supposed in the airways.

The technique of forced oscillometry is described in chapter 3. Results of impedance measurements of the respiratory system by the forced pseudo-random noise oscillation technique are analyzed. Frequency dependence, a decrease of resistance significant or exceeding conventional limits of the normal range with increasing frequency, was described by many authors in COPD patients. The influence of peripheral resistance, airway and lung compliance on the frequency dependence of the impedance are simulated using the model of Leuven. Age and lung volume are reviewed as factors, contributing to the frequency dependent behaviour of the respiratory system.

The impedance of the cheeks and upper airways forms a special problem, when, as in our studies, input impedance is determined. The term input indicates that flow and pressure are measured at the same place. Published data on the influence of upper airways on the impedance of the respiratory system are reviewed.

Measurements of the resistance and reactance of the respiratory system between 4 and $52 \mathrm{~Hz}$ in 20 healthy subjects and in 9 patients with severe chronic airway obstruction are described in chapter 4 . In normal subjects, resistance values increase at higher frequencies. As compared to the results in normal subjects, resistance values are much higher in COPD patients and decrease with frequency. Reactance values are more negative in COPD patients, resulting in an increase of resonant frequency. Using matrix network topography, these findings are analyzed in a modified Mead's model, incorporating the compressibility of alveolar gas. The changes observed in the COPD patients can be simulated by 
an increase of peripheral resistance. By adding gas compliance in the model calculations, resistance and reactance values decrease slightly.

In chapter 5 , the forced pseudo-random noise oscillation technique is compared with maximal forced expiratory spirometry in 100 patients. Resonant frequency and frequency dependence of resistance correlate well with selected parameters of the forced expiratory flow-volume curve: the best correlation is found between resonant frequency and $\mathrm{FEV}_{1}$. No correlation between average resistance and spirometric parameters reachs a statistically significant level. It is discussed that each method has its own characteristics and limitations.

Chapter 6,7 and 8 deal with a special application of the forced oscillation technique namely impedance measurement during helium + oxygen breathing. The calibration of the forced oscillation equipment forms a special problem. This is discussed in chapter 6 . During breathing the low density gas mixture, a significant decrease of resistance values and a significant decrease of reactance values, resulting in an increase of resonant frequency, are observed in 15 normal subjects.

The density dependent decrease of the real part of the impedance is explained by turbulence in the larger airways. The imaginary part of the impedance decreases due to the density dependence of the inductive reactance.

In chapter 7, impedance measurement of the respiratory system were performed in 20 male subjects during air or helium and oxygen breathing before and after inhalation of $0.2 \mathrm{mg}$ salbutamol. During air and helium + oxygen breathing, salbutamol causes a significant decrease of resistance values especially at lower frequencies. The decrease of resistance after salbutamol inhalation can be explained by bronchodilation of the larger airways. This action of salbutamol is not influenced by changing the physical properties of the inhaled gases. A special observation is formed by the increase of reactance values after inhalation of salbutamol even during air as during helium + oxygen breathing. It is hypothesized that the increase of reactance can be explained by a decrease of the capacitive reactance.

However, because it can not be expected that the low dose of salbutamol will change chest wall or lung compliance, the RLC-model of Nagels is too simple to explain this observation. More complex model analyses, reflecting the interregional and intraregional time-constant inequalities in normal lungs, have to be performed to analyse this effect of salbutamol in normal subjects.

In chapter 8 , the results of impedance measurements, performed in 15 normal subjects during air or helium + oxygen breathing before and after inhalation of $0.04 \mathrm{mg}$ ipratropium bromide, are discussed. Contrary to the results after salbutamol inhalation, only during helium-oxygen breathing ipratropium causes a significant decrease of resistance values from 8 to $48 \mathrm{~Hz}$ and a significant increase of reactance values from 12 to $44 \mathrm{~Hz}$.

It can be concluded that breathing gases with decreased kinematic viscosity is preferable for measurement the effects of low doses ipratropium on the tracheobronchial tree in normal subjects. Evaluation with different doses of 
the pharmacological agents will be necessary. Further studies were performed in patients.

In chapter 9 , impedance measurements of the respiratory system were performed in a group of 20 COPD patients before and after inhalation of $0.4 \mathrm{mg}$ salbutamol. A slight, but statistically not significant decrease of resistance is observed in this patient group. However, the observed increase of reactance after salbutamol is statistically significant at all frequencies except at 24 and $52 \mathrm{~Hz}$.

It is hypothesized that the increase of reactance can be explained by an increase of capacitance due to an increase of airway compliance or a decrease of peripheral resistance.

Chapter 10 deals with the influence of helium + oxygen breathing in COPD patients before and after inhalation of $0.4 \mathrm{mg}$ salbutamol.

No statistically significant decrease of resistance values is observed in this patient group after equilibration with the helium + oxygen mixture except at 8, 20 and $24 \mathrm{~Hz}$. When a peripheral airway constriction is present in these COPD patients, it can be supposed that factors other than the physical properties of the respired gas are such as to keep the Reynolds" number below the critical value for turbulence and alterations of the kinematic viscosity will be expected to aller resistance very little because a laminar flow regimen is viscosity dependent and helium + oxygen is 1.13 times as viscous as air. As in normal subjects, a marked decrease of reactance with an increase of resonant frequency is observed during helium + oxygen breathing due to the decrease of inductive reactance. The results during air breathing before and after salbutamol are in accordance with the results as discussed in chapter 9.

Remarkably, inhalation of salbutamol after equilibration with the helium + oxygen mixture, decreases resistance and increases reactance significantly at all frequencies. It is supposed that a distribution of pulmonary resistance with minimal losses in the larger airways is more sensitive to measure the effects of salbutamol on impedance parameters in these patients.

The mechanics of bronchoconstriction and bronchodilation are studied in asthmatics. The results are described in chapter 11 and 12 .

In chapter 11, bronchoconstriction is induced by inhalation of histamine in 25 asthmatic subjects. Histamine causes an increase of resistance especially at lower frequencies, a frequency dependence of resistance and a decrease of reactance at all frequencies. These changes are explained by peripheral airway obstruction. In chapter 12, bronchoconstriction is induced by isocapnic inhalation of cold air. The same changes are observed as after histamine inhalation. It can therefore be concluded that in asthmatics the pattern of bronchoconstriction, measured by forced oscillations, is independent of the used stimulus.

After histamine induced bronchoconstriction, patients were randomized to inhale $0.4 \mathrm{mg}$ or $1.0 \mathrm{mg}$ salbutamol. Impedance measurements, performed 5 minutes after inhalation of $1.0 \mathrm{mg}$ and $0.4 \mathrm{mg}$ salbutamol, show a decrease of resistance values at lower frequencies, a disappearance of the frequency dependence of 
resistance and a significant increase of reactance values. No significant difference in absolute changes of resistance and reactance is observed between both salbutamol regimens. These changes after inhalation of salbutamol can be explained by supposing a predominant action of the drug on the peripheral airways. The same changes are described in chapter 12 after inhalation of ipratropium bromide.

Therefore, it can be supposed that although both drugs have a different pharmacological action, the localization of the response along the tracheobronchial tree is not different for these two drugs. Further evaluations of dose response and time response especially for ipratropium bromide will be necessary.

Finally, in chapter 13 the contribution of impedance parameters of the respiratory system to the bronchial challenge tests is described.

It is demonstrated that after histamine challenge, resistance values significantly increase at all frequencies, but most markedly at the lower frequencies and that reactance values significantly decrease at all frequencies. However, by multiple logistic model analysis, it is demonstrated that by spirometric data only a simple discriminant score is found with great discriminating power to differentiate between asthmatics and non-asthmatics. The discriminating score equals $9 \mathrm{FEV}_{1 \text { after }}-7 \mathrm{FEV}_{1}$ before

The addition of the forced oscillation technique to the equipment for measuring the bronchial response after challenging procedures possibly can give information about the type and the localization of the response to the challenge in the respiratory system.

The clinical studies described in this thesis illustrate that impedance measurement of the respiratory system can give characteristic information, not obtained by other techniques.

Further studies will be necessary to analyse the possible role of this non-invasive technique in daily clinical lung function practice and model analyses have to be performed for better understanding of the observations.

Especially the role of the upper airways on input impedance of the respiratory system thas to be clarified. 


\section{CHAPTER 15}

\section{SAMENVATTING}

De geforceerde pseudo-random noise techniek werd beschreven door Lándsér en medewerkers.

Hiermee is het mogelijk simultaan de impedantie van het ademhalingssysteem bij verschillende frequenties te meten. Aanvankelijk werd een pseudo-random noise signaal van $2 \mathrm{~Hz}$ en de harmonischen tot $30 \mathrm{~Hz}$ gebruikt. Het frequentiespectrum werd door Lándsér e. a. uitgebreid en in onze onderzoekingen wordt aan de mond een pseudo-random noise druksignaal opgelegd, dat alle harmonischen van 4 tot $52 \mathrm{~Hz}$ in stappen van $4 \mathrm{~Hz}$ omvat.

Ter verklaring van het frequentie-afhankelijk gedrag van het ademhalingssysteem zijn verschillende modellen beschreven. In hoofdstuk 2 worden die modellen besproken. Verder worden berekeningen beschrewen over de verdeling van de luchtwegweerstand en inertie in de bronchiaalboom. Hierbij werd gebruik gemaakt van het symmetrische longmodel van Weibel. Uit deze berekeningen blijkt dat $90 \%$ van de totale weerstandswaarde bereikt wordt bij de $12 \mathrm{de}$ generatie en dat $90 \%$ van de totale inertie reeds bereikt is bij de 4 de generatie. Deze berekeningen gelden voor een laminair stromingspatroon in de luchtwegen. De geforceerde oscillatietechniek wordt beschreven in hoofdstuk 3. De resultaten van impedantiemetingen van het ademhalingssysteem met behulp van de geforceerde pseudo-random noise oscillatietechniek worden nader besproken. Aandacht wordt $0 . \mathrm{m}$. besteed aan de frequentie-afhankelijkheid, gedefiniëerd als een significante afname van de weerstand bij toenemende frequenties.

Door vele onderzoekers werd dit verschijnsel bij CARA-patiënten beschreven. De invloed van de perifere weerstand, de luchtweg-en de longcompliantie op het frequentie-afhankelijk gedrag van het ademhalingssysteem worden beschreven, waarbij gebruik wordt gemaakt van het longmodel ontwikkeld in Leuven door Nagels en medewerkers. De invloed van leeftijd en longvolume op het frequentieafhankelijke gedrag van het ademhalingssysteem worden besproken. Wanneer zoals in onze onderzoekingen de inputimpedantie wordt bepaald, vormt de impedantie van de kaken en de bovenste luchtwegen een speciaal probleem. De resultaten van verschillende onderzoekers m.b.t. de invloed van de bovenste luchtwegen op de impedantie van het ademhalingssysteem worden beschreven. De metingen van de weerstand en de reactantie van het ademhalingssysteem tussen 4 en $52 \mathrm{~Hz}$ bij 20 gezonde volwassenen en bij 9 patiënten met ernstig CARA worden besproken in hoofdstuk 4 . Het blijkt dat bij normale personen de weerstandswaarden toenemen met toenemende frequenties. Bij CARA-patiënten daarentegen zijn de weerstandswaarden duidelijk hoger, vooral bij lagere frequenties en nemen de weerstandswaarden met toenemende frequenties af. Bij 
CARA-patiënten zijn de reactantiewaarden meer negatief en is de resonantiefrequentie hoger dan bij normalen. Deze waarnemingen worden nader geanalyseerd in een gemodifiëerd longmodel van Mead, warin ook de compressibiliteit van het alveolair gas is opgenomen. Het blijkt dat de waarnemingen bij CARApatiënten kunnen worden gesimuleerd door een toename van de perifere weerstand te veronderstellen en dat de toevoeging van de gascompliantie in het model sllechts een lichte daling veroorzaakt, zowel van het reële als van het imaginaire deel van de impedantie.

De geforceerde pseudo-random noise techniek wordt in hoofdstuk 5 bij 100 patiënten vergeleken met de resultaten van maximaal geforceerde expiratoire spirometrie. Het blijkt dat de resonantiefrequentie en de frequentieafhankelijkheid van de weerstand het best correleren met geselecteerde parameters uit de geforceerde expiratoire flow-volume curve en dat de beste correlatic wordt gevonden tussen de $\mathrm{FEV}_{1}$ en de resonantiefrequentie. Correlatie tussen de gemiddelde weerstand en spirometrische parameters zijn statistisch niet significant. Het blijkt dat elke meting zijn eigen specifieke bijdrage levert bij de analyse van het mechanisch gedrag wan het ademhalingsstelsel.

Hoofdstuk 6, 7 en 8 handelen over een speciale toepassing van de geforceerde oscillatietechniek, namelijk impedantiemeting tijdens helium + zuurstofademen. De ijking van de meetopstelling vormt in dit geval een speciaal probleem. Dit wordt besproken in hoofdstuk 6 . Het blijkt dat tijdens ademen van het gasmengsel met lage dichtheid bij normalen een significante daling optreedt van de weerstandswaarden, evenals een significante daling van de reactantiewaarden en hierdoor treedt een toename van de resonantiefrequentie op. De dichtheidsafhankelijkheid van het reële deel van de impedantie wordt verklaard door turbulentie in de grotere luchtwegen. Het imaginaire deel van de impedantie daalt ten gevolge de dichtheidsafhankelijkheid van de inductieve reactantie.

In hoofdstuk 7 worden de resultaten voorgesteld, verkregen bij 20 mannen zonder pulmonale klachten tijdens lucht- en helium + zuurstofademen voor en na een inhalatie van $0.2 \mathrm{mg}$ salbutamol. Het blijkt dat salbutamol, zowel tijdens lucht- als tijdens helium + zuurstofademen, een significante daling veroorzaakt van de weerstandswaarden, vooral bij lagere frequenties. Deze dalling van de weerstand na salbutamol wordt verklaard door een verwijding van de grotere luchtwegen en deze werking van salbutamol blijkt niet afhankelijk te zijn van de fysische eigenschappen van de geïnhaleerde gassen.

Een speciale waarneming is de toename van de reactantiewaarden na inhalatie van salbutamol en dat zowel tijdens lucht- als tijdens helium + zuurstofademen. Verondersteld wordt dat de toename van de reactantie het gevolg is van een afname van de capacitieve reactantie. Daar niet kan worden aangenomen dat de toegediende lage dosis salbutamol een invloed heeft op de long- of thoraxwandcompliantie wordt vastgesteld dat het weerstand-inductantie-capacitantie model van Nagels een te eenvoudige weergave is van het ademhalingssysteem. Om deze waarneming te verklaren is een meer complex longmodel noodzakelijk, waarin 
aandacht wordt besteed aan de interregionale en intraregionale ongelijkheid van de tijdsconstanten in normale longen.

In hoofdstuk 8 worden de resultaten van 15 normale personen beschreven, waarbij eveneens impedantiemetingen werden verricht tijdens lucht- en tijdens helium + zuurstofademen, maar tevens voor en na inhalatie van $0.04 \mathrm{mg}$ ipratropium bromide. In tegenstelling tot salbutamol veroorzaakt ipratropium alleen tijdens helium + zuurstofademen een significante daling van de weerstandswaarden van 8 tot $48 \mathrm{~Hz}$ en een significante stijging van de reactantie waarden van 12 tot $44 \mathrm{~Hz}$. Er kan derhalve worden verondersteld dat het ademen van een gas met verlaagde kinematische viscositeit te verkiezen is voor beoordeling van de effecten van lage doses ipratropium op de bronchiaalboom bij normale personen.

Verder onderzoek is nodig naar het effect van verschillende doses van deze farmacologische agentia bij normale personen.

De verdere onderzoekingen hebben betrekking op verschillende patiëntengroepen.

In hoofdstuk 9 wordt de werking onderzocht van salbutamol bij een groep CARA-patiënten. Bij deze patiëntengroep wordt een lichte, maar statistisch niet significante daling van de weerstand vastgesteld na $0.4 \mathrm{mg}$ salbutamol. De waargenomen stijging van de reactantie na salbutamol is echter wel significant bij alle frequenties met uitzondering van 24 en $52 \mathrm{~Hz}$.

Deze toename van de reactantie wordt verklaard door een toename van de capacitantie, ofwel door een toegenomen luchtwegcompliantie ofwel door een afgenomen perifere weerstand.

Hoofdstuk 10 handelt over de invloed van helium + zuurstofademen bij CARApatiënten, zowel voor als na inhalatie van $0.4 \mathrm{mg}$ salbutamol. $\mathrm{Na}$ inhalatie van het helium + zuurstofmengsel kan geen significante daling van de weerstandswaarden worden vastgesteld bij deze patiënten met uitzondering van de weerstandswaarden bij 8,20 en $24 \mathrm{~Hz}$.

Wanneer een perifere luchtwegobstructie aanwezig is bij deze patiënten, dan kan worden verondersteld dat andere factoren dan de fysische eigenschappen van het ingeademde gas het getal van Reynolds onder de kritische waarde voor het optreden van turbulentie houden. Verandering van de kinematische viscositeit van het inademingsgas zal de weerstand in dit geval weinig beïnloeden daar een laminair flowpatroon viscositeitsafhankelijk is en het helium + zuurstofmengsel 1,13 maal visceuzer dan lucht is.

Zoals bij normale personen wordt wel een duidelijke afname van de reactantie, gepaard gaande met een toename van de resonantiefrequentie, vastgesteld tijdens helium + zuurstofademen: dit is een gevolg van de afname van de inductieve reactantie.

De resultaten voor en na salbutamol tijdens luchtademen zijn in overeenstemming met de resultaten besproken in hoofdstuk 9 . Opmerkelijk is dat tijdens helium + zuurstofademen na inhalatie van salbutamol wel een significante da- 
ling van de weerstand en een significante stijging van de reactantie waargenomen wordt en dit bij alle frequenties.

Mogelijk is bij deze patiëntengroep een verdeling van de pulmonale weerstand met minimaal verlies in de grotere luchtwegen meer gevoelig om de effecten van salbutamol op de impedantieparameters te meten.

In hoofdstuk 11 en 12 wordt verder ingegaan op de mechanische aspecten van bronchoconstrictie en bronchodilatatie bij asthmatici.

In hoofdstuk 11 worden 25 asthmatici onderzocht voor en na inhalatie van histamine. Bij deze patiënten veroorzaakt histamine een duidelijke toename van de weerstand vooral bij de lagere frequenties, een frequentie-afhankelijkheid van de weerstand en een daling van de reactantie bij alle frequenties. Deze veranderingen worden uitgelegd door een perifere luchtwegobstructie.

In hoofdstuk 12 worden de resultaten besproken na isocapnische inhalatie van koude lucht. Dezelfde veranderingen als na inhalatie van histamine worden waargenomen. Daarom wordt verondersteld dat bij asthmatici het patroon van bronchoconstrictie, zoals gevonden met behulp van de geforceerde oscillatietechniek, onafhankelijk is van de aard van de gebruikte stimulus.

Na door middel van histamine een bronchoconstrictie te hebben veroorzaakt, zijn de patiënten in hoofdstuk 11 gerandomiseerd voor onderzoek naar het effect van 2 inhalatiedoses salbutamol: $0.4 \mathrm{mg}$ en $1.0 \mathrm{mg}$. Vijf minuten na toediening van beide dosis wordt een afname van de weerstandswaarden bij lagere frequenties, een verdwijnen van de frequentie-afhankelijkheid van de weerstand en een significante toename van de reactantiewaarden gevonden. Geen significant verschil in absolute verandering van de weerstand en de reactantie wordt tussen beide doses salbutamol vastgesteld. Deze veranderingen na inhalatie van salbutamol worden uitgelegd door een overwegende werking te veronderstellen op de perifere luchtwegen.

In hoofdstuk 12 worden dezelfde veranderingen besproken na inhalatie van ipratropium bromide. Alhoewel beide geneesmiddelen verschillend zijn wat betreft hun farmacologische werking, blijkt hieruit dat de localisatie van de respons in de tracheobronchiaalboom voor beide geneesmiddelen niet verschillend is.

Verdere evaluatie van dosisrespons en tijdsrespons, gemeten d.m.v. impedantie, is noodzakelijk vooral na inhalatie van ipratropium bromide.

Tenslotte wordt in hoofdstuk 13 de bijdrage van impedantiemeting geẻvalueerd bij de uitvoering van bronchiale provocatietesten.

Het blijkt dat na histamineprovocatie de weerstandswaarden bij alle frequenties duidelijk toegenomen zijn, maar het meest duidelijk bij de lagere frequenties en dat de reactantiewaarden duidelijk afnemen bij alle frequenties. Na multipele logistische modelanalyse blijkt nochtans, dat alleen reeds d.m.v. spirometrische data een eenvoudige discriminantscore kan worden opgesteld, waarbij een duidelijke scheiding tussen asthmatici en niet-asthmatici mogelijk is. Deze discriminantscore is: $9 . \mathrm{FEV}_{1 \text { na }}-7 . \mathrm{FEV}_{1 \text { voor. }}$ Door toevoeging van de gefor- 
ceerde oscillatietechniek aan de meetopstelling bij bronchiale provocatietesten, wordt wel informatie verkregen over het type en localisatie van de respons op de stimuli.

De klinische onderzoekingen, beschreven in deze thesis tonen aan dat impedantiemeting d.m.v. de geforceerde oscillatietechniek informatie geeft over de mechanische eigenschappen van het ademhalingssysteem, die op geen andere manier verkregen worden.

Verdere onderzoekingen zullen nodig zijn naar de mogelijke rol van deze nietinvasieve meettechniek in het routine longfunktielaboratorium en verdere modelanalyses zullen moeten uitgevoerd worden om een beter inzicht te verkrijgen in de waarnemingen. Vooral de rol van de bovenste luchtwegen op de inputimpedantie van het ademhalingsstelsel moet worden opgehelderd. 



\section{DANKWOORD}

Het beëindigen van een proefschrift biedt de gelegenheid vele mensen te danken die rechtstreeks of onrechtstreeks aan het tot stand komen hiervan hebben meegewerkt. De afronding van een promotie-onderzoek is slechts mogelijk door de hulp van velen.

Hooggeleerde Visser, hooggeachte Promotor, zonder U zou de basis voor dit proefschrift niet gelegd zijn. Uw kennis van de pathofysiologie van de ademhaling heb ik de afgelopen jaren zeer gewaardeerd. Uw kritische opstelling bij het verrichten van het onderzoek heeft mij uitermate gestimuleerd.

Hooggeleerde Greve, hooggeachte Promotor, zonder Uw vertrouwen zou ik vandaag het vak der Longziekten niet beoefenen. Uw helder pulmonologisch denken en klinisch inzicht evenals Uw dynamisme bij de uitbouw van de afdeling Longziekten in Maastricht zal ik steeds blijven waarderen. Voor Uw nooit aflatende steun en belangstelling bij mijn werkzaamheden ben ik $U^{r}$ erg erkentelijk.

Prof. Dr. K.P. Van de Woestijne en Prof. Dr. H.A.J. Struijker Boudier dank ik ten zeerste voor de kritische wijze waarop zij het manuscript hebben beoordeeld.

Prof. Dr. J. Vandenbroucke, Dr. J.M. Coenegracht en Prof. Dr. G. Vantrappen dank ik voor de interne opleiding die ik op hun afdeling mocht genieten.

Dr. F.J. Lándsér, beste Ferenc, mijn dank voor de vele gesprekken die wij over de geforceerde oscillatietechniek hebben gevoerd.

Ir. A.H. Polko, beste Albert, Uw blijvende inzet heeft belangrijk bijgedragen tot de afronding van dit promotie-onderzoek. Waarderend en dankbaar zal ik blijven terugdenken aan onze jarenlange samenwerking.

Mej. M.A.J. Kerckhoffs, beste Marion, U en de longfunktie-assistenten ben ik dankbaar voor de inzet bij het verrichten van de verschillende metingen.

Mevr. G.H.M. van Gerwen-Vries, beste Trudy, mijn dank voor de hulp bij de uitvoering van een gedeelte van de metingen.

Drs. R. Mostert, Drs. M. Quadvlieg en Drs. A.C. Verschoof dank ik voor hun hulp bij de verschillende onderzoekingen.

Mej. A.M.H. Volkers, beste Anita, nooit deed ik zonder gevolg beroep op de hulp van $U$ en $U w$ medewerksters voor het opzoeken van het patiëntenmateriaal. Mijn dank hiervoor.

Drs. H.J.A. Schouten dank ik voor de statistische bewerking van een deel van de onderzoeksgegevens.

Gewaardeerde collegae Drs. G.P.M. ten Velle, Dr. A.P.H. van der Vet en Drs. A.C. Verschoof, beste Guul, Ton en Ad, jullie wil ik danken voor het zonder enig aarzelen waarnemen van de werkzaamheden, indien nodig, zodat ik de gelegenheid kreeg dit proefschrift af te ronden. 
De secretaressen van de afdeling Longziekten dank ik voor hun hulp bij het uittypen van het manuscript. Mevr. Liliane Pistorius-Ubachs, Mej. Marion Moonen en mevr. Tineke Lamers-Driessen, van onschatbare waarde was Uw onuitputtelijk geduld en Uw nauwkeurigheid bij het uittypen en corrigeren van het proefschrift.

Ik dank verder de patiënten en proefpersonen, die mij in staat hebben gesteld dit onderzoek te verrichten.

Een speciaal woord van dank gaat uit naar mijn ouders, die het mij mogelijk hebben gemaakt een medische opleiding te volgen.

Tot slot, maar met minstens evenveel nadruk, wil ik Rita, mijn lieve vrouw, en onze kinderen Kirsten, Elke en Birgit danken. Rita, jouw onbeperkt vertrouwen en begrip zijn voor mij een grote steun geweest. 


\section{CURRIGULUM VITAE}

The author of this thesis was born on May 16, 1953 in Geel, Belgium. He graduated from high school St. Aloysius College, Geel in 1971. In 1971 he went to medical school at the Catholic University of Leuven (Belgium) and graduated in 1978. In August 1978 he started his residency in Internal Medicine at the Department of Internal Medicine of the St. Annadal Hospital Maastricht (Head: Dr. J.M. Coenegracht).

He continued his training in internal medicine at the Department of Internal Medicine of the Academic Hospital Leuven (Head: Prof. Dr. G. Vantrappen). In August 1981 he began his pulmonary training at the Department of Pulmonary Diseases of the Academic Hospital Maastricht (Head: Prof. Dr. L.H. Greve).

After registration as chest physician in August 1984, he became a member of the capaciteitsgroep of Pulmonology of the University of Limburg and a staff member of the Department of Pulmonary Diseases of the Academic Hospital Maastricht. 
Riker/3M B.V. Zoeterwoude, The Netherkands did the excellent job to make this book broadly available to all who are interested. 